\title{
Self-monitoring of physical frailty : a proactive approach in community-dwelling elderly people
}

Citation for published version (APA):

Vermeulen, J. (2014). Self-monitoring of physical frailty : a proactive approach in community-dwelling elderly people. [Doctoral Thesis, Maastricht University]. Maastricht University. https://doi.org/10.26481/dis.20141216jv

Document status and date:

Published: 01/01/2014

DOI:

10.26481/dis.20141216jv

Document Version:

Publisher's PDF, also known as Version of record

\section{Please check the document version of this publication:}

- A submitted manuscript is the version of the article upon submission and before peer-review. There can be important differences between the submitted version and the official published version of record.

People interested in the research are advised to contact the author for the final version of the publication, or visit the DOI to the publisher's website.

- The final author version and the galley proof are versions of the publication after peer review.

- The final published version features the final layout of the paper including the volume, issue and page numbers.

Link to publication

\footnotetext{
General rights rights.

- You may freely distribute the URL identifying the publication in the public portal. please follow below link for the End User Agreement:

www.umlib.nl/taverne-license

Take down policy

If you believe that this document breaches copyright please contact us at:

repository@maastrichtuniversity.nl

providing details and we will investigate your claim.
}

Copyright and moral rights for the publications made accessible in the public portal are retained by the authors and/or other copyright owners and it is a condition of accessing publications that users recognise and abide by the legal requirements associated with these

- Users may download and print one copy of any publication from the public portal for the purpose of private study or research.

- You may not further distribute the material or use it for any profit-making activity or commercial gain

If the publication is distributed under the terms of Article $25 \mathrm{fa}$ of the Dutch Copyright Act, indicated by the "Taverne" license above, 


\section{Self-monitoring of physical frailty}

A proactive approach in community-dwelling elderly people 
The studies presented in this thesis were performed at the School for Public Health and Primary Care (CAPHRI), Department of Health Services Research (HSR) at Maastricht University.

The research presented in this thesis was funded by the Netherlands Organization for Health Research and Development (ZonMw) as part of the Dutch National Care for the Elderly Program.

Cover lay-out: Peter Vermeulen, Helmond

Print: Ipskamp Drukkers, Enschede

\section{ISBN}

Copyright (C) Joan Vermeulen, Maastricht, 2014

No parts of this thesis may be reproduced, stored in a retrieval system, or transmitted, in any forms or by any means, electronically, mechanically, by photocopying, recording or otherwise, without the prior written permission of the author. 


\title{
Self-monitoring of physical frailty
}

A proactive approach in community-dwelling elderly people

\author{
Proefschrift
}

ter verkrijging van de graad van doctor aan de Universiteit van Maastricht op gezag van de rector magnificus, Prof. dr. L.L.G. Soete volgens het besluit van het college van Decanen, in het openbaar te verdedigen op dinsdag 16 december 2014 om 16:00

door

Joan Vermeulen 


\section{Promotor}

Prof. dr. L.P. de Witte

\section{Copromotores}

Dr. J.C.L. Neyens

Dr. M.D. Spreeuwenberg

\section{Beoordelingscommissie}

Prof. dr. J.M.G.A. Schols (voorzitter)

Prof. dr. A.J.H.M. Beurskens

Prof. dr. C.P. van Schayck

Prof. dr. A.E. Stuck (University of Bern, Switserland)

Prof. dr. M.M.R. Vollenbroek-Hutten (Universiteit Twente) 


\section{Contents}

$\begin{array}{lll}\text { Chapter } 1 & \text { General introduction } & 7\end{array}$

Chapter 2 Predicting ADL disability in community-dwelling elderly 21 people using physical frailty indicators: a systematic review BMC Geriatrics. 2011;11:33

Chapter 3 Does a falling level of activity predict disability development 53 in community-dwelling elderly people? Clinical Rehabilitation. 2013;27:546-54

Chapter $4 \quad$ Construct validity of a modified bathroom scale that can 69 measure balance in elderly people Journal of the American Medical Directors Association. 2012;13:665.e1-e5

Chapter 5 The relation between balance measured by a modified 85 bathroom scale and falls and disability in elderly people

Chapter $6 \quad$ Measuring grip strength in older adults: comparing 103 the Grip-ball with the Jamar dynamometer Accepted by Journal of Geriatric Physical Therapy

Chapter 7 Self-monitoring of physical activity with a smartphone in persons aged below and above 65 years old: concurrent validity in daily life

Chapter $8 \quad$ User-centered development and testing of a monitoring system that provides feedback regarding physical functioning to elderly people Patient Preference and Adherence. 2013;7:843-854

Chapter 9 Experiences of multidisciplinary development team 161 members during user-centered design of telecare products and services: a qualitative study Journal of Medical Internet Research. 2014;16:e124

Chapter 10 General discussion

$\begin{array}{lll}\text { Chapter } 11 \quad \text { Valorization of research results } & 207\end{array}$

Summary

Nederlandse samenvatting $\quad 223$

Dankwoord 229

About the author $\quad 235$

$\begin{array}{ll}\text { List of publications } & 237\end{array}$ 



\section{CHAPTER 1}

General introduction 

The number of frail elderly people is increasing in the Netherlands and other Western societies. ${ }^{1}$ Frail elderly people have an increased risk of adverse outcomes such as disability, fall incidents, fractures, hospitalization, institutionalization and even death compared to non-frail elderly people. ${ }^{2-9}$ As a consequence, frailty is also strongly associated with increased use of (informal) healthcare and community services. ${ }^{10,11}$ In view of a decreasing number of caregivers, frailty can be considered a burden not only for elderly people but also for care providers and health care systems as a whole. Providing complex care for frail elderly people in the community that is tailored to their needs will be a challenge for societies in the near future. ${ }^{12}$ Identification of frailty (at an early stage) and providing support to frail community-dwelling elderly people are important components of this challenge. Therefore, this thesis will focus on the development and evaluation of a proactive approach that can support community-dwelling elderly persons in their self-management regarding physical frailty and functioning using innovative care technology.

\section{Defining frailty}

The concept of frailty among elderly people was introduced in the 1980s and various definitions have been used since then. ${ }^{13-16}$ Some emphasize that frailty and its consequences can be predicted by interplay between biological, psychological, and social factors. ${ }^{17-21}$ Others focus strongly on biological factors and indicators of physical functioning, such as weight loss, exhaustion, slow walking speed, low grip strength and low physical activity, when defining frailty and predicting its adverse outcomes. ${ }^{22-24}$ This thesis will focus on physical frailty.

Despite a lack of consensus on a definition, it is widely recognized that frailty can be classified as a syndrome. ${ }^{25}$ Frailty is described as a transitional state in a continuum that ranges from robust at one end to frail at the other. People move back and forth along this continuum between states of robustness, pre-frailty, and frailty. ${ }^{26}$ Definitions that focus on the physical aspects of frailty often include 'an age-related loss of reserves or capacity' and a frequently used definition of frailty is the following: 'a physiologic syndrome characterized by decreased reserves and diminished resistance to stressors, resulting from cumulative decline across multiple physiologic systems'. ${ }^{23}$

\section{Disability prevention in frail elderly people}

The loss of reserves that frail elderly people experience makes them more vulnerable for adverse outcomes, especially for disability since frailty is considered to be a state of pre- 
disability. ${ }^{27}$ Disability can be defined as experienced difficulty in performing activities in any domain of life. ${ }^{28}$ In frail elderly people, disability negatively influences the ability to live at home independently and it is also associated with increased health care consumption. ${ }^{10,11,29}$ Disability is a dynamic process and the risk to develop new disabilities can be reduced, particularly when preventive actions are taken at an early stage. ${ }^{30,31}$ Since frailty is a precursor of disability, many efforts have been put into the prevention and reduction of disability in frail elderly people.

A large meta-analysis regarding disability prevention in community-dwelling elderly people concluded that complex multidimensional preventive interventions can potentially reduce the risk of disability and not living at home. ${ }^{31}$ However, Randomized Controlled Trials (RCTs) have reported inconsistent effects in frail elderly people; some trials showed positive effects regarding disability prevention and/or reduction whereas others found no favorable effects for the intervention group while evaluating similar multidimensional programs. $^{32-36}$

Based on current literature it remains difficult to draw firm conclusions regarding the effectiveness of components of interventions aimed at disability prevention in frail community-dwelling elderly people. ${ }^{37}$ Beswick et al. suggest that tailoring the format of a multicomponent intervention to the needs and preferences of the receiver might therefore be a justified strategy. ${ }^{31}$ Conclusions from a narrative review by Daniels et al. partly confirm this by emphasizing that individualized assessment and case management are promising components of multidimensional interventions, along with working in multidisciplinary teams, long-term follow-up, and the use of technology. ${ }^{38}$ Previous studies indicate that exercise programs could have a positive effect on disability prevention and reduction in frail elderly people. ${ }^{39,40}$ Furthermore, a meta-analysis by Tak et a. revealed that being physically active is an effective strategy in preventing and reducing disability by almost 50 percent in community-dwelling elderly people. ${ }^{41}$

\section{Early risk detection}

A difficulty in offering interventions to frail community-dwelling elderly people aimed at disability prevention or reduction is to identify people who might benefit most from such programs at a stage that disability is not yet present or still reversible. ${ }^{42}$ Various methods have been used to screen elderly people in the community to determine their level of frailty; and with that their eligibility for participation in preventive intervention programs. Most frequently used screening methods are self-report questionnaires, checklists used by care professionals (sometimes including physical performance tests), and clinical judgment of care professionals. ${ }^{43,44} \mathrm{~A}$ disadvantage of all these screening methods is that the decision to offer a preventive intervention program is based on a single cross-sectional 
assessment of frailty. This approach seems contradictory to the dynamic nature of the concepts of frailty and disability that postulate that frailty and disability levels in an individual are subject to change over time. ${ }^{45,46}$

A study by Pijpers et al. concluded that the use of available frailty screening questionnaires and checklists results in too many false-positive classifications. ${ }^{47}$ As a consequence, interventions are offered to persons who are not frail, who do not have an increased risk for disability, and who are therefore less likely to benefit from intervention programs aimed at prevention or reduction of disability. A qualitative study among nurse practitioners who deliver disability prevention programs to community-dwelling elderly people confirms that based on outcomes of current frailty screening instruments, the 'wrong target group' is often selected for such preventive programs. ${ }^{48}$

Care professionals, especially general practitioners and nurse practitioners, currently have a pivotal role in identifying frail elderly people in the community who could benefit from disability prevention programs and in delivering such programs. However, identification of frailty in elderly people is often not part of daily routine in primary care. ${ }^{49}$ This might be due to the fact that some screening instruments are impractical to use in primary care (for example time consuming checklists that contain several physical performance tests) or because these instruments were not developed specifically for this setting and might therefore be less suitable. ${ }^{50}$ In addition to this, frailty screening by care professionals will become more difficult to accomplish in the near future due to an increasing number of elderly persons and a decreasing number of care professionals. ${ }^{51}$ Finally, the current top-down approach in which care professionals decide whether preventive interventions should be started based on the outcome of a frailty screening instrument, does not facilitate the participation of frail elderly people in making decisions regarding their own health care. This is unfortunate since involvement of frail elderly people in their own care process can empower them and improve patient outcomes. ${ }^{52,53}$

\section{Opportunities for care technology}

The uptake of information and communication technology in healthcare is increasing. These technologies can support remote self-monitoring of health conditions, selfmanagement, and the delivery of interventions, thereby improving patient care and changing the traditional organization of care processes. ${ }^{54-56}$ Previous research suggests that appropriate adoption of technology in care can positively contribute to the lives of elderly people by enabling them to live independently longer and by improving their quality of life. $^{57,58}$

The increasing use of every day technologies such as smartphones, computers, and internet among elderly people creates opportunities for the use of technologies in 
healthcare for elderly people. ${ }^{59}$ A review by Piau et al. revealed that there is a growing interest in applying technologies targeting social isolation, autonomy loss, and cognitive disorders in community-dwelling elderly people but that hardly any studies have been conducted yet that focus on frail elderly people. ${ }^{60}$ Wagner et al. suggest that home-based monitoring technologies can be particularly useful in healthcare for elderly people to detect increased risk of adverse outcomes at an early stage at which health problems are not considered catastrophic yet. ${ }^{61}$ In addition to this, Gu Kang et al. point out that continuous monitoring of relevant indicators of health and disease may provide more insight into the dynamic nature of the development of these indicators over time, which in turn might result in better prediction of adverse health outcomes. ${ }^{62}$

Innovative monitoring technology could be used to gain insight into the development of physical frailty in community-dwelling elderly people over time. Such a frailty monitoring system provides feedback to community-dwelling elderly people and healthcare professionals regarding the development of indicators of physical frailty, such as weight, exhaustion, grip strength, gait speed, activity, or balance, over time. This can facilitate a dialogue between elderly people and care professionals regarding the uptake of interventions aimed at disability prevention and may contribute to self-management of community-dwelling elderly people. Longitudinal monitoring of physical frailty indicators could contribute to proactive care that is tailored to the current needs and level of physical functioning of community-dwelling elderly people.

\section{Objectives and outline of this thesis}

The main objective of this thesis is to develop and evaluate a self-monitoring and feedback system that can be used by community-dwelling elderly people to gain insight into (changes in) indicators of physical frailty that are predictors of increased risk of disability. To achieve this, the following research questions are addressed:

1. What is the predictive value of physical frailty indicators on disability in community-dwelling elderly people?

2. Can simple, innovative technologies be used to obtain valid and reliable estimates of physical frailty indicators?

3. How can simple, innovative technologies be integrated into a self-monitoring system that provides regular feedback to elderly people regarding (changes in) physical frailty indicators?

Chapters 2 and 3 of this thesis relate to research question one by reporting on the predictive value of physical frailty indicators in relation to disability. Chapter 2 describes the results of a systematic review regarding the predictive value of physical frailty 
indicators on disability in Activities of Daily Living (ADL) in community-dwelling elderly people. Chapter 3 presents the results of a one-year follow-up study that investigated the predictive value of self-reported decline in physical frailty indicators (weight, exhaustion, walking difficulty, grip strength and physical activity) on development of disabilities in community-dwelling elderly people aged 70 years or older.

Research question two is the main focus of chapters 4, 5, 6 and 7 in which information is provided regarding the validity and reliability of measuring instruments that elderly people can use for self-monitoring of physical frailty indicators (weight, balance, grip strength, and physical activity). Chapter 4 describes a cross-sectional study that was conducted to investigate the construct validity of a modified bathroom scale that can be used to measure balance in elderly people. Chapter 5 reveals the results of a 6 -month follow-up study regarding the relation between balance scores of a modified bathroom scale and falls and disability in elderly people aged 65 years and older. Chapter 6 presents the results of a cross-sectional study that was conducted to gain insight into the reliability and validity of measurements obtained with a Grip-ball that can be used for self-

monitoring of grip strength. Chapter 7 describes a validation study in which a smartphonebased accelerometer for home-based monitoring of physical activity was compared to the Actigraph GT3X in adults aged below and above 65 years old.

Chapters 8 and 9 relate to research question three by describing studies regarding the user-centered development and evaluation of telecare products. Chapter 8 provides detailed information regarding the User-Centered Design (UCD) of a mobile interface of a monitoring system that provides feedback to elderly people regarding changes in physical functioning. Furthermore, this chapter describes the results of a 6-week pilot study in which the usability and experiences with the monitoring and feedback system according to community-dwelling elderly people aged 70 years or older were explored. $\underline{\text { Chapter } 9}$ presents the findings of a qualitative study that investigated the barriers and facilitators that influence the UCD process of telecare products and services according to members of multidisciplinary development teams of four different Research and Development (R\&D) projects.

Chapter 10 discusses the main findings of this thesis and explains which methodological and theoretical issues should be taken into consideration when interpreting the results of the research that was conducted. Implications for practice and recommendations for future research are addressed. Finally, in Chapter 11 the possibilities for valorization of knowledge that was gained during the research presented in this thesis are explored. 


\section{References}

1. Ministerie van VWS. Brief aan de Tweede Kamer. Multimorbiditeit en ouderenzorg. Den Haag: Ministerie van Volksgezondheid, Welzijn en Sport; 2007.

2. Bandeen-Roche K, Xue QL, Ferrucci L, Walston J, Guralnik JM, Chaves P, et al. Phenotype of frailty: characterization in the women's health and aging studies. J Gerontol A Biol Sci Med Sci. 2006;61:262-266.

3. Boyd CM, Xue QL, Simpson CF, Guralnik JM, Fried LP. Frailty, hospitalization, and progression of disability in a cohort of disabled older women. Am J Med. 2005;118:1225-1231.

4. Cawthon PM, Marshall LM, Michael Y, Dam TT, Ensrud KE, Barrett-Connor E, et al. Frailty in older men: prevalence, progression, and relationship with mortality. J Am Geriatr Soc. 2007;55:1216-1223.

5. Ensrud KE, Ewing SK, Cawthon PM, Fink HA, Taylor BC, Cauley J et al. A comparison of frailty indexes for the prediction of falls, disability, fractures, and mortality in older men. J Am Geriatr Soc. 2009;57:492-498.

6. Ensrud KE, Ewing SK, Taylor BC, Fink HA, Cawthon PM, Stone KL, et al. Comparison of 2 frailty indexes for prediction of falls, disability, fractures, and death in older women. Arch Intern Med. 2008;168:382-389.

7. Fried LP, Tangen CM, Walston J, Newman AB, Hirsch C, Gottdiener J, et al. Frailty in older adults: evidence for a phenotype. J Gerontol A Biol Sci Med Sci. 2001;56:M146156.

8. Rothman MD, Leo-Summers L, Gill TM. Prognostic significance of potential frailty criteria. J Am Geriatr Soc. 2008;56:2211-2116.

9. Woods NF, LaCroix AZ, Gray SL, Aragaki A, Cochrane BB, Brunner RL, et al. Frailty: emergence and consequences in women aged 65 and older in the Women's Health Initiative Observational Study. J Am Geriatr Soc. 2005;53:1321-1330.

10. Rochat S, Cumming RG, Blyth F, Creasey H, Handelsman D, Le Couteur DG, et al. Frailty and use of health and community services by community-dwelling older men: the concord health and ageing in men project. Age Ageing. 2010;1:1-6.

11. Hoeck S, Francois G, Geerts J, van der Heyden J, Vandewoude M, van Hal G. Healthcare and home-care utilization among frail elderly persons in Belgium. Eur J Public Health. 2012;22:671-677.

12. Cornwell J. The care of frail older people with complex needs: time for a revolution. London: King's Fund. 2012. Visited on 11 June 2014. http://www.kingsfund.org.uk/sites/files/kf/field/field publication file/the-care-offrail-older-people-with-complex-needs-mar-2012.pdf 
13. Morley JE, Perry HM, Miller DK. Something about frailty. J Gerontol. 2002;57A:698704.

14. Markle-Reid M, Browne G. Conceptualizations of frailty in relation to older adults. J Adv Nurs. 2003;44:58-68.

15. Levers MJ, Estabrooks CA, Ross Kerr JC. Factors contributing to frailty: literature review. J Adv Nurs. 2006;56:282-291.

16. Bergman H, Ferrucci L, Guralnik J, Hogan DB, Hummel S, Karunananthan S, Wolfson C. Frailty: an emerging research and clinical paradigm - issues and controversies. J Gerontol A Biol Sci Med Sci. 2007;62:731-737.

17. Bergman H, Beland F, Karunananthan S, Hummel S, Hogan D, Wolfson C. Developing a working framework for understanding frailty. Gerontology and Society. 2004;109:15-29.

18. De Saint-Hubert M, Swine C. Evolving definitions of frailty. Aging Health. 2007;3:1-5.

19. Strawbridge WJ, Shema SJ, Balfour JL, Hibgy HR, Kaplan GA. Antecedents of frailty over three decades in an older cohort. J Gerontol B Psychol Sci Soc Sci. 1998;53:S916.

20. Rockwood K, Song X, MacKnight C, Bergman H, Hogan DB, McDowell I, Mitnitski A. A global clinical measure of fitness and frailty in elderly people. CMAJ. 2005;173:489495.

21. Slaets JP. Vulnerability in the elderly: frailty. Med Clin North Am 2006;90:593-601.

22. Fried LP, Hadley EC, Walston JD, Newman AB, Guralnik JM, Studenski S, et al. From bedside to bench: research agenda for frailty. Sci Aging Knowledge Environ 2005;31:pe24.

23. Walston J, Hadley EC, Ferrucci L, Guralnik JM, Newman AB, Studenski SA, et al. Research agenda for frailty in older adults: toward a better understanding of physiology and etiology: summary from the American Geriatrics Society/National Institute on Aging Research Conference on Frailty in Older Adults. J Am Geriatr Soc. 2006;54:991-1001.

24. Brown M, Sinacore DR, Binder EF, Kohrt WM. Physical and performance measures for the identification of mild to moderate frailty. J Gerontol A Biol Sci Med Sci 2000;55:M350-355.

25. Fried LP, Ferrucci L, Darer J, Williamson WD, Anderson G. Untangling the concepts of disability, frailty, and comorbidity: implications for improved targeting and care. J Geroltol A Biol Sci Med Sci. 2004;59:M255-263.

26. Romero-Ortun R, O'Shea D. Fitness and frailty: opposite ends of a challenging continuum! Will the end of age discrimination make frailty assessments an imperative? Age Ageing. 2013;42:279-280. 
27. Abellan an Kan G, Rolland $\mathrm{Y}$, Bergman H, Morley JE, Kritchevsky SB, Vellas B. The I.A.N.A. Task Force on frailty assessment of older people in clinical practice. J Nutr Health Aging. 2008;12:29-37.

28. Jette AM. Toward a common language for function, disability, and health. Phys Ther. 2006;86:726-734.

29. Rothman MD, Leo-Summer L, Gill TM. Prognostic significance of potential frailty criteria. J Am Geriatr Soc. 2008;56:221-2116.

30. Huss A, Stuck AE, Rubenstein LZ, Egger M, Clough-Gorr KM. Multidimensional preventive home visit programs for community-dwelling older adults: a systematic review and meta-analysis of randomized controlled trials. J Gerontol A Biol Sci Med Sci. 2008;63A:298-307.

31. Beswick AD, Rees K, Dieppe P, Ayis S, Gooberman-Hill R, Horwood J, Ebrahim S. Complex interventions to improve physical function and maintain independent living in elderly people: a systematic review and meta-analysis. Lancet. 2008;371:725-735.

32. Metzelthin SF, Rossum E van, de Witte LP, Ambergen AW, Hobma S, Sipers W, Kempen $\mathrm{H}$. Effectiveness of interdisciplinary primary care approach to reduce disability in community dwelling frail older people: cluster randomized controlled trial. BMJ. 2013;347:f5264.

33. Melis RJF, Van Eijken MIJ, Teerenstra S, Van Achterberg T, Parker SG, Borm GF, et al. A randomized study of a multidisciplinary program to intervene on geriatric syndromes in vulnerable older people who live at home (Dutch EASYcare study). J Gerontol A Biol Sci Med Sci. 2008;3:283-290.

34. Li CM, Chen CY, Li CY, Wang WD, Wu SC. The effectiveness of a comprehensive geriatric assessment intervention program for frailty in community-dwelling older people: a randomized, controlled trial. Arch Gerontol Geriatr. 2010;50:S39-S42.

35. Fairhall N, Sherrington C, Kurrle SE, Lord SR, Lockwood K, Cameron ID. Effect of a multifactorial interdisciplinary intervention on mobility-related disability in frail older people: randomised controlled trial. BMC Medicine. 2012;10:120.

36. Cameron ID, Fairhall N, Langron Cl, Lockwood K, Monaghan N, Aggar C, et al. A multifactorial interdisciplinary intervention reduces frailty in older people: randomized trial. BMC Medicine 2013;11:65.

37. Daniels R, van Rossum E, de Witte L, Kempen GI, van den Heuvel W. Interventions to prevent disability in frail community-dwelling elderly: a systematic review. BMC Health Serv Res. 2008;8:278.

38. Daniels R, Metzelthin S, Van Rossum E, De Witte L, Van den Heuvel W. Interventions to prevent disability in frail community-dwelling older persons: an overview. Eur J Ageing. 2010;7:37-55. 
39. Chou $\mathrm{CH}$, Hwang $\mathrm{CL}$, Wu YT. Effect of exercise on physical function, daily living activities, and quality of life in the frail older adults: a meta-analysis. Arch Phys Med Rehabil. 2012;93:237-244.

40. Yamada M, Arai H, Sonoda T, Aoyama T. Community-based exercise program is costeffective by preventing care and disability in Japanese frail older adults. J Am Med Dir Assoc. 2012;13:507-511.

41. Tak E, Kuiper R, Chorus A, Hopman-Rock M. Prevention of onset an progression of basic ADL disability by physical activity in community-dwelling older adults: a metaanalysis. Ageing Res Rev. 2013;1:329-338.

42. Ferrucci L, Guralnik JM, Studenski S, Fried LP, Cutler GB Jr, Walstron JD. Designing randomized, controlled trial aimed at preventing or delaying functional decline and disability in frail, older persons: a consensus report. J Am Geriatr Soc. 2004;52:625634.

43. Pialoux T, Goyard J, Lesourd B. Screening tools for frailty in primary health care: a systematic review. Geriatr Gerontol Int. 2012;12:189-197.

44. Sternberg SA, Wershof Schwartz A, Karunananthan S, Bergman H, Mark Clarfiels A. The identification of frailty: a systematic literature review. J Am Geriatr Soc. 2011;59:2129-2138.

45. De Lepeleire J, Iliffe S, Mann E, Degryse JM. Frailty an emerging concept for general practice. Br J Gen Pract. 2009;59:3177-e182.

46. Gill TM, Gahbauer EA, Allore HG, Han L. Transitions between frailty states among community-living older persons. Arch Intern Med. 2006;166:418-423.

47. Pijpers E, Ferreira I, Stehouwer CDA, Nieuwenhuijzen Kruseman AC. The frailty dilemma. Review of the predictive accuracy of major frailty scores. Eur J Inter Med. 2012;23:118-123.

48. Bindels J, Cox K, Widdershoven G, Van Schayck OCP, Abma TA. Care for communitydwelling older people: a practice nurse perspective. J Clin Nurs. 2014;23:2313-2322.

49. Vellas B, Balardy L, Gillette-Guyonnet S, Van Kan A, Ghisolfi-Marque A, Subra J, et al. Looking for frailty in community-dwelling older persons: the Gérontopôle Frailty Screening Tool (GFST). J Nutr Health Aging. 2013;17:629-631.

50. Van Kempen JAL, Schers HJ, Jacobs A, Zuiderma SU, Ruikes F, Robben SHM, et al. Development of an instrument for the identification of frail older people as a target population for integrated care. Br J Gen Pract. 2013;63:e225-e231.

51. United Nations, Department of Economic and Social Affairs, Population Division. World Population Ageing 2013. New York: United Nations; 2013.

52. De Haes, H. Dilemmas in patient centeredness and shared decision making: a case for vulnerability. Patient Educ Couns. 2006;62:291-298. 


\section{Chapter 1}

53. Grifin Sj, Kinmonth AL, Veltman MW, Gillard S, Grant J, Stewart M. Effect on healthrelated outcomes of interventions to alter the interaction between patients and practitioners: a systematic review of trials. Ann Fam Med. 2004;2:595-608.

54. McLean S, Sheikh A, Cresswell K, Nurmatov U, Mukherjee M, Hemmi A, Pagliari C. The impact of telehealthcare on the quality and safety of care: a systematic overview. PLoS One. 2013;8:e71238.

55. Eland-de Kok $P$, van Os-Medendorp H, Vergouwe-Meijer A, Bruijnzeel-Koomen C, Ros W. A systematic review of the effects of e-health on chronically ill patients. J Clin Nurs. 2011;20:2997-3010.

56. Kreps GL, Neuhauser L. New directions in eHealth communication: opportunities and challenges. Pat Educ Couns. 2010;78:329-336.

57. Botsis T, Hartvigsen G. Current status and future perspectives in telecare for elderly people suffering from chronic diseases. J Telemed Telecare. 2008;14:195-203.

58. Koch S, Hagglund M. Health informatics and the delivery of care to older people. Maturitas. 2009;63:195-199.

59. Boulos MNK, Wheeler S, Tavares C, Jones R. How smartphones are changing the face of mobile and participatory healthcare: an overview, with example from eCAALYX. Biomedical engineering online. 2011;10:24.

60. Piau A, Campo E, Rumeau P, Vellas B, Nourhashemi F. Aging society and gerontechnology: a solution for an independent living? J Nutr Health Aging. 2014;18:97-112.

61. Wagner F, Basran J, Dal Bello-Haas V. A review of monitoring technology for use with older adults. 2012;35:28-34.

62. Gu Kang H, Mahoney DF, Hoenig H, Hirth VA, Bonato P, Haijar I, Lipsitz LA. In situ monitoring of health in older adults: technologies and issues. J Am Geriatr Soc. 2010;58:1579-1586. 




\section{CHAPTER 2}

Predicting ADL disability in community-dwelling elderly people using physical frailty indicators: a systematic review

This chapter was published as:

Vermeulen J, Neyens JCL, Spreeuwenberg MD, van Rossum E, de Witte LP. Predicting ADL disability in community-dwelling elderly people using physical frailty indicators: a systematic review. BMC Geriatrics. 2011;11:33. 


\section{Abstract}

Background: Disability in Activities of Daily Living ( $A D L)$ is an adverse outcome of frailty that places a burden on frail elderly people, care providers and the care system. Knowing which physical frailty indicators predict ADL disability is useful in identifying elderly people who might benefit from an intervention that prevents disability or increases functioning in daily life. The objective of this study was to systematically review the literature on the predictive value of physical frailty indicators on ADL disability in community-dwelling elderly people.

Methods: A systematic search was performed in 3 databases (PubMed, CINAHL, EMBASE) from January 1975 until April 2010. Prospective, longitudinal studies that assessed the predictive value of individual physical frailty indicators on ADL disability in communitydwelling elderly people aged 65 years and older were eligible for inclusion. Articles were reviewed by two independent reviewers who also assessed the quality of the included studies.

Results: After initial screening of 3081 titles, 360 abstracts were scrutinized, leaving 64 full text articles for final review. Eventually, 28 studies were included in the review. The methodological quality of these studies was rated by both reviewers on a scale from 0 to 27. All included studies were of high quality with a mean quality score of 22.5 (SD 1.6). Findings indicated that individual physical frailty indicators, such as weight loss, gait speed, grip strength, physical activity, balance, and lower extremity function are predictors of future ADL disability in community-dwelling elderly people.

Conclusions: This review shows that physical frailty indicators can predict ADL disability in community-dwelling elderly people. Slow gait speed and low physical activity/exercise seem to be the most powerful predictors followed by weight loss, lower extremity function, balance, muscle strength, and other indicators. These findings should be interpreted with caution because the data of the different studies could not be pooled due to large variations in operationalization of the indicators and ADL disability across the included studies. Nevertheless, our study suggests that monitoring physical frailty indicators in community-dwelling elderly people might be useful to identify elderly people who could benefit from disability prevention programs. 


\section{Background}

In ageing Western societies, the prevalence of frailty and its adverse outcomes increases. ${ }^{1}$ Disability in Activities of Daily Living (ADL), which are the essential activities that a person needs to perform to be able to live independently, ${ }^{2}$ is an adverse outcome of frailty that places a high burden on frail individuals, care professionals and health care systems. ${ }^{3}$ Frail elderly people have a higher risk of ADL disability compared to non-frail elderly people. ${ }^{4-6}$ Effective interventions that prevent disability can diminish the burden caused by frailty. For the development of such interventions and the identification of people who might benefit from them, it is important to know which factors predict frailty-related ADL disability.

Frailty is a concept that has been defined in many different ways. ${ }^{7-9}$ Various physical, cognitive, psychological, nutritional and social factors have been claimed to contribute to frailty. ${ }^{10}$ A definition of frailty that is often used by geriatricians is the following: 'a biologic syndrome of decreased reserve and resistance to stressors, resulting from cumulative decline across multiple physiologic systems, and causing vulnerability to adverse outcomes' ${ }^{11}$ The well-known frailty phenotype by Fried et al. ${ }^{12}$ which classifies people into categories of robust, pre-frail or frail fits within this physiologic approach of frailty. The frailty phenotype postulates that five indicators of physical functioning (unintentional weight loss, exhaustion, slow walking speed, low grip strength, and low physical activity) are related to each other in a cycle of frailty. A person with none of the indicators is robust, a person with 1 or 2 indicators is pre-frail, and a person with 3 or more indicators is frail. Elderly people who are frail according to the phenotype have a higher risk of disability. $^{4-6}$

Although evidence exists that the phenotype predicts disability, it always involves a combination of the five indicators and provides no insight into the predictive value of the individual indicators. Besides that, the phenotype does not provide insight into the predictive value of other possible indicators of physical functioning that might relate to frailty. If individual indicators can predict ADL disability this could be clinically useful in identifying elderly people who might benefit from an intervention that prevents disability or increases physical functioning in daily life. A systematic literature review was conducted to investigate this in community-dwelling elderly people.

\section{Methods}

\section{Search strategy}

Potentially relevant articles were obtained by performing a search in three databases (PubMed, CINAHL, and EMBASE) from January 1975 until April 2010. This cutoff point was 
chosen because the term frailty was first introduced around the 1980's. To specify the study population the MESH term "aged" was combined with terms such as "frail*", "vulnerable", "low functioning", or "community-dwelling" where * denotes truncated terms. To specify the physical frailty indicators terms such as "grip strength", "weight loss", "balance", "exhaustion", "walking speed", "gait", "physical activity", and related MESH terms were combined with OR. To specify the outcome measure terms such as "disabil*", "Activities of daily living", "functional decline", and related MESH terms were combined with OR. To specify the study design terms such as "cohort studies", "longitudinal", "prognos*”, "predict*”, and related MESH terms were combined with OR. The searches for study population, physical frailty indicators, outcome, and study design were combined with AND, resulting in the final search. Reference lists of selected reviews and studies were screened for relevant publications that were not identified in the original search. Relevant studies found in these reference lists that met all inclusion criteria were also included in the review.

\section{Study selection}

Articles were eligible for inclusion if they met the following inclusion criteria: 1) written in English or Dutch, 2) a prospective longitudinal design, 3) involving community-dwelling elderly people aged 65 years or older, 4) at least 1 physical frailty indicator as independent variable, and 5) ADL disability as outcome measure. Most recent studies on disability in elderly persons focus on the ability or difficulty in carrying out ADL. ${ }^{13}$ The fact that people who suffer from ADL disability, cannot live independently justifies the use of this measure as a key outcome. ${ }^{2}$ Articles with only mobility disability as outcome variable were not included because this does not reflect the much broader concept of ADL disability. Studies that only focused on elderly patients with a disease such as Parkinson, depression, or stroke were excluded from the review.

All retrieved articles were first reviewed by two independent reviewers (JV \& JCLN) based on their title. In case of disagreement or doubt, the article was included in the second phase of the selection process where all abstracts were assessed. Both reviewers independently labeled the remaining abstracts as 'include' or 'exclude'. Disagreement was resolved by consensus and if consensus could not be reached a third reviewer was consulted (MDS). In the third phase of the selection process, the full-text of the articles was retrieved and reviewed by both reviewers independently. Disagreement was resolved by consensus. In two cases the third reviewer had to be consulted. Agreement between the two independent reviewers in the second and third phase of the selection process was checked by calculating Cohen's Kappa. 


\section{Quality assessment and data extraction}

The quality of the included articles was assessed by both reviewers independently using a list of 27 criteria (see Table 1). This list was constructed based on previous research on methodological quality, quality of reporting criteria for observational research, and previous reviews regarding prediction of disability. ${ }^{14-17}$ Each item was scored with 0 or 1 resulting in a possible range of 0 to 27 points per included study. A higher score indicated higher quality.

Data regarding design, duration of follow up, sample size, population characteristics, physical frailty indicators, outcome measures and results were extracted from the included studies. The extracted data were not pooled due to the fact that there was a large heterogeneity in the way physical frailty indicators and ADL disability were measured. In order to draw conclusions on the predictive strength of the different indicators, the number of articles reporting a significantly increased risk of ADL disability were counted for each indicator. The number of studies was then split up into studies that only included participants who were free of disability at baseline and studies that included participants not free of disability at baseline. Higher weight was given to studies that only included participants free of disability at baseline $(++)$ compared to studies that included participants with and without disability at baseline (+). Negative weight was given to studies that reported no significant predictive value of the studied indicator (-). In some cases, two different studies that reported positive findings for the same indicator used data from the same cohort. This was taken into account in the interpretation of the results by counting these findings as one.

Table 1. List of quality criteria

\begin{tabular}{|c|c|c|c|}
\hline Nr. & Criteria & Yes $=1$ & No $=0$ \\
\hline 1 & Was the rationale of the research described? & & \\
\hline 2 & Were the objectives of the research clearly stated? & & \\
\hline 3 & Was the study a prospective cohort study? & & \\
\hline 4 & Was the follow-up of the cohort study 5 years or longer? & & \\
\hline 5 & Were the key-elements of the study design described? & & \\
\hline 6 & $\begin{array}{l}\text { Were the setting, relevant dates and timeframe of the research } \\
\text { described? }\end{array}$ & & \\
\hline 7 & Were the eligibility criteria for participants described? & & \\
\hline 8 & Were the participants free of disability at baseline? & & \\
\hline 9 & Were the predictors and dependent variables described? & & \\
\hline 10 & $\begin{array}{l}\text { Were the measurement methods for the predictors and dependent } \\
\text { variables described? }\end{array}$ & & \\
\hline 11 & Were standardized or valid measurements used for the predictors? & & \\
\hline 12 & Were standardized or valid measurements used for the outcome? & & \\
\hline 13 & Were potential types of bias addressed? & & \\
\hline
\end{tabular}


Table 1 continued. List of quality criteria

\begin{tabular}{|c|c|c|c|}
\hline Nr. & Criteria & Yes $=1$ & No $=0$ \\
\hline 14 & Was it clear how the quantitative data were handled in the analyses? & & \\
\hline 15 & Were appropriate multivariate analysis techniques used? & & \\
\hline 16 & $\begin{array}{l}\text { Did the statistical methods control for confounding and examine } \\
\text { subgroups or interactions? }\end{array}$ & & \\
\hline 17 & $\begin{array}{l}\text { Was there a description on how the final number of participants was } \\
\text { established? }\end{array}$ & & \\
\hline 18 & Was the (loss to) follow-up of the participants described? & & \\
\hline 19 & Was the attrition less than $20 \%$ ? & & \\
\hline 20 & $\begin{array}{l}\text { Was information provided regarding the baseline characteristics of } \\
\text { participants? }\end{array}$ & & \\
\hline 21 & $\begin{array}{l}\text { Was the number of outcome events or summary measures over time } \\
\text { reported? }\end{array}$ & & \\
\hline 22 & $\begin{array}{l}\text { Were the results expressed in an Odds Ratio (OR), Risk Ratio (RR) or } \\
\text { Hazard Ratio (HR) with the corresponding } 95 \% \text { confidence interval? }\end{array}$ & & \\
\hline 23 & If sub-group analyses were performed, were these clearly described? & & \\
\hline 24 & Were the key-results described in the discussion? & & \\
\hline 25 & Were the limitations of the study reported? & & \\
\hline 26 & $\begin{array}{l}\text { Were previous research and the limitations of the study taken into } \\
\text { account when an overall interpretation of the study results was } \\
\text { provided? }\end{array}$ & & \\
\hline 27 & Was the generalizability of the study results described? & & \\
\hline
\end{tabular}

\section{Results}

\section{Selection process}

The search strategy yielded 3081 potentially relevant articles, after which 360 abstracts were scrutinized, leaving 64 full text publications for final review. After the selection process 28 studies were included in the review (see Figure 1 for details). The agreement between the two reviewers during the selection of abstracts and the selection of full-texts, as measured by Cohen's Kappa, was .74 and .82 respectively which is regarded as substantial to excellent. 


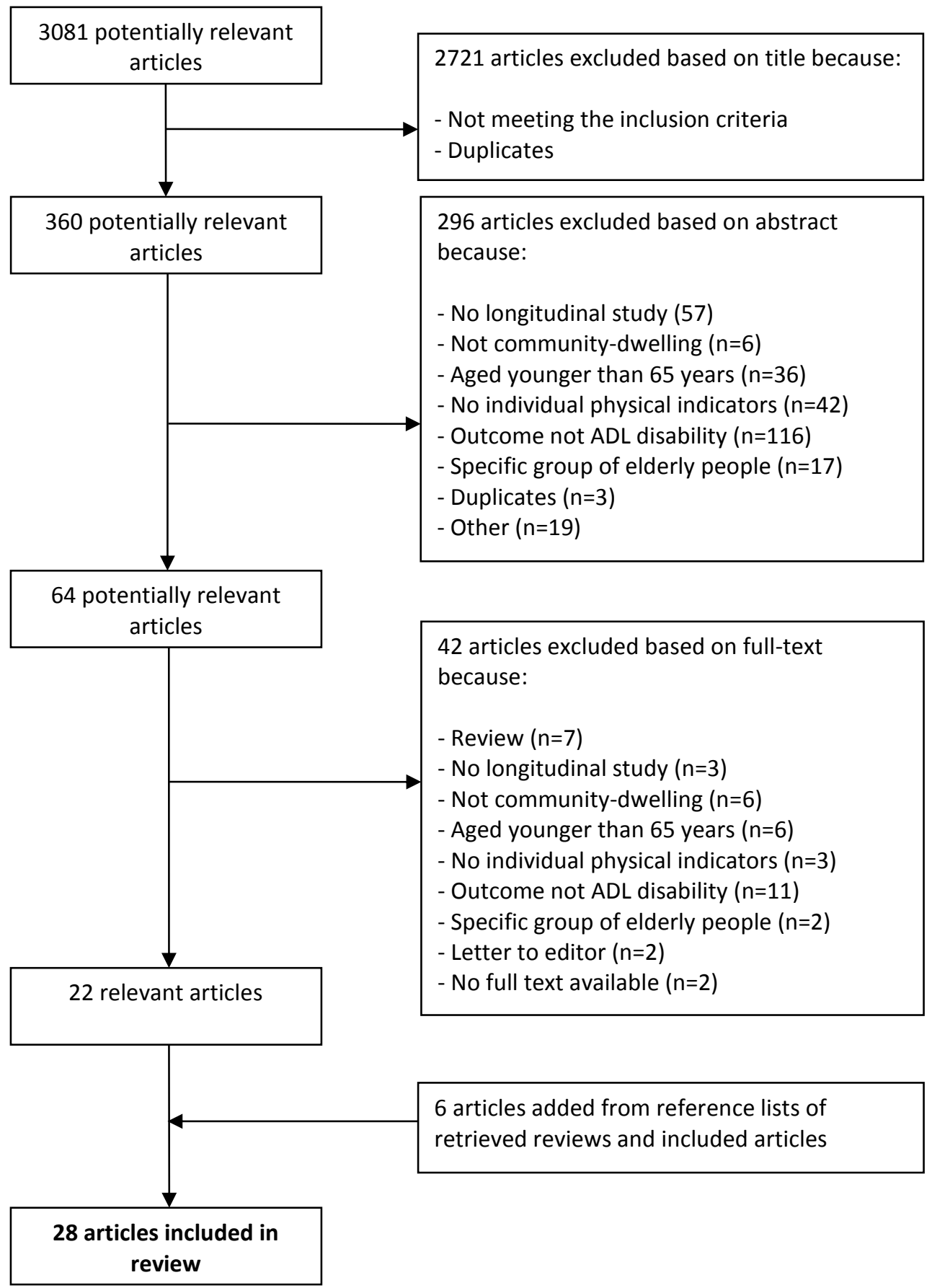

Figure 1. Flow chart of selection process 


\section{Characteristics of included studies}

The characteristics and details of the 28 included studies are presented in Table 2, ordered by year of publication. The main results from the included studies are presented in Table 3. All included studies were longitudinal cohort studies. Various studies reported on the same cohort data: 5 studies were based on the (Hispanic) Established Population for the Epidemiological Study of the Elderly, ${ }^{18-22} 3$ studies on the Precipitating Events Project, ${ }^{23-25}$ 2 studies on the Jerusalem Longitudinal Study, ${ }^{26,27} 3$ studies on the Longitudinal Interdisciplinary Study on Aging, ${ }^{28-30} 2$ studies on the Cardiovascular Health Study, ${ }^{31,32} 2$ studies on the Finland, Italy and The Netherlands Elderly Study, ${ }^{33,34}$ and 2 studies on the Project Safety cohort. ${ }^{35,36}$ The other 9 included studies were based on other cohort studies. ${ }^{37-45}$ The duration of follow-up of the studies varied from 1 year to 14 years (mean 5.4, SD 2.9 years). The sample size of the studies varied from 140 to 5727 (mean 1736, SD 2002). 75\% of the included studies were published between 1995 and 2005.

The quality of the 28 included studies varied between 20 and 26 ( 27 was highest score possible). The mean quality score was high: 22.5 (SD 1.6) points. For each quality item, the Cohen's Kappa was calculated to measure the agreement between the two reviewers. The Kappas varied between 1.00 and .13. Agreement was high (Kappa > .70) for 18 items, moderate (Kappa between .40 and .70) for 7 items, and low (Kappa <.40) for 2 items. Of the included studies, $50 \%$ had a follow-up of 5 years or longer ${ }^{19,21-24,26-29,31,32,34,37,38}$ and $68 \%$ included only participants who were free from disability at baseline. ${ }^{18-23,25,26,28-32,34-36 \text {, }}$ 40-42 Only $11 \%$ of the included studies did not use a standardized or valid measurement to measure the physical frailty indicators ${ }^{26,27,30}$ and only $4 \%$ did not use a standardized or valid measurement to measure ADL disability. ${ }^{38}$ All studies used appropriate multivariate analyses and corrected for confounders in their analyses. $39 \%$ of the included studies had an attrition below $20 \%{ }^{19,20,24,25,29,34-36,40,42,44}$

A variety of physical frailty indicators was measured in the included studies: weight loss, exhaustion, gait speed/walking speed/gait, muscle strength/grip strength, physical activity, balance, lower extremity function, chair stand, $360^{\circ}$ turn, bending over, foot taps, and hand signature. There was considerable variation in the way the same indicators were measured and operationalized in different studies. Also, different cutoff points were used in different studies. More detailed information regarding the measurement of the indicators is presented in Appendix 1.

The operationalization of ADL disability also varied across studies. Some studies defined disability as dependency in ADL at follow-up, others as difficulty in ADL at followup, and some studies used chronic ADL disability as an outcome measure. Some studies only measured disability in 4 different $A D L$, whereas others measured disability in 5,6 , or $7 \mathrm{ADL}$. More detailed information regarding the measurement of ADL disability is also presented in Appendix 1. 


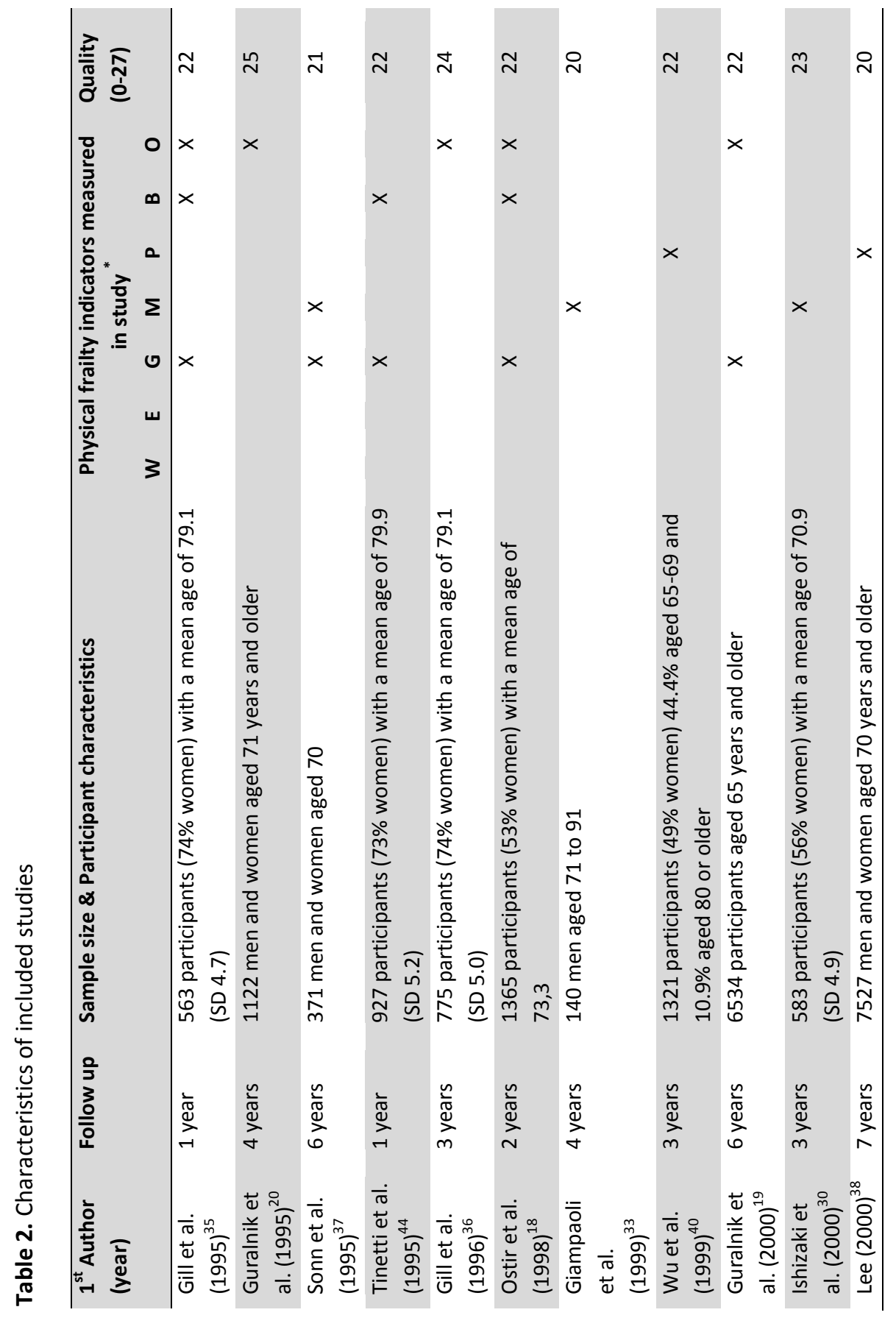




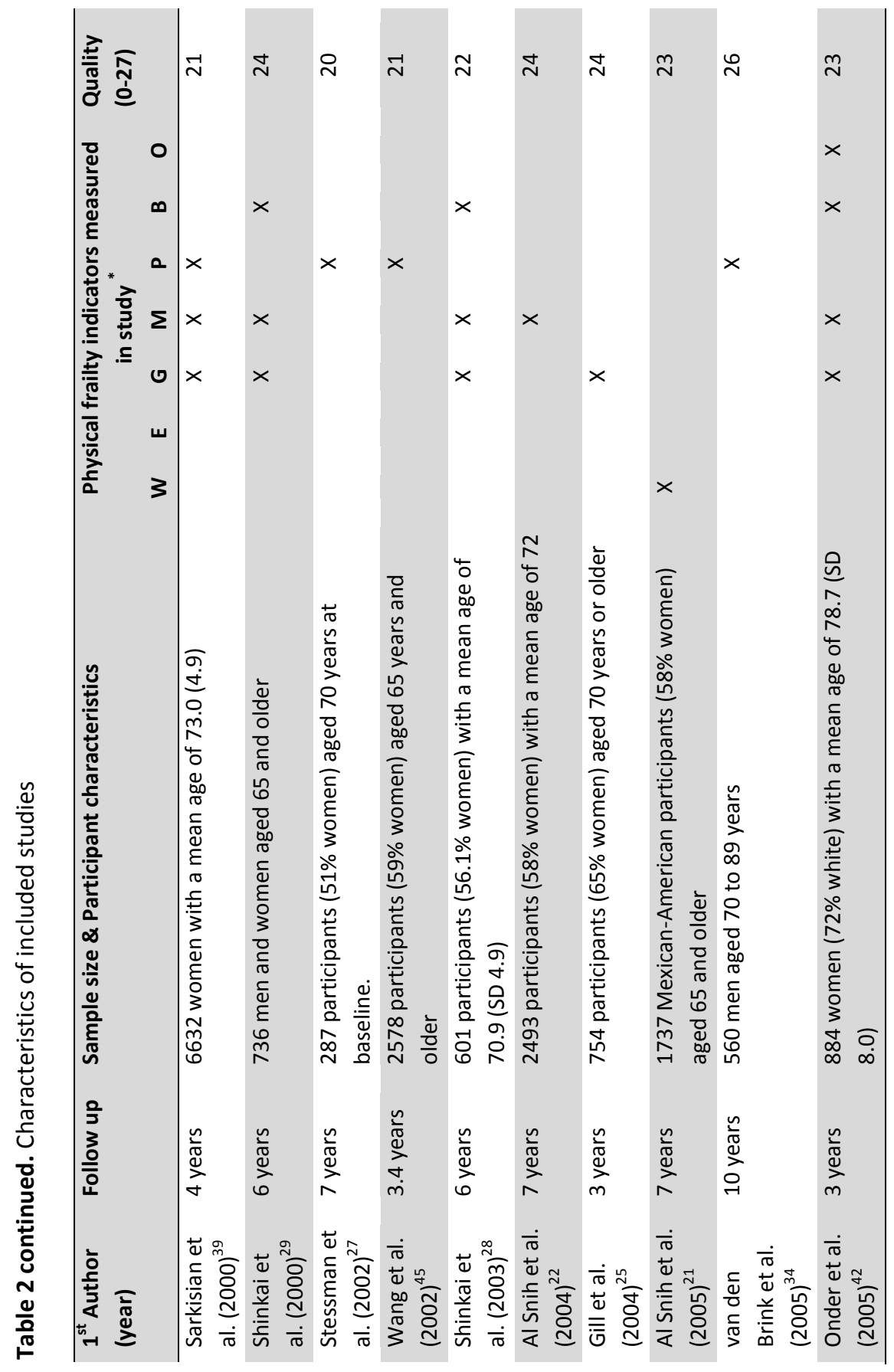




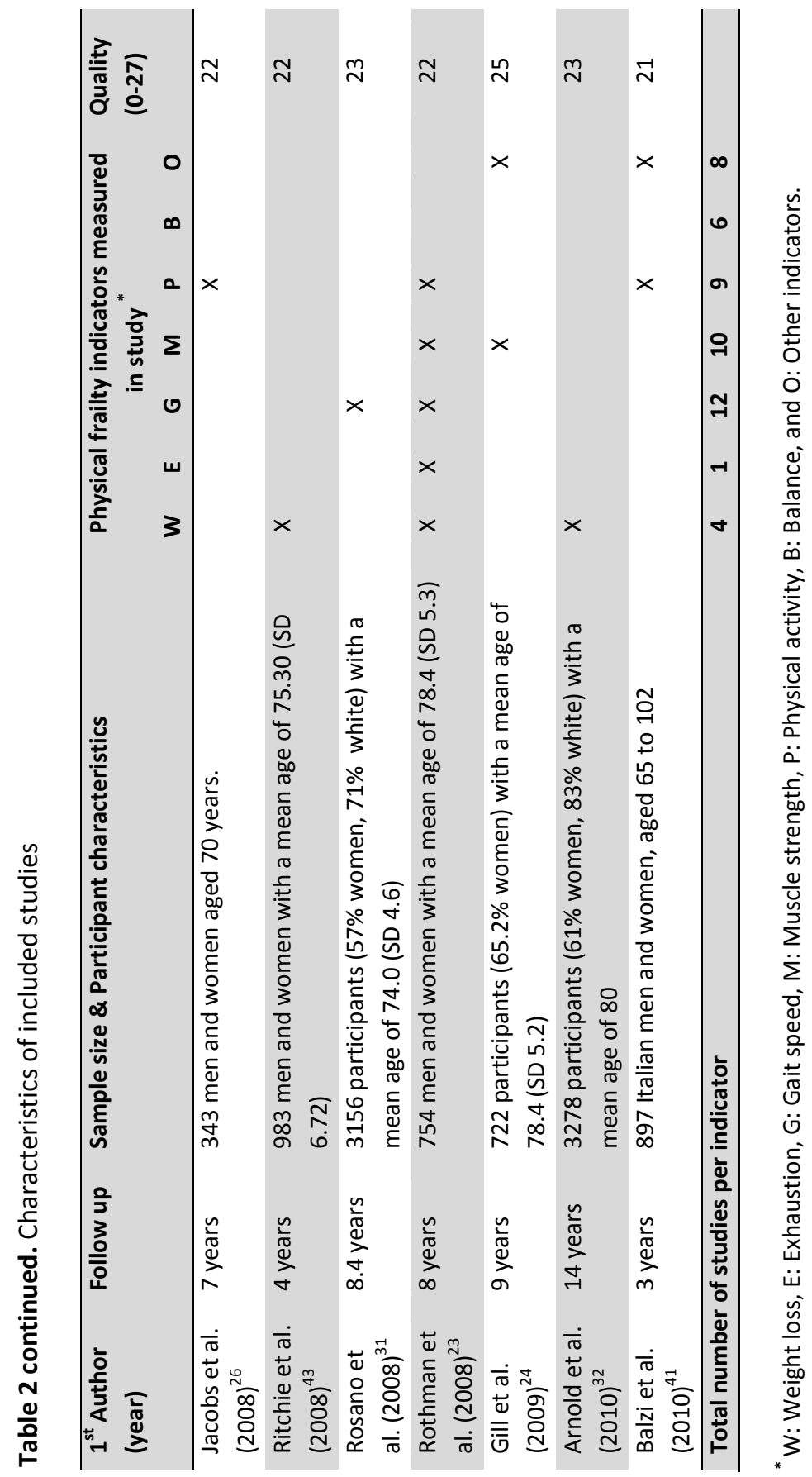




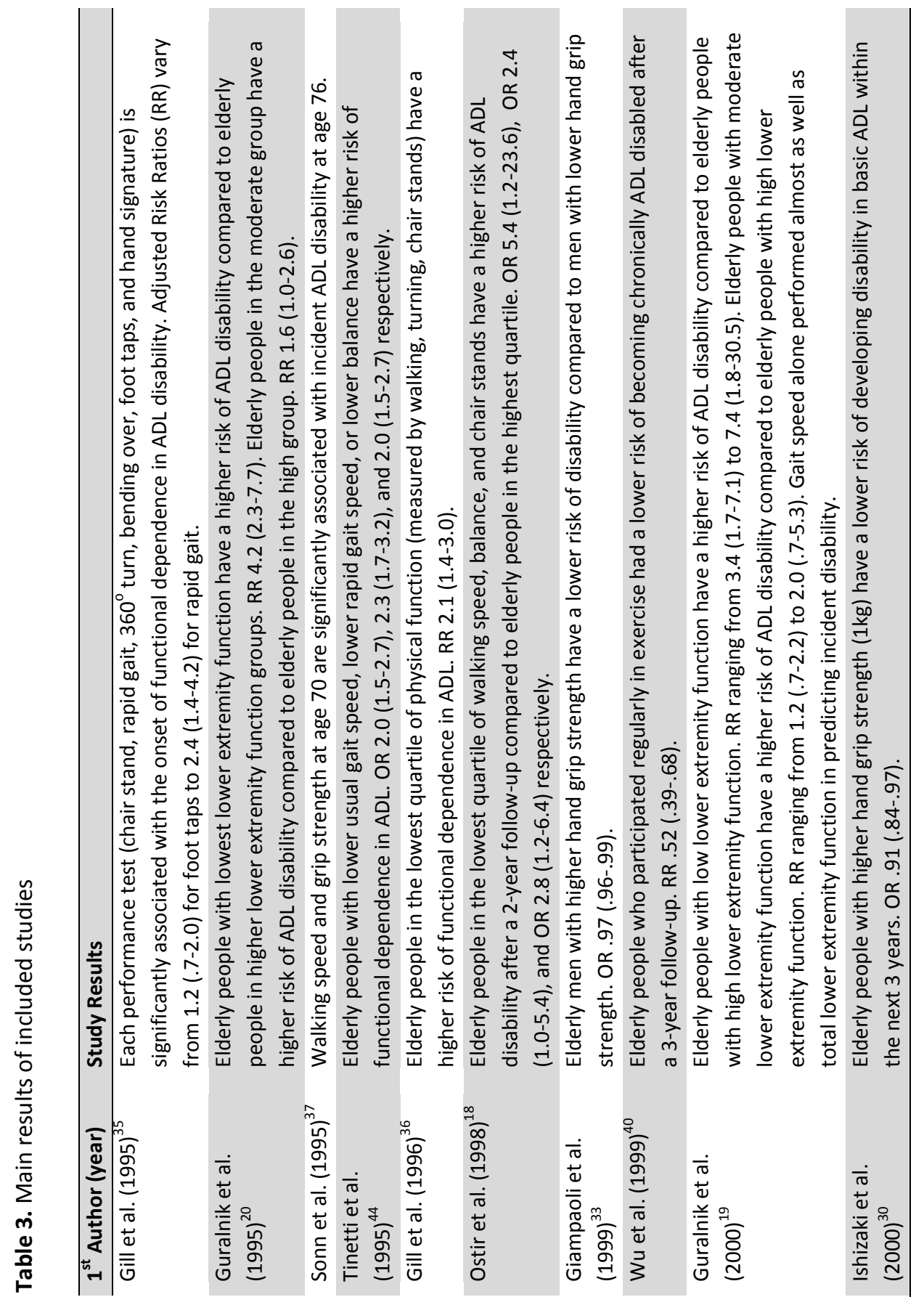




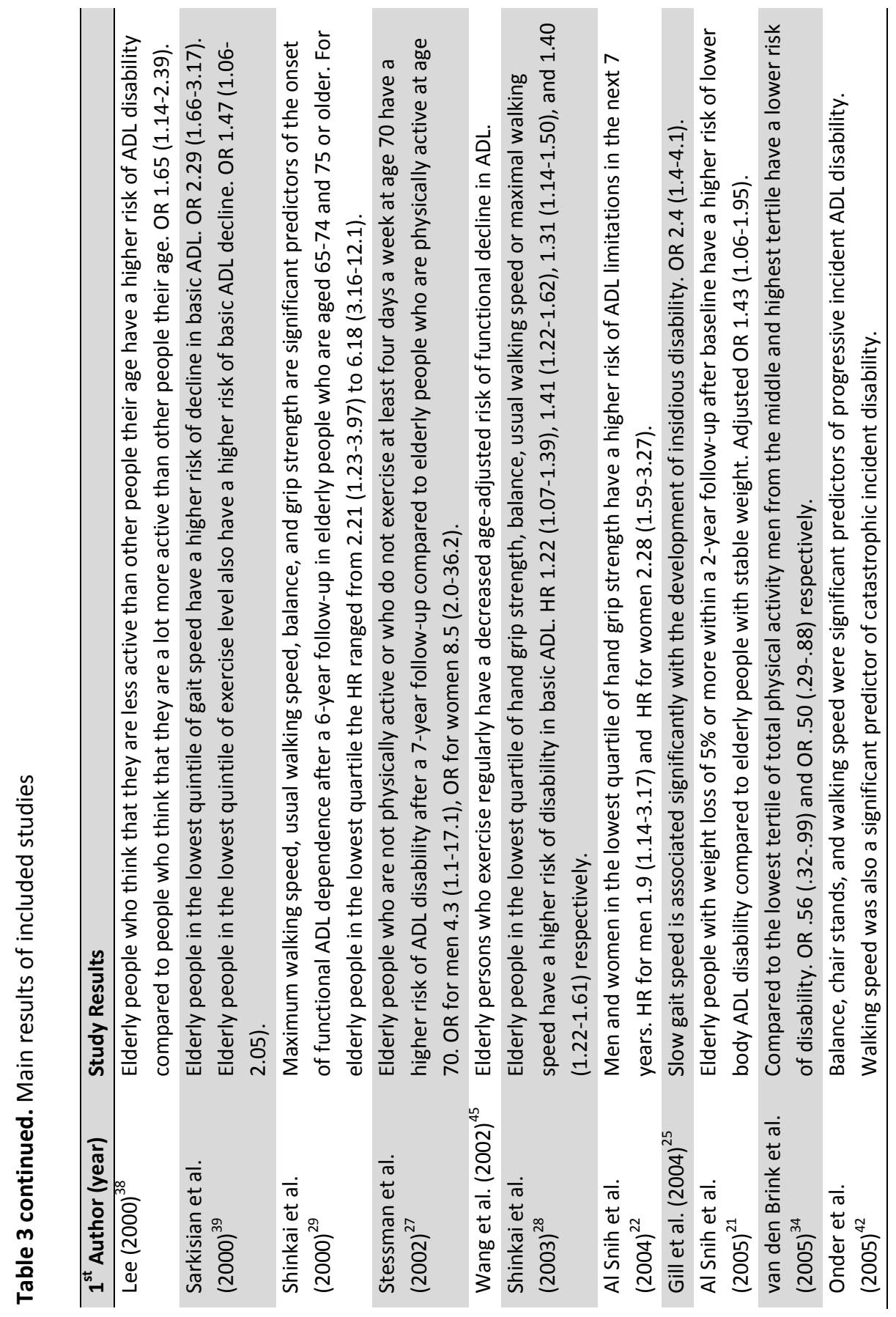




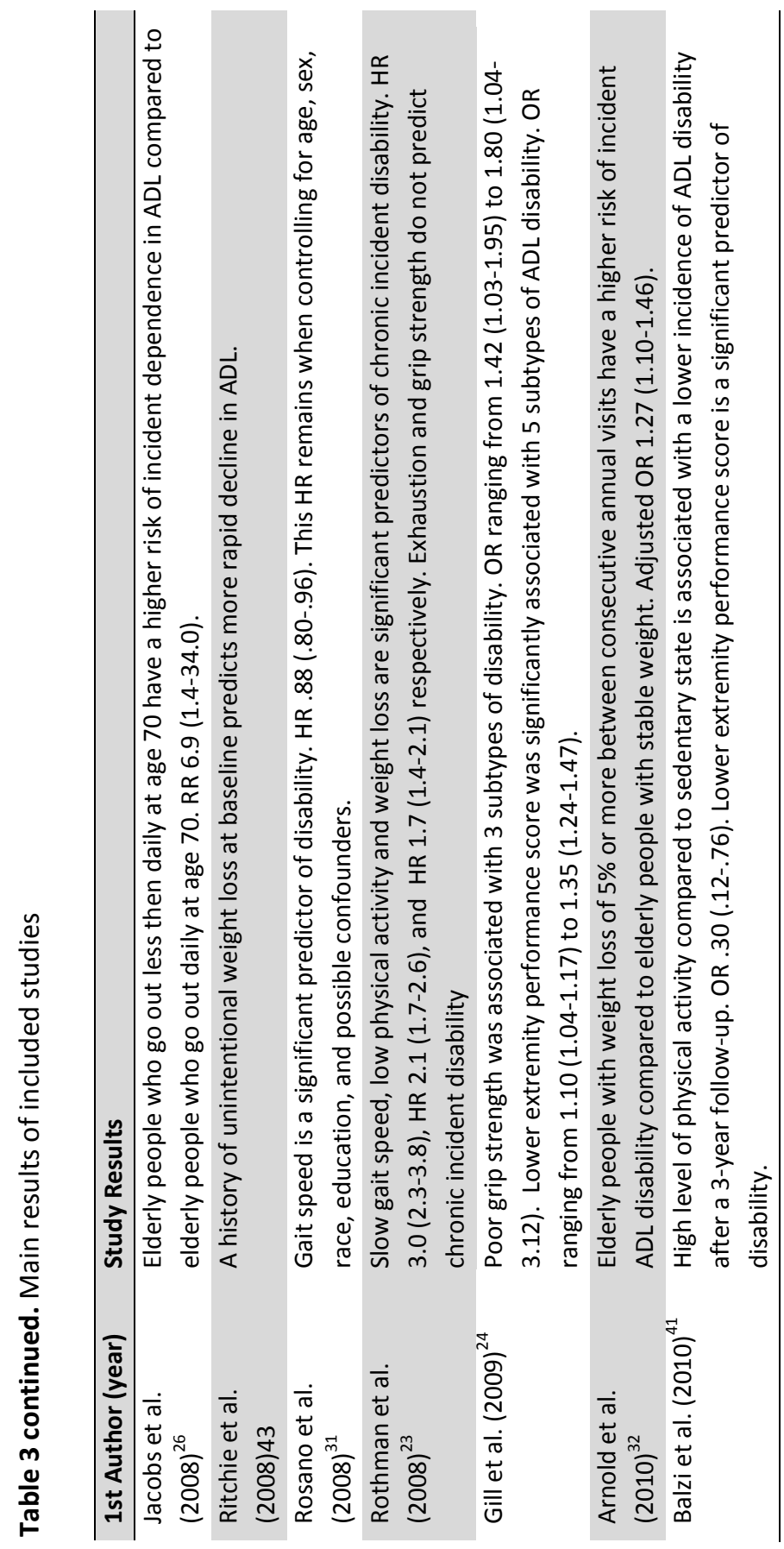




\section{Predictive value of physical frailty indicators on ADL disability}

For each individual physical frailty indicator the evidence regarding the predictive value is described below. The information is summarized in Table 4.

\section{Weight loss}

Four studies provided information regarding the predictive value of weight loss on ADL disability. These four studies were based on separate cohorts that only included participants who were free of disability at baseline. ${ }^{21,23,32,43}$ All four studies concluded that elderly people who report (unintentional) weight loss have a significant higher risk to develop ADL disability.

\section{Exhaustion}

Only one study reported on the predictive value of exhaustion on ADL disability. ${ }^{23}$ This study concluded that feelings of exhaustion are not a significant predictor of ADL disability in elderly people.

\section{Gait speed}

Twelve studies provided information about the predictive value of gait speed (walking speed) as an individual physical frailty indicator on ADL disability. ${ }^{18,19,23,25,28-30,35,37,39,42,44}$ All studies concluded that elderly people with slower gait speed have a higher risk of developing ADL disability. Nine studies were based on six separate cohort studies that only included participants free of ADL disability at baseline. ${ }^{18,19,23,25,28,29,31,35,42}$ The other three studies were separate cohort studies that included participants with and without disability at baseline. ${ }^{37,39,44}$

\section{Muscle strength}

Ten studies provided information about the predictive value of muscle strength or hand grip strength on ADL disability. ${ }^{22-24,28-30,33,37,39,42}$ Seven studies concluded that grip strength is a significant predictor of ADL disability. ${ }^{22,24,28-30,33,37}$ Four studies, using data from two separate cohorts, only included participants free of ADL disability at baseline. ${ }^{22,}$ 28-30 The other three separate cohort studies with a positive finding included participants with and without ADL disability at baseline. ${ }^{24,33,37}$ Three studies concluded that grip strength is not a significant predictor of ADL disability. ${ }^{23,39,42}$

\section{Physical activity}

Nine studies reported on the predictive value of physical activity or exercise on ADL disability. ${ }^{23,26,27,34,38-41,45}$ All nine studies concluded that elderly people who are more physically active or who participate in exercise more regularly have a lower risk of developing ADL disability. Five out of these nine studies only included participants free of 


\section{Chapter 2}

ADL disability at baseline. ${ }^{23,26,34,40,41}$ These five studies were based on five separate cohort studies. The other four separate cohort studies included participants with and without disability at baseline. ${ }^{27,38,39,45}$

\section{Balance}

Six studies provided information about the predictive value of balance. ${ }^{18,28,29,35,42,44}$ Five out of these six studies concluded that elderly people with poorer balance have a higher risk of developing ADL disability. ${ }^{28,29,35,42,44}$ These five studies were based on three separate cohorts that only included participants free of ADL disability at baseline. ${ }^{28,29,35,42}$ The other study with a positive finding included participants with and without ADL disability at baseline. ${ }^{44}$

\section{Other physical frailty indicators}

Eight studies reported on the predictive value of physical frailty indicators that were not mentioned above namely: lower extremity function, chair stands, $360^{\circ}$ turn, bending over, foot taps, and hand signature.

Five of these studies reported on lower extremity function. ${ }^{19,20,24,36,41}$ In all five studies, lower extremity function appeared to be a significant predictor of ADL disability. Elderly people with low lower extremity function had a higher risk of ADL disability at follow-up compared to people with moderate or high lower extremity function. Four of these studies were based on four separate cohorts that only included participants who were free of disability at baseline. ${ }^{19,20,24,36}$ The other cohort study included participants with and without ADL disability at baseline. ${ }^{41}$

Three studies investigated the predictive value of chair stands on ADL disability and concluded that this indicator is a significant predictor of ADL disability. ${ }^{18,35,42}$ Two studies were based on two separate cohorts that only included participants who were free of disability at baseline. ${ }^{18,35}$ The other cohort study included participants with and without ADL disability at baseline. ${ }^{42}$

The study by Gill et al. ${ }^{35}$ also investigated the predictive value of $360^{\circ}$ turn, bending over, foot taps, hand signature and concluded that all indicators were predictors for ADL disability. The cohort study only included participants who were free of disability at baseline. 
Table 4. Predictive strength of physical frailty indicators on ADL disability

\begin{tabular}{|c|c|c|c|c|}
\hline $\begin{array}{l}\text { Physical } \\
\text { frailty } \\
\text { indicator }\end{array}$ & $\begin{array}{l}\text { Total } \\
\text { number } \\
\text { of studies }\end{array}$ & $\begin{array}{l}\text { Number of studies, } \\
\text { only including } \\
\text { participants free of } \\
\text { disability at } \\
\text { baseline, that } \\
\text { reported a } \\
\text { significant increased } \\
\text { risk of ADL disability } \\
\text { (Number of cohorts) } \\
++\end{array}$ & $\begin{array}{l}\text { Number of studies, } \\
\text { including both } \\
\text { participants free and } \\
\text { not free of ADL } \\
\text { disability at } \\
\text { baseline, that } \\
\text { reported a } \\
\text { significant increased } \\
\text { risk of ADL disability } \\
\text { (Number of cohorts) } \\
+\end{array}$ & $\begin{array}{l}\text { Number of studies } \\
\text { reporting no } \\
\text { significant } \\
\text { increased risk of } \\
\text { ADL disability } \\
\text { (Number of } \\
\text { cohorts) } \\
\text { - }\end{array}$ \\
\hline Weight loss & 4 & $4(4)$ & $0(0)$ & $0(0)$ \\
\hline Exhaustion & 1 & $0(0)$ & $0(0)$ & $1(1)$ \\
\hline Gait speed & 12 & $9(6)$ & $3(3)$ & $0(0)$ \\
\hline $\begin{array}{l}\text { Muscle } \\
\text { strength }\end{array}$ & 10 & $4(2)$ & $3(3)$ & $3(3)$ \\
\hline $\begin{array}{l}\text { Physical } \\
\text { activity }\end{array}$ & 9 & $5(5)$ & $4(4)$ & $0(0)$ \\
\hline Balance & 6 & $4(3)$ & $1(1)$ & $1(1)$ \\
\hline $\begin{array}{l}\text { Others: } \\
\text { - Lower } \\
\text { extremity } \\
\text { function }\end{array}$ & 5 & $4(4)$ & $1(1)$ & $0(0)$ \\
\hline $\begin{array}{l}\text { - Chair stands } \\
\text { - } 360^{\circ} \text { turn, } \\
\text { bending over, } \\
\text { foot taps, } \\
\text { hand } \\
\text { signature }\end{array}$ & $\begin{array}{l}3 \\
1\end{array}$ & $\begin{array}{l}2(2) \\
1(1)\end{array}$ & $\begin{array}{l}1(1) \\
0(0)\end{array}$ & $\begin{array}{l}0(0) \\
0(0)\end{array}$ \\
\hline
\end{tabular}

\section{Discussion}

This review provides evidence that physical frailty indicators are predictors of ADL disability in community-dwelling elderly people aged 65 years and older. Elderly people with unintended weight loss, slower gait speed, lower grip strength, lower physical activity, lower exercise, poor balance, or low lower extremity function have a higher risk of ADL disability in the future. Apparently, physical frailty indicators do not only predict disability when they are related in a frailty phenotype ${ }^{12}$ but also independent of each other. 
The number of studies that focused on the predictive value on ADL disability differed per physical frailty indicator. Almost half of the included studies investigated the predictive value of gait speed whereas only one study reported on exhaustion. Besides that, there were large variations in the measurement of frailty indicators and ADL disability across the 28 included studies. Therefore, it is difficult to draw firm conclusions regarding the predictive power of the different indicators compared to each other. Nevertheless, taking into account the number of studies per indicator that suggested a significantly increased risk of ADL disability for this indicator provides some insight into the predictive value. Slow gait speed and low physical activity or exercise seem to have the highest predictive power, followed by weight loss, lower extremity function, balance, muscle strength, and other indicators. These findings should be interpreted with caution because pooling of the data from different studies was not possible.

The follow-up period of the cohorts varied across the included studies. Three studies had a follow-up of 1 or 2 years, six studies had a follow-up of 3 years, and the rest of the studies had a follow-up longer than 3 years. From this can be concluded that certain indicators predict disability in the short-term, long-term or both. For example, gait speed and balance predict the development of ADL disability after a follow up of one year ${ }^{35,44}$ and 6 years ${ }^{29}$ and physical activity predicts the development of disability after a follow-up of 3 years ${ }^{40,41}$ and 10 years. ${ }^{34}$ For the identification of elderly people who could benefit from an intervention that prevents ADL disability, it is more useful to know the 'shortterm' predictive value of the physical frailty indicators. It makes more sense to start with a preventive intervention when 'short-term predictors' are present in elderly people compared to a situation in which it will take another 6 years (or longer) before disability will develop.

A large part of the included studies had a relatively long follow-up period. It would be interesting to see whether indicators that predict disability after a long period of time, are also predictors of disability on the short term, e.g. 1 year. Besides that, it would also be useful to know how much the functioning of the physical frailty indicators would have to decrease before disability starts to develop in elderly people. Many of the included studies used quartile or quintile scores to define high or low physical functioning in the frailty indicators. As a result, many of these studies reported limited generalizability of their findings. Clear cutoff points have not been established yet for all indicators. This could be a focus of future research and should also be taken into account when developing interventions that can prevent disability in community-dwelling elderly people.

The only physical frailty indicator that appeared not to predict ADL disability was exhaustion. However, only one study included in this review focused on this. ${ }^{23}$ Exhaustion is a feeling not only related to physical functioning but also to mental/psychological functioning. Since the search strategy focused strongly on physical functioning, some studies regarding exhaustion might not have been retrieved. Another possibility might be 
that hardly any studies focusing on the predictive value of exhaustion have been conducted.

\section{Limitations of the review}

Despite the effort of the authors to conduct a sensitive search strategy, some relevant studies or unpublished articles may not have been retrieved. It is also very remarkable that almost all selected studies showed positive results and were of (very) high quality. This may indicate publication bias.

A remark must be made regarding the quality scores of the included studies which were quite high. This is not necessarily a limitation of the study but rather an exceptional finding. The high quality scores might have been caused by the selection criteria which allowed only prospective cohort studies to be included. Another possible explanation could be that the criteria that were used to assess the quality of the studies did not only refer to the methodological quality but also to the quality of reporting. This might have elevated the quality scores compared to when the quality of reporting criteria would not have been taken into account.

The term frailty was first introduced in the 1980's. If earlier studies used different definitions or measurement methods for frailty or its adverse outcomes compared to more recent studies, this might have introduced the possibility of time-lapse bias. However, the probability of this type of bias is probably small due to the broad search terms that were used in the search strategy.

Many studies that were included in the review were based on secondary dataanalyses. If measurement of the indicators or ADL disability was not the primary aim of the study, this might have resulted in the use of suboptimal measurement methods. However, the quality assessment of the included articles revealed that the majority of the studies used standardized or validated measurements for the indicators and outcome variables.

\section{Conclusions}

This review showed that physical frailty indicators predict ADL disability in communitydwelling elderly people. Slow gait speed and low physical activity/exercise seem to be the most powerful predictors followed by weight loss, lower extremity function, balance, muscle strength, and other indicators. Monitoring these indicators might be useful for identifying elderly people who could benefit from an intervention aimed at preventing ADL disability. Such an intervention could partly relieve the burden that frailty places on individuals, care providers and the health care system as a whole. 


\section{References}

1. Lally F, Crome P. Understanding frailty. Postgrad Med J. 2007;83:16-20.

2. Covinsky K. Aging, arthritis, and disability. Arthritis Rheum. 2006;55:175-176.

3. Rochat S, Cumming RG, Blyth F, Creasey H, Handelsman D, Le Couteur DG, et al. Frailty and use of health and community services by community-dwelling older men: the concord health and ageing in men project. Age Ageing. 2010;1:1-6.

4. Boyd CM, Xue QL, Simpson CF, Guralnik JM, Fried LP. Frailty, hospitalization, and progression of disability in a cohort of disabled older women. Am J Med. 2005;118:1225-1231.

5. Al Snih S, Graham JE, Ray LA, Samper-Ternent R, Markides KS, Ottenbacher KJ. Frailty and incidence of activities of daily living disability among older Mexican Americans. J Rehabil Med. 2009;41:892-897.

6. Ensrud KE, Ewing SK, Cawthon PM, Fink HA, Taylor BC, Cauley J et al. A comparison of frailty indexes for the prediction of falls, disability, fractures, and mortality in older men. J Am Geriatr Soc. 2009;57:492-498.

7. Morley JE, Perry HM, Miller DK. Something about frailty. J Gerontol A Biol Sci Med Sci. 2002;57A:698-704.

8. Markle-Reid M, Browne G. Conceptualizations of frailty in relation to older adults. J Adv Nurs. 2003;44:58-68.

9. Bergman H, Ferrucci L, Guralnik J, Hogan DB, Hummel S, Karunananthan S, Wolfson C. Frailty: an emerging research and clinical paradigm--issues and controversies. J Gerontol A Biol Sci Med Sci. 2007;62:731-737.

10. Levers MJ, Estabrooks CA, Ross Kerr JC. Factors contributing to frailty: literature review. J Adv Nurs. 2006;56:282-291.

11. Walston J, Hadley EC, Ferrucci L, Guralnik JM, Newman AB, Studenski SA, et al. Research agenda for frailty in older adults: toward a better understanding of physiology and etiology: summary from the American Geriatrics Society/National Institute on Aging Research Conference on Frailty in Older Adults. J Am Geriatr Soc. 2006;54:991-1001.

12. Fried LP, Tangen CM, Walston J, Newman AB, Hirsch C, Gottdiener J, et al. Frailty in older adults: evidence for a phenotype. J Gerontol A Biol Sci Med Sci. 2001;56:M146156.

13. Avlund K. Disability in old age. Longitudinal population-based studies of the disablement process. Dan Med Bull. 2004;51:315-349.

14. Altman DG. Systematic reviews of evaluations of prognostic variables. BMJ. 2001, 323:224-228. 
15. Stuck AE, Walthert JM, Nikolaus T, Büla CJ, Hohmann C, Beck JC. Risk factors for functional status decline in community-dwelling elderly people: a systematic literature review. Soc Sci \& Med. 1999;48:445-469.

16. Von Elm E, Altman DG, Egger M, Pocock SJ, Gotzsche PC, Vandenbroucke JP. The Strengthening the Reporting of Observational Studies in Epidemiology (STROBE) Statement: guidelines for reporting observational studies. Plos Med. 2007;4:16231627.

17. Tas U, Verhagen AP, Bierma-Zeinstra SMA, Odding E, Koes BW. Prognostic factors of disability in older people: a systematic review. Br J of Gen Prac. 2007;57:319-323.

18. Ostir GV, Markides KS, Black SA, Goodwin JS. Lower body functioning as a predictor of subsequent disability among older Mexican Americans. J Gerontol A Biol Sci Med Sci. 1998;53:M491-M495.

19. Guralnik JM, Ferrucci L, Pieper CF, Leveille SG, Markides KS, Ostir GV, et al. Lower extremity function and subsequent disability: consistency across studies, predictive models, and value of gait speed alone compared with the short physical performance battery. J Gerontol A Biol Sci Med Sci. 2000;55:M221-M231.

20. Guralnik JM, Ferrucci L, Simonsick EM, Salive ME, Wallace RB. Lower-extremity function in persons over the age of 70 years as a predictor of subsequent disability. $\mathrm{N}$ Engl J Med. 1995;332:556-561.

21. Al Snih S, Raji MA, Markides KS, Ottenbacher KJ, Goodwin JS. Weight change and lower body disability in older Mexican Americans. J Am Geriatr Soc. 2005;53:17301737.

22. Al Snih S, Markides KS, Ottenbacher KJ, Raji MA. Hand grip strength and incident ADL disability in elderly Mexican Americans over a seven-year period. Aging Clin Exp Res. 2004;16:481-486.

23. Rothman MD, Leo-Summers L, Gill TM. Prognostic significance of potential frailty criteria. J Am Geriatr Soc. 2008;56:2211-2116.

24. Gill TM, Murphy TE, Barry LC, Allore HG. Risk factors for disability subtypes in older persons. J Am Geriatr Soc. 2009;57:1850-1855.

25. Gill TM, Allore H, Holford TR, Guo Z. The development of insidious disability in activities of daily living among community-living older persons. Am J Med. 2004;117:484-491.

26. Jacobs JM, Cohen A, Hammerman-Rozenberg R, Azoulay D, Maaravi Y, Stessman J. Going outdoors daily predicts long-term functional and health benefits among ambulatory older people. J Aging Health. 2008;20:259-272.

27. Stessman J, Hammerman-Rozenberg R, Maaravi Y, Cohen A. Effect of exercise on ease in performing activities of daily living from age 70 to 77: the Jerusalem Longitudinal Study. J Am Geriatr Soc. 2002;50:1934-1938. 
28. Shinkai S, Kumagai S, Fujiwara Y, Amano H, Yoshida Y, Wanatabe S, et al. Predictors for the onset of functional decline among initially non-disabled older people living in a community during a 6-year follow-up. Geriatrics Gerntology International. 2003;3:31S39.

29. Shinkai S, Watanabe S, Kumagai S, Fujiwara Y, Amano H, Yoshida H, et al. Walking speed as a good predictor for the onset of functional dependence in a Japanese rural community population. Age Ageing. 2000;29:441-446.

30. Ishizaki T, Watanabe S, Suzuki T, Shibata $\mathrm{H}$, Haga $\mathrm{H}$. Predictors for functional decline among nondisabled older Japanese living in a community during a 3-year follow-up. J Am Geriatr Soc. 2000;48:1424-1429.

31. Rosano C, Newman AB, Katz R, Hirsch CH, Kuller LH. Association between lower digit symbol substitution test score and slower gait and greater risk of mortality and of developing incident disability in well-functioning older adults. J Am Geriatr Soc. 2008;56:1618-1625.

32. Arnold AM, Newman AB, Cushman M, Ding J, Kritchevsky S. Body weight dynamics and their association with physical function and mortality in older adults: the Cardiovascular Health Study. J Gerontol A Biol Sci Med Sci. 2010;65:63-70.

33. Giampaoli S, Ferrucci L, Cecchi F, Lo Noce C, Poce A, Dima F, et al. Hand-grip strength predicts incident disability in non-disabled older men. Age Ageing. 1999;28:283-288.

34. Van Den Brink CL, Picavet H, Van Den Bos GA, Giampaoli S, Nissinen A, Kromhout D. Duration and intensity of physical activity and disability among European elderly men. Disabil Rehabil. 2005;27:341-347.

35. Gill TM, Williams CS, Tinetti ME. Assessing risk for the onset of functional dependence among older adults: the role of physical performance. J Am Geriatr Soc. 1995;43:603609.

36. Gill TM, Williams CS, Richardson ED, Tinetti ME. Impairments in physical performance and cognitive status as predisposing factors for functional dependence among nondisabled older persons. J Gerontol A Biol Sci Med Sci. 1996;51A:M2830-M288.

37. Sonn U, Frandin K, Grimby G. Instrumental activities of daily living related to impairments and functional limitations in 70-year-olds and changes between 70 and 76 years of age. Scand J Rehabil Med. 1995;27:119-128.

38. Lee $\mathrm{Y}$. The predictive value of self-assessed general, physical, and mental health on functional decline and mortality in older adults. J Epidemiol Community Health. 2000;54:123-129.

39. Sarkisian CA, Liu H, Gutierrez PR, Seeley DG, Cummings SR, Mangione CM. Modifiable risk factors predict functional decline among older women: a prospectively validated clinical prediction tool. The Study of Osteoporotic Fractures Research Group. J Am Geriatr Soc. 2000;48:170-178. 
40. Wu SC, Leu SY, Li CY. Incidence of and predictors for chronic disability in activities of daily living among older people in Taiwan. J Am Geriatr Soc. 1999;47:1082-1086.

41. Balzi D, Lauretani F, Barchielli A, Ferrucci L, Bandinelli S, Buiatti E. Risk factors for disability in older persons over 3-year follow-up. Age Ageing. 2010;39:92-98.

42. Onder G, Penninx BW, Ferrucci L, Fried LP, Guralnik JM, Pahor M. Measures of physical performance and risk for progressive and catastrophic disability: results from the Women's Health and Aging Study. J Gerontol A Biol Sci Med Sci. 2005;60:74-79.

43. Ritchie CS, Locher JL, Roth DL, McVie T, Sawyer P, Allman R. Unintentional weight loss predicts decline in activities of daily living function and life-space mobility over 4 years among community-dwelling older adults. J Gerontol A Biol Sci Med Sci. 2008;63:6775.

44. Tinetti ME, Inouye SK, Gill TM, Doucette JT. Shared risk factors for falls, incontinence, and functional dependence. JAMA. 1995;273:1348-1353.

45. Wang L, Van Belle G, Kukull WB, Larson EB. Predictors of functional change: a longitudinal study of non-demented people aged 65 and older. J Am Geriatr Soc. 2002;50:1525-1534. 
Appendix 1. Measurement of physical frailty indicators and ADL disability

\begin{tabular}{|c|c|c|}
\hline Article & Measurement Indicator & Measurement Disability \\
\hline \multicolumn{3}{|c|}{ Weight } \\
\hline $\begin{array}{l}\text { Al Snih et al. } \\
(2005)^{21}\end{array}$ & $\begin{array}{l}\text { Weight was measured at baseline and } \\
\text { after } 2 \text { years follow-up. Weight loss was } \\
\text { defined as losing } 5 \% \text { or more of the total } \\
\text { body weight after } 2 \text { years follow-up. }\end{array}$ & $\begin{array}{l}\text { Participants were asked whether they } \\
\text { needed help in four ADL (bathing, } \\
\text { dressing, transferring, eating). Lower } \\
\text { body ADL limitation was defined as } \\
\text { needing help with or unable to perform } \\
\text { one or more ADL. }\end{array}$ \\
\hline $\begin{array}{l}\text { Ritchie et al. } \\
(2008)^{43}\end{array}$ & $\begin{array}{l}\text { Participants were asked at baseline } \\
\text { whether they lost more than } 10 \text { pounds } \\
\text { in the past year and whether this was } \\
\text { intentional or not. Answers were coded } \\
\text { into three categories: no loss, } \\
\text { intentional loss, and unintentional loss. }\end{array}$ & $\begin{array}{l}\text { Self-reported difficulty with six ADL } \\
\text { (eating, toileting, dressing, transferring, } \\
\text { bathing, and walking) was measured on } \\
\text { a 4-point scale (0-3). Sum scores were } \\
\text { calculated to indicate the level of } \\
\text { disability. }\end{array}$ \\
\hline $\begin{array}{l}\text { Rothman et } \\
\text { al. }(2008)^{23}\end{array}$ & $\begin{array}{l}\text { Participants were asked at baseline } \\
\text { whether they lost more than } 10 \text { pounds } \\
\text { in the past year. Answers were coded } \\
\text { into two categories: yes and no. }\end{array}$ & $\begin{array}{l}\text { Chronic disability was defined as a new } \\
\text { ADL disability that was present for at } \\
\text { least } 3 \text { consecutive months (bathing, } \\
\text { dressing, walking and transferring). }\end{array}$ \\
\hline $\begin{array}{l}\text { Arnold et al. } \\
(2010)^{32}\end{array}$ & $\begin{array}{l}\text { Weight was measured during annual } \\
\text { exams. Weight loss was defined as a loss } \\
\text { of } 5 \% \text { of total body weight between } \\
\text { consecutive annual visits or from } \\
\text { baseline, without an intervening } 5 \% \text { gain }\end{array}$ & $\begin{array}{l}\text { Disability was defined as any difficulty } \\
\text { with one or more of six ADL (walking } \\
\text { around the home, dressing, eating, } \\
\text { bathing, toileting, and getting out of a } \\
\text { bed or chair). }\end{array}$ \\
\hline
\end{tabular}

\begin{tabular}{|c|c|c|}
\hline \multicolumn{3}{|c|}{ Exhaustion } \\
\hline $\begin{array}{l}\text { Rothman et } \\
\text { al. }(2008)^{23}\end{array}$ & $\begin{array}{l}\text { Participants were asked how often 'they } \\
\text { felt like everything they did was an } \\
\text { effort' and hot often 'they could not get } \\
\text { going'. Exhaustion was defined as } \\
\text { answering 'much or most of the time' to } \\
\text { one of these questions. }\end{array}$ & $\begin{array}{l}\text { Chronic disability was defined as a new } \\
\text { ADL disability that was present for at } \\
\text { least } 3 \text { consecutive months (bathing, } \\
\text { dressing, walking and transferring). }\end{array}$ \\
\hline \multicolumn{3}{|c|}{ Gait speed } \\
\hline $\begin{array}{l}\text { Gill et al. } \\
(1995)^{35}\end{array}$ & $\begin{array}{l}\text { Rapid gait speed was measured while } \\
\text { participants walked back and forth over } \\
\text { a } 10 \text {-foot course as quickly as they } \\
\text { could. Slow gait speed was defined as } \\
\text { the lowest quartile. }\end{array}$ & $\begin{array}{l}\text { Disability was defined as receiving } \\
\text { personal assistance or being completely } \\
\text { dependent in one or more ADL (bathing, } \\
\text { dressing, transferring, eating, personal } \\
\text { grooming, and walking across a small } \\
\text { room). }\end{array}$ \\
\hline
\end{tabular}


Sonn et al. Maximal walking speed was measured $(1995)^{37} \quad$ over 30 meters indoors.

Tinetti et al. $(1995)^{44}$

Ostir et al. $(1998)^{18}$

Guralnik et al. $(2000)^{19}$

Sarkisian et al. $(2000)^{39}$

Shinkai et al. (2003)28

Participants were asked to walk 10 foot back and forth as fast as they could. Slow gait speed was defined as the lowest quartile.

Participants were asked to walk 8 foot twice at a usual pace. The fastest timed walk was used for scoring purposes. Slowest gait speed was defined as taking longer than 9 seconds to walk 8 foot (lowest quartile).

Participants were asked to walk 8 foot twice at a usual pace. The fastest timed walk was used for scoring purposes. Slowest gait speed was defined as taking longer than 5.7 seconds to walk 8 foot (lowest quartile).

Gait speed was determined by measuring the time in seconds needed to walk 6 meters at a rapid pace. Slow gait speed was defined as the lowest quintile.

Shinkai et al. Usual and maximum walking speed (2000)29 (measured over 5 meter of an 11 meter course)

Walking speed was measured over a 5 meter distance (between the 3 and 8 meter marks from the start of the walkway). For maximal walking speed, the fastest result of two attempts was used. Slow gait speed was defined as the lowest quartile.
Disability was defined by dependency on others in one or more of five personal ADL (bathing, toileting, transferring, feeding, dressing).

Disability was defined as self-reported need for human help with one or more ADL (eating, grooming, bathing, dressing, transferring, walking around the house).

Disability was defined as ADL dependency (activities not specified in article).

Disability was defined as inability to perform one or more ADL (transferring, toileting, bathing, walking across a small room) without help from another person.

Disability was defined as a decrease of one or more ADL able to complete without assistance between visits 2 and 4.

Dependence in ADL was defined as needing help from someone else or being unable to perform one of five ADL (bathing, dressing, walking, eating and continence).

Disability was defined as needing help from someone else or being unable to perform one or more ADL (bathing, dressing, walking, eating and continence). 


$\begin{array}{ll}\text { Gill et al. } & \text { Participants walked back and forth over } \\ (2004)^{25} & \text { a } 3 \text { meter course as quickly as possible. } \\ & \text { Slow gait speed was defined as a score } \\ & \text { of } 10 \text { seconds or slower. }\end{array}$

Onder et al. Participants were asked twice to walk as $(2005)^{42}$

Rosano et al. $(2008)^{31}$

Rothman et al. $(2008)^{23}$ fastest as possible over a 4 meter course. Slow walking speed was defined as walking slower than $0.09 \mathrm{~m} / \mathrm{second}$ or being unable to complete the test.
Disability was defined as needing help from someone else or being unable to perform one or more ADL (bathing, dressing, walking around at home, transferring).

Participants were classified with progressive disability if they reported a lot of difficulty or inability to perform an ADL between follow-ups 2 and 6 and they had a little or some difficulty at one or both of the semiannual assessments before the onset of disability (bathing, dressing, eating, transferring, toileting).

Incident disability was defined as selfreported difficulty or inability to perform at least one of six ADL without assistance (bathing, dressing, eating, toileting, walking around the home, and transferring).

Chronic disability was defined as a new ADL disability that was present for at least 3 consecutive months (bathing, dressing, walking and transferring).

\begin{tabular}{ll}
\hline $\begin{array}{l}\text { Sonn et al. } \\
(1995)^{37}\end{array}$ & $\begin{array}{l}\text { Grip stenght in left and right hand was } \\
\text { measured with a Vigorimeter at an } \\
\text { elbow-angle of } 90^{\circ} \text { and with the } \\
\text { shoulder joint in neutral position } \\
\text { (medium-sized ball for women and big } \\
\text { ball for men). The strongest measure } \\
\text { was scored. }\end{array}$ \\
& $\begin{array}{l}\text { Giampaoli et } \\
\text { al. (1999) }\end{array}$ \\
& $\begin{array}{l}\text { by the hand-grip test using the Martin } \\
\text { dynamometer, women and men were } \\
\text { divided into quartiles. }\end{array}$
\end{tabular}

Disability was defined by dependency on others in one or more of five personal ADL (bathing, toileting, transferring, feeding, dressing).

Disability was defined by inability to perform one or more ADL without help (walking around in the house, transferring, toileting, bathing, dressing). 


\begin{tabular}{ll}
\hline $\begin{array}{l}\text { Ishizaki et al. } \\
(2000)^{30}\end{array}$ & $\begin{array}{l}\text { Handgrip strength was measured twice } \\
\text { in the dominant had using a hand } \\
\text { dynamometer. The best out of these } \\
\text { two efforts was used in the analyses. }\end{array}$ \\
Sarkisian et & $\begin{array}{l}\text { Maximum grip strength was measured } \\
\text { al. (2000) }\end{array}$ \\
& $\begin{array}{l}\text { with a grip dynamometer in both hands } \\
\text { and averaged. Low grip strength was } \\
\text { defined as the lowest quintile. }\end{array}$ \\
Shinkai et al. & $\begin{array}{l}\text { Handgrip strength was evaluated twice } \\
(2000)^{29}\end{array}$ \\
& $\begin{array}{l}\text { using a mechanical dynamometer in the } \\
\text { dominant hand. The strongest out of } \\
\text { two efforts was used in the analyses. } \\
\text { Low grip strength was defined by the } \\
\text { lowest quartile. }\end{array}$
\end{tabular}

Shinkai et al. Handgrip strength was evaluated twice $(2003)^{28} \quad$ using a mechanical dynamometer in the dominant hand. The strongest out of two efforts was used in the analyses. Low grip strength was defined by the lowest quartile.

Al Snih et al. Hand grip strength in the dominant (2004)22

Onder et al. (2005)42

Rothman et al. (2008)23 hand was measured in kilograms using a hand-held dynamometer in a sitting position with elbow residing on the table.

The best effort of three measurements of grip strength was used in the analyses. Participants who scored $5 \mathrm{~kg}$ or less were classified as worst performers.

Grip strength was measured using a handheld dynamometer and considered low when below sex- and body mass index-specific cutoff points.
Disability was defined as a loss of independence in one or more ADL (walking, feeding, continence, bathing, dressing).

Disability was defined as a decrease of one or more $A D L$ able to complete without assistance between visits 2 and 4.

Dependence in ADL was defined as the subject needing help from someone else or being unable to perform one of five ADL (bathing, dressing, walking, eating and continence).

Disability was defined as needing help from someone else or being unable to perform one or more ADL (bathing, dressing, walking, eating and continence).

Disability was defined by needing help or being unable to perform one or more ADL (walking across a small room, bathing, grooming, dressing, eating, transferring, toileting).

Participants were classified with progressive disability if they reported a lot of difficulty or inability to perform an ADL between follow-ups 2 and 6 and they had a little or some difficulty at one or both of the semiannual assessments before the onset of disability (bathing, dressing, eating, transferring, toileting).

Chronic disability was defined as a new ADL disability that was present for at least 3 consecutive months (bathing, dressing, walking and transferring). 


$\begin{array}{ll}\text { Gill et al. } & \text { Grip strength was measured using a } \\ (2009)^{24} & \text { handheld dynamometer and considered } \\ & \text { low when below sex- and body mass } \\ & \text { index-specific cutoff points. }\end{array}$

Gill et al.
Disability is defined as needing help with one or more ADL. Five different types of disability were defined (transient, short-term, long-term, recurrent, unstable).

\begin{tabular}{|c|c|c|}
\hline \multicolumn{3}{|c|}{ Physical activity } \\
\hline $\begin{array}{l}\text { Wu et al. } \\
(1999)^{40}\end{array}$ & $\begin{array}{l}\text { Participants who exercised (folk } \\
\text { dancing, hiking, jogging or walking) at } \\
\text { least twice a week were considered as } \\
\text { routine recreational exercisers. }\end{array}$ & $\begin{array}{l}\text { Participants incapable of performing } \\
\text { one of six ADL (bathing, dressing, } \\
\text { transfers, toileting, eating, walking } \\
\text { inside the home) independently for } \\
\text { more than } 3 \text { months were considered } \\
\text { chronically disabled. }\end{array}$ \\
\hline Lee $(2000)^{38}$ & $\begin{array}{l}\text { Participants were asked whether they } \\
\text { think they are more, the same, or less } \\
\text { active compared to others their age to } \\
\text { assess the level of physical activity. } \\
\text { Besides that, participants who thought } \\
\text { they get enough exercise were defined } \\
\text { as exercisers. }\end{array}$ & $\begin{array}{l}\text { Disability was defined as having } \\
\text { difficulty with or dependence in ADL } \\
\text { (bathing, dressing, eating, transferring, } \\
\text { toileting) }\end{array}$ \\
\hline $\begin{array}{l}\text { Sarkisian et } \\
\text { al. }(2000) 39\end{array}$ & $\begin{array}{l}\text { Exercise level was examined with a } \\
\text { modified Paffenbarger survey. } \\
\text { Participant with scores in the lowest } \\
\text { quintile were classified as low activity } \\
\text { level. }\end{array}$ & $\begin{array}{l}\text { Disability was defined as a decrease of } \\
\text { one or more } A D L \text { able to complete } \\
\text { without assistance between visits } 2 \text { and } \\
4 .\end{array}$ \\
\hline $\begin{array}{l}\text { Stessman et } \\
\text { al. }(2002) 27\end{array}$ & $\begin{array}{l}\text { Participants who exercised at least four } \\
\text { days a week were classified as } \\
\text { exercisers. }\end{array}$ & $\begin{array}{l}\text { Disability was defined as independency } \\
\text { in four } A D L \text { (bathing, toileting, dressing, } \\
\text { rising from a chair). }\end{array}$ \\
\hline $\begin{array}{l}\text { Wang et al. } \\
(2002) 45\end{array}$ & $\begin{array}{l}\text { Participants who participated in one of } \\
\text { the following forms of exercise at least } \\
\text { three times per week were classified as } \\
\text { performing regular exercise (walking, } \\
\text { hiking, bicycling, aerobics, swimming, } \\
\text { water aerobics, weight training or other } \\
\text { exercise). }\end{array}$ & $\begin{array}{l}\text { The level of disability in six ADL (walking } \\
\text { around the house, bathing, dressing, } \\
\text { transferring, eating, toileting) was } \\
\text { assessed on an scale from } 0 \text { to } 3 \\
\text { resulting in a maximum score. }\end{array}$ \\
\hline $\begin{array}{l}\text { van den Brink } \\
\text { et al. } \\
(2005) 34\end{array}$ & $\begin{array}{l}\text { Physical activity was measured with a } \\
\text { standardized self-administered } \\
\text { questionnaire that measures duration } \\
\text { and intensity. Participants were divided } \\
\text { into three categories: low, middle, high } \\
\text { activity. }\end{array}$ & $\begin{array}{l}\text { Disability was defined as needing help } \\
\text { with one or more ADL (walking, } \\
\text { transferring, eating, washing, dressing, } \\
\text { toileting). }\end{array}$ \\
\hline
\end{tabular}




\begin{tabular}{|c|c|c|}
\hline $\begin{array}{l}\text { Jacobs et al. } \\
(2008)^{26}\end{array}$ & $\begin{array}{l}\text { Physical activity was measured by asking } \\
\text { participant how frequent they go } \\
\text { outdoors (daily, nearly daily, } 2-3 \text { times a } \\
\text { week, once a week, less than once a } \\
\text { week) }\end{array}$ & $\begin{array}{l}\text { Disability was defined as needing } \\
\text { assistance of another person in one or } \\
\text { more ADL (transferring, dressing, } \\
\text { bathing, toileting, eating, continence). }\end{array}$ \\
\hline $\begin{array}{l}\text { Rothman et } \\
\text { al. }(2008)^{23}\end{array}$ & $\begin{array}{l}\text { Physical activity was measured with the } \\
\text { PASE questionnaire. Low physical } \\
\text { activity was defined as a score below } 64 \\
\text { for men and below } 52 \text { for women. }\end{array}$ & $\begin{array}{l}\text { Chronic disability was defined as a new } \\
\text { ADL disability that was present for at } \\
\text { least } 3 \text { consecutive months (bathing, } \\
\text { dressing, walking and transferring). }\end{array}$ \\
\hline $\begin{array}{l}\text { Balzi et al. } \\
(2009)^{41}\end{array}$ & $\begin{array}{l}\text { Physical activity was measured with an } \\
\text { ordinal 7-point scale and dichotomized } \\
\text { into absent/light activity vs. moderate } \\
\text { activity. }\end{array}$ & $\begin{array}{l}\text { Worsening and development of new } \\
\text { disability was defined as needing help } \\
\text { from another person in ADL. }\end{array}$ \\
\hline
\end{tabular}

\begin{tabular}{ll}
\hline & Balance \\
\hline Gill et al. & Balance was examined as part of the \\
$(1995)^{35}$ & $\begin{array}{l}\text { balance subscale of the Performance } \\
\text { Oriented Mobility Assessment. }\end{array}$
\end{tabular}

Tinetti et al. Participants performed various balance $(1995)^{44} \quad$ maneuvers from the Performance Oriented Mobility Assessment including side-by-side, sterna nudge, tandem, and one-leg stands

Ostir et al. Participants performed three balance $(1998)^{18} \quad$ related tasks of increasing difficulty (side-by-side, semi-tandem and tandem stand) which were timed. Performance was scored on a 3-point scale.

Shinkai et al. Balance was measured by timing how $(2000)^{29} \quad$ long participants could stand on 1 leg until balance was lost. The scores were divided into quartiles.

Shinkai et al. Balance was measured by timing how $(2003)^{28} \quad$ long participants could stand on 1 leg until balance was lost. The scores were divided into quartiles.
Disability was defined as receiving personal assistance or being completely dependent in one or more ADL (bathing, dressing, transferring, eating, personal grooming, and walking across a small room).

Disability was defined as self-reported need for human help with one or more ADL (eating, grooming, bathing, dressing, transferring, walking around the house).

Disability was defined as ADL dependency (activities not specified in article).

Dependence in ADL was defined as needing help from someone else or being unable to perform one of five $A D L$ (bathing, dressing, walking, eating and continence).

Disability was defined as needing help from someone else or being unable to perform one or more ADL (bathing, dressing, walking, eating and continence). 
Onder et al. Participants performed a chair stand $(2005)^{42} \quad$ test and balance test.
Participants were classified with progressive disability if they reported a lot of difficulty or inability to perform an ADL between follow-ups 2 and 6 and they had a little or some difficulty at one or both of the semiannual assessments before the onset of disability (bathing, dressing, eating, transferring, toileting).

\begin{tabular}{|c|c|c|}
\hline \multicolumn{3}{|c|}{ Others } \\
\hline $\begin{array}{l}\text { Gill et al. } \\
(1995)^{35}\end{array}$ & $\begin{array}{l}\text { The following timed performance tests } \\
\text { were administered to the participants: } \\
\text { ten foot taps, three chair stands, } 360^{\circ} \\
\text { turn, time to bend over and pick up a } \\
\text { pen, and time to pick up a pencil and } \\
\text { complete a signature. Participants } \\
\text { performed these tests as fast as } \\
\text { possible. Participants were divided into } \\
\text { quartiles of performance. }\end{array}$ & $\begin{array}{l}\text { Disability was defined as receiving } \\
\text { personal assistance or being completely } \\
\text { dependent in one or more ADL } \\
\text { (bathing, dressing, transferring, eating, } \\
\text { personal grooming, walking across a } \\
\text { small room). }\end{array}$ \\
\hline $\begin{array}{l}\text { Guralnik et } \\
\text { al. }(1995)^{20}\end{array}$ & $\begin{array}{l}\text { A summary performance score was } \\
\text { created for each participant by adding } \\
\text { the scores for the tests of standing } \\
\text { balance, walking, and repeatedly rising } \\
\text { from a chair. Scores ranged from } 3 \text { to } 12 \\
\text { and three groups were created based } \\
\text { on this score. These groups were } \\
\text { compared in the analysis. }\end{array}$ & $\begin{array}{l}\text { Disability was defined as the inability to } \\
\text { perform one or more of the basic } \\
\text { activities without the help of another } \\
\text { person (moving from a bed to a chair, } \\
\text { using the toilet, bathing, walking across } \\
\text { a small room). }\end{array}$ \\
\hline $\begin{array}{l}\text { Gill et al. } \\
(1996)^{36}\end{array}$ & $\begin{array}{l}\text { The following timed performance tests } \\
\text { were administered to the participants: } \\
\text { three chair stands, } 360^{\circ} \text { turn, and rapid } \\
\text { gait back and forth over a } 10 \text {-foot } \\
\text { course. Participants performed these } \\
\text { tests as fast as possible. Participants } \\
\text { were divided into quartiles of } \\
\text { performance. }\end{array}$ & $\begin{array}{l}\text { Disability was defined as requiring } \\
\text { personal assistance in one or more of } \\
\text { seven ADL at either the 1- or 3-year } \\
\text { follow-up interview (walking around the } \\
\text { house, bathing, dressing, transferring, } \\
\text { eating, toileting, personal grooming). }\end{array}$ \\
\hline
\end{tabular}




\begin{tabular}{|c|c|c|}
\hline $\begin{array}{l}\text { Ostir et al. } \\
(1998)^{18}\end{array}$ & $\begin{array}{l}\text { For each participant, an overall lower } \\
\text { body function score was calculated by } \\
\text { summing the three individual scores on } \\
8 \text {-foot walk, chair stands, and a balance } \\
\text { test. Total summed scores ranged from } \\
\text { a low of } 1 \text { to a high of } 11 \text {. Participants } \\
\text { were divided into quartiles of } \\
\text { performance. }\end{array}$ & $\begin{array}{l}\text { Disability was defined as ADL } \\
\text { dependency (activities not specified in } \\
\text { article). }\end{array}$ \\
\hline $\begin{array}{l}\text { Guralnik et } \\
\text { al. }(2000)^{19}\end{array}$ & $\begin{array}{l}\text { Lower extremity function was measured } \\
\text { using tests of gait speed, standing } \\
\text { balance, and time to rise from a chair } \\
\text { five times. Scores ranged from } 3 \text { to } 12 \\
\text { and three groups were created based } \\
\text { on this score. These groups were } \\
\text { compared in the analysis. }\end{array}$ & $\begin{array}{l}\text { Disability was defined as inability to } \\
\text { perform one or more ADL without help } \\
\text { from another person (transferring, } \\
\text { toileting, bathing, walking across a small } \\
\text { room). }\end{array}$ \\
\hline $\begin{array}{l}\text { Onder et al. } \\
(2005)^{42}\end{array}$ & $\begin{array}{l}\text { Summary performance scores were } \\
\text { calculated for lower extremities by } \\
\text { adding the rescaled scores for the } \\
\text { walking speed test, chair stands test, } \\
\text { and standing balance test. }\end{array}$ & $\begin{array}{l}\text { Participants were classified with } \\
\text { progressive disability if they reported a } \\
\text { lot of difficulty or inability to perform } \\
\text { an ADL between follow-ups } 2 \text { and } 6 \text { and } \\
\text { they had a little or some difficulty at } \\
\text { one or both of the semiannual } \\
\text { assessments before the onset of } \\
\text { disability (bathing, dressing, eating, } \\
\text { transferring, toileting). }\end{array}$ \\
\hline $\begin{array}{l}\text { Gill et al. } \\
(2009)^{24}\end{array}$ & $\begin{array}{l}\text { Three tests were administered to all } \\
\text { participants to test physical } \\
\text { performance: standard balance } \\
\text { maneuvers, three timed chair stands, } \\
\text { and timed rapid gait. The scores on } \\
\text { these tests were added creating a } \\
\text { performance score between } 0 \text { and } 12 \\
\text { for each participant. }\end{array}$ & $\begin{array}{l}\text { Disability is defined as needing help } \\
\text { with one or more ADL. Five different } \\
\text { types of disability were defined } \\
\text { (transient, short-term, long-term, } \\
\text { recurrent, unstable). }\end{array}$ \\
\hline $\begin{array}{l}\text { Balzi et al } \\
(2010)^{41}\end{array}$ & $\begin{array}{l}\text { Walking speed over } 4 \text { meters, five timed } \\
\text { repeated chair rises and standing } \\
\text { balance were measured in all } \\
\text { participants. The scores on these tests } \\
\text { were added creating a performance } \\
\text { score between } 0 \text { and } 12 \text { for each } \\
\text { participant. Three groups were created } \\
\text { based on this score. These groups were } \\
\text { compared in the analysis. }\end{array}$ & $\begin{array}{l}\text { Worsening and development of new } \\
\text { disability was defined as needing help } \\
\text { from another person in ADL. }\end{array}$ \\
\hline
\end{tabular}





\section{CHAPTER 3}

Does a falling level of activity predict disability development in community-dwelling elderly people?

This chapter was published as:

Vermeulen J, Spreeuwenberg MD, Daniëls R, Neyens JCL, van Rossum E, de Witte LP. Does a falling level of activity predict disability development in community-dwelling elderly people? Clinical Rehabilitation. 2013;27:546-54. 


\section{Abstract}

Objective: To investigate the predictive value of self-reported decline in weight, exhaustion, walking difficulty, grip strength and physical activity on development of disabilities in community-dwelling elderly people.

Design: A one-year follow-up study.

Setting: Participants were recruited via four Dutch general practitioners.

Participants: Community-dwelling elderly people aged 70 years or older.

Methods: 687 participants received a questionnaire at baseline regarding weight loss, exhaustion, walking difficulty, grip strength, physical activity, and disability. The same questionnaire was sent to them after one year follow-up. Disability was operationalized in two ways: as increased dependence and as increased difficulty in daily activities.

Univariate and multivariate logistic regression analyses were used to determine whether self-reported decline in five physical indicators at baseline predicted development of dependence or increased difficulty in daily activities after 1 year. The analyses were controlled for age, gender and baseline disability.

Results: 401 participants with a mean age of 76.9 years (SD 5.2) were included in the analyses. 84 of them reported increased dependence (21\%) and 76 reported increased difficulty (19\%) in daily activities after one year follow-up. All physical indicators, except weight loss, were significant univariate predictors of disability. Multivariate analyses revealed that self-reported decrease in physical activity (e.g. walking, cycling, gardening) was a significant predictor of development of dependence $(\mathrm{OR}=1.89,95 \% \mathrm{Cl}=1.02-3.51)$ and development of difficulty $(\mathrm{OR}=1.98,95 \% \mathrm{Cl}=1.05-3.71)$ in daily activities.

Conclusion: Community-dwelling elderly people who report decreased physical activity have a higher risk to develop disability after 1-year follow-up. 


\section{Introduction}

As people get older, their biological, physical, psychological, or social functioning can decrease. The interplay between these decreasing functions is referred to as 'frailty' ${ }^{1-4}$ and causes an elderly person to become more vulnerable to adverse health outcomes such as disability, falls, hospitalization and death. ${ }^{5-9}$ The use of healthcare and community services is higher is this group of vulnerable elderly people. ${ }^{10}$ Early identification followed by adequate interventions might therefore be beneficial to these elderly people and healthcare systems as a whole.

A recent review shows that physical indicators that are related to frailty, such as weight loss, low gait speed, low grip strength, low physical activity, poor balance, and low lower extremity function, are predictors of disability in community-dwelling elderly people. ${ }^{11}$ Disability is often defined as experienced difficulty in performing activities in any domain of life. ${ }^{12}$ Monitoring the development of physical indicators may help to identify elderly people in healthcare who could benefit from disability prevention programs. Previous research suggests that there are interventions that can positively influence disability in community-dwelling elderly people. ${ }^{13-15}$

Decline in physical indicators over time might only be well observed by healthcare professionals conducting performance tests on a regular basis. Due to the increasing number of elderly people and decreasing number of professionals this is very difficult, if not impossible, to accomplish in daily clinical practice. Professionals need easy instruments as a first step in determining who is at risk for disability. ${ }^{16}$ Self-reported measurements on physical indicators might be such an easy instrument since they are easier and cheaper compared to performance based measures.

Most previous studies on the predictive value of physical indicators on disability development had a follow-up of at least three years. When professionals who work in clinical practice want to decide whether a preventive intervention should be offered to their patient, it might be more useful to know the 'short-term' predictive value of the physical indicators. Once an elderly patient is considered to be at risk of developing disability within the next year, action should be taken on the short term to prevent this. In a situation where patients have an increased risk of disability development in the next 3 or 5 years, the (perceived) need for initiation of preventive interventions might be lower. Therefore the aim of this study was to investigate the predictive value of self-reported decline in weight, exhaustion, walking difficulty, grip strength and physical activity on the development of disabilities in daily activities in community-dwelling elderly people after one year follow-up. 


\section{Methods}

\section{Design and participants}

This paper reports analyses of data collected from community-dwelling elderly people from the panels of four Dutch general practitioners. ${ }^{17}$ At baseline, all community-dwelling elderly people aged 70 years or older from the panels $(N=687)$ received an invitation letter from their general practitioner. No other inclusion or exclusion criteria were used. The letter was accompanied by a consent form and a questionnaire. Elderly people who decided to participate provided written informed consent and filled out the questionnaire. After two weeks, a reminder was sent to non-responders. One year later all respondents, except the ones who had been admitted to a nursing home, received the same questionnaire again. All collected data were handled confidentially.

\section{Measurements}

The questionnaire contained questions regarding age, gender, five indicators of physical functioning, and disability.

Decline in five physical indicators in the past 3-6 months was measured by five questions with yes/no or agree/disagree answer categories. These questions were: 'Have you experienced high unintended weight loss, $\geq 6 \mathrm{~kg}$ in the past 6 months or $\geq 3 \mathrm{~kg}$ in one month?' ${ }^{18}$, 'In the past 3-6 months everything took more energy/effort', 'In the past 3-6 months I experienced more difficulty with walking', 'In the past 3-6 months I had more difficulty grabbing things with my hands', and 'In the past 3-6 month I did not do as many strenuous physical activities as before (such as walking, working in and around the house, sports, cycling, gardening)'.

Disability in daily activities at baseline and after one year follow-up was measured with the Groningen Activity Restriction Scale (GARS), which has been proven to be valid and reliable. ${ }^{19} \mathrm{~A}$ copy of the questionnaire is provided in Appendix 1. The GARS consists of two subscales. The first subscale measures disability in Activities of Daily Living (ADL) and consists of 11 items e.g. getting dressed, getting in and out of bed, and washing yourself. The second subscale relates to Instrumental Activities of Daily Living (IADL) and consists of 7 items e.g. preparing breakfast or lunch, shopping, and ironing. Both ADL and IADL were measured with the GARS and this combination will be referred to as daily activities throughout this article. For each item, participants indicated on a 4-point scale whether they could perform the activity independently without any difficulty (1), independently with some difficulty (2), independently with great difficulty (3), or whether they could not execute the activity independently (4). So, if participants scored 4 they depended on other people for the performance of that activity. Disability total sumscores were calculated and 
range from 18 till 72 (ADL and IADL subscale sumscores range from 11 till 44 and 7 till 28 respectively).

Disability in daily activities (ADL and IADL combined) was operationalized in two ways. The primary operationalization focused on increased dependence in daily activities and the secondary operationalization focused on increased difficulty in daily activities. The secondary operationalization was constructed because it might be a more sensitive measure of disability that captures more subtle decreases in the performance of daily activities. According to the primary operationalization disability was present after one year follow-up if a participant was dependent in at least 1 more activity at follow-up compared to baseline. This was calculated by subtracting the number of activities in which a participant was dependent at baseline from the number of activities in which a participant was dependent at follow-up. According to the secondary operationalization disability was present if the number of activities in which a participant suffered from increased difficulty of at least two points after follow-up, exceeded the number of activities in which a participant improved at least two points after follow-up.

\section{Statistical methods}

Descriptive statistics were used to provide information on the baseline characteristics of the participants. If participants had one or two missing values on the GARS, the mean score of the non-missing items of that participant on the relevant subscale was imputed. If there were three or more missing values on the GARS the participant was excluded from the analyses. The participant was also excluded if there were missing values on one or more of the physical indicators. Independent samples t-tests were used to investigate whether baseline characteristics of participants who were lost to follow-up differed from those who remained in the sample.

Eight univariate logistic regression analyses were conducted to investigate the predictive value of the five indicators at baseline, age, gender, and total disability sum score at baseline on the development of dependence in daily activities after one year follow-up. The same univariate logistic regression analyses were conducted with development of difficulty in daily activities after one year follow-up as dependent variable. Odds Ratios and 95\% confidence intervals were calculated to determine the predictive value of each independent variable.

Two multivariate logistic regression analyses were conducted then to investigate which set of physical indicators at baseline is most predictive of the development of dependence in daily activities and the development of difficulty in daily activities after one year followup, while adjusting for age, gender and baseline disability. 


\section{Results}

Of the 687 elderly people who were invited, 532 (77\%) returned the postal questionnaire for baseline measurement and written consent. The same questionnaire was sent to 514 of these 532 participants after one year ( 15 participants had died and 3 had been admitted to a nursing home). Of these 514 participants, 439 (85\%) returned the questionnaire. 38 participants were excluded from the analyses because of too many missing values $(n=27)$ or because a different person filled out the questionnaire at baseline compared to follow-up $(n=11)$. Finally, 401 participants were included in the analyses. The follow-up of the participants is displayed in the flow chart in Figure 1.

687 participants received questionnaire at baseline

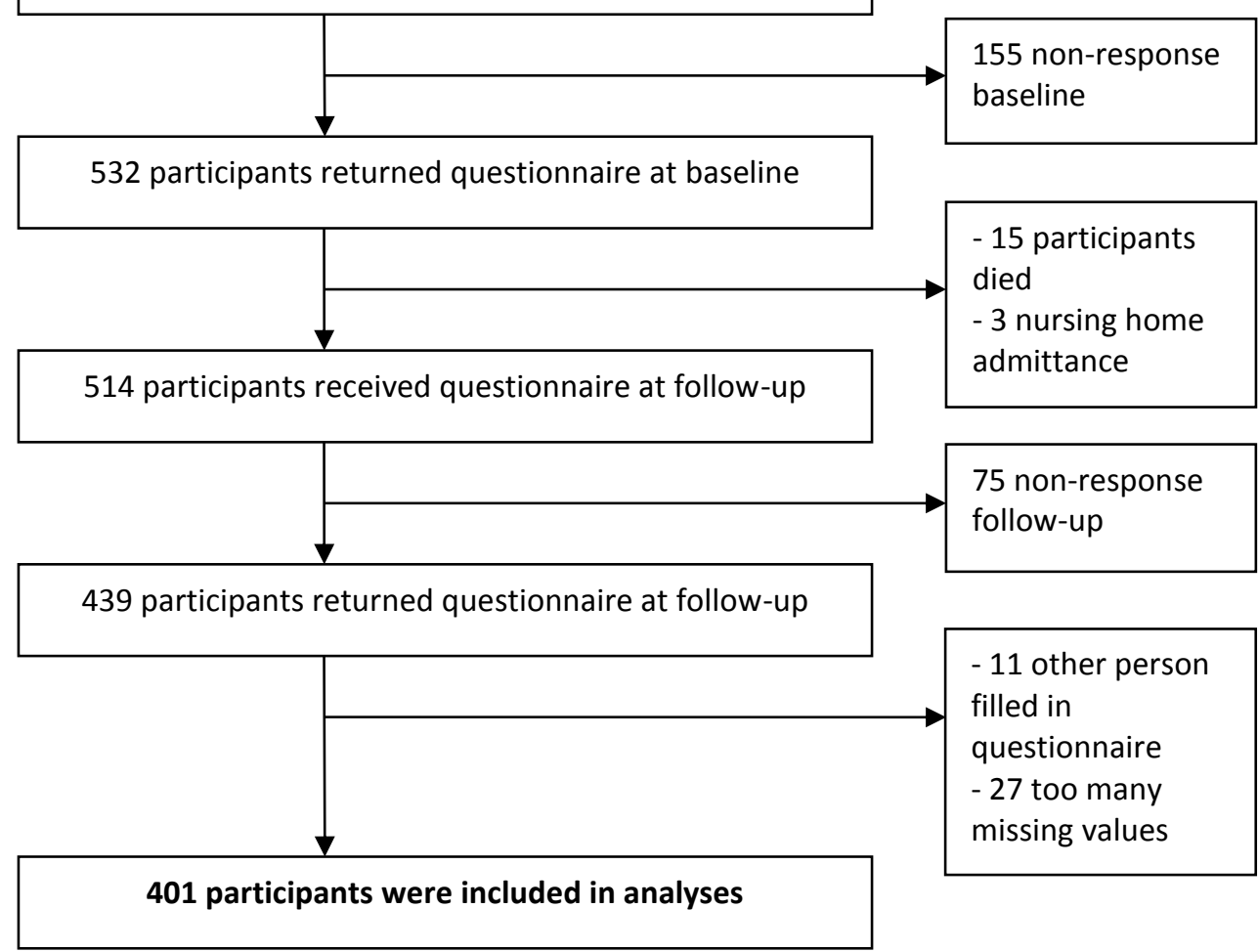

Figure 1. Flow-chart inclusion participants

In Table 1 information regarding age, gender, prevalence of physical indicators and level of disability of the study sample at baseline is presented. After one year follow-up the level of dependence increased in 84 of the participants (21\%), meaning that these 
participants needed help from another person with at least one more activity compared to baseline. Development of dependence was reported most frequent in the following activities: 30 participants developed dependence in taking care of feet and toenails (7.5\%), 30 in shopping (7.5\%), 24 in washing and ironing clothes (6\%), and 24 in doing 'light' housework (6\%). After one year follow-up, 76 of the participants (19\%) suffered from increased difficulty in daily activities. Development of difficulty was reported most frequent in the following activities: 25 participants developed difficulty in washing and ironing clothes (6.2\%), 24 in taking care of feet and toenails (6\%), and 19 in doing 'light' housework (4.7\%).

Some differences in baseline measurements were found between participants who were lost to follow-up and participants who remained in the sample. Those lost to followup reported significantly more weight loss $(11 \%) \mathrm{P}<0.001$, walking difficulty $(49 \%) \mathrm{P}=$ 0.004 , and low grip strength (21\%) $P=0.04$, and reported higher disability sum scores at baseline (28.6 (SD 12.4)) $P<.001$.

Table 1. Baseline characteristics of participants

\begin{tabular}{lc}
\hline Characteristics & Mean (SD) or $\mathbf{n}$ (\%) \\
\hline Age in years & 76.9 (SD 5.2) \\
Gender: & $164(41 \%)$ \\
Men & $237(59 \%)$ \\
Women & $23.9($ SD 7.9$)$ \\
GARS total sumscore (ADL + IADL) & \\
Physical indicators: & $20(5 \%)$ \\
Self-reported weight loss & $128(32 \%)$ \\
Self-reported exhaustion & $163(34 \%)$ \\
Self-reported walking difficulty & $48(12 \%)$ \\
Self-reported low grip strength & $140(35 \%)$ \\
Self-reported low physical activity & \\
Disability: & $44(11 \%)$ \\
Dependent in 1 activity & $32(8 \%)$ \\
Dependent in 2 activities & $32(8 \%)$ \\
Dependent in 3 activities & $36(9 \%)$ \\
Dependent in 4 or more activities & \\
\hline *
\end{tabular}

GARS = Groningen Activity Restriction Scale (range 18-72), ADL = subscale Activities of Daily Living (range 11-44), and IADL = subscale Instrumental Activities of Daily Living (range 7-28).

Table 2 presents the results of the univariate analyses. A significant association was found between four physical indicators at baseline and development of dependence in daily activities after one year follow-up. Decreased physical activity at baseline was the 
strongest predictor of the development of dependence in daily activities after one year follow-up $(\mathrm{OR}=3.16,95 \% \mathrm{Cl}=1.93-5.19)$. Weight loss was the only non-significant indicator (OR $=1.67,95 \% \mathrm{Cl}=.62-4.47)$.

Total GARS sum score at baseline also predicted development of dependence in daily activities after one year follow-up (OR $=1.07,95 \% \mathrm{Cl}=1.04-1.10)$. Age (OR $=1.06,95 \% \mathrm{Cl}$ $=1.00-1.12$ ) and gender ( $O R=.78,95 \% \mathrm{Cl}=.47-1.28)$ were not significant (univariate) predictors of increased dependence in daily activities.

The eight univariate regression analyses with increased difficulty in daily activities as dependent variable yielded similar results.

Table 2. Univariate association between single variables at baseline and disability development after one year follow-up

\begin{tabular}{lcc}
\hline $\begin{array}{l}\text { Independent variable at } \\
\text { baseline }\end{array}$ & $\begin{array}{c}\text { Dependent variable: Increased } \\
\text { dependence in daily activities } \\
\text { at follow up } \\
\text { OR }(95 \% \mathrm{Cl})\end{array}$ & $\begin{array}{c}\text { Dependent variable: Increased } \\
\text { difficulty in daily activities at } \\
\text { follow-up }\end{array}$ \\
\hline Unintended weight loss & $1.67(.62-4.47)$ & OR (95\% Cl) \\
\hline Increased exhaustion & $2.67(1.64-4.40)^{*}$ & $1.06(.34-3.25)$ \\
\hline Increased walking difficulty & $2.26(1.38-3.70)^{*}$ & $2.71(1.63-4.51)^{*}$ \\
\hline Decreased grip strength & $2.00(1.03-3.92)^{*}$ & $2.13(1.29-3.54)^{*}$ \\
\hline Decreased physical activity & $3.16(1.93-5.19)^{*}$ & $2.88(1.49-5.58)^{*}$ \\
\hline Age & $1.06(1.00-1.12)$ & $2.87(1.73-4.78)^{*}$ \\
\hline Gender & $.78(.47-1.28)$ & $1.08(1.03-1.13)^{*}$ \\
\hline GARS total sum score & $1.07(1.04-1.10)^{*}$ & $.63(.37-1.07)$ \\
\hline
\end{tabular}

\section{* Significant predictor $\mathrm{p}<.05$}

${ }^{* *}$ Increased dependence was present in a person if they were dependent in at least 1 more activity at follow-up compared to baseline

${ }^{+}$Increased difficulty was present in a person if the number of activities with increased difficulty (of at least two points) after follow-up, exceeded the number of activities in which a participant improved (at least two points) after follow-up.

Table 3 shows the results of the two multivariate logistic regression analyses. Selfreported decreased physical activity at baseline $(\mathrm{OR}=1.89,95 \% \mathrm{Cl}=1.02-3.51)$ and baseline disability as measured by the GARS sumscore $(\mathrm{OR}=1.04,95 \% \mathrm{Cl}=1.01-1.08$ ) were the two independent variables that significantly predicted increased dependence in daily activities after one year follow-up. If an elderly person scored 10 points higher on the GARS at baseline, their risk for increased dependence after one year follow-up increased with $1.54(95 \% \mathrm{Cl}=1.06-2.23)$. If an elderly person scored 20 points higher on the GARS at baseline, their risk for increased dependence after one year follow-up increased with 2.36 $(95 \% \mathrm{Cl}=1.12-4.98)$. It should be noted that multivariate logistic regression analyses with 
increased ADL or IADL dependence as dependent variable, instead of a combination of the two as described above, yielded similar results.

The second multivariate logistic regression analysis revealed that self-reported decreased physical activity at baseline $(O R=1.98,95 \% \mathrm{Cl}=1.05-3.71)$ was also the only indicator of physical functioning that was a significant predictor of increased difficulty in daily activities after controlling for age, gender, and baseline disability. In this model, age was also a significant predictor of increased difficulty in daily activities $(\mathrm{OR}=1.06,95 \% \mathrm{Cl}=$ $1.01-1.12)$.

Table 3. Multivariate predictors of disability development after one year follow-up

\begin{tabular}{lcc}
\hline $\begin{array}{l}\text { Independent variables at } \\
\text { baseline }\end{array}$ & $\begin{array}{c}\text { Dependent variable: Increased } \\
\text { dependence in daily activities } \\
\text { at follow- up** } \\
\text { OR (95\% CI) }\end{array}$ & $\begin{array}{c}\text { Dependent variable: Increased } \\
\text { difficulty in daily activities at } \\
\text { follow-up }\end{array}$ \\
\hline Weight loss & $\begin{array}{c}{ }^{* *} \text { (95\% CI) } \\
\text { OR }\end{array}$ \\
\hline Increased exhaustion & $1.06(.37-3.07)$ & $.69(.21-2.26)$ \\
\hline Increased walking difficulty & $1.35(.65-2.78)$ & $1.59(.77-3.30)$ \\
\hline Decreased grip strength & $.93(.46-1.87)$ & $.97(.48-1.97)$ \\
\hline Decreased physical activity & $.85(.38-1.92)$ & $1.91(.87-4.20)$ \\
Age & $1.89(1.02-3.51)^{*}$ & $1.98(1.05-3.71)^{*}$ \\
\hline Gender & $1.03(.98-1.08)$ & $1.06(1.01-1.12)^{*}$ \\
GARS sumscore & $.90(.52-1.53)$ & $.82(.47-1.44)$ \\
\hline
\end{tabular}

Significant predictor $\mathrm{p}<.05$

${ }^{* *}$ Increased dependence was present in a person if they were dependent in at least 1 more activity at follow-up compared to baseline

${ }^{+}$Increased difficulty was present in a person if the number of activities with increased difficulty (of at least two points) after follow-up, exceeded the number of activities in which a participant improved (at least two points) after follow-up.

\section{Discussion}

From the results it can be concluded that for community-dwelling elderly people who report decreased physical activity (e.g. walking, cycling, gardening) in the past 3-6 months at baseline, the risk of increased dependence and the risk of increased difficulty in daily activities at follow-up was significantly higher. Community-dwelling elderly people who answered 'no' to the question: 'Did you do as many strenuous physical activities as before in the past 3-6 months' had almost twice as much risk to become more dependent or to suffer from increased difficulty in daily activities after one year follow-up. These analyses were controlled for the four other physical indicators (weight loss, exhaustion, walking 
difficulty, and grip strength), baseline disability, age, and gender. These findings are in line with previous research. ${ }^{20}$

Previous research has shown that physical indicators, such as weight loss, gait speed, grip strength, and physical activity are all predictors of the development of disability. ${ }^{21-32}$ In the multivariate analyses of this study, only physical activity was a significant predictor of disability development after one year. A possible explanation for this discrepancy might be that most previous studies did not include the same physical indicators in their multivariate analyses. In the current study, almost all indicators were significant univariate predictors of the development of disabilities but when correcting for all indicators in one multivariate model, only self-reported physical activity was a significant predictor.

When comparing the results from the present study to previous research it appears that answering 'no' to a simple question provides us with disability-risk estimates of about the same magnitude as performance based measures or multi-item questionnaires regarding indicators of physical functioning. ${ }^{10,24,25,27,28,32,33}$ Self-reported physical activity predicts disability development in the next year which is a relevant timeframe for professionals who are involved in the care for elderly people.

\section{Limitations of the study}

One might consider the use of only self-report data a limitation of this study. When community-dwelling elderly people are asked to report on their physical functioning, they often overestimate their own physical functioning. ${ }^{34,35}$ Performance-based measures therefore might identify more limitations in physical functioning compared to self-report measures. ${ }^{36}$ Furthermore, the questions that were asked in this study to retrieve information regarding physical indicators sometimes focus on surrogates of that indicator. For example: it might be difficult for people to tell whether their walking speed has decreased or whether they have lower grip strength and therefore questions regarding these indicators focus on difficulty with walking or difficulty in grabbing things with your hands. Besides that, baseline status was measured as 'a single snapshot' which might have influenced the stability of the measurements. Also, the psychological state and selfperceived health status of a participant at the moment of filling out the questionnaire may have influenced the results because these concepts are related to the self-reported physical indicators that were measured. ${ }^{37}$ However, this does not mean that self-reported measures are not valid. Previous research has shown that self-reported measurements of physical indicators can be used as a simple screening instrument. ${ }^{38,39}$

A limitation of this study was that participants who remained in our sample reported less weight loss, walking difficulty, decreased grip strength and disability at baseline compared to participants who were lost to follow-up. If these participants would not have been lost to follow-up, the level of disability and the variation in physical indicators and disability would possibly have been higher. Therefore, it is likely that the results from our 
study underestimate the predictive strength of the indicators. However, this cannot be confirmed with the available data. Furthermore, the analyses were only adjusted for age, gender, and baseline disability and not for other factors such as medical condition, cognitive status or comorbidity which can be considered a limitation of this study since these factors are related to functional status. ${ }^{40}$

Finally, a remark should be made regarding the operationalization of disability in this study. All regression analyses were performed twice, with a different operationalization of disability as outcome. This was done to check whether more subtle changes in performance of daily activities are predicted by the same physical indicators, which seemed to be the case. However the cutoff point that was chosen to define difficulty in daily activities ( 2 points increase on a GARS activity) was arbitrary and changing the cutoff point might lead to other risk estimates.

\section{Implications for clinical practice and future research}

Providing interventions aimed at preventing disability to elderly people at risk may be beneficiary to the health status of these people and health care systems as a whole. ${ }^{41}$ This study shows that a simple indicator, self-reported decrease in physical activity, is a good predictor of disability development within the next year. For clinical practice this is a highly relevant finding. When an elderly person reports that he or she stopped cycling or walking, this might be a strong signal that requires attention from care professionals. By monitoring the progression of indicators of physical functioning, healthcare professionals can select elderly people who can optimally benefit from an intervention that aims to improve their level of functioning in daily life.

Although there is no consensus yet on the effective components of interventions, previous research indicates that multifactorial and multidisciplinary treatment and prevention strategies are likely to yield the best results and can have a positive effect on disability. ${ }^{14-16,42}$ An example of such an intervention program in primary care is described by Daniels et al. ${ }^{43}$ Future research should focus on developing effective interventions that prevent or decrease disability in elderly people and systematic procedures that can be used to identify elderly people who could benefit from such interventions.

\section{References}

1. Bergman H, Beland F, Karunananthan S, Hummel S, Hogan D, Wolfson C. Developing a working framework for understanding frailty. Gerontology and Society. 2004;109:15-29. 
2. Rockwood K, Song X, Macknight C, Bergman H, Hogan DB, McDowell I, Mitnitski A. A global clinical measure of fitness and frailty in elderly people. CMAJ. 2005;173:489-495.

3. Slaets JP. Vulnerability in the elderly: frailty. Med Clin North Am. 2006;90:593-601.

4. De Saint-Hubert M, Swine C. Evolving definitions of frailty. Aging Health. 2007;3: 15.

5. Fried LP, Tangen CM, Walston J, Newman AB, Hirsch C, Gottdiener J, et al. Frailty in older adults: evidence for a phenotype. J Gerontol A Biol Sci Med Sci. 2001;56:M146-156.

6. Boyd CM, Xue QL, Simpson CF, Guralnik JM, Fried LP. Frailty, hospitalization, and progression of disability in a cohort of disabled older women. Am J Med. 2005;118:1225-1231.

7. Bandeen-Roche K, Xue QL, Ferrucci L, Walston J, Guralnik JM, Chaves P, et al. Phenotype of frailty: characterization in the women's health and aging studies. J Gerontol A Biol Sci Med Sci. 2006;61:262-266.

8. De Lepeleire J, Iliffe S, Mann E, Degryse JM. Frailty: an emerging concept for general practice. Br J Gen Pract. 2009;59:e177-182.

9. Rothman MD, Leo-Summers L, Gill TM. Prognostic significance of potential frailty criteria. J Am Geriatr Soc. 2008;56:2211-2216.

10. Rochat S, Cumming RG, Blyth F, Creasey H, Handelsman D, Le Couteur DG, et al. Frailty and use of health and community services by community-dwelling older men: the concord health and ageing in men project. Age Ageing. 2010;1:1-6.

11. Vermeulen J, Neyens JC, Spreeuwenberg MD, van Rossum E, de Witte LP. Predicting ADL disability in community-dwelling elderly people using physical frailty indicators: a systematic review. BMC Geriatr. 2011;11:33.

12. Jette $A M$, Toward a common language for function, disability, and health. Phys Ther. 2006;86:726-734.

13. Melis FJ, van Eijken MI, Teerenstra S, van Achterberg T, Parker SG, Borm GF, et al. A randomized study of a multidisciplinary program to intervene on geriatric syndromes in vulnerable older people who live at home (Dutch EASYcare Study). J Gerontol A Biol Sci Med Sci. 2008;63:283-290.

14. Gitlin LN, Winter L, Dennis MP, Corcoran M, Schinfield S, Hauck WW. A randomized trial of a multicomponent home intervention to reduce functional difficulties in older adults. J Am Geriatr Soc. 2006;54:809-816.

15. Worm C, Vad E, Puggaard L, Stovring H, Lauritsen J, Kragstrup J. Effects of a multicomponent exercise program on functional ability in community-dwelling frail older adults. JAPA. 2001;9:414-424.

16. De Lepeleire J, Degryse J, Iliffe S, Mann E, Buntinx F. Family physicians need easy instruments for frailty. Age Ageing. 2008;37:484-485. 
17. Daniels R, van Rossum E, Beurskens A, van den Heuvel, W. de Witte L. The predictive validity of three self-report screening instruments for identifying frail older people in the community. BMC Public Health. 2012;12:69.

18. Schuurmans $H$, Steverink N, Lindenberg, Frieswijk N, Slaets JP. Old or frail: what tells us more? J Gerontol. 2004;59A:962-965.

19. Kempen GIJM, Miedema I, Ormel J, Molenaar W. The assessment of disability with the Groningen Activity Restriction Scale. Conceptual framework and psychometric properties. Soc Sci Med. 1996;43:1601-1610.

20. Fried LP, Bandeen-Roche K, Chaves PH, Johnson BA. Preclinical mobility disability predicts incident mobility disability in older women. J Gerontol A Biol Sci Med Sci. 2000;55:M43-M54.

21. Guralnik JM, Ferrucci L, Simonsick EM, Salive ME, Wallace RB. Lower-extremity function in persons over the age of 70 years as a predictor of subsequent disability. N Engl J Med. 1995;332:556-561.

22. Ishizaki T, Watanabe S, Suzuki T, Shibata H, Haga H. Predictors for functional decline among nondisabled older Japanese living in a community during a 3-year follow-up. J Am Geriatr Soc. 2000;48:1424-1429.

23. Sarkisian CA, Liu H, Gutierrez PR, Seeley DG, Commings SR, Mangione CM. Modifiable risk factors predict functional decline among older women: a prospectively validated clinical prediction tool. The Study of Osteoporotic Fractures Research Group. J Am Geriatr Soc. 2000;48:170-178.

24. Al Snih S, Markides KS, Ottenbacher KJ, Maji, MA. Hand grip strength and incident ADL disability in elderly Mexican Americans over a seven-year period. Aging Clin Exp Res. 2004;16:481-486.

25. Al Snih S, Raji MA, Markides KS, Ottenbacher KJ, Goodwin JS. Weight change and lower body disability in older Mexican Americans. J Am Geriatr Soc. 2005;53:17301737.

26. DiPietro L. Physical activity in aging: changes in patterns and their relationship to health and function. J Gerontol A Biol Sci Med Sci. 2001;56:13-22.

27. Gill TM, Allore H, Holford TR, Guo, Z. The development of insidious disability in activities of daily living among community-living older persons. Am J Med. 2004;117:484-491.

28. Van Den Brink CL, Picavet H, Van Den Bos GA, Giampaoli S, Nissinen A, Kromhout D. Duration and intensity of physical activity and disability among European elderly men. Disabil Rehabil. 2005;27:341-347.

29. Jacobs JM, Cohen A, Hammerman-Rozenberg R, Azoulay D, Maaravi Y, Stessman J. Going outdoors daily predicts long-term functional and health benefits among ambulatory older people. J Aging Health. 2008;20:259-272. 
30. Balzi D, Lauretani F, Barchielli A, Ferrucci L, Bandinelli S, Buiatti E. Risk factors for disability in older persons over 3-year follow-up. Age Ageing. 2010;39:92-98.

31. Rosano C, Newman AB, Katz R, Hirsch CH, Kuller LH. Association between lower digit symbol substitution test score and slower gait and greater risk of mortality and of developing incident disability in well-functioning older adults. J Am Geriatr Soc. 2008;56:1618-1625.

32. Gill TM, Murphy TE, Barry LC, Allore HG. Risk factors for disability subtypes in older persons. J Am Geriatr Soc. 2009;57:1850-1855.

33. Pialoux T, Goyard J, Lesourd B. Screening tools for frailty in primary health care: a systematic review. Geriatr Gerontol Int. 2012;12:189-197.

34. Reuben DB, Valle LA, Hays RD, Siu AL. Measuring physical function in communitydwelling older persons: a comparison of self-administered, intervieweradministered, and performance-based measures. J Am Geriatr Soc. 1995;43:17-23.

35. Sherman SE, Reuben D. Measures of functional status in community-dwelling elders. J Gen Intern Med. 1998;13:817-823.

36. Brach JS, VanSwearingen JM, Newman AB, Kriska AM. Identifying early decline of physical function in community-dwelling older women: performance-based and self-report measures. Phys Ther. 2002;82:320-328.

37. Hultsch DF, Hammer M, Small BJ. Age diffenrences in cognitive perforemance in later life: relationships to self-reported health and activity life style. J Gerontol. 1993;48:1-11.

38. Santos-Eggimann B, Cuenoud P, Spagnoli J, Junod J. Prevalence of frailty in middleaged and older community-dwelling Europeans living in 10 countries. J Gerontol A Biol Sci Med Sci. 2009;64:675-681.

39. Romero-Ortuno R, Walsh CD, Lawlor BA, Kenny RA. A frailty instrument for primary care: findings from the Survey of Health, Ageing and Retirement in Europe (SHARE). BMC Geriatr. 2010;10:57.

40. Fried LP, Ferrucci L, Darer J, Williamson WD, Anderson G. Untangling the concepts of disability, frailty, and comorbidity: implications for improved targeting and care. J Geroltol A Biol Sci Med Sci. 2004;59:M255-263.

41. King AC, Guralnik JM. Maximizing the potential of an aging population. JAMA. 2010;304:1944-1945.

42. Daniels R, van Rossum E, de Witte L, van den Heuvel. Frailty in older age: concepts and relevance for occupational and physical therapy. Phys \& Occup Ther Geriatr. 2008;27:81-95.

43. Daniels R, van Rossum E, Metzelthin S, Sipers W, Habets H, Hobma S, et al. A disability prevention programme for community-dwelling frail older persons. Clin Rehabil. 2011;25:963-974. 
Appendix 1. Groningen Activity Restriction Scale (GARS)

The following questions refer to daily activities which should be performed frequently. In each question it is asked whether you are able to perform the activity at this moment. It is not intended to assess whether you are actually performing the activities, but if you can do them if necessary.

Response categories for each item

1. Yes, I can do it fully independently without any difficulty

2. Yes, I can do it fully independently but with some difficulty

3. Yes, I can do it fully independently but with great difficulty

4. No, I cannot do it fully independently, I can only do it with someone's help

\section{GARS items}

1. Can you, fully independently, dress yourself?

2. Can you, fully independently, get in and out of bed?

3. Can you, fully independently, stand up from sitting in a chair?

4. Can you, fully independently, wash your face and hands?

5. Can you, fully independently, wash and dry your whole body?

6. Can you, fully independently, get on and off the toilet?

7. Can you, fully independently, feed yourself?

8. Can you, fully independently, get around in the house (if necessary with a cane or walker)?

9. Can you, fully independently, go up and down the stairs?

10. Can you, fully independently, walk outdoors (if necessary with a cane or walker)?

11. Can you, fully independently, take care of your feet and toenails?

12. Can you, fully independently, prepare breakfast or lunch?

13. Can you, fully independently, prepare dinner?

14. Can you, fully independently, do "light" household activities (for example, dusting and tidying up)?

15. Can you, fully independently, do "heavy" household activities (for example mopping, cleaning the windows, and vacuuming)?

16. Can you, fully independently, wash and iron your clothes?

17. Can you, fully independently, make the beds?

18. Can you, fully independently, do the shopping? 



\section{CHAPTER 4}

Construct validity of a modified bathroom scale that can measure balance in elderly people

This chapter was published as:

Vermeulen J, Neyens JCL, Spreeuwenberg MD, van Rossum E, Hewson DJ, Duchêne J, de Witte LP. Construct validity of a modified bathroom scale that can measure balance in elderly people. Journal of the American Medical Directors Association. 2012;13:665.e1-5. 


\section{Abstract}

Objectives: To investigate the construct validity of a bathroom scale measuring balance in elderly people.

Design: Cross-sectional study.

Setting: Participants were recruited via nursing homes and an organization that provides exercise classes for community-dwelling elderly people.

Participants: Nursing home patients were compared to active community-dwelling elderly people. Eligibility criteria for both groups were: aged 65 years or older and being able to step onto a bathroom scale independently.

Measurements: The balance measurement of the bathroom scale was compared to the following three clinical balance measurements: Performance Oriented Mobility Assessment (POMA), Timed Up and Go (TUG), and Four Test Balance Scale (FTBS). An independent samples t-test was performed to determine whether nursing home patients scored lower on these four balance tests compared to community-dwelling elderly people. Correlations were calculated between the bathroom scale balance scores and those of the clinical balance tests for nursing home patients and community-dwelling elderly people separately.

Results: Forty-seven nursing home patients with a mean age of 81 years (SD 6.40) and 54 community-dwelling elderly people with a mean age of 76 years (SD 5.06) participated in the study. The results showed that nursing home patients had significantly lower scores on all four balance tests compared to community-dwelling elderly people. Correlations between the bathroom scale scores and the POMA, TUG, and FTBS in nursing home patients were all significant: .49, -.60, and .63 respectively. These correlations were not significant in active community-dwelling elderly people, $-.04,-.42$, and .33 respectively. Linear regression analyses showed that the correlations for the bathroom scale and POMA, bathroom scale and TUG, and bathroom scale and FTBS did not differ statistically between nursing home patients and community-dwelling elderly people.

Conclusion: These results suggest that the modified bathroom scale is useful for measuring balance in elderly people. However, the added value of this assessment method for clinical practice remains to be demonstrated. 


\section{Introduction}

When people become older balance often decreases. ${ }^{1}$ Those who suffer from poor balance have an increased risk of disability in activities of daily living, mobility-related disability, falls, and other adverse health outcomes. ${ }^{2-9}$ Monitoring the development of balance over time in elderly people could help to detect balance decline at an early stage. Providing an intervention to these people that is aimed at preventing further balance decline might decrease their risk of the adverse health outcomes mentioned above.

Balance can be measured using clinical physical performance tests, laboratory tests, or self-reported information. ${ }^{10,11}$ In current care, physical performance tests are used most often because they provide more objective and reliable information compared to selfreported information and because they are less costly and easier to administer compared to laboratory tests (e.g. force plate). ${ }^{12-14} \mathrm{~A}$ literature review by Langley et al. identified 17 different clinical balance tests that are used to measure functional balance in elderly people. ${ }^{11}$ Two tests with good psychometric properties that are often used in clinical practice are the Performance Oriented Mobility Assessment (POMA) and the Timed Up and Go test (TUG). ${ }^{10,15-17}$ To get a good impression of the development of balance over time, performance based tests should be administered on a regular basis. This is very difficult, if not impossible, to accomplish in daily practice.

A modified bathroom scale that enables elderly people to measure their own balance by stepping onto the scale could be a solution for this problem. Such a scale was developed by the University of Technology of Troyes in France. ${ }^{18,19}$ An algorithm is used to extract information regarding balance from the sensors that are embedded in the bathroom scale. ${ }^{20}$ The bathroom scale is equipped with Bluetooth ${ }^{\circledR}$ which enables the transfer of balance and weight data to a database that can be accessed by healthcare professionals. The acceptability and usability of the device were evaluated in a longitudinal study. Elderly people accepted the modified bathroom scale and were able to use it because it does not differ from a normal bathroom scale. ${ }^{21} \mathrm{~A}$ recent validation study compared balance measurements of the bathroom scale to those of a force plate. The results indicated that the validity of the bathroom scale was good, with no differences found between standard balance parameters measured with a force plate and the bathroom scale. ${ }^{22}$ A clear advantage of the bathroom scale over the force plate is that it is much less expensive. ${ }^{23}$

As mentioned above, clinicians usually use physical performance tests to measure balance in elderly people. Force plates and other sophisticated laboratory tests are rarely used in clinical practice because the equipment is quite costly. ${ }^{12,23}$ Therefore, the aim of this study was to determine the construct validity of the bathroom scale by comparing its balance measurements to those of clinical tests that are used in daily practice. This study 
focused on the following two research questions: (1) do the measurements of the bathroom scale confirm that nursing home patients have poorer balance compared to community-dwelling elderly people, and (2) how do the balance scores of the bathroom scale relate to those of clinical balance tests that are used in daily practice?

\section{Methods}

\section{Design, setting, and participants}

This study had a cross-sectional design. To determine known-groups validity, elderly people with poor and good balance needed to be represented in the study sample. Therefore, participants were recruited via nursing homes and an organization that provides exercise classes for community-dwelling elderly people. This choice was based upon the expectation that the first group has poorer balance compared to the second group. To be eligible for inclusion, participants had to be aged 65 years or older and able to step onto a bathroom scale independently.

Patients from two nursing homes $(n=54)$ were handed an invitation letter by their physiotherapist. Community-dwelling elderly people $(n=64)$ received an invitation letter from the instructor of their exercise class. People who met the eligibility criteria and signed informed consent were included in the study. In the nursing homes, the physiotherapists checked in the patient records whether a person was capable of signing his/her own consent form. If this was not the case, the guardian of that patient was asked to sign the consent form. This study was approved by the Medical Ethical Committee Atrium-Orbis-Zuyd (Reference: NL35961.096.11, 19 July 2011).

\section{Procedures}

Once written informed consent was provided by 47 nursing home patients and 54 community-dwelling elderly people, the researcher visited the nursing homes and the exercise classes to conduct all balance measurements. To ensure that the balance tests would not be too strenuous, only a limited number of clinical tests could be conducted per participant. All 101 participants performed one balance measurement with the bathroom scale. The Performance Oriented Mobility Assessment (POMA) ${ }^{16}$ was conducted in 69 participants. The Timed Up and Go test (TUG) ${ }^{17}$ and Four Test Balance Scale (FTBS) ${ }^{24}$ were administered instead of the POMA in the remaining 32 participants.

\section{Measurements}

In total, four different balance measurements were conducted. The bathroom scale measurements were conducted under supervision of the researcher. The three clinical balance tests were conducted by a physiotherapist specialized in geriatrics. 
The bathroom scale balance measurement was conducted in all participants. The scale is equipped with an infrared sensor at the front which activates the bathroom scale. All participants were instructed to stand in front of the scale and to step onto it when the number ' 0.0 ' appeared on the display. They were instructed to step down backwards once their weight appeared on the screen. The modified bathroom scale uses the signals from four force sensors located in the corners of the scale to collect information regarding various parameters. An overall balance indicator is calculated using the information from four parameters: step on delay, rise rate, surface under the stabilogram, and the average velocity of the trajectory. Each parameter is scored on a scale from 0 till 4 which results in an overall balance score between 0 and 16. A higher score indicates better balance. More detailed information regarding the parameters and the calculation of the overall balance score is described in a previous article by Duchêne and Hewson. ${ }^{21}$

The POMA ${ }^{16}$ consists of a balance and gait subscale. Among the balance tasks were: balance while sitting, rising, attempting to rise, immediate standing, standing with alterations in base of support, sternal nudge, standing with eyes closed, turning $360^{\circ}$, and sitting down again. Among the gait tasks were: initiation, step length, step height, step symmetry, step continuity, path, trunk stability, and step width. Each task was scored by a trained physiotherapist with 0,1 or 2 . Scores on the POMA ranged from 0 to 28 . A higher score indicates better performance on the tasks.

The TUG ${ }^{17}$ assessed how long it took participants to rise from a chair, walk three meters, turn around, walk back and sit back down in the chair. Participants wore regular footwear and were allowed to use a walking aid if they did so for their routine daily activities. The time it took to perform the TUG was scored in seconds. A lower score indicates better performance.

The $\mathrm{FTBS}^{24}$ was used to measure how long participants could hold a parallel stand, a semi-tandem stand, a tandem stand, and stand on one leg. Participants were encouraged to hold each standing test for 10 seconds without losing balance, starting with standing in parallel and increasing the difficulty after each 10 seconds if possible. A total score was calculated for the FTBS by adding the seconds a person was able to remain standing without losing balance on each of the four standing tests. This resulted in a sumscore between 0 and 40 where a higher score indicates better balance.

\section{Statistical methods}

Descriptive statistics were used to provide information on the characteristics of the participants and the balance measurements. Categorical variables were expressed with percentages and continuous variables with means and standard deviations. An independent samples t-test was used to investigate whether the four balance measurement instruments confirmed different levels of balance in nursing home patients and active community-dwelling elderly people. Pearson's correlations between the 


\section{Chapter 4}

balance scores of the bathroom scale and the POMA, TUG, and FTBS scores were calculated for nursing home patients and community-dwelling elderly people separately. To statistically compare the Pearson's correlations between the nursing home patients and community-dwelling elderly people, linear regression analyses were conducted. Three models were analyzed with bathroom scale balance score as dependent variable. Independent variables added to model 1 were: score on the POMA, group (nursing home vs. community-dwelling), and interaction between POMA score and group. Independent variables added to model 2 were: score on the TUG, group, and interaction between TUG score and group. Independent variables added to model 3 were: score on the FTBS, group, and interaction between FTBS score and group. The significance of the regression coefficient of the interaction variables indicated whether the correlations between the bathroom scale and POMA, bathroom scale and TUG, and bathroom scale and FTBS differed statistically between nursing home patients and community-dwelling elderly people. After that, the analyses were controlled for age by adding this variable to each regression model.

\section{Results}

\section{Participants}

The participation rate in the group of nursing home patients was $87 \%$. In the first nursing home 29 of the 34 invited patients participated (85\%). In the second nursing home, 18 of the 20 invited patients participated (90\%). The participation rate in the group of community-dwelling elderly people was $84 \%, 54$ of the 64 invited elderly people participated. In the first exercise class 13 of the 23 invited elderly people participated (56\%). In the other three exercise classes, all people who were invited participated in the study. So in total, 101 participants were included in the analyses. Not all clinical balance tests were administered to all participants; Figure 1 shows which clinical balance tests were administered in which participants. 

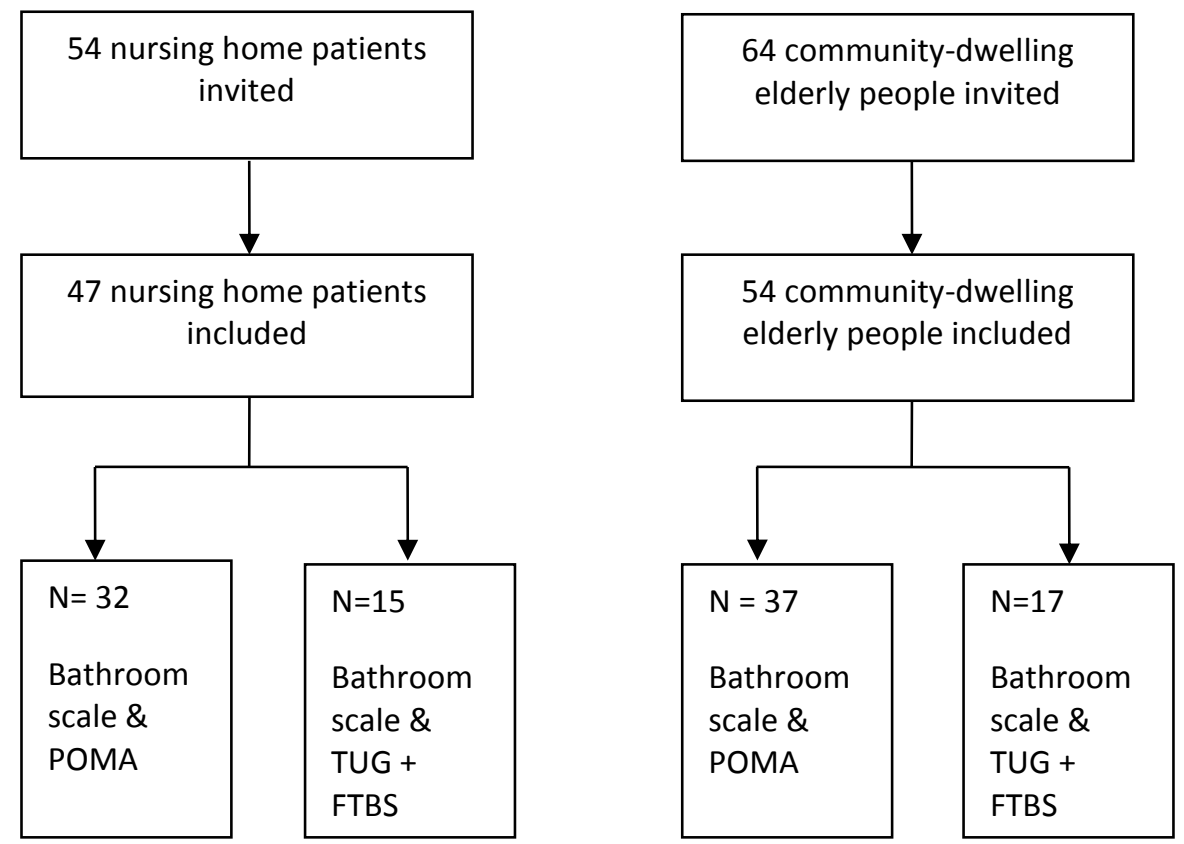

Figure 1. Balance tests administered in study population

The test with the modified bathroom scale was conducted in all participants. The POMA was administered to 32 nursing home patients ( 9 men and 23 women) and 37 community-dwelling elderly people ( 5 men and 32 women). The TUG and FTBS were administered to 15 nursing home patients ( 7 men and 8 women) and 17 communitydwelling elderly people (17 women). Table 1 presents the characteristics of the participants for nursing home patients and active community-dwelling elderly people separately. More men were included in the group of nursing home patients compared to the group of community-dwelling elderly people. Besides that, nursing home patients were older. Nursing home patients scored lower on all balance tests compared to community-dwelling elderly people. T-test statistics were T(99) $=-6.76, p<.01, \mathrm{~T}(67)=-$ $7.57, p<.01, \mathrm{~T}(30)=4.27, p<.01$, and $\mathrm{T}(30)=-3.24, p<.01$ for the bathroom scale, POMA, TUG and FTBS respectively. 
Table 1. Characteristics of participants

\begin{tabular}{|c|c|c|}
\hline & $\begin{array}{l}\text { Nursing home patients } \\
\qquad(N=47)\end{array}$ & $\begin{array}{l}\text { Community-dwelling } \\
\text { elderly people }(\mathrm{N}=54)\end{array}$ \\
\hline \multicolumn{3}{|l|}{ Gender: } \\
\hline Male* & $16(34.0 \%)$ & $5(9.3 \%)$ \\
\hline Female & $31(66.0 \%)$ & 49 (90.7\%) \\
\hline Age $^{*}$ & 80.57 (SD 6.40) & 75.67 (SD 5.06) \\
\hline Weight in Kg & 74.45 (SD 15.79) & 74.50 (SD 12.61) \\
\hline $\begin{array}{l}\text { Balance score bathroom scale } \\
\text { (Possible range } 0-16 \text { ) }\end{array}$ & 6.68 (SD 3.96) & 11.33 (SD 2.94) \\
\hline $\begin{array}{l}\text { Total score on POMA* } \\
\text { (Possible range } 0-28 \text { ) }\end{array}$ & 19.81 (SD 4.73) & 25.97 (SD 1.38) \\
\hline $\begin{array}{l}\text { Total score on TUG } \\
\text { (Time in seconds) }\end{array}$ & 15.14 (SD 4.99) & 9.54 (SD 1.98) \\
\hline $\begin{array}{l}\text { Total score on } \mathrm{FSBT}^{*} \\
\text { (Possible range } 0-40 \text { ) }\end{array}$ & 25.24 (SD 5.65) & 31.88 (SD 5.74) \\
\hline
\end{tabular}

\section{Relation between balance measurements}

Table 2 presents the correlations between the balance measurements of the four different tests for the nursing home patients and community-dwelling elderly people separately. In nursing home patients, all correlations were of moderate strength and were significant whereas in community-dwelling elderly people the correlations were weaker and not significant. The linear regression analyses showed that the correlations between the bathroom scale and POMA, bathroom scale and TUG, and bathroom scale and FTBS did not differ statistically between nursing home patients and community-dwelling elderly people. P-values of the interaction effect included in each model were $p=.29, p=.95$, and $p=.09$ respectively. Controlling for age did not influence these results.

Table 2. Correlations between bathroom scale and clinical balance measurements

\begin{tabular}{lcc}
\hline & Nursing home patients & $\begin{array}{c}\text { Community-dwelling } \\
\text { elderly people }\end{array}$ \\
\hline Correlation Bathroom scale - POMA & $.49^{* * *}$ & -.04 \\
Correlation Bathroom scale - TUG & $-.60^{*}$ & -.42 \\
\hline Correlation Bathroom scale - FTBS & $.63^{*}$ & .33 \\
Correlation TUG - FTBS & $-64^{* *}$ & -.42 \\
${ }^{*} \mathrm{p}<0.05,{ }^{* *} \mathrm{p}<0.01$ & &
\end{tabular}


The scatterplots in Figure $2 \mathrm{a} / \mathrm{b} / \mathrm{c} / \mathrm{d}$ illustrate how the balance scores on the four tests compared to each other in nursing home patients and community-dwelling elderly people.

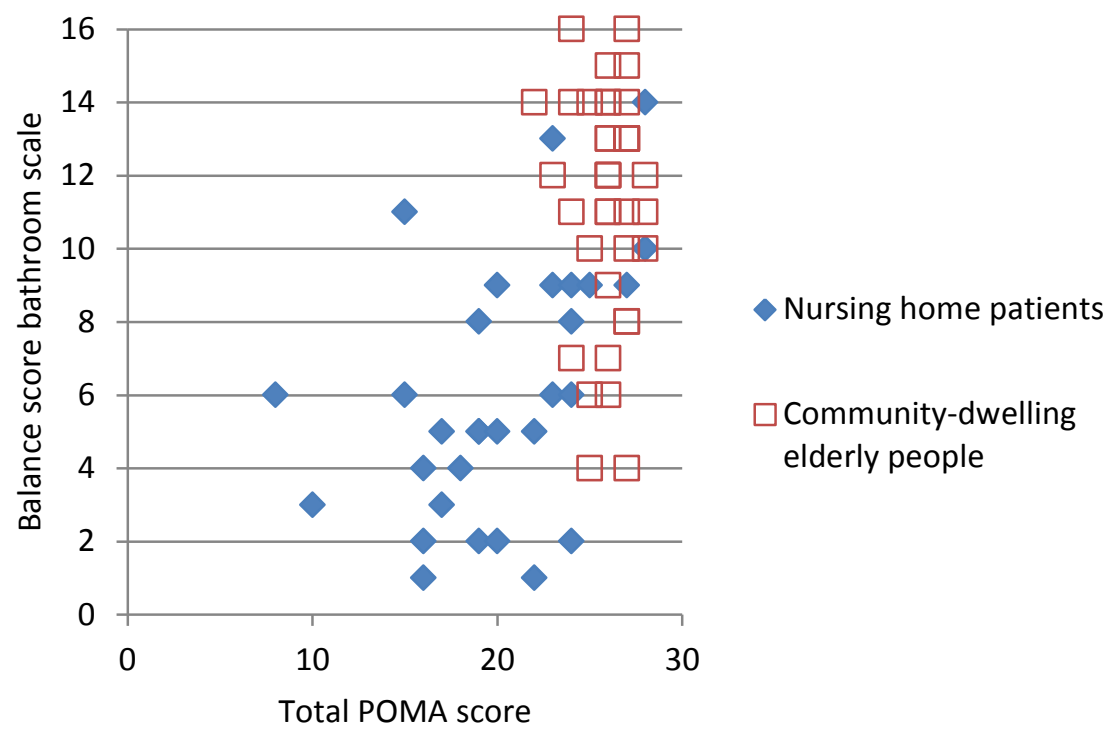

Figure 2a. Scatterplot comparing bathroom scale score and POMA score

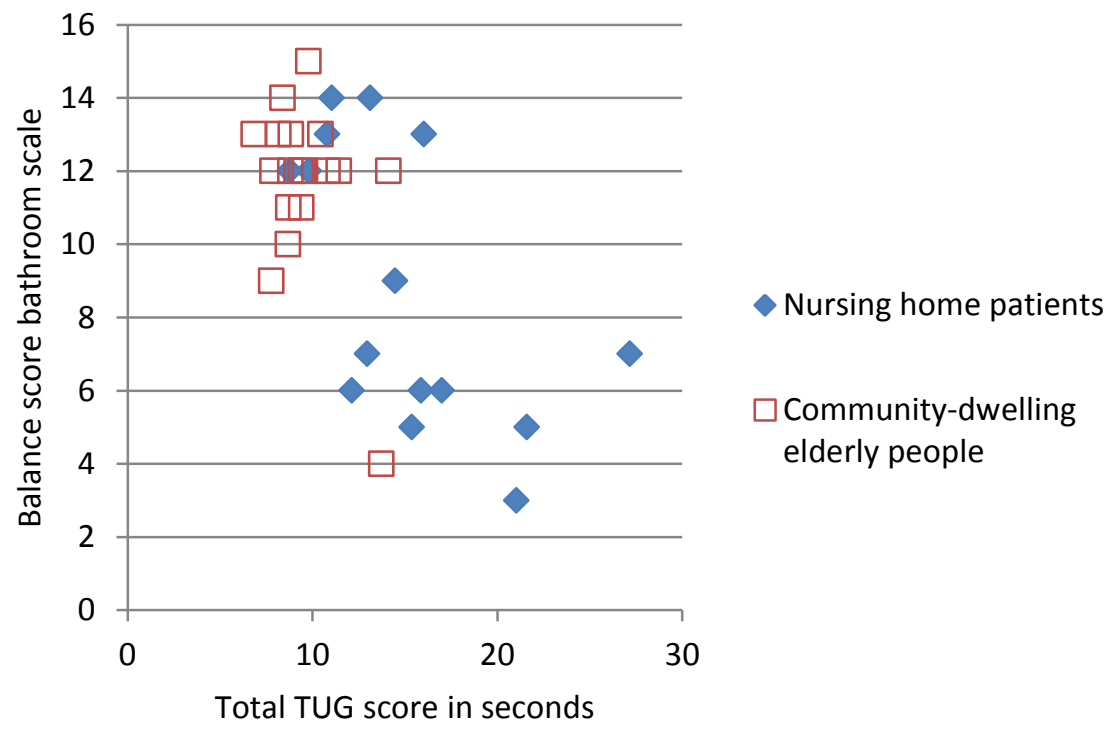

Figure $\mathbf{2 b}$. Scatterplot comparing bathroom scale score and TUG score 


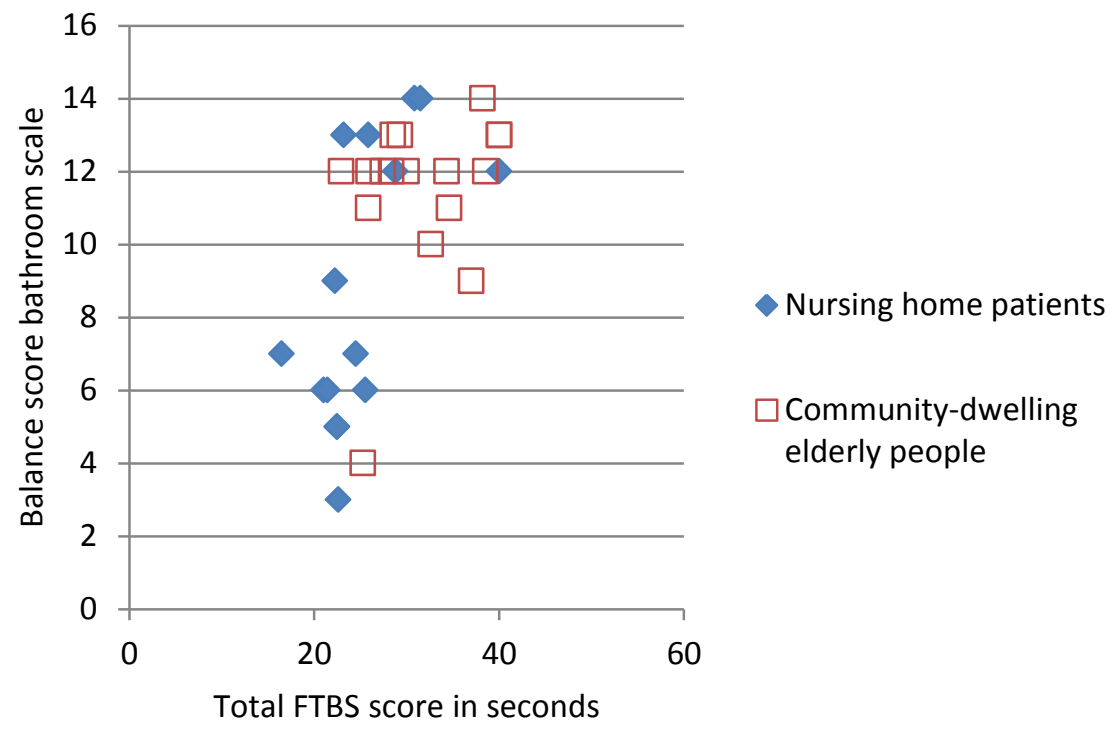

Figure 2c. Scatterplot comparing bathroom scale score and FTBS score

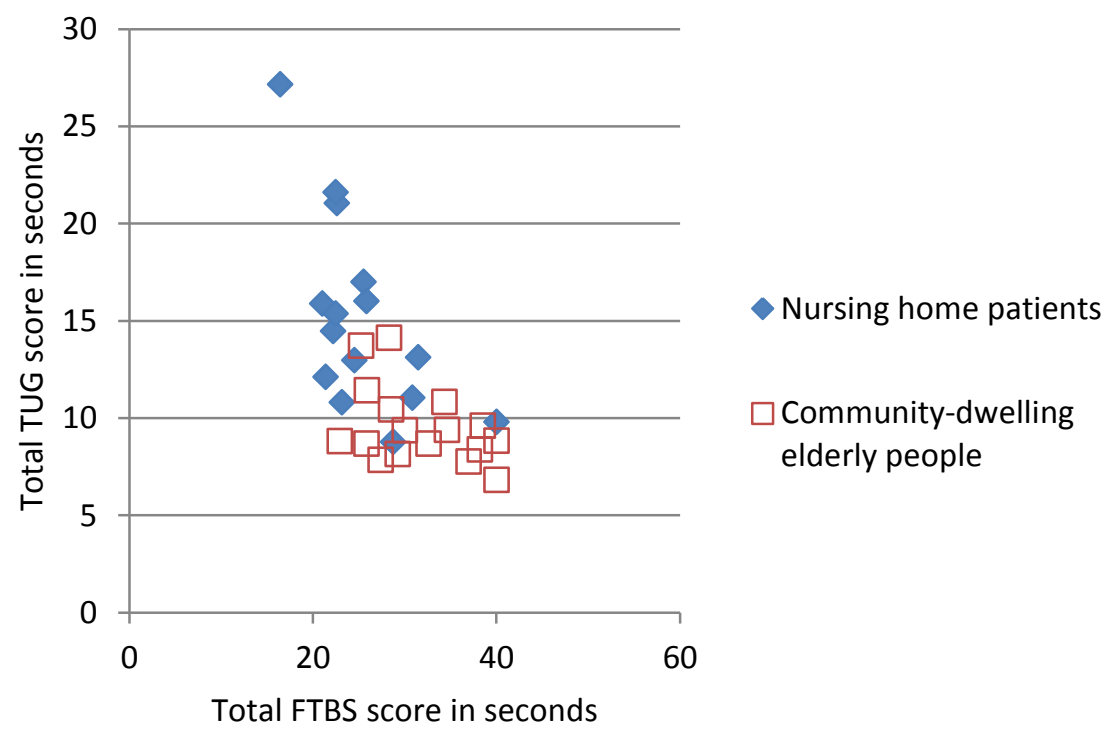

Figure 2d. Scatterpot comparing TUG score and FTBS score 


\section{Discussion}

From the results of this study can be concluded that balance measurements with the modified bathroom scale are in line with the results from clinical balance tests. The results also revealed that the bathroom scale confirmed that nursing home patients have poorer balance compared to active community-dwelling elderly people, just as the three clinical balance tests did. These findings suggest that the bathroom scale could be a useful tool for measuring balance in elderly people. Previous research has suggested that force plates or balance boards could be used to assess balance. An advantage that the modified bathroom scale has over force plates is that it is much less expensive and easier to use. Also, the bathroom scale can be used in the home instead of a laboratory setting. ${ }^{12,23}$ However, the clinical meaning of the balance scores of the bathroom scale remains to be demonstrated.

Generally, the correlations that were presented in the results were moderate. This is in line with previous studies that have compared clinical balance tests to each other and to force plate measures. ${ }^{10,25,26}$ Despite the fact that the correlations between the bathroom scale and the POMA, TUG, and FTBS were significant in nursing home patients and not significant in community-dwelling elderly people, these correlations did not differ statistically between the two groups. This could be due to small group sizes. Moreover, the correlation between the bathroom scale and the clinical tests were about the same as the correlation between the two clinical tests; the TUG and FTBS. A possible explanation for the fact that the correlations in the group of community-dwelling elderly people were not significant is that the variation in balance scores on the bathroom scale was much larger compared to variation on the clinical tests. This ceiling effect was especially evident in the scores of the community-dwelling elderly people on the POMA. So, where clinical tests reach their maximum score, the modified bathroom scale is able to detect variation in balance in community-dwelling elderly people. Whether this additional measurement power is meaningful or is able to detect clinically relevant changes in balance cannot be concluded based on the data that was collected during this study.

The results of the study are based on a single measurement of balance with the modified bathroom scale. Therefore, no conclusions can be drawn regarding test-retest reliability. A previous longitudinal study with the modified bathroom scale in communitydwelling elderly people has shown that the reliability of the balance measurements can be greatly improved by using an average score over the course of one week instead of one measurement. ${ }^{21}$ The main reason for this is that the use of only one test from the bathroom scale can increase the variability in the measurements. Despite this, the current study was able to show that a single measurement of balance with the bathroom scale might be as good as a single measurement of balance with a clinical test. However, before 
the value of the bathroom scale for clinical practice can be determined, test-retest reliability should be investigated.

The overall participation rate in the study was high. An explanation for this might be that measurements that were conducted for the study were embedded in usual daily activities as much as possible. For example, in nursing home patients the balance tests were administered during regular physiotherapy sessions and in community-dwelling elderly people the measurements were conducted during the exercise classes participants attended every week. Besides that, the participating organizations showed commitment and interest in the study.

Despite the fact that the participation rate in nursing home patients and communitydwelling elderly people in this study was high, the sample size was quite small. This could be a limitation of this study; the TUG and FTBS were only conducted in 15 nursing home patients and 17 community-dwelling elderly people.

Balance scores may have been influenced by cognitive function because the time it takes a person to step onto the bathroom scale is one of the four parameters that determine the overall bathroom scale balance score. As we did not measure cognitive function in our study, no conclusions can be drawn regarding this. This can be considered a limitation of our study and should be taken into account in future research.

\section{Conclusion}

Our results suggest that the modified bathroom scale might be useful for measuring balance in elderly people. Previous research has suggested that poor balance is a relevant predictor for adverse health outcomes. ${ }^{9,27}$ The modified bathroom scale can be used to measure balance in elderly people and to monitor the development of this predictor over time. Advantages of the modified bathroom scale compared to clinical balance tests are that it is easy for elderly people to perform, that the test can be conducted without professional involvement, and that elderly people can monitor their own balance, which can support self-management. The modified bathroom scale can also support healthcare professionals by transferring data via Bluetooth ${ }^{\circledR}$ which can enable them to monitor the development of balance in their patients from a distance.

The results of this study show that the bathroom scale can detect differences where some clinical tests reach a ceiling effect. At present, it remains difficult to determine whether these differences are clinically relevant or not. Future research should focus on how clinically relevant changes can be detected with the modified bathroom scale. It is also necessary to study the predictive value of balance as measured by the modified bathroom scale on adverse health outcomes such as disability, falls, and hospitalization. Therefore, a longitudinal follow-up study has been planned, which starts in September 
2012, during which elderly people will measure their balance daily with the bathroom scale.

\section{References}

1. Steffen TM, Hacker Mollinger TA, Mollinger L. Age and Gender related test performance in community-dwelling elderly people: six minute walk test, berg balance scale, time up \& go test and gait speeds. Phys Ther. 2002;82:128-137.

2. Tinetti ME, Inouye SK, Gill TM, Doucette JT. Shared risk factors for falls, incontinence, and functional dependence. JAMA. 1995;273:1348-1353.

3. Onder G, Penninx BW, Ferrucci L, Fried LP, Guralnik JM, Pahor M. Measures of physical performance and risk for progressive and catastrophic disability: results from the Women's Health and Aging Study. J Gerontol A Biol Sci Med Sci. 2005;60:74-79.

4. Gill TM, Williams CS, Tinetti ME. Assessing risk for the onset of functional dependence among older adults: the role of physical performance. J Am Geriatr Soc. 1995;43:603609.

5. Shinkai S, Kumagai S, Fujiwara Y, Amano H, Yoshida Y, Wanatabe S, et al. Predictors for the onset of functional decline among initially non-disabled older people living in a community during a 6-year follow-up. Geriatrics Gerntology International. 2003;3:S31-S39.

6. Wang $\mathrm{CY}$, Yeh $\mathrm{CJ}, \mathrm{Hu} \mathrm{MH}$. Mobility related performance test to predict mobility disability at 2- year follow-up in community-dwelling older adults. Arch Gerontol Geriatr. 2011;52:1-4.

7. Robbins AS, Rubenstein LZ. Predictors of falls among elderly people; results of two population based studies. Arch Intern Med. 1989;149:1628-1633.

8. Pajala S, Era P, Koskenvuo M, Kaprio J, Tormakangas T, Rantanen T. Force platform balance measures as predictors of indoor and outdoor falls in community-dwelling women aged 63-76. J Gerontol. 2008;63:171-178.

9. Cesari M, Kritchevsky SB, Newman AB, Simonsick EM, Harris TB, Penninx, et al. Added value of physical performance measures in predicting adverse health related events: results from the health aging and body composition study. J Am Geriatr Soc. 2009;57:251-259.

10. Lin MR, Hwang HF, Hu MH, Wu HD, Wang YW, Huang FC. Psychometric comparison of the timed up and go, one-leg stand, functional reach, and tinetti balance measures in community-dwelling older people. J Am Geriatr Soc. 2004;52:1343-1348.

11. Langley FA, Mackintosh SFH. Functional balance assessment of older community dwelling adults: a systematic review of the literature. IJAHSP. 2007;5:1-11. 
12. Berg K, Maki, BE, Williams JI, Holliday PJ, Wood-Dauphinee SL. Clinical and laboratory measures of postural control in an elderly population. Arch Phys Med Rehab. 1992;73:1073-1080.

13. Farrell M. Using functional assessment and screening tools with frail older adults. Top Geriatr Rehabil. 2004;20:14-20.

14. Reuben DB, Valle LA, Hays RD, Siu AL. Measuring physical functioning in communitydwelling older persons: a comparison of self-administered, interviewer-administered, and performance-based measured. J Am Geriatr Soc. 1995;43:17-23.

15. Pérennou D, Decavel P, Manckoundia P, Penven $Y$, Mourey F, Launay F, et al. Evaluation of balance in neurologic and geriatric disorders. Ann Readapt Med Phys. 2005;48:317-335.

16. Tinetti M. Performance oriented assessment of mobility problems in elderly patients. J Am Geriatr Soc. 1986;34:119-126.

17. Mathias S, Nayak US, Isaacs B. Balance in elderly patients: the "get-up and go" test. Arch Phys Med Rehabil. 1986;67:387-389.

18. Amoud H, Abadi M, Hewson DJ, Michel-Pellegrino V, Doussot M, Duchêne J. Fractal time series analysis of postural stability in elderly and control subjects. J Neuroeng Rehab. 2007;4:12.

19. Michel-Pellegrino V, Li K, Hewons DJ, Hogrel JY, Duchêne. Techniques d'évaluation a domicile de la qualité de l'équilibre et de la force de préhension chez la personne âgée en perte d'autonomie. IRBM. 2009;30:262-267.

20. Hewson DJ, Duchêne J, Charpillet F, Saboune J, Michel-Pellegrino V, Amoud H, et al. The PARAChute project: remote monitoring of posture and gait for fall prevention. J Adv Sign Proc. 2007;1:109.

21. Duchêne J, Hewson DJ. Longitudinal evaluation of balance quality using a modified bathroom scale: usability and acceptability. J Telemed Telecare. 2011;00:1-6.

22. Hewson DJ, Duménil J, Duchêne JY. Validation of balance-quality assessment using a modified bathroom scale. Under review.

23. Clark RA, Bryant AL, Pua Y, McCrory P, Bennell K, Hunt M. Validity and reliability of the Nintendo Wii Balance Board for assessment of standing balance. Gait \& Posture. 2010;31:307-310.

24. Rossiter-Fornoff JE, Wolf SL, Wolfson LI, Buchner DM. A cross-sectional validation study of the FICSIT common data base static balance measures. J Gerontol A Biol Med Sci. 1995; 50A:M291-M297.

25. Cho BL, Scarpace D, Alexander NB. Tests of stepping as indicators of mobility, balance, and fall risk in balance-impaired older adults. J Am Geriatr Soc. 2004;52:1168-1173.

26. Karlsson A, Frykberg G. Correlations between force plate measures for assessment of balance. Clin Biomech. 2000;15:365-369. 
27. Vermeulen J, Neyens JCL, Spreeuwenberg MD, van Rossum E, de Witte LP. Predicting ADL disability in community-dwelling elderly people using physical frailty indicators: as systematic review. BMC Geriatr. 2011;11:33. 



\section{CHAPTER 5}

\section{The relation between balance measured by a modified bathroom scale and falls and disability in elderly people}

This chapter was submitted to Journal of Medical Internet Research as:

Vermeulen J, Neyens JCL, Spreeuwenberg MD, van Rossum E, Boessen ABCG, Sipers W, de Witte LP. The relation between balance measured by a modified bathroom scale and falls and disability in elderly people. 


\section{Abstract}

Background: There are indications that older adults who suffer from poor balance have an increased risk for adverse health outcomes such as falls and disability. Monitoring the development of balance over time enables early detection of balance decline which can help to identify older adults who could benefit from interventions aimed at prevention of these adverse outcomes. An innovative and easy-to-use device that can be used by older adults for home-based monitoring of balance is a modified bathroom scale.

Objective: To study the relation between balance scores of a modified bathroom scale and falls and disability in a sample of older adults.

Methods: For this six-month follow-up study, participants were recruited via physiotherapists working in a nursing home, geriatricians, exercise classes, and at an event about health for older adults. Inclusion criteria were aged 65 years or older, being able to stand on a bathroom scale independently and able to sign informed consent. Forty-one nursing home patients and 139 community-dwelling older adults stepped onto the modified bathroom scale 3 consecutive times at baseline to measure their balance. Their mean balance score on a scale from 0 to 16 was calculated; higher scores indicated better balance. Falls and disability were measured at baseline and after 6-months follow-up using questionnaires. The cross-sectional relation between balance and falls and disability at baseline was studied using t-tests and Spearman correlations. Univariate and multivariate logistic regression analyses were conducted to study the relation between balance measured at baseline and falls and disability development after 6 months follow-up. Results: Hundred twenty-eight participants with complete data sets (25.8\% male, 24 nursing home patients) and a mean age of 75.33 years (SD 6.26) were included in the analyses of this study. Balance scores of participants who reported at baseline that they had fallen at least once in the past 6 months were lower compared to non-fallers, 8.9 and 11.2 respectively $(P<.001)$. The correlation between mean balance score and disability sumscore at baseline was $-.51(P<.001)$. No significant associations were found between balance at baseline and falls after 6 months follow-up. Baseline balance scores were significantly associated with the development of disability after 6-months follow-up in the univariate analysis $(\mathrm{OR}=.86,95 \% \mathrm{Cl}=.76-.98)$ but not in the multivariate analysis when correcting for age, gender, and baseline disability (OR $=.95,95 \% \mathrm{Cl}=.80-1.12)$.

Conclusions: There is a cross-sectional relation between balance measured by a modified bathroom scale and falls and disability in older adults. Despite this cross-sectional relation, longitudinal data showed that balance scores have no predictive value for falls and might only have limited predictive value for disability development after 6-months follow-up. 


\section{Introduction}

There are indications that older adults who suffer from poor balance have an increased risk for adverse health outcomes such as falls, mobility-related disability, and disability in daily activities. ${ }^{1-4}$ Monitoring the development of balance over time enables early detection of balance decline. Providing interventions aimed at improving balance and preventing falls or disability could be beneficial to older adults with decreased balance because it can reduce their risk of these adverse outcomes. ${ }^{5-8}$

Options for monitoring the development of balance over time in older adults are: clinical balance tests that are conducted by care professionals, ${ }^{9-11}$ (expensive) force plate equipment that is available in clinical/laboratory settings, ${ }^{12}$ and innovative telemonitoring devices. ${ }^{13-16}$ The latter can be used by older adults in their own home without the interference of a care professional which facilitates regular measurements that enable early detection of change over time. Furthermore, such telemonitoring devices can provide direct information regarding balance (changes) to the user, which can support self-management.

A telemonitoring device appropriate for home-based self-monitoring of balance is a modified bathroom scale. ${ }^{13}$ This device uses an algorithm to calculate balance parameters and is equipped with Bluetooth ${ }^{\circledR}$ which enables the transfer of balance and weight data to an application on a smartphone. Via the application older adults can receive information about (changes in) their own balance scores. Furthermore, the data could be forwarded to a database that can be accessed by care professionals which enables them to monitor the development of balance in their patients over time from a distance. ${ }^{17,18}$ Older adults are able to use the modified bathroom scale for home-based self-monitoring of balance because it does not differ from a normal bathroom scale. ${ }^{13,19}$ Previous research that compared balance scores of the modified bathroom scale to clinical balance tests, such as the Performance Oriented Mobility Assessment or Timed Up and Go, suggests good construct validity especially in older adults with (slightly) diminished balance. ${ }^{20}$ Besides that, the modified bathroom scale provides balance estimates similar to those of a force plate. $^{21}$

Since the bathroom scale seems to be able to provide valid balance measurements, it can be used for the early detection of balance decline in older adults. However, no studies have been conducted yet in which the predictive validity of balance scores of the modified bathroom scale on adverse outcomes has been studied. Information regarding predictive validity can help older adults and care professionals to interpret the balance scores. Furthermore, it is important to know whether lower balance scores are associated with adverse outcomes in order to decide whether (or which) preventive interventions would be justified when balance decline is detected. Therefore, the aim of this study is to explore 
the relation between balance scores of the modified bathroom scale and falls and disability in older adults.

\section{Methods}

\section{Design, setting, and participants}

A longitudinal study with 6 months follow-up was conducted. Participants were recruited via various settings to ensure that different balance levels, ranging from very poor to very good, were represented in the study sample. Participants were recruited via physiotherapists from two nursing homes, via the outpatient clinic of a geriatrician, via exercise classes for older adults, and at an event about health for older adults. To be eligible for inclusion participants had to be aged above 65 years, able to stand on the bathroom scale independently, and able to provide written informed consent.

Potential participants received an invitation letter from their physiotherapist $(n=48)$, geriatrician $(n=28)$, exercise instructor $(n=72)$, or the researcher $(n=60)$ that contained information regarding the study. Before handing out the invitations, it was checked whether a person was able to provide written informed consent. Those who met the eligibility criteria and signed informed consent were included in the study. Once written informed consent was provided, participants measured their balance using the modified bathroom scale and filled-out a paper-based questionnaire. After 6 months follow-up the same questionnaire was sent to the participants. Non-responders received a reminder after three weeks asking them to return the questionnaire. This study was approved by the Medical Ethical Committee Atrium-Orbis-Zuyd (Reference: NL 142245709, 23 July 2012).

\section{Measurements}

Participants conducted balance measurements at baseline and filled out a questionnaire regarding participant characteristics (age, gender, chronic conditions, psychotropic drug use), falls, and disability at baseline and after 6 months follow-up.

Balance was measured using the modified bathroom scale. The scale is equipped with an infrared sensor at the front which activates the bathroom scale. All participants were instructed to stand in front of the bathroom scale and to step onto it when the number ' 0.0 ' appeared on the display. They were instructed to step down backwards once their weight appeared on the screen. The modified bathroom scale uses the signals from four pressure sensors located in the corners of the scale to collect information regarding two dynamic and two static balance parameters. An overall balance score is calculated using the information from the following four parameters: step on delay, rise rate, surface under the stabilogram, and the average velocity of the trajectory. Each parameter is 
scored on a scale from 0 till 4 which results in an overall balance score between 0 and 16 . A higher score indicates better balance. More detailed information regarding the parameters and the calculation of the overall balance score is described in a previous article by Duchêne and Hewson. ${ }^{13}$ Participants stepped onto the bathroom scale 3 consecutive times which resulted in 3 balance scores. The mean balance score of these 3 measurements was calculated and used in the analyses.

Falls were defined as unintentionally coming to rest on the ground, floor, or other lower level. Via the questionnaire participants were asked to report whether they had fallen in the past six months. Those who had fallen at least once in the past six months were considered fallers.

Disability was measured using the Groningen Activity Restriction Scale (GARS) which is a valid and reliable measuring instrument. ${ }^{22}$ The GARS consists of 18 items of which 11 refer to Activities of Daily Living ( $A D L)$ and 7 refer to Instrumental Activities of Daily Living (IADL). A copy of the GARS is provided in Appendix 1. For each item, participants indicated on a 4-point scale whether they could perform the activity independently without any difficulty (1), independently with some difficulty (2), independently with great difficulty (3), or whether they could not execute the activity independently (4). So, if participants scored 4 they depended on other people for the performance of that activity. Overall disability, ADL disability, and IADL disability sumscores were calculated and range from 18 till 72, 11 till 44, and 7 till 28 respectively; higher scores indicated higher disability levels. Disability development after six months follow-up was operationalized as increased dependence in daily activities ( $A D L$ and IADL combined); meaning that a participant was dependent in at least 1 more activity of the GARS at follow-up compared to baseline. This was calculated by subtracting the number of activities in which a participant was dependent at baseline from the number of activities in which a participant was dependent at follow-up.

\section{Statistical analyses}

Descriptive statistics were used to provide information regarding the baseline characteristics of the participants. Categorical variables were expressed with percentages and continuous variables with means and standard deviations.

To study reliability of the modified bathroom scale, Intraclass Correlation Coefficients (ICC) of the balance scores were calculated. ICCs were calculated for the three repeated balance scores and for each of the four balance parameters (step on delay, rise rate, surface under the stabilogram, and average velocity of the trajectory) separately.

To study the relation between balance scores and falls at baseline, an independent samples t-test was conducted to determine whether participants who reported at baseline that they had fallen at least once in the past 6 months had a lower mean balance score compared to participants who had not fallen in the 6 months before the baseline 
measurement. To study the relation between balance scores and disability at baseline Spearman correlations between the mean balance score and overall, ADL, and IADL disability sumscores at baseline were calculated.

To study the relation between balance scores at baseline and falls and disability after 6 months follow-up, univariate and multivariate logistic regression analyses were conducted. Five univariate regression analyses were conducted with baseline balance score of the modified bathroom scale, faller at baseline ( $1=y e s, 0=n o$ ), psychotropic drug use at baseline ( $1=y e s, 0=$ no), gender, and age as independent variables and faller at 6 months follow-up as dependent variable. Four univariate regression analyses were conducted with baseline balance score of the modified bathroom scale, baseline disability (GARS overall sumscore), gender, and age as independent variables and disability development after 6 months follow-up as dependent variable. In addition, 2 multivariate logistic regression analyses were conducted to study the predictive value of the bathroom scale balance score at baseline on falling and development of disability after 6 months follow-up while correcting for relevant baseline variables (age, gender, faller at baseline ( $1=y e s, 0=$ no), use of psychotropic drugs ( $1=y e s, 0=$ no), and GARS sumscore at baseline).

\section{Results}

\section{Participants}

Figure 1 provides an overview of the inclusion process. Of the 208 participants who received an invitation, 180 provided written informed consent and participated in the baseline measurement. After 6-months follow-up, 4 participants had died and 2 could not be approached for the follow-up measurement due to advanced illness. Of the 174 participants who received the 6-month follow-up questionnaire, 143 returned it ( $82 \%$ ). Finally, 15 participants were excluded from the analyses because they had 4 or more missing values on the GARS or because they had not answered the question regarding falls. This resulted in a study sample of 128 participants with complete data sets $(25.8 \%$ male) and a mean age of 75.33 years (SD 6.26). More information regarding the baseline characteristics of the study sample is provided in Table 1. 


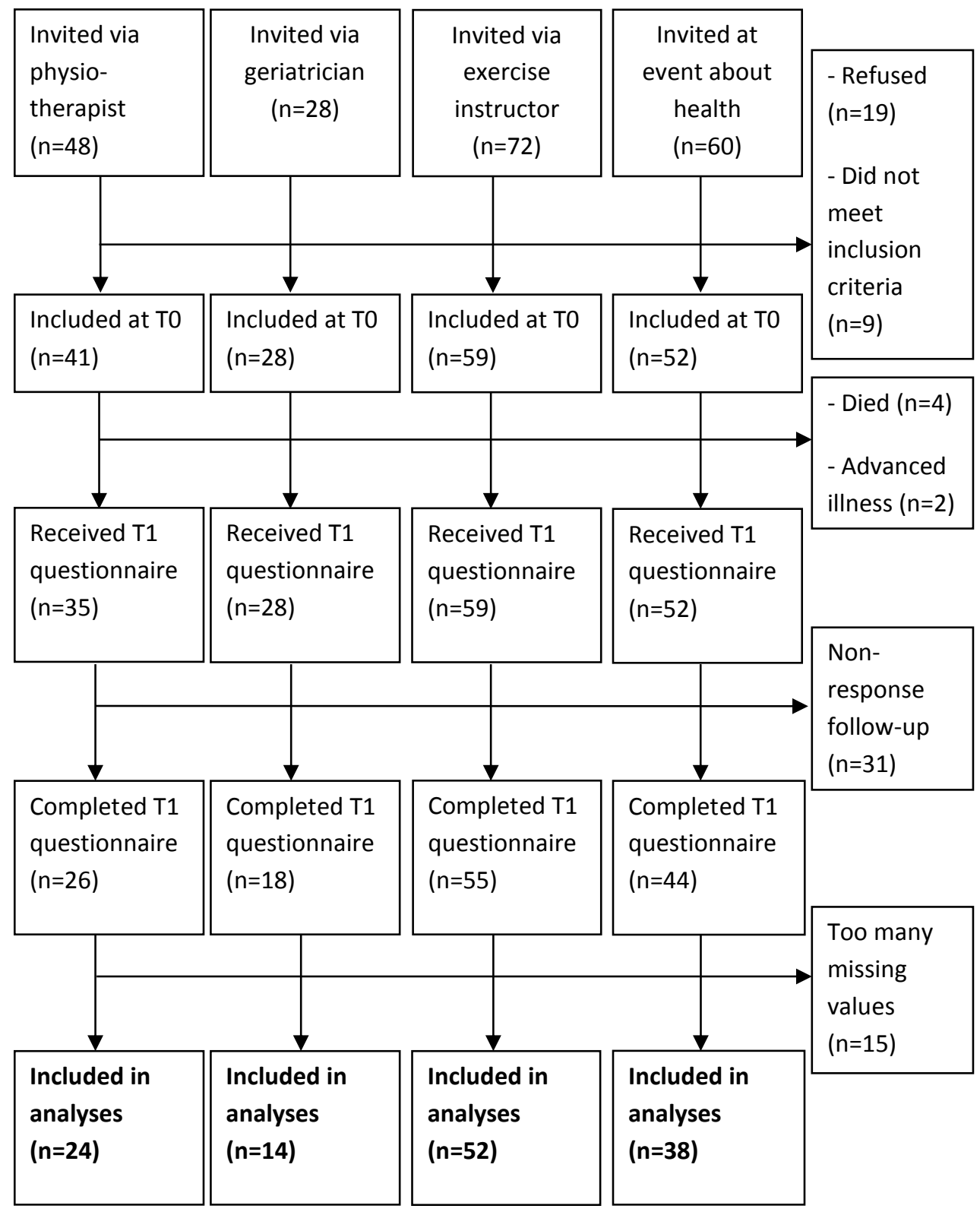

Figure 1. Flow chart of participants 
Table 1. Baseline characteristics of participants $(n=128)$

\begin{tabular}{lc}
\hline Characteristics & Mean (SD) or $\mathbf{n}$ (\%) \\
\hline Age in years & $75.33(6.26)$ \\
Gender & $33(25.8 \%)$ \\
Men & $95(74.2 \%)$ \\
$\quad$ Women & $10.63(3.17)$ \\
Mean balance score & $31(24.2 \%)$ \\
Falls in past 6 months & $27.42(12.00)$ \\
GARS overall sumscore (ADL + IADL) ${ }^{*}$ & $15.13(5.96)$ \\
GARS ADL sumscore ${ }^{*}$ & $12.29(6.61)$ \\
GARS IADL sumscore & \\
Chronic diseases: & $21(16.4 \%)$ \\
Diabetes & $7(5.5 \%)$ \\
COPD/Asthma & $39(30.5 \%)$ \\
Cardiovascular diseases & $36(28.1 \%)$ \\
Arthritis & $7(5.5 \%)$ \\
Parkinson/MS & \\
Disability: & $20(15.6 \%)$ \\
Dependent in 1 activity & $12(9.4 \%)$ \\
Dependent in 2 activities & $10(7.8 \%)$ \\
Dependent in 3 activities & $25(19.5 \%)$ \\
Dependent in 4 or more activities & \\
\hline * & \\
\hline
\end{tabular}

GARS = Groningen Activity Restriction Scale (range 18-72), ADL = subscale Activities of Daily Living (range 11-44), and IADL = subscale Instrumental Activities of Daily Living (range 7-28).

Twenty-three participants (18\%) reported that they had fallen at least once during the follow-up period of the study. Of these 23 participants, 15 participants also reported a fall during the 6 months before the baseline measurement. After 6 months follow-up the level of dependence increased in 32 participants (25\%), meaning that these participants needed help from another person with at least one more activity compared to baseline.

The mean balance scores of participants who dropped-out of the study after the baseline measurement were significantly lower, namely 9.26 (SD 3.69), compared to those of participants who completed the study and were included in the analyses, namely 10.63 (3.17) $(P=.009)$. Furthermore, baseline IADL disability sumscores were higher in the group of participants who were not included in the analyses of this study, namely 14.52 (SD 7.35 ,) compared to those who were included in the study sample, namely $12.29(6.61)(P=$ .049). Drop-out was highest in the participants who were recruited via the physiotherapists working in a nursing home and via the geriatrician ( $50 \%$ in both groups). 


\section{Reliability}

The ICC for three consecutive balance scores of the modified bathroom scale was .70 (95\% $\mathrm{Cl}=.62-.77)$. The ICCs for the four separate balance parameters step on delay, rise rate, surface under the stabilogram, and average velocity of the trajectory were $.31(95 \% \mathrm{Cl}=$ $.20-.43), .72(95 \% \mathrm{Cl}=.64-.79), .54(95 \% \mathrm{Cl}=.43-.63)$ and $.54(95 \% \mathrm{Cl}=.44-.64)$ respectively.

\section{Cross-sectional relation between balance, falls, and disability}

Balance scores of participants who had fallen at least once in the past 6 months before baseline were lower compared to non-fallers, 8.9 and 11.2 respectively $(P<.001)$.

Correlations between mean balance score and overall, ADL, and IADL disability sumscores at baseline were $-.51,-.42$, and -.46 respectively $(P<.001)$.

\section{Relation between baseline balance and falls and disability at follow-up}

Results of the univariate regression analyses are presented in Table 2 and results of the multivariate regression analyses are presented in Table 3. Falls reported at baseline is the only variable that is significantly associated with falls during 6 -months follow-up in the univariate analysis $(\mathrm{OR}=10.43,95 \% \mathrm{Cl}=3.80-28.63)$ and in the multivariate analysis (OR = $14.58,95 \% \mathrm{Cl}=4.26-49.94)$. Baseline balance scores are significantly associated with the development of disability after 6 -months follow-up in the univariate analysis (OR $=.86$, $95 \% \mathrm{Cl}=.76-.98)$. Furthermore, disability level at baseline is significantly associated with disability development after 6 months follow-up in the univariate analysis (OR $=1.04,95 \%$ $\mathrm{Cl}=1.00-1.07)$. None of the variables entered into the multivariate regression model was predictive of disability development after 6 months follow-up.

Table 2. Univariate association between baseline variables and falls and disability development after 6-months follow-up

\begin{tabular}{lcc}
\hline $\begin{array}{l}\text { Independent variable at } \\
\text { baseline }\end{array}$ & $\begin{array}{c}\text { Dependent variable: Falls at } \\
\text { follow-up } \\
\text { OR }(\mathbf{9 5 \%} \mathrm{Cl}), \boldsymbol{P}\end{array}$ & $\begin{array}{c}\text { Dependent variable: disability } \\
\text { development at follow-up } \\
\text { OR (95\% Cl), } \boldsymbol{P}\end{array}$ \\
\hline Mean balance score & $.96(.84-1.11), P=.62$ & $.86(.76-.98), P=.03^{*}$ \\
\hline Age & $1.00(.93-1.07), P=.95$ & $1.07(1.00-1.14), P=.05$ \\
\hline Gender & $.59(.22-1.543), P=.28$ & $.47(.20-1.11), P=.08$ \\
\hline Falls at baseline & $10.43(3.80-28.63), P<.001^{*}$ & $\mathrm{NA}^{* *}$ \\
\hline Psychotropic drug use & $2.50(.76-8.19), P=.13$ & $\mathrm{NA}^{* *}$ \\
\hline GARS overall sumscore & $\mathrm{NA}^{* *}$ & $1.04(1.00-1.07), P=.03^{*}$ \\
\hline
\end{tabular}

"Significant association (univariate).

${ }^{* *}$ Not applicable: variable not entered in analysis. 
Table 3. Multivariate predictors of falls and disability development after 6-months followup

\begin{tabular}{lcc}
\hline $\begin{array}{l}\text { Independent variable at } \\
\text { baseline }\end{array}$ & $\begin{array}{c}\text { Dependent variable: Falls at } \\
\text { follow up } \\
\text { OR }(\mathbf{9 5 \%} \mathrm{Cl}), \boldsymbol{P}\end{array}$ & $\begin{array}{c}\text { Dependent variable: Overall } \\
\text { disability at follow-up } \\
\text { OR (95\% Cl), } \boldsymbol{P}\end{array}$ \\
\hline Mean balance score & $1.15(.91-1.45), P=.26$ & $.95(.80-1.12), P=.52$ \\
\hline Age & $1.00(.91-1.11), P=.99$ & $1.04(.96-1.12), P=.32$ \\
\hline Gender & $.52(.17-1.64), P=.27$ & $.47(.19-1.15), P=.10$ \\
\hline Falls at baseline & $14.58(4.26-49.94), P<.001^{*}$ & $\mathrm{NA}^{* *}$ \\
\hline Psychotropic drug use & $1.38(.34-5.66), P=.66$ & $\mathrm{NA}^{* *}$ \\
\hline GARS overall sumscore & $\mathrm{NA}^{* *}$ & $1.02(.99-1.06), P=.26$ \\
\hline
\end{tabular}

Significant association (multivariate).

${ }^{* *}$ Not applicable: variable not entered in model.

\section{Discussion}

\section{Principal results and comparison to previous research}

The results of this study indicate that the reliability of the balance scores of the modified bathroom scale is acceptable. ${ }^{23}$ There seems to be a significant cross-sectional relation between balance scores and falls since the group of participants who suffered a fall in the past six months before baseline had significantly poorer balance compared to those who did not fall. The difference between these groups was 2.3 points on a scale from 0 till 16 . Furthermore, there was a significant and substantial correlation between balance scores and disability sumscores at baseline which revealed that poorer balance was associated with higher disability levels. Despite this cross-sectional relationship, longitudinal data show that balance scores have no predictive value for falls in the next 6 months and maybe only limited predictive value for disability development after 6 months follow-up. No significant associations were found between balance at baseline and falls after 6 months follow-up in the univariate and multivariate regression analyses. Baseline balance was associated with disability development in the univariate regression analysis which indicated that older adults with poorer balance have a higher risk to develop disability after 6 months follow-up. However, when correcting for age, gender, and baseline disability in the multivariate regression analysis this association was no longer significant.

Previous studies have been conducted regarding the relation between balance measured by clinical balance tests, force plates, or telemonitoring devices and falls and disability in older adults. Most studies focused on the predictive validity of clinical balance tests and these studies suggest that poor balance predicts a (moderately) increased risk of these adverse outcomes in older adults. ${ }^{1-3,24}$ Previous studies regarding the predictive value of balance-related parameters measured with a force plate on falls revealed 
contradictory results: some studies report that force plate measurements predict falls whereas other studies report that no associations were found. ${ }^{25,26}$ Previous research regarding innovative telemonitoring technologies that can be used for home-based selfmonitoring of balance mostly concerns the Nintendo Wii. A recent review regarding the use of the Nintendo Wii for the assessment and training of balance revealed that, despite the fact that the Wii Balance Board can be used as a proxy for measurements conducted with a force plate, its software is not very effective in determining balance status. ${ }^{27}$ Furthermore, correlations between balance scores of the Wii Balance Board and clinical balance tests are low. ${ }^{28,29}$ No previous studies have been conducted yet regarding the predictive value of the Wii Balance Board (or other home-based balance telemonitoring devices) on adverse health outcomes in older adults. The results of our study were in line with previous research that indicated that falls in the past are a strong predictor of falls in the future. ${ }^{30,31}$

The current study only partly confirmed findings from previous research since it revealed a cross-sectional relation between balance and falls and disability, but no association between balance scores at baseline on falls and disability development after 6 months follow-up could be demonstrated. A possible explanation for this could be that the follow-up of this study was short compared to other studies that focused on the predictive validity of (clinical) balance tests on falls and disability. Due to this shorter follow-up period not many falls or changes in the level of dependence occurred in this study. In addition, previous research has suggested that balance is not a very strong predictor of future falls and disability development which could explain why no significant relation was found when correcting for other relevant baseline characteristics. Another possible explanation why studies focusing on clinical balance tests revealed moderate predictive value of balance in older adults and why scores of the modified bathroom scale were not predictive of future falls and disability in this study, could be that professionals who conduct such clinical balance tests often take into account different aspects of balance (or physical functioning) and have their clinical expertise to rely on when estimating the risk for falls or disability development.

\section{Strengths and limitations}

In total 128 participants, which is $71 \%$ of the baseline study sample, could be included in the analyses of this study. The follow-up period of six month is relatively short compared to previous research regarding the predictive validity of balance in older adults. Possibly as a result of the shorter follow-up period, only 23 participants (18\%) reported that they had suffered a fall during the study. The relatively short follow-up period of our study is not necessarily a limitation since, for the early identification of older adults with balance decline who could benefit from preventive intervention programs, it is more useful to know the 'short-term' predictive value of the balance scores of the modified bathroom 
scale. It makes more sense to start with a preventive intervention when 'short-term predictors' are present in older adults compared to a situation in which it will take a few years before adverse outcomes will develop.

The number of participants who reported increased overall disability after 6 months follow-up was higher, namely $32(25 \%)$, compared to the number of participants who reported a fall. However, a possible limitation of this study could be that participants who were lost to follow-up reported higher disability levels and lower balance scores at baseline compared to those who remained in the sample. This may have influenced the results of our study because the disability levels at follow-up and the variation in scores on dependent and independent variables might have been higher if those participants could have been included in the analyses. Based on the available data, no firm conclusions can be drawn regarding the extent to which this selective loss to follow-up has influenced the results of our study.

It should be noted that all balance measurements were performed under supervision of a researcher. This can yield different results compared to home-based measurements using the modified bathroom scale. Balance scores of the modified bathroom scale could have been higher during this study because participants might be more alert, step onto the bathroom scale quicker, or try to stand very still when the researcher is present, whereas they might not do this when performing home-based measurements alone. Based on this study, no estimates can be provided on how the reliability of balance scores of the modified bathroom scale are influenced by the setting in which they are conducted (research setting vs. home-based setting) and to which extent the setting might influence the relation with falls and disability. The ICCs that were calculated to evaluate test-retest reliability revealed that one of the four balance parameters, namely step on delay (which is the time it takes a person to transfer their whole bodyweight onto the modified bathroom scale), had very low test-retest reliability. This means that the score of this parameter differed considerably across the three consecutive measurements in a participant. To which extent step on delay, and thereby the balance scores, are influenced by learning of the participant, presence of the researcher, cognitive functioning, or other factors cannot be concluded based on the current study.

\section{Conclusion}

There is a cross-sectional relation between balance measured by a modified bathroom scale and falls and disability in older adults. Longitudinal data did not confirm this and suggest that balance scores of the modified bathroom scale have no predictive value for falls and might have only limited predictive value for disability development after 6 months follow-up. Research with more participants and a longer follow-up is needed to 
confirm or contradict this and to determine whether balance score cutoff points can be formulated (for different subpopulations) that identify older adults with increased risk for adverse health outcomes. Follow-up studies in which older adults use the bathroom scale on a regular basis (e.g. daily or weekly) for home-based monitoring of balance would provide useful information regarding the variation in balance scores among older adults and regarding clinically relevant changes. Such information is needed before the bathroom scale can be implemented in practice.

\section{References}

1. Muir SW, Berg K, Chesworth B, Klar N, Speechley M. Quantifying the magnitude of risk for balance impairment on falls in community-dwelling older adults: a systematic review and meta-analysis. J Clin Epid. 2010;63:389-406.

2. Vermeulen J, Neyens JCL, van Rossum E, Spreeuwenberg MD, de Witte LP. Predicting ADL disability in community-dwelling elderly people using physical frailty indicators: as systematic review. BMC Geriatr. 2011;11:33.

3. Tinetti ME, Inouye SK, Gill TM, Doucette JT. Shared risk factors for falls, incontinence, and functional dependence. JAMA. 1995;273:1348-1353.

4. Lin MR., Hwang HF, Hu MH, Isaac HD, Wang YW, Huang FC. Psychometric comparison of the Timed Up and Go, One-leg Stand, Functional Reach and Tinetti Balance measures in community-dwelling older people. J Am Geriatr Soc. 2004;5:1343-1348.

5. Hess JA, Woollacott M. Effect of high-intensity strength training on functional measures of balance ability in balance-impaired older adult. Journal of Manipulative and Physiological Therapeutics. 2005;28:582-590.

6. Clemson L, Fiatarone-Singh MA, Bundy A, Cumming RG, Manollaras K, O'Loughlin P. Integration of balance and strength training into daily life activity to reduce rate of falls in older people (the LiFE study): randomized parallel trial. BMJ. 2012;345:e4547e4562.

7. Liu CJ, Latham NK. Progressive resistance strength training for improving physical function in older people. Cochrane Database Syst Rev. 2009;3:CD002759.

8. Van het Reve E, Silveira P, Daniel F, Casati F, De Bruin ED. Tablet-based strengthbalance training to motivate and improve adherence to exercise in independent living older people: part 2 of a phase II preclinical exploratory trial. J Med Internet Res. 2014;16:e159.

9. Tinetti M. Performance oriented assessment of mobility problems in elderly patients. J Am Geriatr Soc. 1986;34:119-126.

10. Mathias S, Nayak US, Isaacs B. Balance in elderly patients: the "get-up and go" test. Arch Phys Med Rehabil. 1986;67:387-389. 
11. Berg KO, Wood-Dauphinee SL, Williams JI, Gayton D. Measuring balance in the elderly: preliminary development of an instrument. Physiotherapy Canada. 1989;41:304-311.

12. Chaudhry H,Bukiet B, Ji Z, Findley T. Measurement of balance in computer posturography: comparison of methods - a brief review. J Bodyw Mov Ther. 2011;15:82-91.

13. Duchêne J, Hewson DJ. Longitudinal evaluation of balance quality using a modified bathroom scale: usability and acceptability. J Telemed Telecare. 2011;00:1-6.

14. Clark RA, Bryant AL, Pua Y, McCrory P, Bannell K, Hunt M. Validity and reliability of the Nintendo Wii Balance Board for assessment of standing balance. Gait \& Posture. 2010;31:307-310.

15. Matjacic Z, Bohinc K, Cikajlo I. Development of an objective balance assessment method for purposes of telemonitoring and telerehabilitation in elderly people. Disabil Rehabil. 2010;32:259-266.

16. Najafi B, Horn D, Marclay S, Crews RT, Wu S, Wrobel JS. Assessing postural control and postural control strategy in diabetes patients using innovative and wearable technology. J Diabetes Sci Technol. 2010;4:780-791.

17. Amoud H, Abadi M, Hewson DJ, Michel-Pellegrino V, Doussot M, Duchêne J. Fractal time series analysis of postural stability in elderly and control subjects. J Neuroeng Rehab. 2007;4:12.

18. Michel-Pellegrino V, Li K, Hewons DJ, Hogrel YJ, Duchêne J. Techniques d'évaluation a domicile de la qualité de l'équilibre et de la force de préhension chez la personne âgée en perte d'autonomie. IRBM. 2009;30:262-267.

19. Vermeulen J, Neyens JCL, Spreeuwenberg MD, van Rossum E, Sipers W, Habets H, et al. User-centered development and testing of a monitoring system that provides feedback regarding physical functioning to elderly people. Patient Prefer Adherence. 2013;7:843-854.

20. Vermeulen J, Neyens JCL, Spreeuwenberg MD, van Rossum E, Hewson DJ, Duchêne, de Witte LP. Construct validity of a modified bathroom scale that can measure balance in elderly people. J Am Med Dir Assoc. 2012;13:665.e1-5.

21. Hewson DJ, Duménil J, Duchêne JY. Validation of balance-quality assessment using a modified bathroom scale. Under review.

22. Kempen GIJM, Miedema I, Ormel J, Molenaar W. The assessment of disability with the Groningen Activity Restriction Scale. Conceptual framework and psychometric properties. Soc Sci Med. 1996;43:1601-1610.

23. Fleiss JL. Design and analysis of clinical experiments. Vol. 73. John Wiley \& Sons, 2011.

24. Lee J, Geller AI, Strasser DC. Analytical review: focus on fall screening assessments. PM R. 2013;5:609-621. 
25. Pijrtola M, Era P. Force platform measurements as predictors of falls among older people: a review. Gerontology. 2006;52:1-16.

26. Pajala S, Era P, Koskenvuo M, Kaprio J, Tormakangas T, Rantanen. Force platform balance measures as predictors of indoor and outdoor falls in community-dwelling women aged 63-76 years. J Gerontol A Biol Sci Med Sci. 2008;63:171-178.

27. Goble DJ, Cone BL, Fling BW. Using the Wii Fit as a tool for balance assessment and neurorehabilitation: the first half decade of "Wii-search". J Neuroeng Rehabil. 2014;11:12.

28. Reed-Jones RJ, Dorgo S, Hitchings MK, Bader JO. WiiFit Plus balance test scores for the assessment of balance and mobility in older adults. Gait Posture. 2012;36:430433.

29. Wikstrom EA. Validity and reliability of Nintendo Wii Fit balance scores. J Athl Train. 2012;47:306-313.

30. Manty M, Heinonen A, Viljanen, Pajala S, Koskenvuo M, Rantanen T. Self-reported preclinical mobility limitation and fall history as predictors of future falls in older women: prospective cohort study. Osteoporo Int. 2010;21:689-693.

31. Finlayson ML, Peterson EW. Falls, aging, and disability. Phy Med Rehabil Clin N Am. 2010;21:357-373. 
Appendix 1. Groningen Activity Restriction Scale (GARS)

The following questions refer to daily activities which should be performed frequently. In each question it is asked whether you are able to perform the activity at this moment. It is not intended to assess whether you are actually performing the activities, but if you can do them if necessary.

\section{Response categories for each item}

1. Yes, I can do it fully independently without any difficulty

2. Yes, I can do it fully independently but with some difficulty

3. Yes, I can do it fully independently but with great difficulty

4. No, I cannot do it fully independently, I can only do it with someone's help

\section{GARS items}

1. Can you, fully independently, dress yourself?

2. Can you, fully independently, get in and out of bed?

3. Can you, fully independently, stand up from sitting in a chair?

4. Can you, fully independently, wash your face and hands?

5. Can you, fully independently, wash and dry your whole body?

6. Can you, fully independently, get on and off the toilet?

7. Can you, fully independently, feed yourself?

8. Can you, fully independently, get around in the house (if necessary with a cane or walker)?

9. Can you, fully independently, go up and down the stairs?

10. Can you, fully independently, walk outdoors (if necessary with a cane or walker)?

11. Can you, fully independently, take care of your feet and toenails?

12. Can you, fully independently, prepare breakfast or lunch?

13. Can you, fully independently, prepare dinner?

14. Can you, fully independently, do "light" household activities (for example, dusting and tidying up)?

15. Can you, fully independently, do "heavy" household activities (for example mopping, cleaning the windows, and vacuuming)?

16. Can you, fully independently, wash and iron your clothes?

17. Can you, fully independently, make the beds?

18. Can you, fully independently, do the shopping? 




\section{CHAPTER 6}

Measuring grip strength in older adults: comparing the Gripball with the Jamar dynamometer

This chapter was accepted by Journal of Geriatric Physical Therapy as:

Vermeulen J, Neyens JCL, Spreeuwenberg MD, van Rossum E, Hewson DJ, de Witte LP. Measuring grip strength in older adults: comparing the Grip-ball with the Jamar dynamometer. 


\section{Abstract}

Background and Purpose: Decreased grip strength is a predictor of adverse outcomes in older adults. A Grip-ball was developed that can be used for home-based self-monitoring of grip strength in order to detect decline at an early stage. The purpose of this study was to evaluate the reliability and validity of measurements obtained with the Grip-ball in older adults.

Methods: Forty nursing home patients and 59 community-dwelling older adults aged 60 years or older were invited to participate in this study. Grip strength in both hands was measured 3 consecutive times during a single visit using the Grip-ball and Jamar dynamometer. Test-retest reliability was described using intraclass correlation coefficients (ICCs). Concurrent validity was evaluated by calculating Pearson's correlations between the mean Grip-ball and Jamar dynamometer measurements and between the highest measurement out of 3 trials. Known-groups validity was studied using t-tests.

Results: Eighty eight participants ( 33 men) with a mean age of 75 years old (SD 6.8) were included. ICCs for the Grip-ball were .97 and .96 for the left and right hand respectively $(P<.001)$. ICCs for the Jamar dynamometer were .97 and .98 for the left and right had respectively $(P<.001)$. Pearson's correlations between the mean scores of the Grip-ball and Jamar dynamometer were .71 $(P<.001)$ and .76 $(P<.001)$ for the left and right hand respectively. Pearson's correlations between the highest scores out of 3 trials were 69 ( $P$ $<.001)$ and .78 $(P<.001)$ for the left and right hand respectively. T-tests revealed that the Grip-ball and Jamar dynamometer both detected grip strength differences between men and women, and not between nursing home patients and community-dwelling older adults. Grip-ball measurements did not confirm higher grip strength of the dominant hand whereas the Jamar dynamometer did.

Conclusion: The Grip-ball provides reliable grip strength estimates in older adults. Correlations found between the Grip-ball and the Jamar dynamometer measurements suggest acceptable concurrent validity. The Grip-ball seems capable of detecting 'larger' grip strength differences but might have difficulty detecting 'smaller' differences that were detected by the Jamar dynamometer. The Grip-ball could be used in practice to enable home-based self-monitoring of grip strength in older adults. However, for the implementation of the Grip-ball as a screening and monitoring device in practice, it is important to gain insight into intersession reliability during home-based use of the Gripball and clinical relevance of changes in grip strength. 


\section{Introduction}

Grip strength is an indicator of physical functioning that decreases with age. ${ }^{1}$ Previous research has shown that grip strength decreases faster in some older adults compared to others. ${ }^{2,3}$ Several factors have been suggested to influence grip strength decline, for example disease, pain, medication use, lifestyle related factors (e.g. low physical activity), or environmental factors. ${ }^{3-5}$ Since low grip strength is a predictor of adverse outcomes, such as disability, mobility problems, falls, or mortality, early detection of grip strength decline might facilitate identification of older adults who could benefit from preventive interventions aimed at reducing the risk of these adverse outcomes. ${ }^{6-9}$

Various devices are available with which grip strength can be assessed relatively easy. ${ }^{10}$ However, most of these devices are almost exclusively reserved for healthcare professionals. To enable home-based self-monitoring of grip strength, a Grip-ball was developed by researchers from the Université de Technologie de Troyes in France. ${ }^{11}$ The Grip-ball contains a pressure sensor that is used to measure grip strength and a Bluetooth compound which enables the transmission of grip strength data to a smartphone or computer. ${ }^{12}$ Via the smartphone or computer feedback can be provided to the patient regarding (changes in) grip strength. Furthermore, the measurements can be forwarded to a database that can be used by healthcare professionals to identify decline in grip strength at an early stage or to monitor progress of rehabilitation in their patients. ${ }^{13}$ So besides making the users aware of (changes in) their grip strength, the Grip-ball can also support healthcare professionals in providing proactive healthcare that is tailored to the current needs or strength level of their patients. ${ }^{14}$

An advantage that the Grip-ball has over hydraulic grip strength measuring devices such as the Jamar dynamometer is that it causes less discomfort because the ball that people squeeze is made of supple plastic. An advantage that the Grip-ball has over other pneumatic grip strength measuring devices such as the Vigorimeter is that the pressure inside the Grip-ball can be modified using a valve which can reduce the 'stiffness' of the ball. ${ }^{12}$ Variation of stiffness can be useful for training purposes and it can also improve comfort during the measurements. Previous research by Jaber et al. ${ }^{12}$ and by Chkeir et al. ${ }^{15}$ in a laboratory setting has revealed that changing the pressure inside the ball does not influence the validity of the grip force estimates that are provided. This research has also shown that the pressure sensor in the Grip-ball provides similar grip pressure estimates compared to a Martin Vigorimeter when force is applied by a Stentor force calibration system, which is a motorized test stand that applies a calibrated force to the device at a controlled velocity. ${ }^{12}$

No validation studies have been conducted yet in which the measurements of the Grip-ball in older adults were compared to those of the Jamar dynamometer, which is 


\section{Chapter 6}

considered the gold standard for grip strength measurements in clinical practice. ${ }^{16}$ The comparability of the grip strength estimates of the Grip-ball with the Jamar dynamometer is of importance for its implementation and usefulness in practice. Therefore, the purpose of this study was to evaluate the reliability and validity of measurements obtained with the Grip-ball by comparing them with measurements obtained with the Jamar dynamometer in a sample of older adults.

\section{Methods}

\section{Design, setting, and participants}

From April till June 2013, older adults were invited to participate in a single visit for this study during which grip strength measurements would be conducted. Forty nursing home patients were recruited by their physical therapist and 59 community-dwelling older adults were recruited by their physical therapist $(\mathrm{N}=31)$ or by the leader of their activity club $(\mathrm{N}=28)$. The reason why participants were recruited in these different settings was to ensure that there was enough variation in grip strength in the study sample. Two weeks before the start of the study the researcher sent an invitation letter to potential participants that contained information regarding the study. Eligibility criteria were: aged 60 years or older and being capable to provide written informed consent. Older adults who had an impairment of one of the upper limbs were included in the study, but grip strength of the affected hand/limb was not measured. People who met the eligibility criteria and signed written informed consent were included. Ethical principles that are outlined in the Declaration of Helsinki were followed throughout this study.

\section{Procedures and measurements}

At the start of the study participants were asked whether they were right- or left-handed. If a participant did not know this, the researcher asked with which hand the participant wrote. The researcher then explained to the participants that grip strength in the left and right hand would be measured 3 times using the Grip-ball and Jamar dynamometer (manufacturer: Saehan, model: SH5001). To ensure that the measurement sequence varied among the participants they were assigned randomly to one of the following measuring sequences in which each measurement was performed 3 consecutive times before moving to the next measurement with the other hand/device:

- Sequence 1: left hand Grip-ball, right hand Jamar dynamometer, left hand Jamar dynamometer, right hand Grip-ball,

- Sequence 2: right hand Jamar dynamometer, left hand Grip-ball, right hand Gripball, left hand Jamar dynamometer, 
- Sequence 3: right hand Grip-ball, left hand Jamar dynamometer, right hand Jamar dynamometer, left hand Grip-ball,

- Sequence 4: left hand Jamar dynamometer, right hand Grip-ball, left hand Gripball, right hand Jamar dynamometer.

Participants sat down on a chair with back support and fixed arms. Participants were instructed to sit straight and to rest their forearm on the arm of the chair with their wrist just over the end of it. Figures $1 \mathrm{a}$ and $1 \mathrm{~b}$ show the position of the participants while measuring grip strength with the Grip-ball and Jamar dynamometer respectively. The researcher demonstrated a measurement with each device. After that, the device was handed over to the participants and the researcher indicated when the participants could start and stop squeezing. Before they started squeezing, participants received the following instruction from the researcher: "please squeeze the device as hard as you can during the following 5 seconds". The outcome of every single grip strength measurement was recorded on a scoring sheet. The Jamar dynamometer was in the second handle position and the largest Grip-ball bulb with a diameter of $6 \mathrm{~cm}$ was used during the measurements in all participants. Measurements with the Jamar dynamometer were registered in Kg. Measurements with the Grip-ball were automatically forwarded to a smartphone and registered in $\mathrm{KPa}$.

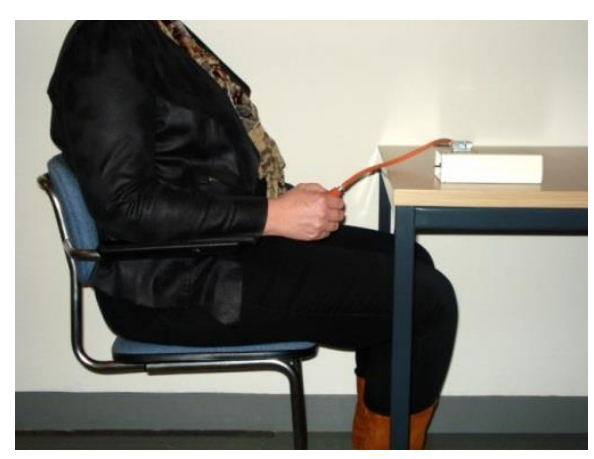

Figure 1a. Testing grip strength using the Grip-ball

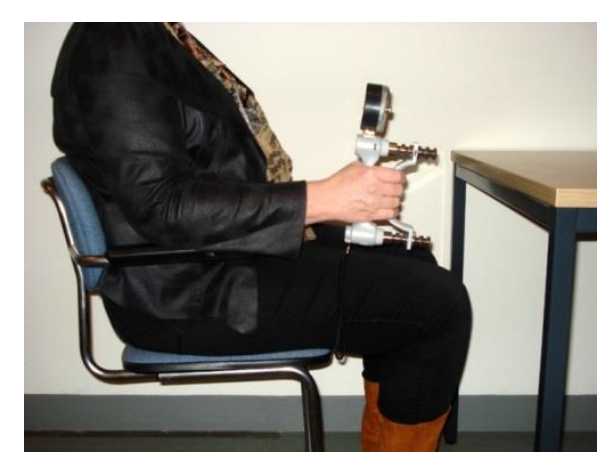

Figure 1b. Testing grip strength using the Jamar dynamometer

\section{Statistical methods}

Descriptive statistics were used to provide information on the characteristics of the participants and the grip strength measurements of both devices. Mean grip strength was calculated for 3 trials with the Grip-ball and Jamar dynamometer for the left and right hand separately. 
Various tests were conducted to compare the Grip-ball and Jamar dynamometer scores. Firstly, intraclass correlation coefficients (ICCS) were calculated to describe the test-retest reliability of measurements obtained with the Grip-ball and Jamar dynamometer. Secondly, normal distribution of the data was checked using Q-Q Plots. Subsequently, Pearson's correlations were calculated between the Grip-ball and Jamar dynamometer scores to study concurrent validity. Pearson's correlations were calculated for mean grip strength scores on both devices for both hands and for highest scores out of 3 measurements on both devices for both hands. Finally, known-groups validity was studied by testing the ability of the Grip-ball to detected grip strength differences between men and women, between nursing home patients and community-dwelling older adults, and between the dominant and non-dominant hand. Independent samples t-tests were conducted to determine whether the Grip-ball and Jamar dynamometer both confirmed grip strength differences between men and women and between communitydwelling older adults and nursing home patients. Paired t-tests were conducted to determine whether the Grip-ball and Jamar dynamometer both confirmed that grip strength in the dominant hand was higher compared with the non-dominant hand. Participants with upper limb impairment were not included in the paired t-tests. All analyses were conducted using SPSS version 19.0 (SPSS, Inc. IBM Corp, Armoch, NY). To adjust for multiple testing Bonferroni corrections were applied, so all effects are reported at a $P=.01$ level of significance.

\section{Results}

\section{Participants}

Of the 99 potential participants who were invited, 88 participants $(88.8 \%)$ with a mean age of 75 years old (SD 6.8) were included in the analyses. Figure 2 illustrates the inclusion of participants. Of the 40 invited nursing home patients, 35 (87.5\%) with a mean age of 77 years old (SD 6.8) participated (4 participants refused and 1 participant was too young). Five nursing home patients who were included had an impairment of the left upper limb and 1 nursing home patient suffered from an impairment of the right upper limb. These 6 participants only performed measurements with the hand of their unaffected limb. All participants with an impaired limb indicated that their right hand was their dominant hand before injury. Of the 59 invited community-dwelling older adults, 53 (89.8\%) with a mean age of 73 years old (SD 6.5) participated (4 participants refused, 1 participant was too young, and 1 participant was ill on the test day). Of the total sample, 83 participants (94\%) were right handed. More information regarding the participants is provided in Table 1. 
Invited:

40 Nursing home patients

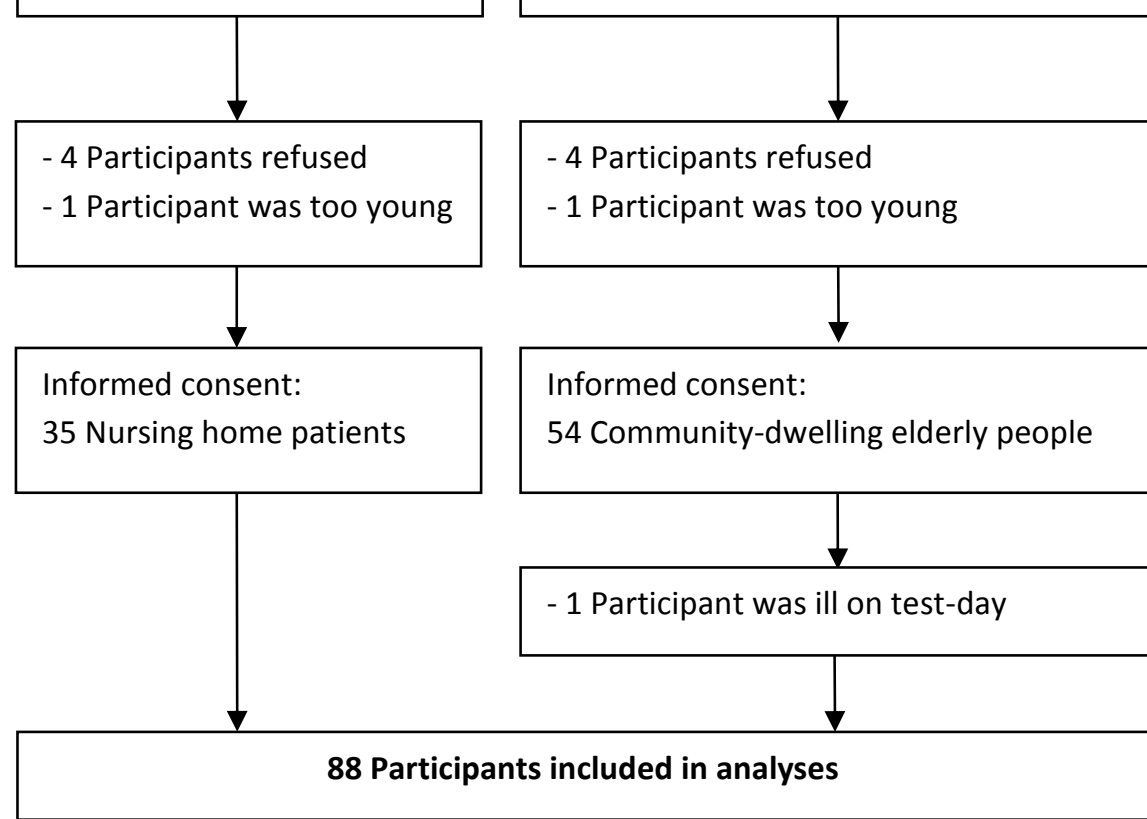

Figure 2. Inclusion of participants

Table 1. Characteristics of participants $(n=88)$

\begin{tabular}{lc}
\hline Characteristic & $\mathbf{n}(\%)$ or Mean (SD) \\
\hline Gender: & \\
Male & $33(37.5 \%)$ \\
Female & $55(62.5 \%)$ \\
Age & 75 (SD 6.8) \\
Mean Grip-ball score dominant hand in KPa & 51 (SD 22) \\
Mean Grip-ball score non-dominant hand in Kpa & 52 (SD 21) \\
Mean Jamar dynamometer score dominant hand in Kg & 28 (SD 13) \\
Mean Jamar dynamometer score non-dominant hand in Kg & 26 (SD 11) \\
\hline
\end{tabular}

\section{Reliability and validity}

ICCs for the 3 consecutive Grip-ball measurements were .97 ( $95 \% \mathrm{Cl}=.95-.98, P<.001)$ and $.96(95 \% \mathrm{Cl}=.95-.97, P<.001)$ for the left and right hand respectively. ICCs for the 3 consecutive Jamar dynamometer measurements were $.97(95 \% \mathrm{Cl}=.96-.98, P<.001)$ and $.98(95 \% \mathrm{Cl}=.97-.99, P<.001)$ for the left and right hand respectively. 
Pearson's correlations between the mean scores of the Grip-ball and Jamar dynamometer were $.71(95 \% \mathrm{Cl}=.58-.80, P<.001)$ and $.76(95 \% \mathrm{Cl}=.65-.84, P<.001)$ for the left and right hand respectively. Pearson's correlations between the highest scores out of 3 trials were $.69(95 \% \mathrm{Cl}=.56-.79, P<.001)$ and $.78(95 \% \mathrm{Cl}=.68-.85, P<.001)$ for the left and right hand respectively. Figure 3 a shows the scatterplot comparing the mean grip strength measurements of the Grip-ball and Jamar dynamometer for the left and right hand. Figure $3 b$ shows the scatterplot comparing the highest grip strength score out of 3 trials of the Grip-ball and Jamar dynamometer for the left and right hand. Since these graphs suggest that there might be a few outliers in the study sample, z-scores were calculated for mean and highest grip strength. Based on these z-scores there was only one participant with grip strength scores that significantly deviated from the sample. Deleting this participant from the analyses did not influence the results.

\section{Detecting grip strength differences}

Independent samples t-tests showed that both the Grip-ball and the Jamar dynamometer confirmed that men had significantly higher mean grip strength compared with women. Mean grip strength measured with the Grip-ball was $65 \mathrm{KPa}$ (SD 24) for men vs. $42 \mathrm{KPa}$ (SD 15) for women with the dominant hand $(T(49)=4.93, P<.001)$ and $66 \mathrm{KPa}(\mathrm{SD} 24)$ for men vs. $43 \mathrm{Kpa}$ (SD 14) for women with the non-dominant hand $(T(44)=4.90, P<.001)$. Mean grip strength measured with the Jamar dynamometer was $34 \mathrm{Kg}$ (SD 10) for men vs. $24 \mathrm{Kg}$ (SD 13) for women with the dominant hand $(T(85)=4.00, P<.001)$ and $32 \mathrm{Kg}(\mathrm{SD} 9)$ for men vs. $23 \mathrm{Kg}$ (SD 11) for women with the non-dominant hand $(\mathrm{T}(81)=4.11, P<.001)$.

Furthermore, independent samples t-tests revealed that grip strength in the dominant hand did not differ significantly between community-dwelling older adults and nursing home patients according to the Grip-ball $(\mathrm{T}(85)=2.50, P=.014)$ and Jamar dynamometer measurements $(\mathrm{T}(85)=2.49, P=.015)$. The Grip-ball measurements $(\mathrm{T}(81)=1.79, P=$ $.078)$ and Jamar dynamometer measurements $(T(81)=1.43, P=.158)$ of grip strength in the non-dominant hand also revealed no significant differences between communitydwelling older adults and nursing home patients.

Paired t-tests showed that the Grip-ball did not detect a significant difference between the mean grip strength measured in the dominant hand compared with the non-dominant hand $(\mathrm{T}(81)=.43, P=.672)$ whereas the Jamar dynamometer did detect a significant difference of $2 \mathrm{Kg}$ between the dominant and non-dominant hand $(\mathrm{T}(81)=4.10, P<.001)$. 


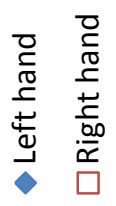

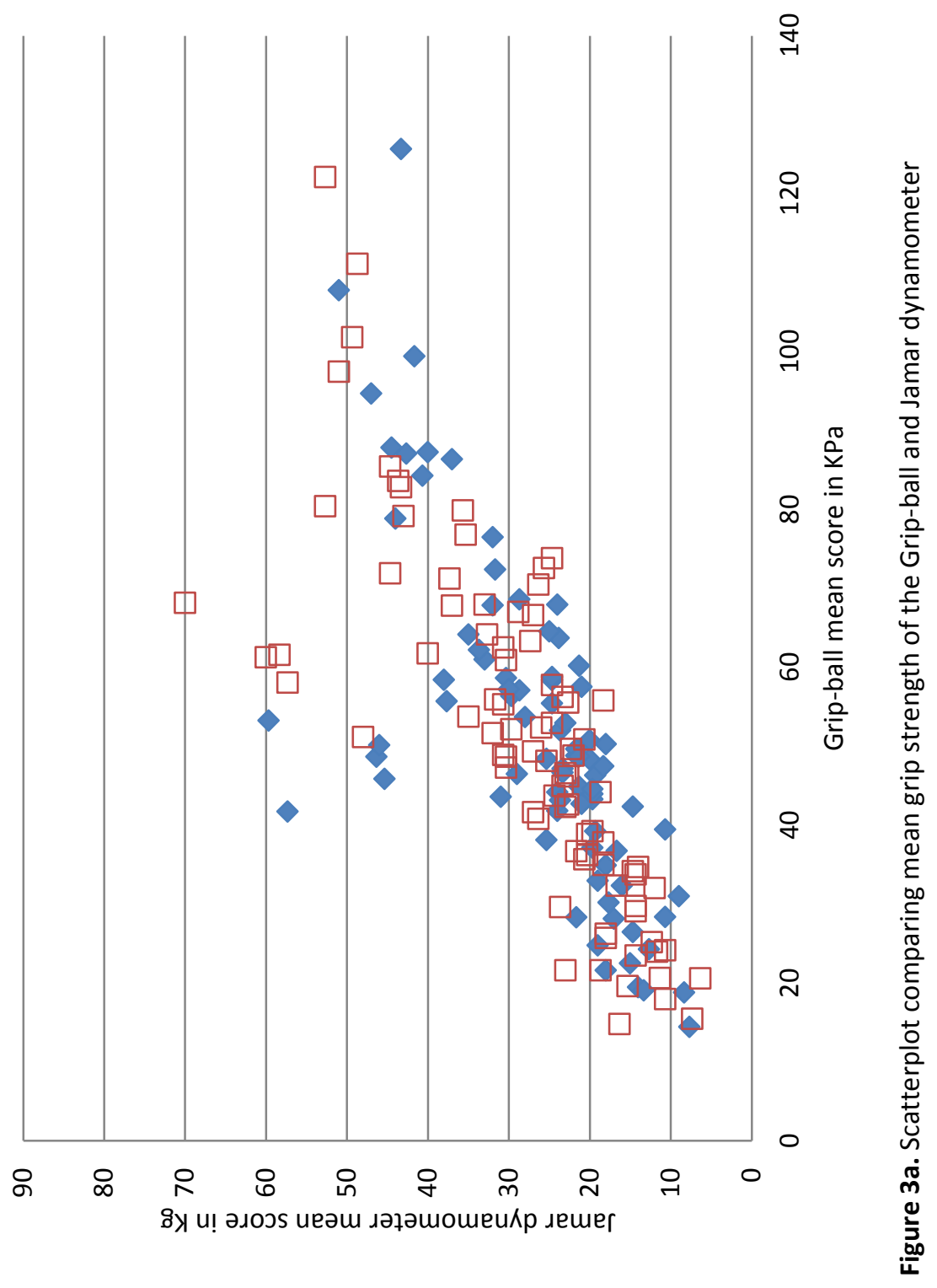




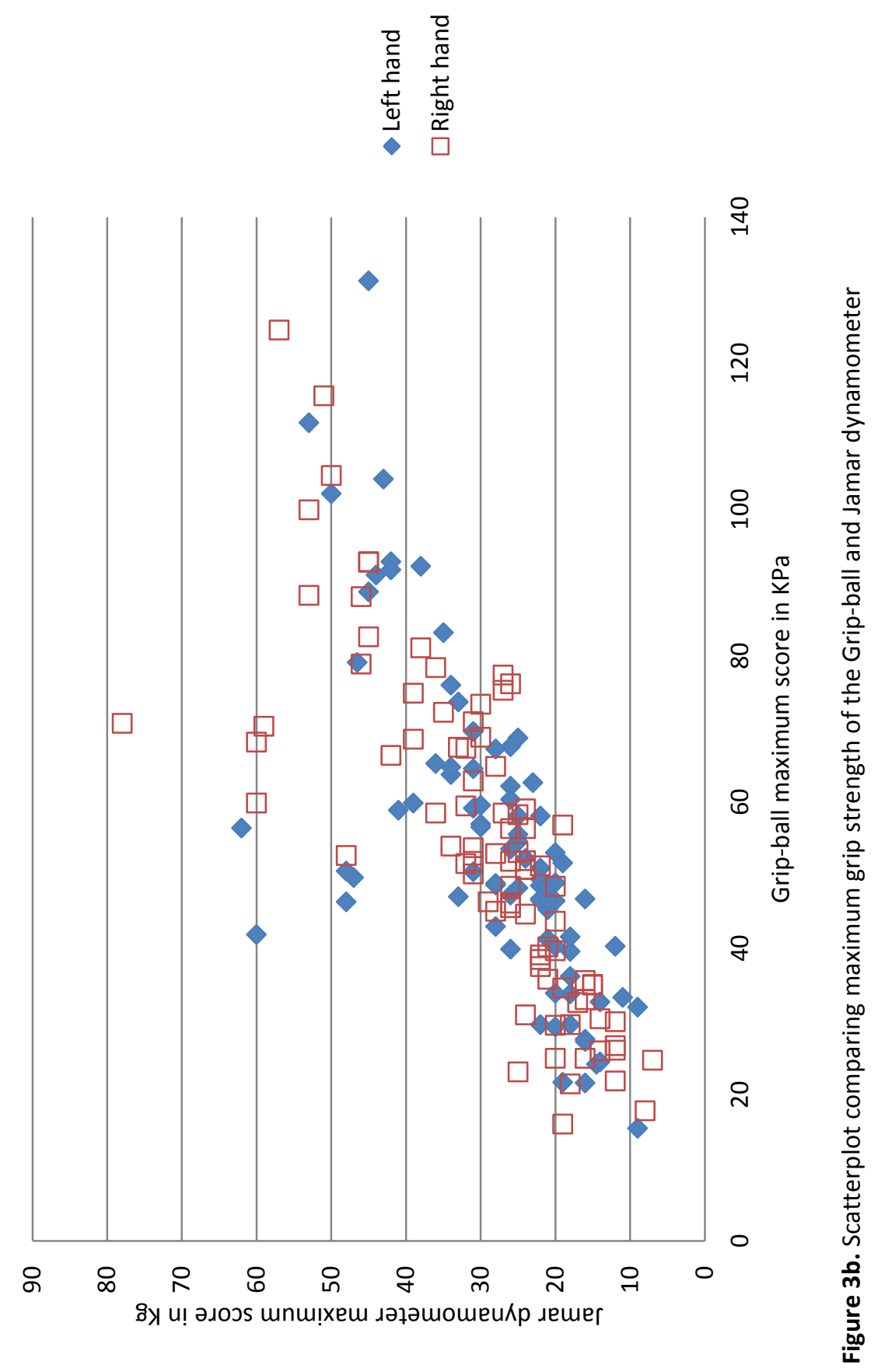




\section{Discussion}

The results of this study show that the Grip-ball provides reliable grip strength estimates in older adults. Furthermore, this study revealed significant correlations between measurements of the Grip-ball and the Jamar dynamometer that varied between .69 and .78. These correlations are considered strong enough to suggest concurrent validity of measurements obtained with the Grip-ball. Correlations were lower for grip strength measurements of the left hand. Finally, the Grip-ball appears capable of detecting 'larger' grip strength differences (e.g. between men and women) but might have difficulty detecting 'smaller' differences (e.g. between the dominant and non-dominant hand).

The results of this study confirm those of previous research comparing hydraulic grip strength measuring devices (e.g. Jamar dynamometer) with pneumatic grip strength measuring devices (e.g. Grip-ball or Martin Vigorimeter). ${ }^{17,18}$ However, studies showing lower correlations ${ }^{19,20}$ and higher correlations ${ }^{21}$ between these different types of devices exist as well. Difference in compressibility and hand position between the devices could have influenced the correlations found in the current study. ${ }^{22}$ Participants might have pressed their fingers into the Grip-ball while squeezing it, although they were instructed not to do this. This might have caused an overestimation of their grip strength as measured by the Grip-ball which could have had a negative impact on the correlations. The correlation between the measurements of the two devices might also have been influenced by the fact that the Grip-ball measures pressure applied to the ball whereas the Jamar dynamometer measures force.

The largest Grip-ball bulb and second handle position of the Jamar dynamometer were used in all participants in this study was to increase the comparability with previous validation studies and research regarding normative reference values for grip strength in older adults. ${ }^{23-25}$ Not adapting the measuring devices to the anthropometric characteristics of the participants might be considered a limitation of this study since previous research has shown that hand grip span can influence performance. ${ }^{26}$ Furthermore, there is a size difference of about $1.2 \mathrm{~cm}$ between the largest bulb of the Grip-ball and the second handle position of the Jamar dynamometer. Since previous research has revealed that handle size influences maximal grip strength ${ }^{27}$ this could have had an impact on the results reported in the current study.

The Grip-ball appeared to overestimate grip strength in the left hand which might explain to some extent why the correlations between the Grip-ball and Jamar dynamometer scores were higher for the right than for the left hand measurements. Despite the fact that grip strength is typically higher in the dominant hand, current literature is inconsistent about the effect that handedness has on grip strength estimates. ${ }^{28-30}$ There is not enough convincing evidence that confirms significant 


\section{Chapter 6}

differences between grip strength in the dominant and non-dominant hand and there seems to be a large variety of 'between-hand-differences' across study samples. ${ }^{29}$

Since all data was collected during a single session and under supervision of a researcher, no conclusions can be drawn based on this study regarding intersession reliability which is a limitation of the study design. More information regarding intersession reliability and the effect of home-based use of the Grip-ball on reliability and validity of its measurements is needed before it can be implemented for monitoring of grip strength development in older adults over time to detect decline. The pressure sensor and other electronics that were validated in this study are currently being incorporated into an improved version of the Grip-ball that does not look like a measuring/medical device. This new version of the Grip-ball might be considered not as stigmatizing which will most likely improve acceptability of the device for home-based grip strength monitoring. This will be an advantage of the Grip-ball compared to available devices used for grip strength measurement. A picture of the Grip-ball under development is provided in Figure 4.

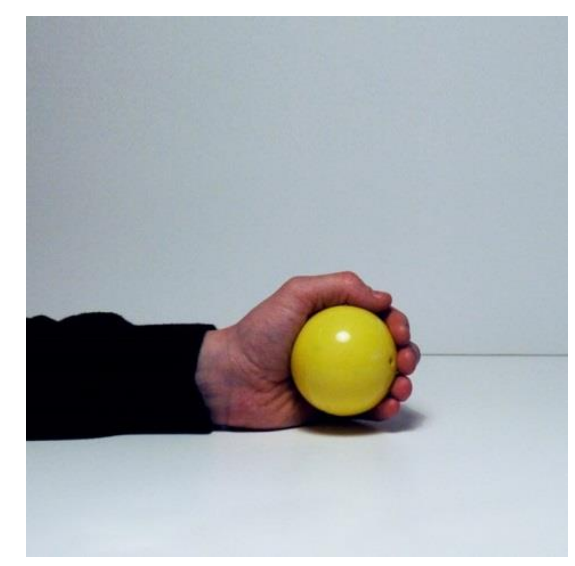

Figure 4. Grip-ball under development

Current literature provides cutoff points for normal grip strength values for men and women at a certain age. ${ }^{23-25}$ Measurements performed by the Grip-ball can be interpreted by comparing them to the normative cutoff points that were established for the Martin Vigorimeter by Desrosiers et $\mathrm{al}^{24}$ since previous research showed high correlations between the Grip-ball and Vigorimeter. However, not much is known yet about clinically relevant changes in grip strength over time and the predictive value of such changes. ${ }^{23-25}$ For the implementation of the Grip-ball as a screening and monitoring device in practice, more information is needed about the clinical relevance of changes in grip strength since there is a large variation in guidelines for normative grip strength values in older adults. ${ }^{28}$ If a grip strength decline of $2 \mathrm{Kg}$ is considered clinically relevant in all older adults, the 
Grip-ball is probably not a suitable device for detecting changes since the results of this study suggest that the device is not capable of detecting that small of a change. However, longitudinal research in which the Grip-ball is used repeatedly over time is needed to confirm this. Such studies should also focus on the between session reliability of (homebased use of) the Grip-ball. Insights from such research could also be of importance for healthcare professionals and patients who want to use the Grip-ball to support them during the rehabilitation process.

\section{Conclusions}

The Grip-ball provides reliable and valid estimates of grip strength in older adults. Therefore, the device could be used in practice by older adults to monitor the development of their grip strength over time in order to detect decline at an early stage. Future research should explore the possibility of detecting clinically relevant grip strength changes over time and should study how the Grip-ball can be used for rehabilitation purposes.

\section{References}

1. Frederiksen H, Hjelmborg J, Mortensen J, McGue M, Vaupel JW, Christensen K. Age trajectories of grip strength: cross-sectional and longitudinal data among 8,342 Danes aged 46 to 102. Ann Epidemiol. 2006;16:554-562.

2. Carmelli $D$, Reed T. Stability and change in genetic and environmental influences on hand-grip strength in older male twins. J Appl Physiol. 2000;89:1879-1883.

3. Hurley BF. Age, gender and muscular strength. J Gerontol A Biol Sci Med Sci. 1995;50:41-44.

4. Forrest KY, Zmuda JM, Cauley JA. Patterns and determinants of muscle strength change with aging in older men. Aging Male. 2005;8:151-156.

5. Kallman DA, Plato CC, Tobin JD. The role of muscle loss in the age-related decline of grip strength: cross-sectional and longitudinal perspectives. J Gerontol. 1990;45:8288.

6. Bohannon RW. Hand-grip dynamometry predicts future outcomes in aging adults. J Geriatr Phys Ther. 2008;31:3-10.

7. Vermeulen J, Neyens JCL, Spreeuwenberg MD, Van Rossum E, De Witte LP. Predicting ADL disability in community-dwelling elderly people using physical frailty indicators: a systematic review. BMC Geriatr. 2011;11:33. 
8. Low Choy NL, Braer SG, Nitz JC. Age-related changes in strength and somatosensation during midlife: rationale for targeted preventive intervention programs. Ann NY Acad Sci. 2007;1114:180-193.

9. Ishizaki T, Wantanabe S, Suzuki T, Shibata H, Haga H. Predictors for functional decline among nondisabled older Japanese living in a community during 3-year follow-up. J Am Geriatr Soc. 2000;48:1424-1429.

10. Roberts HC, Denison HJ, Martin HJ, Patel HP, Syddall H, Cooper C, Sayer AA. A review of the measurement of grip strength in clinical and epidemiological studies: toward a standardized approach. Age Ageing. 2011;40:423-429.

11. Hogrel JY, Duchêne J. Device for evaluating and/or reinforcing gripping strength. Patent \#FR08/05193; 2008.

12. Jaber R, Hewson DJ, Duchêne J. Design and validation of the Grip-ball for measurement of hand grip strength. Med Eng Phys. 2012;34:1356-1361.

13. Hewson DJ, Li K, Frerejean A, Hogrel JY, Duchêne J. Domo-grip: functional evaluation and rehabilitation using grip force. Conf Proc IEEE Eng Med Biol Soc. 2010;2010:13081311.

14. Vermeulen J, Neyens JCL, Spreeuwenberg MD, van Rossum E, Sipers W, Habets H, et al. User-centered development and testing of a monitoring system that provides feedback to elderly people regarding physical functioning. Patient Prefer Adherence. 2013;7:843-854.

15. Chkeir A, Jaber R, Hewson DJ, Duchêne J. Estimation of grip force using the Grip-ball dynamometer. Med Eng Phys. 2013;35:1698-1702.

16. Fess EE. Grip strength. In: Casanova JS, editor. Clinical assessment recommendations, $2^{\text {nd }}$ edition. American society for Hand Therapists. 1981:pp 41-45.

17. Hamilton GF, McDonald C, Chenier TC. Measurement of grip strength - validity and reliability of the sphygmomanometer and Jamar grip dynamometer. J Orthop Sports Phys Ther. 1992;16:215-219.

18. Li K, Hewson DJ, Duchêne J, Hogrel JY. Analysis of maximal grip strength using three types of dynamometer. Proc of the $6^{\text {th }}$ IASTED International Conference of Biomedical Engineering. Feb 13-15, 2008, Innsbruck, Austria pp 139-144.

19. Lusardi MM, Bohannon RW. Hand grip strength: comparability of measurements obtained with a Jamar dynamometer and a modified sphygmomanometer. J Hand Therapy. 1991;4:117-122.

20. Finke ML, Rousseau E. Measurement of adult hand strength: a comparison of 2 instruments. Occup Ther J Res. 1982;2:43-49.

21. Derosiers J, Hébert R, Bravo G, Dutil E. Comparison of the Jamar dynamometer and the Martin Vigorimeter for grip strength measurements in a healthy elderly population. Scand J Rehab Med. 1995;27:137-143. 
22. Kondraske GV. Measurement of the quality of hand contractions [letter]. Med Biol Eng Comput. 1985;23:399.

23. Desrosiers J, Bravo G, Hébert R, Dutil E. Normative data for grip strength of elderly men and women. Am J Occup Ther. 1995;49:637-644.

24. Peters MJ, Van Nes SI, Vanhoutte EK, Bakkers M, van Doorn PA, Merkies IS, et al. Revised normative values for grip strength with the Jamar dynamometer. Journal Peripher Nerv Syst. 2011;16:47-50.

25. Massy-Westropp NM, Gill TK, Taylor AW, Bohannon RW, Hill CL. Hand grip strength: age and gender stratified normative data in a population-based study. BMC Research Notes. 2011;2:127.

26. Petrofsky JS, Williams C, Kamen G, Lind AR. The effect of handgrip span on isometric exercise performance. Ergnomics. 1980;23:1129-1135.

27. Firrell JC, GM. Which setting of the dynamometer provides maximal grip strength? J Hand Surg Am. 1996;21:397-401.

28. Innes E. Handgrip strength testing: a review of the literature. Australian Occup Ther J. 1999;46:120-140.

29. Bohannon RW. Grip strength: a summary of studies comparing dominant and nondominant limb measurements. Percept Mot Skills. 2003;96:728-730.

30. Clerke A, Clerke J. A literature review of the effect of handedness on isometric grip strength differences of the left and right hands. Am J Occup Ther. 2001;55:206-211. 



\section{CHAPTER 7}

Self-monitoring of physical activity with a smartphone in persons aged below and above 65 years old: concurrent validity in daily life

This chapter was submitted to Gerontology as:

Vermeulen J, Hammoud A, Neyens JCL, Hewson DJ, de Witte LP. Self-monitoring of physical activity with a smartphone in persons aged below and above 65 years old: concurrent validity in daily life. 


\section{Abstract}

Background: Since smartphones are equipped with built-in accelerometers they can be used for self-monitoring of physical activity which is an important health behavior and predictor of functioning, especially in older adults.

Objective: The objective of this study is to investigate the validity of a smartphone-based activity monitoring application in adults aged below and above 65 years old.

Methods: Ten adults aged below 65 years and ten adults aged 65 years or older were asked to monitor their daily physical activity with a smartphone and an ActiGraph GT3X for 7 consecutive days. Spearman correlations between the counts per minute of the two devices were calculated for adults aged below and above 65 years separately. For both devices, each monitored minute was classified into four categories of activity intensity based on the counts per minute: sedentary, light, moderate, and high activity intensity. Association and agreement between the two devices was analyzed using Pearson's correlations, paired t-tests and Bland-Altman plots.

Results: Data from 8 adults aged below 65 years and 7 adults aged above 65 years could be included in the analyses. Spearman correlations between the counts per minute of the smartphone and the ActiGraph were .76 and .84 for adults aged below and above 65 years respectively. Pearson's correlations between the two devices for total number of minutes spent in different activity intensity categories per day per participant were high in both groups (range .79-.99). Paired t-tests and Bland-Altman plots revealed that the smartphone underestimates the number of sedentary minutes per day in participants aged below and above 65 years with $5.74 \%$ and $6.35 \%$ respectively compared to the ActiGraph. In addition, the smartphone overestimated the number of minutes spent at moderate intensity in adults aged below 65 years by indicating almost twice as many minutes spent in this activity intensity category compared to the Actigraph. Furthermore, the number of minutes spent at light activity intensity in adults aged above 65 years was overestimated with $8.22 \%$ by the smartphone compared to the ActiGraph.

Conclusion: The activity monitoring application needs to be optimized before it can be implemented in practice. Concurrent validity of the smartphone-based activity monitoring application was better in adults aged above 65 years compared to adults aged below 65 years. Differences seem to exist between individual participants. 


\section{Introduction}

Physical activity is an important health indicator and predictor of functioning in older adults. ${ }^{1}$ Community-dwelling older adults with low or decreased levels of physical activity have a higher risk to develop disability in activities of daily living which is a threat to their independence. ${ }^{2-4}$ Furthermore, it is recommended to reduce sedentary behavior in (older) adults in order to promote physical activity and avoid negative health outcomes. ${ }^{5,6}$ Selfmonitoring of daily physical activity and receiving tailored feedback related to personal goals can support older persons and patients with chronic health conditions in their selfmanagement and in maintaining an active lifestyle. ${ }^{7,8}$

Information regarding daily physical activity can be collected using activity monitors, energy expenditure measurements, questionnaires, and observations. ${ }^{9}$ Advantages of activity monitors compared to energy expenditure measurements and questionnaires are that they can be used to monitor activity at home over a longer period of time and that they do not rely on recollection. Accelerometers are activity monitors that can measure the quantity and intensity of movements. ${ }^{10}$ A systematic review by Remoortel et al. revealed that many different accelerometers exist and that the tri-axial ones seem most valid for measuring physical activity. ${ }^{11}$ Unfortunately, information regarding the validity of tri-axial accelerometers in older adults for daily monitoring of activity at home is often lacking. Most previous validation studies were conducted in a controlled situation, for example during 10 minutes of walking on a treadmill at a controlled speed, often with adults aged below 65 years. ${ }^{11-13}$ Validation studies in older adults in daily living are needed because walking in daily life is different from walking on a treadmill and because differences in walking pattern and gait characteristics between older adults and younger adults might influence the validity of accelerometer-based activity measurements for this group. $^{14,15}$

The current gold standard for monitoring activity in daily life, with well-established validity in different age groups, is the ActiGraph GT3X. The ActiGraph is an accelerometerbased activity monitoring system that is particularly developed as a tool for research. As a result it is expensive (including software) and might not be very user-friendly for individuals who want to receive feedback regarding their own daily activity levels. Since smartphones are equipped with built-in tri-axial accelerometers they can be used to monitor physical activity and provide feedback at the same time via the screen of the phone. The increasing uptake of smartphones and mobile health applications can facilitate this and results from previous studies suggest that physical activity monitoring in older adults using smartphones is feasible. ${ }^{16-18}$ In close collaboration with end-users, a smartphone-based application was developed that can be used to monitor physical activity and that provides feedback regarding the number of active minutes per day. ${ }^{19}$ 
Feedback should be easy to interpret and should fit the goals and physical abilities of a person. For example: for an older person with a sedentary lifestyle and mobility problems, 20 minutes of activity per day at a light intensity level might be a relevant goal whereas this might not be the case for a younger adult. Therefore, the smartphone-based application facilitates personal goal setting, not only in terms of the number of active minutes per day but also in terms of intensity of activity measured.

Studies among adults aged below 65 years have shown that mobile phone based accelerometers can yield valid physical activity estimates. However, until now no studies have been conducted yet that focused on the validity of home-based physical activity measurements using a smartphone in older adults. ${ }^{20}$ The aim of this study is to investigate the concurrent validity of a smartphone-based physical activity monitoring application in adults aged below and above 65 years in daily life by comparing its measurements to those of the ActiGraph GT3X. Including adults of all ages allows us to gain insight into differences that might exist between adults aged below and above 65 years in validity of daily life activity measurements conducted with a smartphone.

\section{Materials and Methods}

\section{Design and participants}

Adults aged below 65 years old and adults aged 65 years or older were invited to participate in this validation study. All participants were invited via the professional or informal network of the researchers using snowball sampling. Ten adults aged below 65 years ( 6 women) and ten adults aged above 65 years ( 4 women) received an invitation and information letter from the researcher and provided written informed consent. They were asked to monitor their daily physical activity with a smartphone-based application and an ActiGraph GT3X for 7 consecutive days. Ethical principles that are outlined in the Declaration of Helsinki were followed throughout this study. The study was approved by the Medical Ethical Committee Atrium-Orbis-Zuyd (NL35961.096.11).

\section{Procedures}

At the start of the study the researcher (JV) visited the participants and provided them with an ActiGraph attached to an elastic waist belt, a smartphone (Nokia N8) equipped with a built-in tri-axial accelerometer and activity monitoring application, a docking charger, a separate elastic waist belt that participants could use to carry the smartphone with them during the day, and a written instruction manual that explained the use of the devices. The researcher explained to the participants how they should monitor their activity and if necessary they practiced this with the participants. Four smartphones and four ActiGraphs were used during this validation study. 
Participants were instructed to start activity monitoring in the morning (after getting dressed) by putting on the elastic belt with the ActiGraph in such a way that the device was on their back near their center of gravity. After that, they switched on the activity monitoring application of the smartphone. To optimize resemblance with daily life, participants could choose whether they wanted to wear the mobile phone with them in their trouser pocket or on the elastic waist belt during the day. Participants were instructed to wear both activity monitors during the day (except when showering, bathing, or swimming) and stop activity monitoring in the evening before they went to bed. They were instructed to put the phone in the docking charger every evening. A diary was used by the participants to register when they started and stopped wearing the devices, where they wore the phone on each day (belt vs. trouser pocket) and whether any problems occurred.

\section{Measurements}

Both devices measured the amount of activity that was performed by the participants using a tri-axial accelerometer that was incorporated in the smartphone and ActiGraph respectively. Raw data from these accelerometers was extracted from the smartphone and ActiGraph and summarized into 1-minute intervals. Acceleration measured by both accelerometers was expressed in 'counts per minute' which is representative of the intensity of the movements that were registered during that minute. The time stamp from the smartphone and information from the diary was used to identify and synchronize timeframes where the participant wore both the smartphone and ActiGraph. Data from those timeframes was included in the analyses.

For both devices, each monitored minute was classified into four categories of activity intensity based on the counts per minute. The following cutoff points were used for sedentary, light, moderate, and high activity intensity for the smartphone: 0-99, 100-4490, 4491-14045, and > 14045 counts per minute for adults aged below 65 years; and 0-199, 200-5389, 5390-16455, and > 16455 counts per minute for adults aged above 65 years. The following cutoff points were used for sedentary, light, moderate, and high activity intensity for the ActiGraph: 0-99, 100-3207, 3208-8564, and > 8564 counts per minute for adults aged below 65 years; and 0-199, 200-2750, 2751-9358, and > 9358 counts per minute for adults aged above 65 years. Cutoff points of the Actigraph for the moderate and high intensity category were based on previous research by Santos-Lozano et al. in which different cutoff points for adults and older adults were validated. ${ }^{21}$ Cutoff points of the ActiGraph for the sedentary and light category were also based on previous research. $^{22,23}$ 


\section{Data analyses}

Baseline characteristics of participants who were included in the analyses and average wear time of the smartphone and ActiGraph were expressed in mean (SD) or $n$ (\%). Normal distribution of the registered counts per minute was checked using normality plots.

Firstly, Spearman correlations between the counts per minute of the smartphone and ActiGraph were calculated for the group of adults aged below and above 65 years separately. In addition, Spearman correlations between the counts per minute of the smartphone and ActiGraph were calculated for data collected using the phone in the trouser pocket and for data collected using the phone on the belt separately.

Furthermore, Spearman correlations between the counts per minute of the smartphone and ActiGraph were calculated for each individual participant.

Secondly, cutoff points described above were used to calculate the number of minutes spent in each activity intensity category per day by each participant. Pearson's correlations were calculated between the smartphone and Actigraph for the total number of minutes spent in the sedentary, low, moderate and high intensity category per day per participant. Pearson's correlations were calculated for adults aged below and above 65 years separately. In addition, Pearson's correlations were calculated for data collected using the phone in the trouser pocket and using the phone on the belt separately.

Thirdly, the average (SD) number of minutes spent in each activity intensity category per day by adults aged below and above 65 years was calculated. Paired t-tests were conducted to study differences between the smartphone and ActiGraph in average number of minutes spent in each activity intensity category per day for both age groups separately. The above mentioned analyses were all conducted using SPSS version 20.0.

Finally, MedCalc statistical software version 13.1 was used to study the limits of agreement between the two devices regarding classification of minutes in activity intensity categories using Bland-Altman plots for repeated measurements. These Bland Altman plots were constructed for adults aged below and above 65 years separately.

\section{Results}

Data from 8 adults aged below 65 years and 7 adults aged above 65 years could be included in the analyses due to malfunctioning of the ActiGraph ( $n=3$ participants) or smartphone ( $n=1$ participant) or due to usability problems with the activity monitoring application on the mobile phone ( $n=1$ participant). Baseline characteristics of the participants that were included in the analyses are presented in Table 1. For the adults aged below 65 years, data collected during 42 days was included in the analyses. During these days the smartphone and ActiGraph were worn for a total of 29276 minutes. The 
smartphone and ActiGraph were worn on average 696 minutes (SD 209) per day by participants aged below 65 years. Of the 42 days, the phone was worn on the belt during 11 days (26.2\%) and in the trouser pocket during 31 days (73.8\%). For the adults aged above 65 years, data collected during 34 days was included in the analyses. During these days the smartphone and ActiGraph were worn for a total of 21892 minutes. The smartphone and ActiGraph were worn on average 643 minutes (SD 182) per day by participants aged above 65 years. Of the 34 days, the phone was worn on the belt during 6 days (17.6\%) and in the trouser pocket during 28 days (82.4\%). Reasons for missing data in both age groups were problems with data retrieval from the ActiGraph or smartphone ( $n=16$ days) and non-wear of both devices by various participants ( $n=6$ days in total).

Table 1. Baseline characteristics of participants included in analyses

\begin{tabular}{lcc}
\hline & $\begin{array}{c}\text { Adults }<65(\mathbf{n}=8) \\
\text { Mean (SD) or } \mathbf{n}(\%)\end{array}$ & $\begin{array}{c}\text { Adults } 65 \leq(\mathbf{n}=\mathbf{7}) \\
\text { Mean (SD) or } \mathbf{n}(\%)\end{array}$ \\
\hline Women & $5(62.5 \%)$ & $3(42.9 \%)$ \\
Age & $34.75(14.89)$ & $74.43(4.35)$ \\
Weight in Kg & $71.14(12.64)$ & $79.40(9.24)$ \\
Height in cm & $175.86(7.22)$ & $166.50(6.56)$ \\
Total number of days included in analyses & $42(75 \%)$ & $34(67.4 \%)$ \\
Total number of days phone worn on belt & $11(26.2 \%)$ & $6(17.6 \%)$ \\
Average wear time per day in minutes & $696(209)$ & $643(182)$ \\
\hline
\end{tabular}

\section{Relation between counts per minute of smartphone and ActiGraph}

Spearman correlations between the counts per minute of the smartphone and ActiGraph were .76 and .84 for adults aged below and above 65 years respectively. The scatterplots in Figure $1 \mathrm{a}$ and $1 \mathrm{~b}$ illustrate how the counts per minute of the smartphone and the ActiGraph related to each other in both groups.

In the group of adults aged below 65 years, the correlation between counts per minute of the smartphone on the belt and the ActiGraph was .81 and the correlation between the smartphone worn in the trouser pocket and the ActiGraph was .75. In the group of adults aged above 65 years, the correlation between counts per minute of the smartphone on the belt and the ActiGraph was .86 and the correlation between the smartphone worn in the trouser pocket and the ActiGraph was .84.Correlations between the counts per minute registered by the smartphone and ActiGraph in the 8 individual participants aged below 65 years were $.89, .83, .81, .78, .78, .78, .71$, and .63. Correlations between the counts per minute registered by the smartphone and ActiGraph in the 7 individual participants aged above 65 years were $.98, .97, .82, .82, .80, .79$, and .73 . 


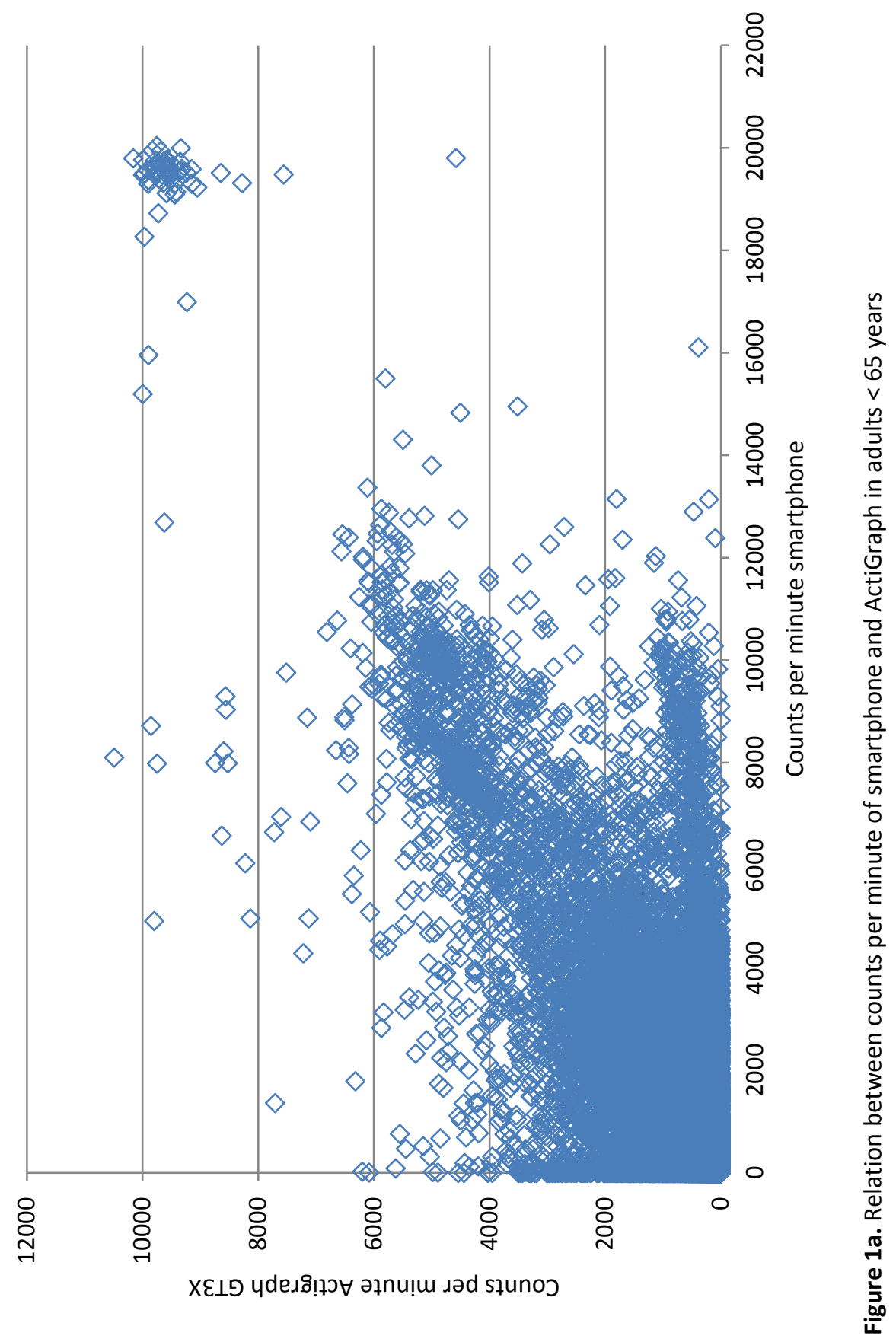




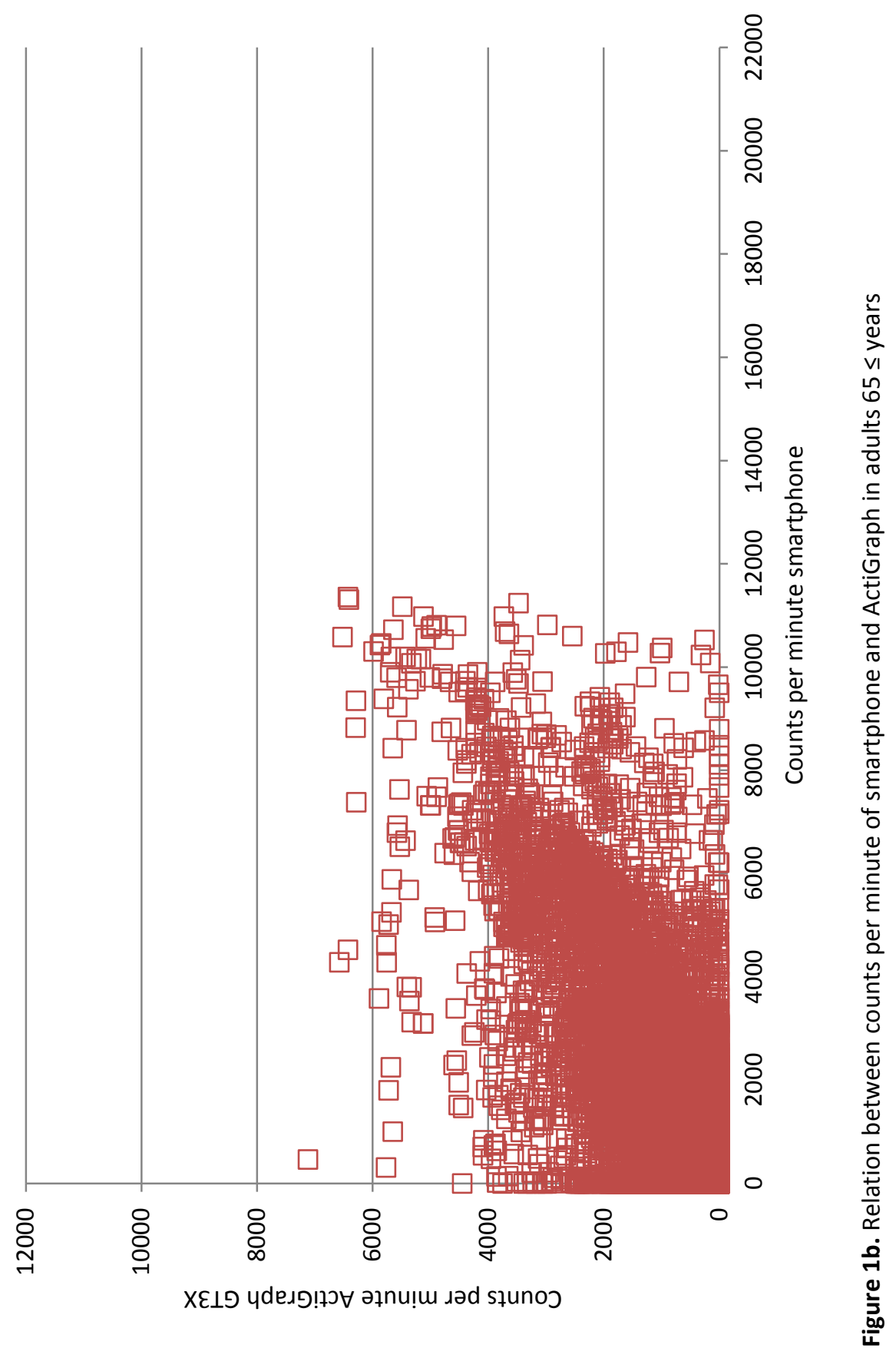




\section{Relation between activity intensity measured by the smartphone and ActiGraph}

Pearson's correlations between the two devices for minutes spent in the sedentary, low, moderate, and high activity intensity category per day per participant were .94, .90, .80, and .99 respectively for adults aged below 65 years (all $p<0.01$ ). Pearson's correlations between the two devices for minutes spent in the sedentary, low, and moderate activity intensity categroy per day per participant were $.98, .94$, and .79 respectively for adults aged above 65 years (all $p<0.01$ ). Pearson's correlations could not be calculated for the high activity intensity category for adults aged above 65 years due to the fact that no activity was registered in that category. Conducting the same analyses only including data that was obtained during days that the smartphone was worn in the trouser pocket, yielded similar results. No analyses were conducted for the belt data separately due to the small number of days that the smartphone was worn on the belt.

Table 2 presents the results of the paired t-tests that were conducted to study the differences between the smartphone and ActiGraph in average minutes per day spent in different activity intensity categories for both age groups separately.

Table 2. Relation between average time spent in different activity intensity categories as measured by the smartphone and Actigraph in adults aged below and above 65 years

\begin{tabular}{llccc}
\hline & $\begin{array}{l}\text { Activity intensity } \\
\text { category }\end{array}$ & $\begin{array}{c}\text { Smartphone } \\
\text { mean minutes per } \\
\text { day (SD) }\end{array}$ & $\begin{array}{c}\text { Actigraph mean } \\
\text { minutes per day } \\
\text { (SD) }\end{array}$ & $\begin{array}{c}\text { Mean difference } \\
\text { ActiGraph - } \\
\text { smartphone }\end{array}$ \\
\hline Adults & Sedentary & $355.74(151.90)$ & $377.40(163.74)$ & $21.67^{*}$ \\
$<65$ & Light & $288.81(122.38)$ & $292.02(112.71)$ & 3.21 \\
years & Moderate & $50.12(33.04)$ & $25.26(26.72)$ & $-24.86^{* *}$ \\
& High & $1.43(8.63)$ & $1.43(8.22)$ & 0.00 \\
Adults & Sedentary & $349.94(129.67)$ & $373.65(139.72)$ & $23.71^{* *}$ \\
$65 \leq$ & Light & $270.20(85.10)$ & $249.68(85.367)$ & $-20.53^{* *}$ \\
years & Moderate & $23.24(26.18)$ & $20.29(28.55)$ & -2.94 \\
& High & 0.00 & 0.00 & 0.00 \\
\hline$p<0.05$ & & & & \\
${ }_{p *}^{* *} p<0.01$ & & & & \\
\hline$p<0$ & & & \\
& & & & \\
\end{tabular}

Paired t-tests revealed that the smartphone underestimates the number of sedentary minutes per day in adults aged below and above 65 years with $5.74 \%$ and $6.35 \%$ respectively compared to the Actigraph. In addition, the smartphone overestimated the number of minutes spent at moderate intensity in adults aged below 65 years by indicating almost twice as many minutes spent in this activity intensity category compared to the Actigraph. Furthermore, the number of minutes spent at light activity intensity in adults aged above 65 years was overestimated with $8.22 \%$ by the smartphone compared to the ActiGraph. 
The Bland-Altman plots presented for adults aged below and above 65 years in Figure $2 a / b / c$ and Figure $3 a / b / c$ respectively confirmed the structural differences between the smartphone and the ActiGraph that were demonstrated in the paired t-tests. No BlandAltman plots were made for the high intensity activity category due to the small number of minutes that were registered in this category by both devices. Symbols in Figure $2 \mathrm{a} / \mathrm{b} / \mathrm{c}$ and $3 a / b / c$ represent days measured in the same participant of that specific age group. Limits of agreement were larger for adults aged below 65 years compared to adults aged above 65 years. Furthermore, some participants seemed to contribute more to the mean differences between the two devices compared to other participants in both groups.

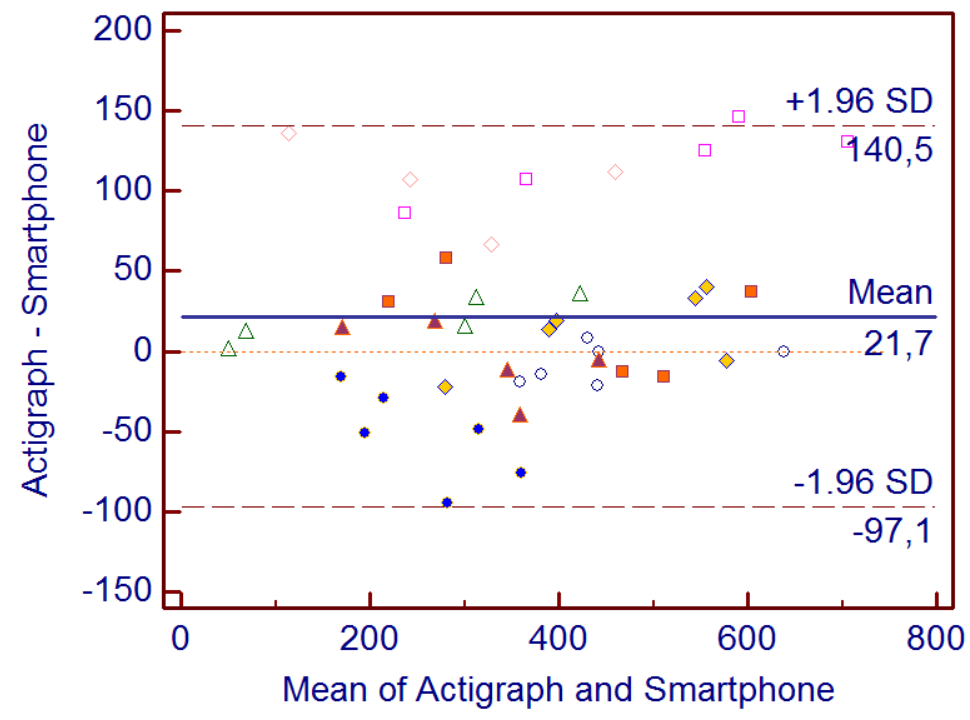

Figure 2a. Agreement between smartphone and ActiGraph in adults $<65$ years for number of minutes of activity per day spent in the sedentary category 


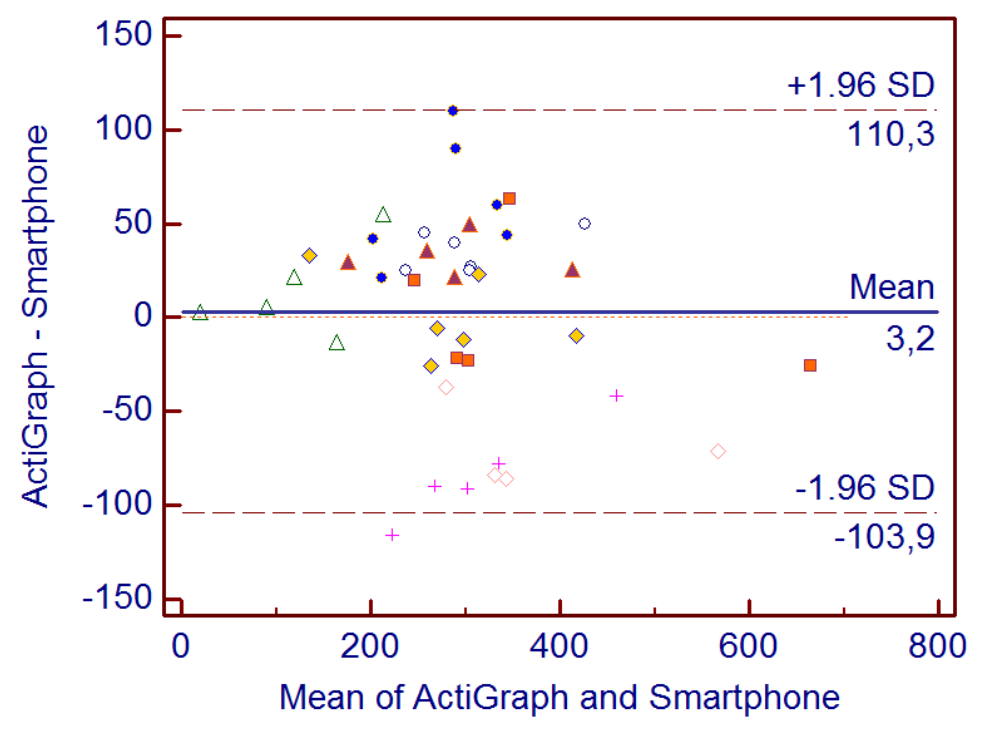

Figure 2b. Agreement between smartphone and ActiGraph in adults $<65$ years for number of minutes of activity per day spent in the light activity intensity catergory

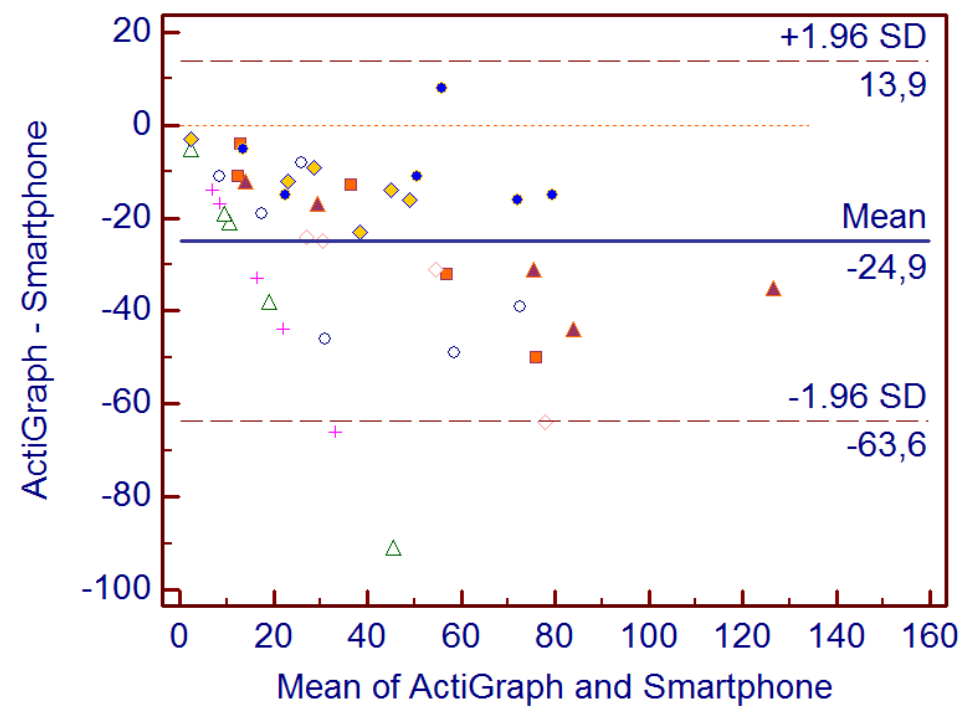

Figure 2c. Agreement between smartphone and ActiGraph in adults $<65$ years for number of minutes of activity per day spent in moderate activity intensity category 


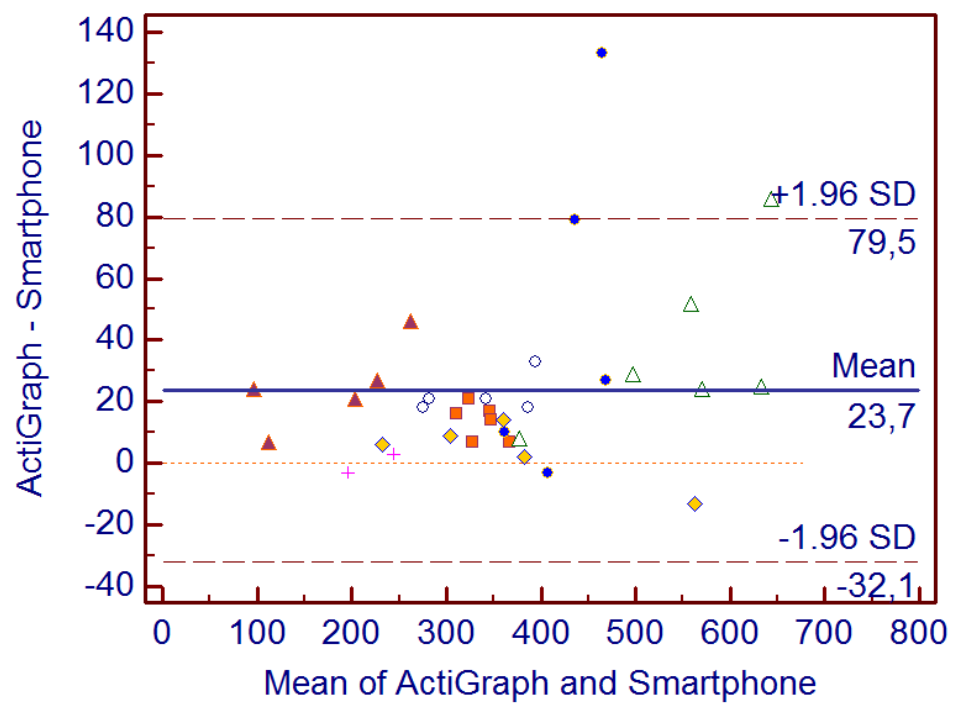

Figure 3a. Agreement between smartphone and ActiGraph in adults $65 \leq$ years for number of minutes of activity per day spent in the sedentary category

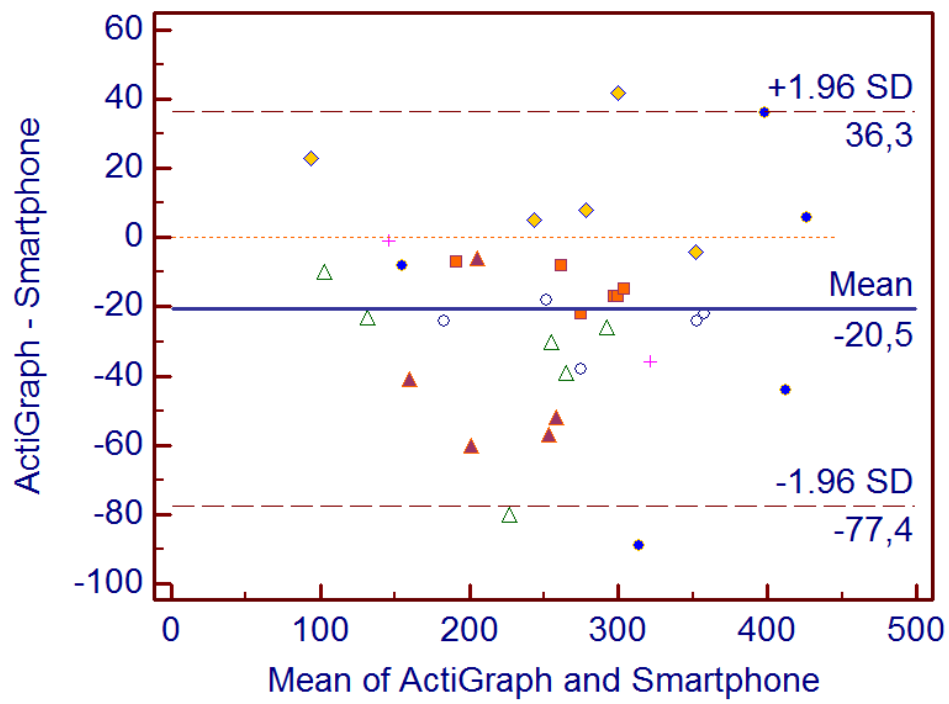

Figure 3b. Agreement between smartphone and ActiGraph in adults $65 \leq$ years for number of minutes of activity per day spent in the light activity intensity category 


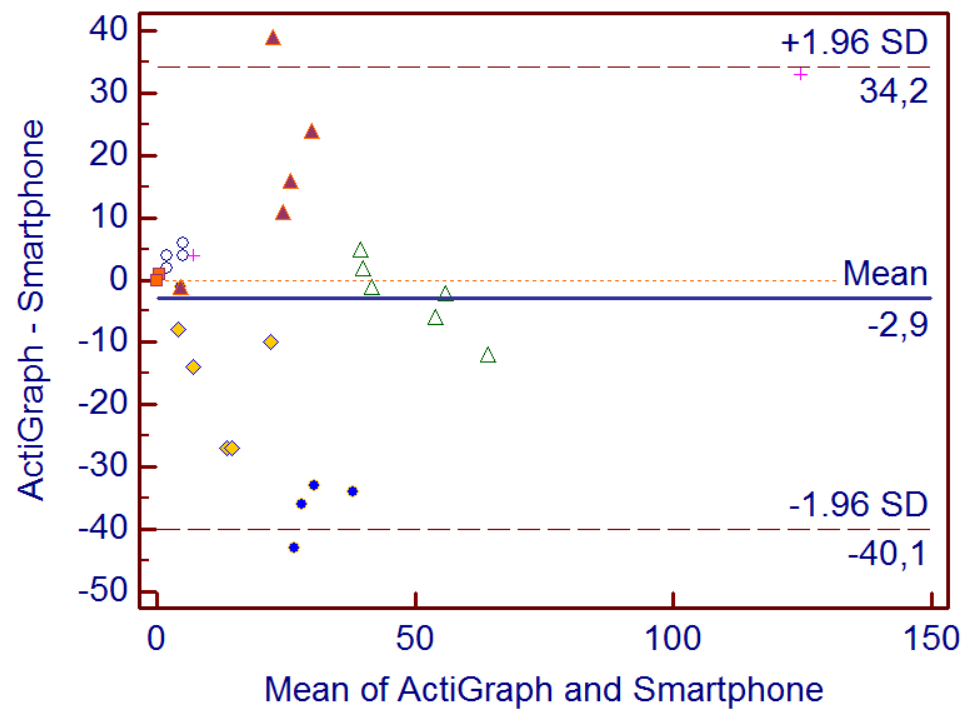

Figure 3c. Agreement between smartphone and ActiGraph in adults $65 \leq$ years for number of minutes of activity per day spent in the moderate activity intensity category

\section{Discussion}

The results of this study revealed that there is a high correlation between the counts per minute registered by the smartphone-based application and the ActiGraph in adults aged below and above 65 years. However, these correlations differed strongly between individual participants. The results of this study are comparable to previous research that compared smartphone-based activity monitors or other devices used to monitor activity using tri-axial accelerometers with the ActiGraph GT3X in daily life in adults aged below 65 years. $^{20,24}$

Despite the high correlations between the counts per minute registered by both devices, three structural classification errors were identified between times spent in different activity intensity categories according to the smartphone and ActiGraph. Firstly, the smartphone structurally underestimated the number of minutes spent in the sedentary activity intensity category compared to the ActiGraph in both age groups. Secondly, the smartphone overestimated the number of minutes spent in the light activity intensity category compared to the ActiGraph in adults aged above 65 years. Thirdly, the smartphone overestimated the number of minutes in the moderate intensity category in adults aged below 65 years. It should be noted that the first two classification errors did not exceed $10 \%$ whereas the third classification error was more substantial since the 
smartphone indicated on average almost twice as many minutes spent in the moderate activity intensity category per day compared to the Actigraph.

An explanation for the classification errors found in this study are the cutoff points that were chosen to divide the monitored minutes into different intensity categories. For example, previous research has suggested that 150 counts per minute might be a more appropriate cutoff point for defining sedentary behavior in adults instead of the cutoff point of 100 counts per minute which is most frequently used in other studies. ${ }^{25}$ Changing the cutoff points would probably alter the findings of this study. Other researchers have recognized that this is one of the difficulties encountered in these type of validation studies since introducing cutoff points automatically introduces classification errors. ${ }^{20,24,26,27}$ When interpreting the severity of such errors one should not only take into account the statistical significance of the error detected, but also the (clinical) relevance of it, which might depend on the purpose or setting in which the activity is being measured.

A previous study that focused on the relation between a smartphone-based activity monitoring system and the ActiGraph in adults aged below 65 years in daily life found smaller differences between the devices compared to the current study. ${ }^{20}$ A possible explanation for this could be that in the current study participants could choose themselves where they wanted to wear the smartphone whereas in previous research, in daily life and laboratory conditions, participants were always instructed to wear the phone on the same belt as the ActiGraph. The reason why participants were allowed to choose themselves where to wear the smartphone was that this resembles their real life situation. This difference in our study design compared to previous research revealed that firstly, participants seem to prefer wearing a smartphone in their trouser pocket instead of on a belt when monitoring physical activity in daily life and that secondly, correlation between counts per minute registered by the smartphone and Actigraph was still acceptable when the smartphone was worn in the trouser pocket, especially in adults aged above 65 years. However, it should be noted that wearing the smartphone on the belt might have yielded results more comparable to the ActiGraph considering the higher correlations between counts per minute registered by both devices when both worn on a belt in the two age groups.

Furthermore, this study revealed that the limits of agreement between the two devices were quite large, which is in line with previous research. ${ }^{20,24}$ An interesting finding from the Bland-Altman plots constructed in this study is that the limits of agreement seem to be larger for adults aged below 65 years compared to adults aged above 65 years. Possible explanations for this could be that these two groups wear different types of clothing or that they have different walking patterns which could explain part of the variation between these groups. ${ }^{11,12}$ 


\section{Strengths and limitations}

A strength of this study is that the validity of a smartphone-based activity monitoring system was validated in adults aged below and above 65 years in daily life and that age specific cutoff points were used for the smartphone and ActiGraph to classify monitored minutes into four different categories of activity intensity. This allowed us to gain insight into differences between validity of smartphone-based daily activity monitoring between these age groups. Furthermore, in the current study the validity of daily measurements was assessed whereas previous research often focused on the validity of the average amount of activity over the monitored days. ${ }^{20}$ The advantage of looking at the validity of daily measurements is that this information is more useful in daily practice since feedback regarding physical activity, for example during self-monitoring or intervention programs, is mostly provided per day. In addition, number of active minutes per day is an outcome that is understood by most people and might be easier to use for goal setting compared to energy expenditure or steps per day.

Limitations of this study are the small number of participants and the problems with data retrieval from both devices which resulted in a high percentage of missing data. It is difficult to draw conclusions regarding the influence that these missing data might have had on the results of our study. Furthermore, it should be noted that one older adult who participated in this study had difficulty using the interface of the smartphone to operate the activity monitoring application. Due to this, data of this participant could not be included in the analyses. For the implementation of the smartphone-based activity monitoring application it should be taken into account that such usability problems might influence the validity of the measurements. Since older adults are often less familiar with smartphone technology compared to younger adults, this problem will probably be more apparent in that group. Finally, since different types of smartphones might have different sizes, weights and types of built-in accelerometers, the validity of the application could be influenced by the type of phone. The extent to which the type of phone influences the validity of the measurements of this application is difficult to estimate and might be a subject for further research. Another aspect that requires further research is the effect that 'regular/normal' use of the phone has on physical activity estimates since the phone in this study was not used for calling or sending (text) messages.

\section{Conclusion}

Concurrent validity of the smartphone-based activity monitoring application was better in adults aged above 65 years compared to adults aged below 65 years. Differences seem to exist between individual participants. The activity monitoring application of the smartphone needs to be optimized before it can be implemented in practice. 


\section{References}

1. Di Pietro L. Physical activity in aging: changes in patterns and their relationship to health and function. J Gerontol A Biol Sci Med Sci. 2001;56:13-22.

2. Balzi D, Lauretani F, Barchielli A, Ferrucci L, Bandinelli S, Buiatti E. Risk factors for disability in older persons over 3-year follow-up. Age Ageing. 2010;39:92-98.

3. Jacobs JM, Cohen A, Hammerman-Rozenberg R, Azoulay D, Maaravi Y, Stessman J. Going outdoors daily predicts long-term functional and health benefits among ambulatory older people. J Aging Health. 2008;20:259-272.

4. Vermeulen J, Neyens JCL, Spreeuwenberg MD, Van Rossum E, De Witte LP. Predicting ADL disability in community-dwelling older adults using physical frailty indicators: a systematic review. BMC Geriatr. 2011;11:33.

5. Conn VS, Valentine JC, Cooper HM. Interventions to increase physical activity among aging adults: a meta-analysis. Ann Behav Med. 2002;24:190-200.

6. Nelson ME, Rejeski WJ, Blair SN, Duncan PW, Judge JO, King AC, et al. Physical activity and public health in older adults: recommendation from the American College of Sports Medicine and the American Heart Association. Circulation. 2007;116:11051094.

7. Nicklas BJ, Gaukstern JE, Beavers KM, Newman JC, Leng X, Rejeski WJ. Self-monitoring of spontaneous physical activity and sedentary behavior to prevent weight regain in older adults. Obesity. 2014;22:1406-1412.

8. Brawley LR, Rejeski WJ, King AC. Promoting physical activity for older adults: the challenges for changing behavior. Am J Prev Med. 2003;25;172-183.

9. Washburn RA. Assessment of physical activity in older adults. Res Q Exerc Sport. 2000;71:79-88.

10. Plasqui G, Westerterp KR. Physical activity assessment with accelerometers: an evaluation against doubly labeled water. Obesity. 2007;15:2371-2379.

11. Van Remoortel H, Giavedoni S, Raste Y, Burtin C, Louvaris Z, Gimeno-Santos E, et al. Validity of activity monitors in health and chronic disease: a systematic review. Int J Behav Nutr Phys Act. 2012;9:84.

12. De Bruin ED, Hartmann A, Uebelhart D, Murer K, Zijlstra W. Wearable systems for monitoring mobility-related activities in older people: a systematic review. Clin Rehabil. 2008;22:878-895.

13. Cheung VH, Gray L, Karunanithi M. Review for accelerometry for determining daily activity among elderly patients. Arch Phys Med Rehabil. 2011;92:998-1014.

14. Winter DA, Patle AE, Frank JS, Walt SE. Biomechanical walking pattern changes in the fit and healthy elderly. Phys Ther. 1990;70:340-347. 
15. Ostrosky KM, VanSwearingen JM, Burdett RG, Gee Z. A comparison of gait characteristics in young and old subjects. Phys Ther. 1994;74:637-644.

16. Patrick K, Griswold WG, Raab F, Intille SS. Health and the mobile phone. Am J Prev Med. 2008;35:177-181.

17. Schenk AK, Witbrodt BC, Hoarty CA, Carlson RH, Goulding EH, Potter JF. Cellular telephones measure activity and lifespace in community-dwelling adults: proof of principle study. J Am Geriatr Soc. 2011;59:345-352.

18. Fontecha J, Hervás R, Sánches L, Navarro FJ, Bravo J. A proposal for elderly frailty detection by using accelerometer-enabled smartphones. In: 5th International Symposium of Ubiquitous Computing and Ambient Intelligence (UMCAml'11), December 5-9, 2011, Riviera Maya, Mexico.

19. Vermeulen J, Neyens JCL, Spreeuwenberg MD, Van Rossum E, Sipers W, Habets H, et al. User-centered development and testing of a monitoring system that provides feedback regarding physical functioning to elderly people. Patient Prefer Adherence. 2013;7:843-854.

20. Donaire-Gonzalez D, de Nazelle A, Seto E, Mendez M, Nieuwenhuijsen MJ, Jerrett M. Comparison of physical activity measures using mobile phone-based CalFit and ActiGraph. J Med Internet Res. 2013;15:111.

21. Santos-Lozano A, Santin-Medeiros F, Cardon G, Torres-Lugue G, Bailon R, Bergmeir C, et al. ActiGraph GT3X: validation and determination of physical activity intensity cutpoints. Int J Sports Med. 2013;34:975-982.

22. Matthews CE, Chen KY, Freedson PS, Buchowski MS, Beech BM, Pate RR, Troiano RP. Amount of time spent in sedentary behaviors in the United States, 2003-2004. Am J Epidemiol. 2008;167:875-881.

23. Aguilar-Farias N, Brown WJ, Peeters GMEE. ActiGraph GT3X+cut-points for identifying sedentary behavior in older adults in free-living conditions. J Sci Med Sport. 2013;17:293-299.

24. Herman SD, Hart TL, Lee CD, Ainsworth BE. Evaluation of the MyWellness Key accelerometer. Br J Sports Med. 2011;45:109-113.

25. Kozey-Keadle S, Libertine A, Lyden K, Staudenmayer J, Freedson PS. Validation of wearable monitors for assessing sedentary behavior. Med Sci Sports Exerc. 2011;43:1561-1567.

26. Vanhelst J, Mikulovic J, Biu-Xuan G, Dieu O, Blondeau T, Fardy P, Béghin L. Comparison of two ActiGraph accelerometer generations in the assessment of physical activity in free living conditions. BMC Res Notes. 2012;5:187.

27. Esliger DW, Rowlands AV, Hurst TL, Catt M, Murray P, Eston RG. Validation of the GENEA accelerometer. Med Sci Sprot Exerc. 2011;43:1085-1093. 




\section{CHAPTER 8}

\section{User-centered development and testing of a monitoring system that provides feedback regarding physical functioning to elderly people}

This chapter was published as:

Vermeulen J, Neyens JCL, Spreeuwenberg MD, van Rossum E, Sipers W, Habets H, Hewson DJ, de Witte LP. User-centered development and testing of a monitoring system that provides feedback regarding physical functioning to elderly people. Patient Preference and Adherence. 2013;7:843-854. 


\section{Abstract}

Purpose: To involve elderly people during the development of a mobile interface of a monitoring system that provides feedback to them regarding changes in physical functioning and to test the system in a pilot study.

Methods and participants: The iterative user-centered development process consisted of the following phases: (1) Selection of user representatives; (2) Analysis of users and their context; (3) Identification of user requirements; (4) Development of the interface; and (5) Evaluation of the interface in the lab. Subsequently, the monitoring and feedback system was tested in a pilot study by five patients who were recruited via a geriatric outpatient clinic. Participants used a bathroom scale to monitor weight and balance, and a mobile phone to monitor physical activity on a daily basis for six weeks. Personalized feedback was provided via the interface of the mobile phone. Usability was evaluated on a scale from 1 till 7 using a modified version of the Post-Study System Usability Questionnaire (PSSUQ); higher scores indicated better usability. Interviews were conducted to gain insight into the experiences of the participants with the system.

Results: The developed interface uses colors, emoticons, and written and/or spoken text messages to provide daily feedback regarding (changes in) weight, balance, and physical activity. The participants rated the usability of the monitoring and feedback system with a mean score of 5.2 (SD .90) on the modified PSSUQ. The interviews revealed that most participants liked using the system and appreciated that it signaled changes in their physical functioning. However, usability was negatively influenced by a few technical errors.

Conclusion: Involvement of elderly users during the development process resulted in an interface with good usability. However, the technical functioning of the monitoring system needs to be optimized before it can be used to support elderly people in their selfmanagement. 


\section{Introduction}

Disability, often defined as experienced difficulty in performing activities in any domain of life, poses a threat to independence of community-dwelling elderly people. ${ }^{1}$ Elderly people suffering from a decrease in certain indicators of physical functioning, such as gait speed, physical activity, weight, grip strength, balance and lower extremity function, have an increased risk to develop disability. ${ }^{2-5}$ Elderly people and care professionals are often not aware of decreases in indicators of physical functioning at an early stage and decline can continue until (health) problems arise. ${ }^{6}$ Innovative technologies can play an important role in remote monitoring and early identification of elderly people who suffer from functional decline and therefore have an increased risk to develop disabilities. ${ }^{7,8}$ These people are the ones who are most likely to benefit from existing disability prevention programs. ${ }^{9,10}$ Furthermore, literature reviews reveal that such care technologies can also positively influence self-management, health behaviors, medical outcomes, and quality of life of elderly people. ${ }^{11,12}$

Researchers from Maastricht University (MU) in the Netherlands and engineers from the Institute Charles Delaunay at the Université de Technologie de Troyes (UTT) in France collaborated to develop an innovative telecare system that monitors indicators of physical functioning in elderly people over time and provides feedback regarding changes. The system consists of three devices: a bathroom scale for monitoring weight and balance, a Grip-ball for monitoring grip strength, and a mobile phone with a built-in accelerometer for monitoring physical activity. ${ }^{13-16}$ The devices are equipped with Bluetooth so that the information can be transferred automatically to the mobile phone. Via the interface of the mobile phone, feedback can be provided to the users regarding changes in their physical functioning. This can support them in their self-management. Furthermore, the mobile phone can transfer the data to a database that is accessible to care professionals who can use the information to provide proactive care to their patients. The monitoring and feedback system is depicted in Figure 1.

Previous research has shown that it is important that telecare technologies, such as the monitoring and feedback system described above, should meet the needs and preferences of the users. ${ }^{17,18}$ Furthermore, usability remains a critical issue in such telecare technologies. ${ }^{11}$ Because if elderly users are not able to use the monitoring system and mobile phone properly or do not understand the feedback that is presented via the mobile interface, it is unlikely that the system will be used to support self-management. Involving end-users during the development of care technologies can ensure that the technology meets the needs and preferences of the users and it can improve the usability of the technology. ${ }^{19-21}$ Therefore, the objective of this study was to involve elderly people 


\section{Chapter 8}

during the development of the mobile interface of the monitoring and feedback system and to test the monitoring and feedback system in real life.

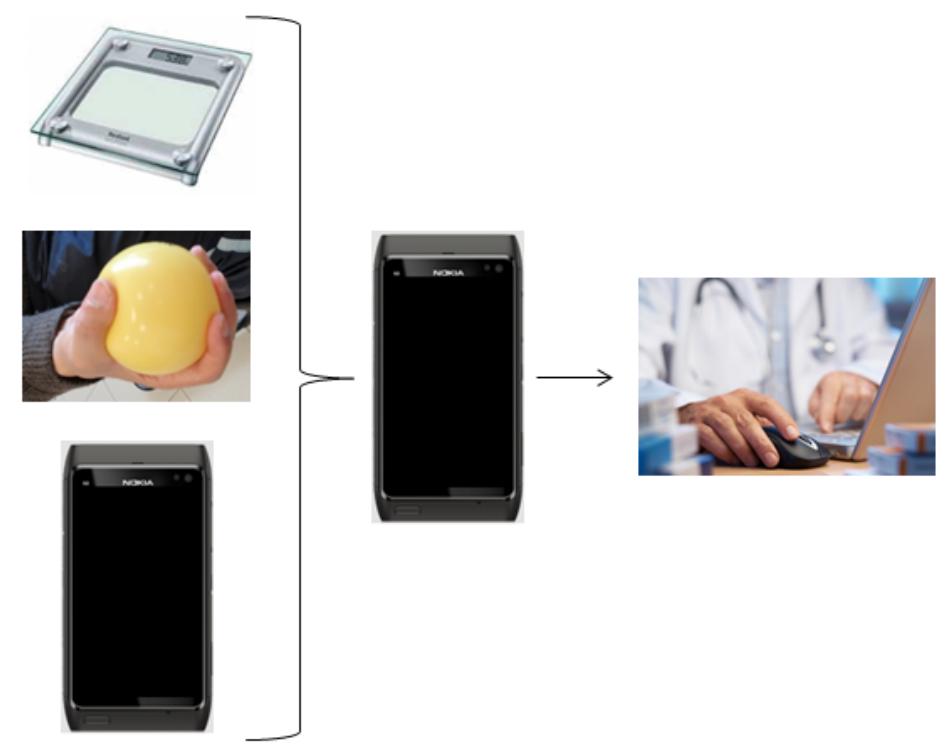

Figure 1. Monitoring and feedback system

\section{Materials and methods}

The methods section is divided into two parts. The first part focuses on the methods that were used during the different phases of the user-centered development process. The second part focuses on the methods that were used during the pilot study.

\section{Part 1: Methods user-centered development process}

The user-centered development process of the interface consisted of the following phases: (1) Selection of user representatives; (2) Analysis of users and their context; (3) Identification of user requirements; (4) Development of the interface; and (5) Evaluation of the interface in the lab. Figure 2 provides an overview of the methods that were used during the different phases of the development process.

A key principle of user-centered design is that the process should be iterative. ${ }^{22}$ This was the case in the development process because the different phases, often referred to as iterations, were repeated until the desired result was obtained. Each phase delivered the 
Phase 1: Selection of user representatives

- $\quad$ Three user representatives volunteered to be part of the development team during a meeting that was organized by the House for Care.
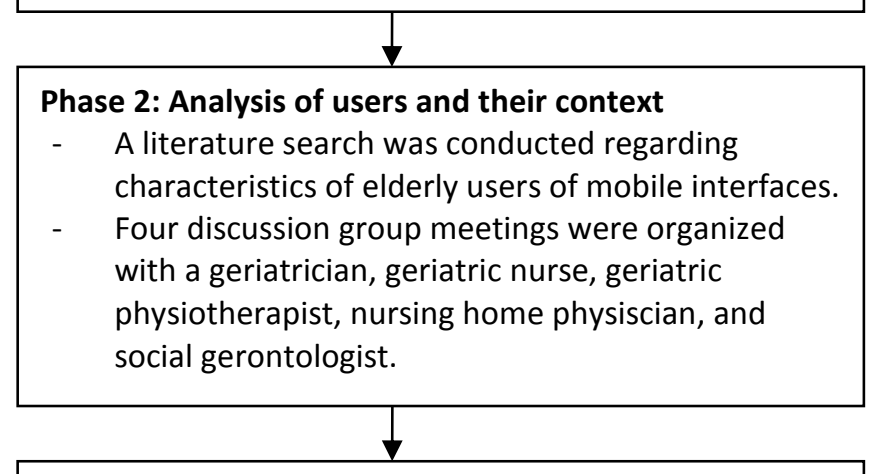

\section{Phase 3: Identification of user requirements}

- Three user-group meetings were organized with the user representatives and their advisor.

- Community-dwelling elderly people provided their input during a workshop.

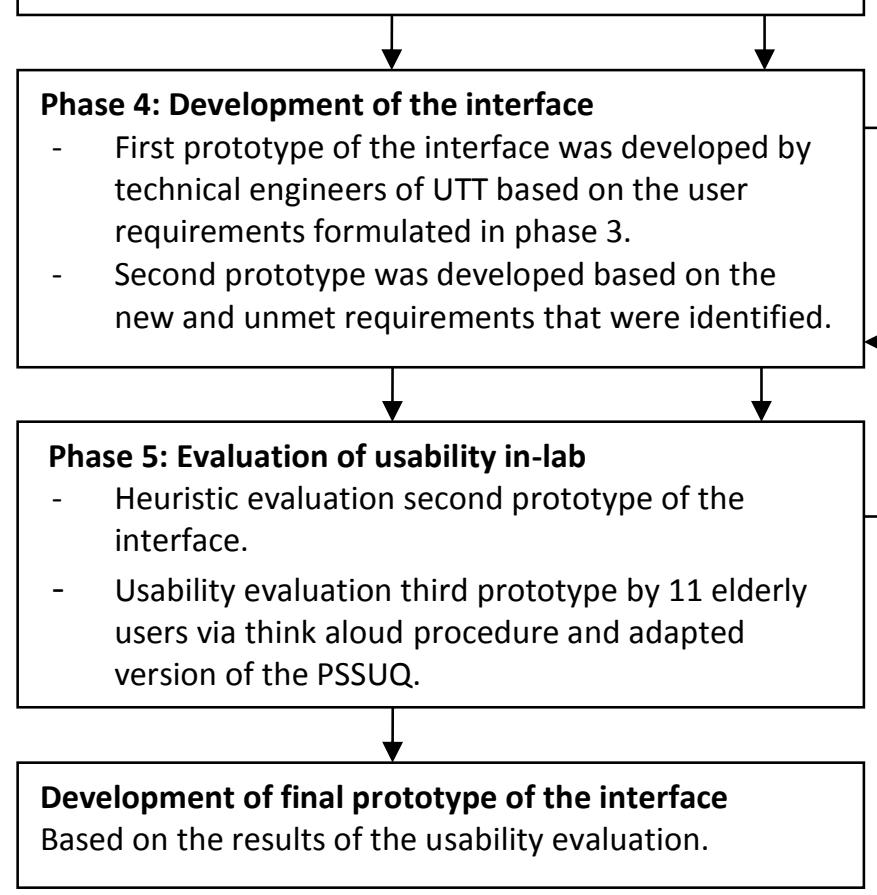

\section{Review first prototype Elderly representatives and their advisor reviewed the first prototype and identified new and unmet requirements that guided the development of the second prototype.}

\section{Adjust second} prototype The third prototype was developed based on the results of the heuristic evaluation.

Figure 2. User-centered development process 


\section{Chapter 8}

input for the next phase and at the end of each phase the development team checked whether the results were compatible with those of the previous phase. Other key principles of user-centered design, such as active user involvement and working in multidisciplinary teams were followed as well throughout the development process to ensure that the interface would fit the preferences and requirements of the potential users. This will be illustrated in the next paragraphs.

\section{Phase 1: Selection of user representatives}

Three elderly user representatives, all men aged above 65 years old, volunteered to be part of the development team after attending a meeting during which several researchers presented their projects. This meeting was organized by the House for Care (in Dutch: "Huis voor de Zorg") which is an independent organization that advocates patient empowerment and is committed to defending the interests and increasing the say and control of patients and other users of care. Together with researchers from MU and engineers from UTT, these representatives and their advisor from the House for Care formed the development team throughout the entire process.

\section{Phase 2: Analysis of users and their environmental context}

A literature search was performed to gain more insight into the characteristics of community-dwelling elderly people that are relevant to the development of a mobile interface. Furthermore, a geriatrician, geriatric nurse, geriatric physiotherapist, nursing home physician and social gerontologist advised the development team during four discussion meetings regarding important characteristics of potential users of the interface that provides feedback about (changes in) physical functioning.

\section{Phase 3: Identification of user requirements}

Three user-group meetings were organized with the elderly representatives from the House for Care and their advisor during which they provided their input regarding the user requirements to the researchers from $\mathrm{MU}$. The first user-group meeting focused on the feedback and the second meeting focused on the mobile interface. During the third usergroup meeting the information from the two previous user-group meetings was discussed and prioritized, which resulted in a list of requirements.

Furthermore, 24 elderly people who attended regular social gatherings organized by the Catholic Association for Elderly People participated in a workshop that took place during one of their gatherings. The monitoring system was presented to them and the requirements for the interface, as identified previously by the user representatives, were explained. The participants of the workshop were invited to discuss whether they liked and agreed with these requirements or not. New ideas or requirements were added to the list of requirements. 


\section{Phase 4: Development of the interface}

The list of requirements that resulted from Phase 3 was used as the foundation for the development of the first prototype of the interface. This prototype was developed by engineers from UTT. During a fourth user-group meeting, the user representatives and their advisor explored whether their requirements were met by the first prototype of the interface. Unmet or new requirements were added to the list of requirements and were used to guide the development of the second prototype of the interface.

\section{Phase 5: Evaluation of the usability of the interface in the lab}

The usability of the interface was evaluated first in a heuristic evaluation by non-users. After that it was evaluated by potential elderly users via a think-aloud procedure.

\section{Heuristic evaluation by non-users}

Three system developers and five non-experts evaluated the second prototype in a heuristic evaluation. The evaluators checked whether the following ten heuristics were violated while clicking through the interface: visibility of system status, match between system and real world, user control and freedom, consistency and standards, error prevention, recognition rather than recall, flexibility and efficiency of use, aesthetic and minimalist design, help users recognize/diagnose/recover from errors, and help and documentation. ${ }^{23,24}$ Identified violations were remedied in the third prototype of the interface.

\section{Think aloud usability test by users}

Elderly people who participated in the workshop in phase 3 were invited to evaluate the third prototype of the interface using a think-aloud procedure. Participants individually performed eleven tasks using the mobile interface after receiving general instructions. They provided feedback on the process and indicated what caused difficulties by thinking aloud. Participants were observed by a trained observer who registered whether the participants made mistakes during the tasks and whether they needed assistance. The observers also ensured that all the "think aloud" comments of the participants were registered.

Furthermore, the participants evaluated the usability of the interface using a questionnaire that contained translated items from the Post-Study System Usability Questionnaire (PSSUQ). ${ }^{25} \mathrm{~A}$ few items of the original PSSUQ were replaced by items regarding specific features of the interface. Each item of the questionnaire was rated on a scale from 1 (I strongly disagree) to 7 (I strongly agree) and participants could explain their rating in the free text space. Examples of the items were: 'Overall, I am satisfied with how easy it is to use this system,' 'The information that was provided on the screen of the mobile phone was clear,' and 'The menu on the mobile phone has all functions I expect it 


\section{Chapter 8}

to have.' The modified version of the PSSUQ that was used during the think aloud procedure is presented in Appendix 1.

Means and standard deviations were calculated to determine the usability of the interface; higher scores indicated better usability. Results from the think-aloud procedure and PSSUQ were used to develop the fourth and final prototype.

\section{Part 2: Methods pilot study}

\section{Design and participants}

The final prototype of the mobile interface was integrated into the monitoring system so that the system could provide feedback to the user. Originally, the monitoring system consists of three devices: a bathroom scale, a Grip-ball, and a mobile phone but unfortunately the Grip-ball could not be included in the pilot study due to problems in its production process. Therefore, a system consisting of the bathroom scale and mobile phone was tested during the pilot study with six weeks follow-up.

Participants were recruited via the geriatric outpatient clinic at Orbis Medical Center in Sittard, the Netherlands. Inclusion criteria were: 70 years or older, community-dwelling, mobility or functional problems, cognitively not impaired (Mini Mental State Examination (MMSE) > 23), able to step onto a bathroom scale independently, and willing to learn how to use the interface of the mobile phone. Exclusion criteria were: planned admission to a nursing home/hospital during the study, being confined to bed, serious visual or hearing impairments, and contra-indication for physical exercise. Eight patients were invited by their geriatrician and received an information letter and a consent form via mail. The researcher contacted them after two weeks to ask whether they were willing to participate and whether they had any questions. Patients who decided to participate provided written informed consent. This pilot study was approved by the Medical Ethical Committee Atrium Orbis Zuyd (NL35961.096.11).

\section{Procedure}

Participants were instructed to step onto the bathroom scale every day between 7:00 and 10:30 to monitor their weight and balance. Feedback regarding (changes in) these indicators was provided to the user via the mobile interface directly after the measurement. To monitor their physical activity, the users were instructed to wear the phone with them in their pocket or on a belt. Participants monitored their activity from the morning until after 20:00 and received feedback about (changes in) their activity directly after pressing 'stop-activity monitoring'. After that, they were instructed to put the phone back in the docking-station for charging. 
More detailed information about the content and presentation of the feedback and feedback algorithm is provided in the last paragraph of part 1 of the results section where the final prototype that was developed will be explained.

\section{Measurements}

After three weeks the participants received a modified version of the PSSUQ. ${ }^{25}$ This modified version differed from the one that was used during the think aloud procedure. Some items were removed from the version of the PSSUQ that is presented in Appendix 1 because they were not applicable and some questions which focused on the usability of the bathroom scale were added. As a result, the items of the modified PSSUQ that was used during the pilot study could be divided into three subscales: usability of the bathroom scale (5 items), usability of the mobile phone (10 items), and usability of the system as a whole (10 items). The participants rated each item on a scale from 1 till 7; higher scores indicated better usability. Besides that, free space was available after each question so that the participant could provide an explanation or clarification. Examples of the items were: 'I liked using the bathroom scale daily to measure my weight and balance', 'I needed a lot of help with using the mobile phone', 'I liked using the monitoring system', and 'Overall I am satisfied with the monitoring system'.

After six weeks follow-up, semi-structured interviews were conducted to gain insight into the experiences of the participants with the system. Topics discussed were: use of the bathroom scale and the mobile phone, feedback messages, satisfaction with the system, and usefulness of the system on a larger scale in the future.

Finally, all weight, balance, and activity measurements were registered automatically by the mobile phone. These data were used to study the adherence to the daily monitoring regimen.

\section{Analyses}

Firstly, mean usability scores (SD) were calculated for the total modified PSSUQ and its three subscales. Besides that, usability sumscores were calculated for each participant separately, higher scores indicated better usability. Secondly, the interviews were transcribed verbatim and analyzed using Nvivo version 9.0. Finally, adherence to the daily monitoring regimen was calculated by counting the number of days that data on all three physical indicators (weight, balance, and activity) were saved by the mobile phone and dividing this by the total number of days that a participant was included in the pilot study. 


\section{Results}

The results section is divided into two parts. The first part focuses on the results that were obtained during the phases of the user-centered development process. The second part focuses on the results of the pilot study.

\section{Part 1: Results user-centered development process}

\section{Users and their environmental context}

The literature study revealed that elderly people more often suffer from loss of cognitive capacities, sight loss, hearing loss, and decreased motor skills than younger people. These restrictions can cause difficulty with the use of small screen mobile interfaces. ${ }^{26-28}$ Therefore, it is important to take possible cognitive, sensory, and motor restrictions into account in developing an interface that provides feedback to elderly people regarding their own physical functioning. ${ }^{29}$ Attention should be paid to factors such as screen size, font size, density of information, and level of contrast. ${ }^{30-33}$ This can prevent usability problems. $^{34,35}$

Advice from the professionals during the discussion meetings revealed that elderly people who are at risk for, or already suffer from, decreased physical functioning should be the users of the interface. They are the ones who can benefit from the feedback messages supporting self-management. An important remark was that we should be very careful with the feedback that is provided because feedback about decreases in physical functioning can be very confronting to elderly users. Elderly people should not become 'scared' of the feedback as this will cause (unnecessary) distress and might result in discontinued use of the system. Furthermore, the professionals stressed the importance of the social environment and the facilitating role that spouses, children, or neighbors can play in learning how the interface works and in understanding the feedback messages. This was later confirmed by elderly people during the user-group meetings and workshop.

\section{Identification of user requirements}

The requirements that were identified during the user-group meetings and workshop are presented in Table 1. The requirements that were identified by the user representatives and their advisor after reviewing the first prototype are included in the table as well.

\section{Usability of the interface in the lab}

Violations of heuristics identified by non-users 
The heuristic evaluation revealed some consistency violations in the second prototype of the interface. Arrows were used on the interface to indicate whether a certain physical indicator had increased, decreased or stayed the same, but the use of the arrows was not consistent across the different indicators. Therefore, the arrows were deleted from the interface in the third prototype. There was also a mismatch between the color, emoticon, and the text on some of the screens. Another heuristic violated according to some evaluators was the user language heuristic. In some cases, words that were used on the buttons were not common and therefore difficult to understand for the potential end users. An example is the word "parameter". These violations were remedied in the third prototype of the interface.

Table 1. User requirements

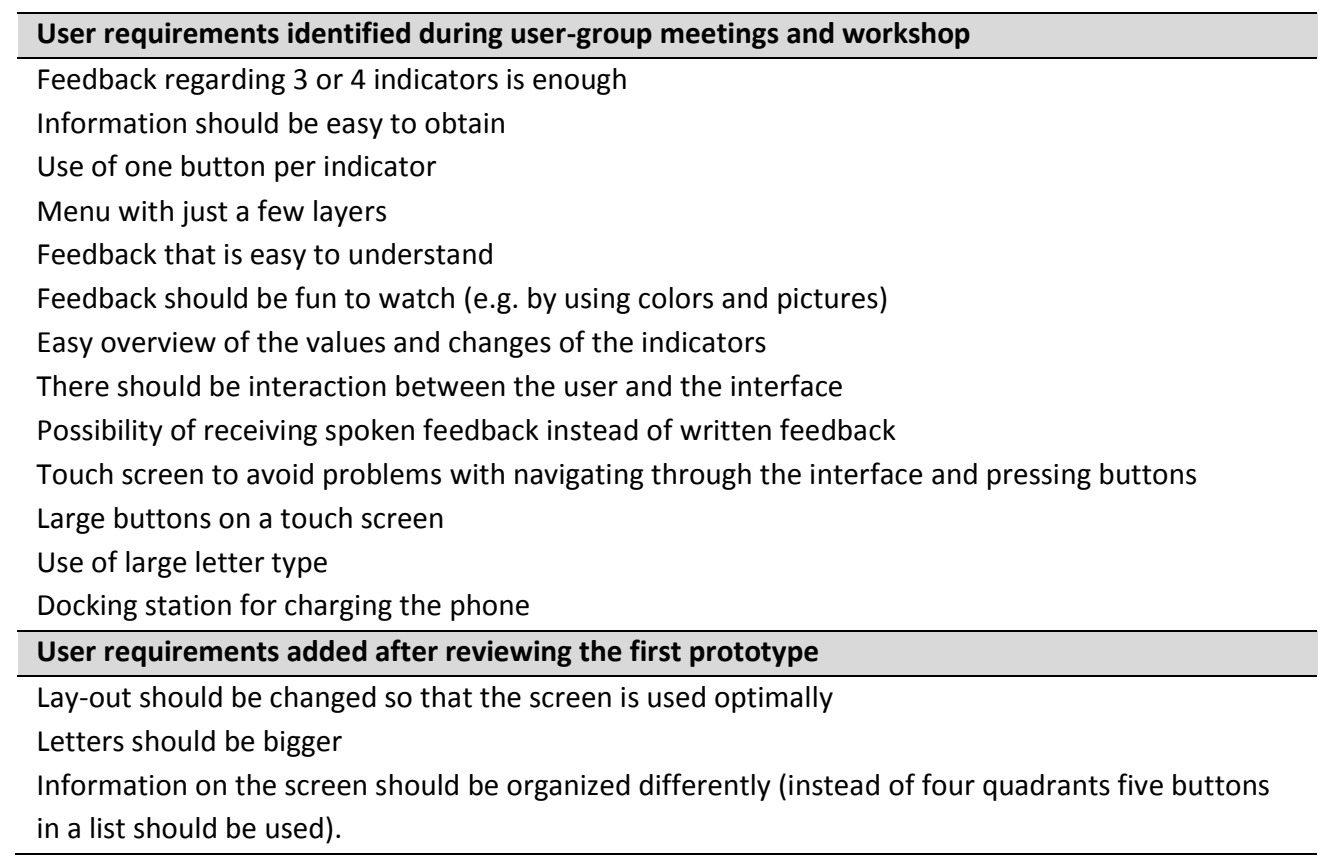

\section{Usability of interface in think aloud procedure}

Four men and seven women with a mean age of 79 years (SD 5.0 years) participated in the think aloud evaluation of the third prototype of the interface. Most participants had never used a phone with a touch screen before. Some of them had experience with regular mobile phones. Their comments during the tasks indicated that some buttons on the interface were too small and other buttons did not attract sufficient attention and were 
overlooked. Furthermore, some participants preferred bigger letters and others preferred black text instead of white text.

In addition to the think aloud comments, the observers noticed that most participants handled the phone correctly but that they had to get used to the touch screen.

Sometimes, they needed to press the same button a few times before it would respond, but most participants became accustomed to the touch screen after practicing a few times. Most participants sought confirmation from the observer at the beginning of the session, but their confidence seemed to increase after successful completion of the first few tasks.

The mean usability score on the modified version of the PSSUQ was 5.90 (SD 1.1). One participant gave a mean score of 3.7 whereas the other 10 participants all gave mean usability scores of 5.6 or higher.

\section{The final version of the developed interface}

Figure 3 shows three screenshots of the developed interface. The application consists of three layers. The screenshot on the left shows the first layer which is the start screen of the interface consisting of five buttons; one for each physical indicator that users receive feedback on and one for changing the settings (e.g. volume, text color etc.). When users touch one of the first four buttons in the left screenshot, for example the "balance" button, they enter the second layer of the application which is represented by the middle screenshot. In the middle screenshot, users receive feedback regarding the measurement they performed today and how this relates to their personal goal which is based on their previous measurements. When the 'history' button on the middle screenshot is touched, users enter the third layer of the application and the screenshot on the right appears. In the right screenshot an overview is provided of the last six balance measurements. Users can change the overview period to 2 weeks, 1 month, 3 months, or 6 months by touching the bar above the graph.

An automated feedback algorithm is responsible for the content of the feedback that is provided. To personalize the feedback, a 'baseline profile' for each indicator is defined for each participant based on the mean and variation of the measurements during the first two weeks that they use the system. During these first two weeks, participants receive neutral feedback: the value of their measurement is presented on the mobile interface with a grey background. The feedback that participants receive after the first two weeks is personalized by comparing the daily measurements with the 'baseline profile' also referred to as 'goal' in the application. This comparison reveals whether each of the physical indicators increased, decreased, or remained the same. When changes are positive or when an indicator is stable, positive feedback messages are provided combined with a green background and happy smiley like in the middle screenshot of Figure 3 . When indicators decrease, the feedback message explains how much the measurement differs 
from a participant's goal and this is combined with an orange or red background (depending on how much the indicator has decreased).

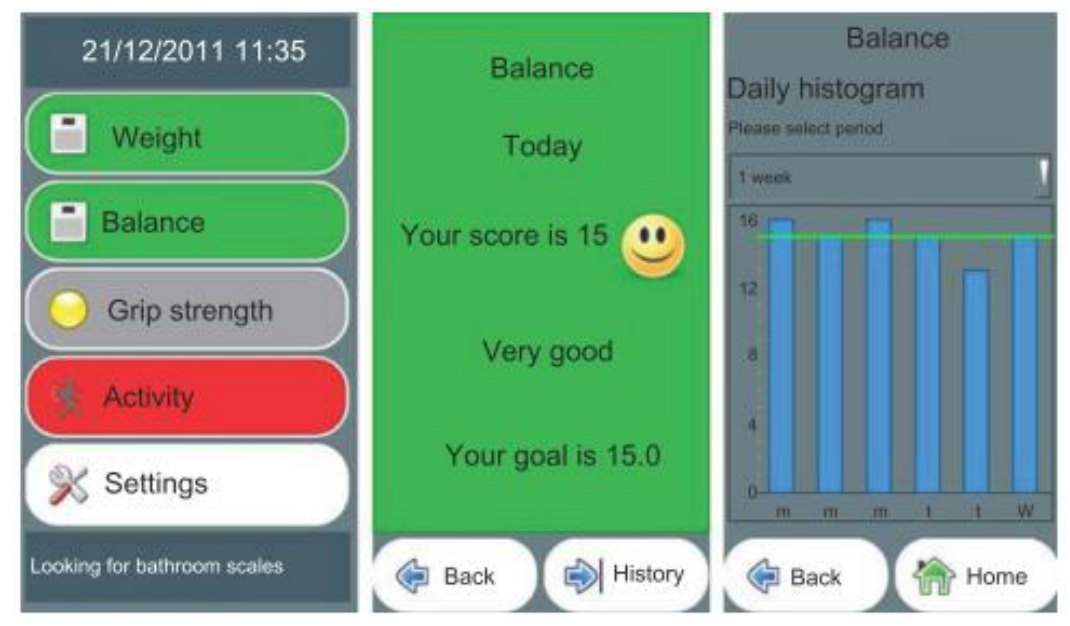

Figure 3. Three screenshots of the final interface

\section{Part 2: Results pilot-study}

\section{Characteristics of included participants}

Two men (participant 2 and 3 ) and four women aged between 79 and 83 years old provided written informed consent. Participants 5 and 6 lived alone independently; the others lived together with their spouse. All participants visited the outpatient clinic of the geriatrician because they had fallen recently. All participants indicated at baseline that they owned a mobile phone that they only used sporadically. None of the participants used a smartphone before. Participant 1, 2, 3, and 5 completed the pilot study and participated $42,42,42$, and 37 days respectively. Participant 4 decided to stop participation after using the monitoring system for 6 days; main reason for her drop-out was that she did not feel supported enough by her husband. Participant 6 dropped out after two days because she was admitted to the hospital unexpectedly.

\section{Usability of the monitoring and feedback system}

The usability scores on the modified version of the PSSUQ are presented in Figure 4 for each participant separately. The mean overall usability score was 5.2 (SD .9) and scores varied between participants from 3.8 till 6.2. The mean scores of the subscales for the bathroom scale, mobile phone and system as a whole were 6.2 (SD .6), 5.0 (SD .8), and 4.8 (SD 1.0) respectively on a scale from 1 till 7. The participant who dropped-out of the study after 6 days (participant 4) gave the lowest usability scores on all subscales. 


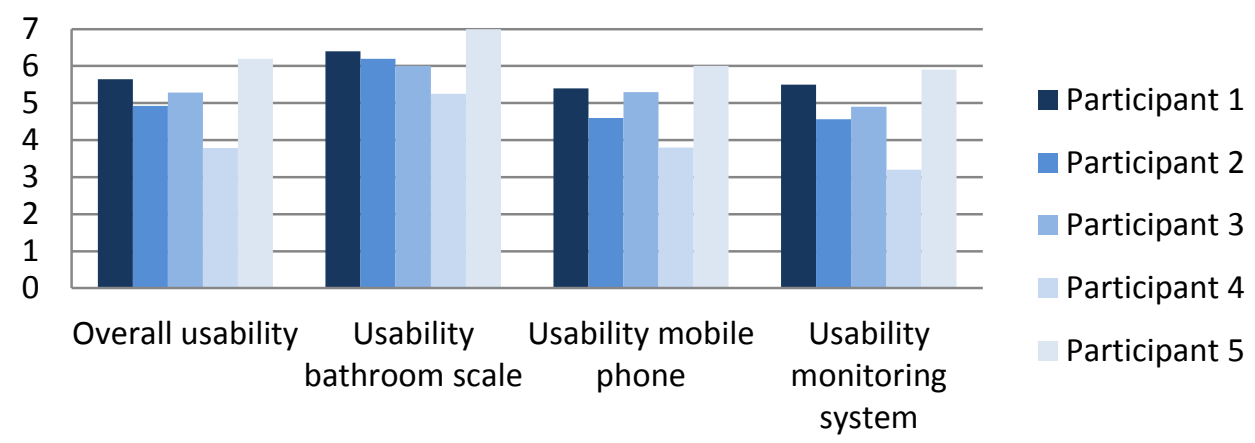

Figure 4. Mean usability scores per participant

\section{Experiences with the monitoring and feedback system}

The data that was gathered during the interviews was clustered into four themes:

receiving feedback, use of the monitoring system, technical functioning of the devices, and use of the system in the future.

\section{Receiving feedback}

Most participants appreciated the feedback messages and indicated that these made them more aware of their own physical functioning.

I appreciate that it signals changes. At a certain point you see that your weight drops from 81.5 to 78.6. Then I think: I have not been eating less than before. So then I will keep an eye on that. [male, 80 years old]

When the feedback colors first appeared after two weeks of baseline monitoring with neutral feedback, some of the participants were confused because they forgot what was explained about these colors at the start of the study. They did not understand why the colors appeared and some participants even thought that this was an error of the mobile phone, so extra explanation from the researcher was needed. Despite this, the use of colors to provide feedback was appealing according to the participants.

The device is alive. It is not a dead thing. It can change colors after a while. [female, 83 years old]

Furthermore all participants noticed that they sometimes received red feedback messages for balance and activity that should have been green. For example when a person with an activity goal of 35 minutes was active for $\mathbf{4 0}$ minutes and still received a red feedback message stating that activity decreased. The participants experienced these incorrect red feedback messages as bothersome but it did not scare nor panic them. These wrong feedback messages resulted from a flaw in the feedback algorithm. 
Use of the monitoring system

Three participants indicated that they liked using the monitoring system every day and one was neutral. Using the monitoring system was not very difficult for them but one of the participants kept using the instruction manual every day while performing the measurements.

It is actually pretty easy. ..... I press the buttons according to the manual, and then it's OK. [male, 79 years old]

Some aspects were mentioned that could improve the usability of the monitoring system. Firstly, the participants indicated that the 'Start' and 'Stop' button for the activity monitoring functionality should be separate buttons whereas during the study the 'Start' button became the 'Stop' button once activity monitoring was started. Secondly, all participants would appreciate a reset button that they can use when pressing a wrong button by accident on the touch screen. Thirdly, the female participants did not like the elastic waist band that they could use to carry the phone with them for activity monitoring on days that they wore clothes without pockets. They indicated that a less flexible belt would be more suitable to carry the weight of the mobile phone.

\section{Technical functioning}

Two types of technical errors occurred during the pilot study: on 3 occasions participants reported that the bathroom scale did not transfer the data to the mobile phone and on 4 occasions the participants reported that the application on the mobile phone had shut down automatically. Despite the fact that these errors did not occur often, they had a negative impact on the experiences of the participants with the monitoring system. Participants dealt with the errors differently. Some participants found a solution by looking in the instruction manual, others tried pushing different buttons but this did not solve the error, which frustrated them. Most participants called the researcher to report the error. In some cases the researcher visited the participant at home to solve the problem.

When everything works as it should, it's OK, then I am happy. Otherwise I panic a bit. [female, 84 years old]

When the screen with the buttons (the application) disappears, it is quite a fuss to get things back like they were. [male, 79 years old]

Use of system in the future

Participants think that self-monitoring physical functioning with the system could be useful to other elderly people. They especially like the idea that the mobile phone can send their measurements to a database where their care professionals can see them. 
But I think it is a good system indeed that the doctor can use to keep an eye on things. [male, 80 years old]

The participants also identified possible difficulties/obstacles for the use of the monitoring and feedback system in the future. For example: forgetfulness in elderly people can cause that they do not use the system every day, or it might be difficult to learn how to use the monitoring system (due to lack of experience with a computers/mobile phones or because of character traits), or elderly people might grow tired of using the system for a longer time.

\section{Adherence to daily monitoring regimen}

Frequency calculations revealed that participant 1, 2, and 5 did not use the bathroom scale and mobile phone on 7 days (17\%), 2 days (5\%), and 13 days (35\%) of the pilot study respectively. Participant 3 used the monitoring and feedback system every day. No adherence rate was calculated for participants 4 and 6 because they dropped out of the study. The frequency data from the four participants who completed the pilot study resulted in an average adherence rate of $87 \%$ to the daily monitoring regimen.

\section{Discussion}

Mixed-methods were used and key principles of user-centered design were respected throughout the development process to ensure that the developed interface would meet the needs and preferences of the end users. ${ }^{18,22}$ The involvement of elderly people during the development process resulted in a usable mobile interface that provides feedback regarding (changes in) indicators of physical functioning that is easy to understand. The interface that emerged from the user-centered development process was integrated in the monitoring and feedback system and tested in a pilot study. Participants of the pilot study were able to use the system and liked the feedback that was provided to them. The monitoring and feedback system satisfied most needs and preferences of the end users and was considered easy-to-use which resulted in good adherence to the daily monitoring regimen. Previous research also shows that ease of use is a very important predictor of adherence to telecare systems in elderly persons with functional or mobility problems. ${ }^{36}$ Only one participant had lower adherence during the pilot study, which was mainly caused by the fact that the participant could not restart the application by herself after it had shut down automatically. So, her low adherence was a result of an error in the application which caused a usability problem. The few technical errors that occurred during the pilot study annoyed the users and sometimes caused confusion. These errors need to be remedied before the system can be evaluated in a larger group since an important prerequisite for 
the uptake of technology in practice is that the monitoring system should operate without interruptions. $^{11}$

A recent review by van den Berg et al. regarding telemedicine and telecare for older patients revealed that the majority of studies in this field are carried out in 'younger older patients' who do not always represent the target group of the innovation. ${ }^{37}$ A strength of this pilot study is that only 'older patients' were included. Another advantage is that the monitoring and feedback system was tested in the daily lives of elderly people instead of in a controlled lab-situation; this provides more accurate and detailed information into the experiences and problems that can occur. ${ }^{38}$

The experiences of the participants with the monitoring and feedback system cannot be generalized due to the small study sample which is a limitation of the pilot study. Despite this, most usability problems were probably identified during the usability test in the lab and the pilot study since, according to Nielssen et al., five participants is sufficient to identify $80 \%$ of the these problems. ${ }^{39}$ Another limitation of this study is that, although both based on the PSSUQ, different questionnaires were used to test the usability of the interface in lab during the development phase and to test the usability of the monitoring and feedback system during the pilot study and that both versions were not validated.

\section{Implications for clinical practice and future research}

In order to have an added value for community-dwelling elderly people and care professionals the monitoring and feedback system should not function as a stand-alone intervention but instead it should be integrated in usual care. Previous research has shown that 'blended-care' approaches, where telecare interventions are embedded in

professional care processes, yield more positive results and are more sustainable. ${ }^{40,41}$ However, before the monitoring and feedback system can be integrated in care, more insight is needed into its long-term acceptance according to elderly users and their care providers. Therefore, the monitoring system and interface are currently being improved based on the results of the pilot-study. Subsequently, a six-month follow-up study is being organized during which community-dwelling elderly people will use the improved system including the grip ball. This follow-up study will not only focus on the experiences of the elderly users, but also on the care professionals who will use the database to monitor their patients from a distance. We expect that the follow-up study will also provide more insight into the possibility of detecting clinically relevant changes in physical functioning with the devices of the monitoring system.

\section{References}

1. Jette AM. Towards a common language for function, disability, and health. Phys Ther. 
2006;86:726-734.

2. Vermeulen J, Neyens JC, Spreeuwenberg MD, van Rossum E, de Witte LP. Predicting ADL disability in community-dwelling elderly people using physical frailty indicators: a systematic review. BMC Geriatr. 2011;11:33.

3. Rothman MD, Leo-Summers L, Gill TM. Prognostic significance of potential frailty criteria. J Am Geriatr Soc. 2008;56:2211-2216.

4. Gill TM, Allore H, Holford TR, Guo Z. The development of insidious disability in activities of daily living among community-living older persons. Am J Med. 2004;117:484-491.

5. Balzi D, Lauretani F, Barchielli A, Ferrucci L, Bandinelli S, Buiatti E. Risk factors for disability in older persons over 3-year follow-up. Age Ageing. 2010;39:92-98.

6. Besdine RW, Fox-Wetle T. Improving health for elderly people: an international health promotion and disease prevention agenda. Aging Clin Exp Res. 2010;22:219230.

7. Boulos MNK, Wheeler S, Tavares $C$, Jones R. How smartphones are changing the face of mobile and participatory healthcare: an overview, with example from eCAALYX. Biomedical engineering online. 2011;10:24.

8. Patrick K, Griswold WG, Raab R, Intille SS. Health and the mobile phone. Am J Prev Med. 2008;35:177-181.

9. Gitlin LN, Winter L, Dennis MP, Corcoran M, Schinfeld S, Hauck WW. A randomized trial of a multicomponent home intervention to reduce functional difficulties in older adults. J Am Geriatr Soc. 2006;54:809-816.

10. Worm C, Vad E, Puggaard L, Stovring H, Lauritsen J, Kragstrup J. Effects of a multicomponent exercise program on functional ability in community-dwelling frail older adults. JAPA. 2001;9:414-424.

11. Botsis T, Hartvigsen G. Current status and future perspectives in telecare for elderly people suffering from chronic diseases. J Telemed Telecare. 2008;14:195-203.

12. Koch S, Hagglund M. Health informatics and the delivery of care to older people. Maturitas. 2009;63:195-199.

13. Vermeulen J, Neyens JCL, Spreeuwenberg MD, Van Rossum E, Hewson DJ, Duchêne J, De Witte LP. Construct validity of a modified bathroom scale that can measure balance in elderly people. J Am Med Dir Assoc. 2012;13:665.e1-5.

14. Duchêne J, Hewson DJ. Longitudinal evaluation of balance equality using a modified bathroom scale: usability and acceptability. J Telemed Telecare. 2011;17:421-426.

15. Hewson DJ, Li K, Frerejean A, Hogrel JY, Duchêne J. Domo-grip: functional evaluation and rehabilitation using grip force. Conference Proceedings IEEE Eng Med Biol Soc. 2010:1308-1311.

16. Hewson DJ, Duchêne J, CHarpillet F. The PARAChute project: remote monitoring of posture and gait for fall prevention. J Activ Sign Proc. 2007;1:109. 
17. Teixeira L, Ferreira C, Sousa Santos B. User-centered requirements engineering in health information systems: a study in the hemophilia field. Comput Methods Programs Biomed. 2012;106:160-174.

18. Kujala S. User involvement: a review of the benefits and challenges. Behaviour \& Information Technology. 2003;22:1-16.

19. Van Gemert-Pijnen JEWC, Nijland N, Van Limburg M,Ossebaard HC, Kelders SM, Eysenbach G, Seydell ER. A holistic framework to improve the uptake and impact of ehealth technologies. J Med Internt Res. 2011;13:e111.

20. De Vito Dabbs A, Myers BA, McCurry KR, Dunbar-Jacobs J, Hawkins RP, Begey A, Dew MA. User-centered design and interactive health technologies for patients.

Computers Inform Nurs. 2009;27:175-183.

21. De Rouck S, Jacobs A, Leys M. A methodology for shifting the focus of e-health support design onto user needs. Intern J Med Inform. 2008;77:589-601.

22. Gulliksen J, Goransson B, Boivie I, Blomkvist S, Persson J, ASA Cajander. Key principles for user-centered systems design. Behaviour \& Information Technology. 2003;22:379-409.

23. Nielsen J. Usability Engineering. $1^{\text {st }}$ Ed. Cambridge: AP Professional; 1993.

24. Nielsen J, Mack RL, editors. Usability Inspection Methods. $1^{\text {st }}$ ed. New York: John Wiley \& Sons; 1994.

25. Lewis JR. Psychometric evaluation of the PSSUQ using data from five years of usability studies. Int J Hum Comput Interact. 2002;14:463-488.

26. Gregor $P$, Newell $A F$, Zajicek $M$. Designing for dynamic diversity: interfaces for older people. Assets. 2002;1:151-156.

27. Edlin-White R, Cobb S, D'Cruz M, Floyde A, Lewthwaite S, Riedel J. Accessiblity for older users through adaptive interfaces: opportunities, challenges and achievements. Hum Comp Interact. 2011;6763:483-489.

28. Lorenz A, Oppermann R. Mobile health monitoring for the elderly: designing for diversity. Pervasive Mob Comp. 2009;5:478-495.

29. Hawthorn D. Possible implications of aging for interface designers. Interact Comp. 2000;12:507-528.

30. Darroch I, Goodman J, Brewster S, Gray P. The effect of age and font size on reading text on handheld computers. INTERACT. 2005;1:253-266.

31. Zhou J, Rau PLP, Salvandy G. Use and design of handheld computers for older adults: a review and appraisal. Intern J Human-Computer Interaction. 2012;28;799-826.

32. Sanchez CA, Goolsbee JZ. Character size and reading to remember from small displays. Comp \& Educ. 2010;55:1056-1062.

33. Sweeney S, Crestani F. Effective search results summary size and device screen size: is there a relationship? Information Processing \& Management. 2006;42:1056-1074. 


\section{Chapter 8}

34. Holzinger A, Searle G, Nischelwitzer A. On some aspects of improving mobile applications for the elderly. Universal Acess in HCl. 2007;1:923-932.

35. Ziefle M. Information presentation in small screen devices: the trade-off between visual density and menu foresight. Applied Ergonomics. 2010;41:719-730.

36. Wade R, Cartwright C, Shaw K. Factors relating to home telehealth acceptance and usage compliance. Risk Management and Healthcare Policy. 2012;5:25-33.

37. Van den Berg N, Schumann M, Kraft K, Hoffmann W. Telemedicine and telecare for older patients: a systematic review. Maturitas. 2012;73:94-114.

38. Kangas $E$, Kinnunen T. Applying user-centered design to mobile application development. Communications of the ACM. 2005:48;55-59.

39. J. Nielssen, "Why you only need to test with 5 users" Alertbox 2000, retreived from http://www.useit.com/alertbox/20000319.html on $18 \mathrm{dec} 2012$.

40. May CR, Finch TL, Cornford J, Exley C, Gately C, Kirk S, et al. Integrating telecare for chronic disease management in the community: what needs to be done? BMC Health Serv Res. 2011:11:131.

41. Weinstein RS, Lopez AM, Krupinski EA, Beinar SJ, Holcomb M, McNeely RA, et al. Integrating telemedicine and telehealth: putting it all together. Stud Health Technol Inform. 2008;131:23-38. 
Appendix 1. Modified version Post Study System Usability Questionnaire (PSSUQ) used during think-aloud procedure.

Each item on the questionnaire was rated on a 7-point scale from 1 (/ strongly disagree) to 7 (I strongly agree).

$\begin{array}{lllllllll}\begin{array}{l}\text { I strongly } \\ \text { disagree }\end{array} & 1 & 2 & 3 & 4 & 5 & 6 & 7 & \begin{array}{l}\text { I strongly } \\ \text { agree }\end{array}\end{array}$

1. Overall, I am satisfied with how easy it is to use this system.

2. It was easy to switch on the mobile phone.

3. It was easy to connect the adapter to the mobile phone.

4. The menu on the mobile phone was easy to use.

5. I could complete the tasks effectively using the mobile phone.

6. I was able to complete the tasks quickly using the mobile phone.

7. I was able to complete the tasks efficiently using the mobile phone.

8. I felt comfortable using the mobile phone.

9. It was easy to learn to use the mobile phone.

10. Whenever I made a mistake using the mobile phone, I could recover easily and quickly.

11. The information that was provided on the screen of the mobile phone was clear.

12. It was easy to find the right information on the mobile phone.

13. The information provided on the screen of the mobile phone was easy to understand.

14. The information on the screen of the mobile phone was effective in helping me complete the tasks.

15. The organization of the information on the screen of the mobile phone was clear.

16. The interface of the mobile phone looked pleasant.

17. I liked using the interface of the mobile phone.

18. The menu on the mobile phone has all functions I expect it to have.

19. Overall, I am satisfied with the mobile phone.

20. The letters and words on the screen of the mobile phone were easy to read.

21. The contrast of the colors on the screen of the mobile phone was good.

22. The images on the screen were clearly visible.

23. Next week, I will remember as well as now how the mobile phone works. 



\section{CHAPTER 9}

Experiences of multidisciplinary development team members during user-centered design of telecare products and services: a qualitative study

This chapter was published as:

Vermeulen J, Verwey R, Hochstenbach LMJ, van der Weegen S, Man YP, de Witte LP. Experiences of multidisciplinary development team members during user-centered design of telecare products and services: a qualitative study. Journal of Medical Internet Research. 2014;16:e124. 


\section{Abstract}

Background: User-centered design (UCD) methodologies can help to take the needs and requirements of potential end-users into account during the development of innovative telecare products and services. Understanding how members of multidisciplinary development teams experience the UCD process might help to gain insight into factors that members with different backgrounds consider critical during the development of telecare products and services.

Objective: The primary objective of this study was to explore how members of multidisciplinary development teams experienced the UCD process of telecare products and services. The secondary objective was to identify differences and similarities in the barriers and facilitators they experienced.

Methods: 25 members of multidisciplinary development teams of four Research and Develop (R\&D) projects participated in this study. The R\&D projects aimed to develop telecare products and services that can support self-management in elderly people or patients with chronic conditions. Seven participants were representatives of end-users (elderly persons or patients with chronic conditions), three were professional end-users (geriatrician and nurses), five were engineers, four were managers (of R\&D companies or engineering teams), and six were researchers. All participants were interviewed by a researcher who was not part of their own development team. The following topics were discussed during the interviews: aim of the project, role of the participant, experiences during the development process, points of improvement, and what the project meant to the participant.

Results: Experiences of participants related to the following themes: creating a development team, expectations regarding responsibilities and roles, translating user requirements into technical requirements, technical challenges, evaluation of developed products and services, and valorization. Multidisciplinary team members from different backgrounds often reported similar experienced barriers (e.g. different members of the development team speak a 'different language') and facilitators (e.g. team members should voice expectations at the start of the project to prevent miscommunication at a later stage). However, some experienced barriers and facilitators were only reported by certain groups of participants. For example: only managers reported that they experienced that having different ideas about what a good business case is within one development team was a barrier whereas only end-users emphasized the facilitating role of project management in end-user participation and the importance of continuous feedback from researchers on input of end-users.

Conclusions: Many similarities seem to exist between the experienced barriers and facilitators of members of multidisciplinary development teams during UCD of telecare products and services. However, differences in experiences between team members from various backgrounds exist as well. Insights into these similarities and differences can improve understanding between team members from different backgrounds which can optimize collaboration during the development of telecare products and services. 


\section{Introduction}

The number of people who suffer from chronic conditions and the number of elderly people is increasing, and at the same time, the number of care professionals is decreasing. ${ }^{1}$ The gap between the demand for and supply of care that results from these changes will put a burden on patients, care professionals, and health care systems in the near future. ${ }^{2,3}$ Telecare products and services have the potential to alleviate this burden by supporting self-management, remote monitoring of health conditions, and the delivery of interventions. ${ }^{4-6}$ The appropriate adoption of telecare technologies can contribute to the lives of patients with chronic conditions and elderly people by improving their quality of life and enabling them to live independently for as long as possible. 7,8

Unfortunately, previous studies show that telecare does not always fulfill its potential because the telecare products and services that are developed do not fit the needs and preferences of end-users or because they do not fit the context in which they should be implemented. ${ }^{9-12}$ Involving end-users in the development of telecare products and services can ensure that human and non-technology issues are taken into consideration, which improves the usability and acceptability of the technology that is being developed. ${ }^{13-15}$

Theoretical frameworks regarding user-centered design (UCD) have been used as guidelines during the development processes of telecare products and services. ${ }^{16-22}$ Such frameworks take into account important key principles of UCD, for example, the development process should be iterative and incremental, the end-users should be actively involved from early development stages onwards, design options should be explained to end-users in a language that they understand, the developed services and products should be evaluated in a real life context, and the development process should be performed by effective multidisciplinary teams. ${ }^{23}$ Previous studies revealed that various barriers and challenges can occur during UCD processes that can influence the collaboration between multidisciplinary stakeholders. Examples of such barriers are communication between team members from different backgrounds, management of expectations, and availability of resources for the involvement of users. ${ }^{14,24,25}$

Understanding how members of multidisciplinary development teams with different backgrounds experience the UCD process might help gain insight into factors that different members consider critical during the development of telecare products and services. Furthermore, it might reveal how they deal with barriers and challenges they encounter. Therefore, the primary objective of this study was to explore how members of multidisciplinary development teams experienced the UCD process of telecare products and services. The secondary objective was to identify differences and similarities in the barriers and facilitators they experienced. 


\section{Methods}

\section{Design and participants}

This qualitative study was conducted in parallel with four (subsidized) Research and Development (R\&D) projects that were initiated by Maastricht University and/or Zuyd University of Applied Sciences. The projects were selected because they developed a variety of telecare products and services to support self-management in different usergroups: patients with diabetes or chronic obstructive pulmonary disease (COPD) ${ }^{26-28}$, patients with cancer pain, frail elderly people, or elderly people living at home. ${ }^{29} \mathrm{~A}$ prerequisite for project selection was that end-users were considered official members of the development team. Appendix 1 provides information regarding the four projects. Principle investigators of the projects had a background in health sciences.

For this study, a purposeful sample of the "core members" of the four development teams, who were involved throughout the whole development process from the beginning onwards, were invited to participate in a semistructured interview. Principle investigators of each development team identified the core members in consultation with their team and asked them whether they would like to receive an invitation for this study via email. The 25 core members were identified across the four R\&D projects: 3 elderly persons, 2 professional advisors of these elderly persons (specialized in facilitating participation of elderly persons during research projects), 2 patients with chronic conditions, 1 geriatrician, 2 nurses, 5 software/technical engineers, 4 managers of R\&D companies or engineering teams, and 6 researchers/principle investigators of the R\&D projects. All these potential participants received an invitation letter via email from the researcher (JV) explaining the purpose and details of this qualitative study. All invitees accepted the invitation.

\section{Procedures}

After invitees agreed to participate, the interview was scheduled at a place and time that was convenient for the participant. As a result, 13 interviews were conducted the university, nine at the workplace of the participant, and 3 via Skype/telephone call. The 6 participants of this study who were researchers or principle investigators in one of the four R\&D projects (JV, RV, LMJH, SvdW, YPM, LdW) were interviewed by an experienced external interviewer who was not involved in any of the R\&D projects described above. JV, $\mathrm{RV}, \mathrm{LMJH}, \mathrm{SvdW}$, and YPM interviewed the remaining 19 participants of this study. All participants were interviewed by a researcher who was not involved in the same R\&D project as the participant. Interviews with members of development teams of Projects 1 , 3 , and 4 were conducted when final products were already developed. Interviews with members of the development team of Project 2 were conducted at a prototype stage. 
Interviews were recorded using a digital voice recorder and lasted between 35 and 65 minutes. Average duration of an interview was 46 minutes.

All semistructured interviews were based on the following topic list: the role of the participant in the project, the aim of the project, experiences during the development process, points of improvement for the development process, and what the project meant to the participant. This topic list was established before the start of the study and was not changed during the course of the study. Interviewers used reflective listening techniques to encourage participants to elaborate on their views. By reflecting back to the participants during the interview what the interviewer believed was said, the statements of the participant were verified and/or clarified. By keeping an open posture and by emphasizing at the beginning of the interview that there were no right or wrong answers, participants were encouraged to share their own personal opinions and thoughts. All participant answers were kept confidential. To guarantee anonymity, the following terms are used in this article to refer to the data obtained from certain groups of participants:

- 'End-user' refers to data obtained from an elderly person, an advisor of an elderly person, or a patient with a chronic condition $(n=7)$.

- 'Professional end-user' refers to data obtained from a geriatrician or a nurse $(n=3)$.

- 'Engineer' refers to data obtained from a software/technical engineer $(n=5)$.

- 'Manager' refers to data obtained from a technical project leader or owner of an R\&D company $(n=4)$.

- 'Researcher' refers to data obtained from a researcher or principle investigator of the $R \& D$ projects $(n=6)$.

\section{Data analyses}

Once all interviews were conducted they were transcribed verbatim by two of the researchers (JV/RV) or a research assistant. Afterwards, JV checked the transcripts against the audio recordings. All transcripts were coded using NVivo version 9.0. Field notes from the interviews were also included in the analyses if they were available. Two researchers (JV \& RV) started analyzing the data using a conventional content analysis approach. They independently coded six transcripts of interviews that were conducted with members from different development teams with different backgrounds. After initial coding, the 2 researchers checked for consensus and after discussion they agreed on the main themes and subthemes of the coding scheme. This coding scheme was used by JV to analyze the remaining interviews. If in doubt about whether data from these remaining interviews fitted the coding scheme or not, JV consulted RV. Themes and subthemes were refined or extended based on the data from the remaining interviews to be analyzed and if necessary new (sub)themes were added. Once all transcripts were analyzed, the content of the themes and subthemes of the coding scheme were discussed with the research group that included all co-authors of this paper. Consensus was reached on themes that were related 


\section{Chapter 9}

to different phases of the development process and subthemes that related to barriers and facilitators participants experienced during these phases. After completing the data analyses, findings related to themes and subthemes were reported back to all participants for a member check.

\section{Results}

The main themes that emerged from the analyses related to different phases of the UCD process: creating a development team, expectations regarding responsibilities and roles, translating user requirements into technical requirements, technical challenges, evaluation, and valorization. Experiences of participants during these different phases are described below. Tables 1 and 2 provide an overview of which experienced barriers and facilitators respectively were reported by which members of the development team, to gain insight into differences and similarities.

\section{Creating a development team}

Due to the fact that members of the development teams had different backgrounds, there was also a difference in knowledge about the project, UCD processes, telecare products and services, intended end-users of the technology, and ways of conducting research in a health care setting. In addition, different members of the development team seemed to speak a "different language" (use different terminology):

We have researchers, we have doctors, we have technicians, and it is very, it is not the same world. Because we do not speak the same language...Sometimes we think something and for example the researcher understands something else... We speak technical, she (the researcher) talks with elderly people, she talks with other worlds. That is why it is so difficult. [P20, male, engineer]

Participants reported that overcoming these differences was sometimes difficult. A benefit of these differences, mentioned by most participants, is that members of the team could really complement each other which resulted in a positive "team spirit":

They (technical engineers) did not know anything about medication and then you think; well I don't know anything about computers. So together that was fun, as if you speak a different language but still have to come up with a solution together. [P23, female, professional end-user]. 
Table 1. Experienced barriers in the UCD process of telecare products and services

\begin{tabular}{|c|c|c|c|c|c|c|}
\hline \multirow[t]{2}{*}{ Theme } & \multirow[t]{2}{*}{ Barriers } & \multicolumn{5}{|c|}{ Participant groups ${ }^{*}$} \\
\hline & & EU & PU & EN & MA & RE \\
\hline $\begin{array}{l}\text { Creating a } \\
\text { development team }\end{array}$ & $\begin{array}{l}\text { Team members come from different } \\
\text { backgrounds and therefore do not speak the } \\
\text { same 'language' (use different terminology). }\end{array}$ & $x$ & $x$ & $x$ & $x$ & $\mathrm{X}$ \\
\hline $\begin{array}{l}\text { Expectations } \\
\text { regarding } \\
\text { responsibilities and } \\
\text { roles }\end{array}$ & $\begin{array}{l}\text { Team members have different implicit } \\
\text { expectations regarding project management, } \\
\text { tasks of team members, and delivery of } \\
\text { content (especially at the start of the project). }\end{array}$ & $x$ & $x$ & $x$ & $x$ & $\mathrm{x}$ \\
\hline \multirow{2}{*}{$\begin{array}{l}\text { Translation of user } \\
\text { requirements into } \\
\text { technical } \\
\text { requirements }\end{array}$} & $\begin{array}{l}\text { Prioritizing user-requirements with various } \\
\text { stakeholders is more time consuming than } \\
\text { expected. }\end{array}$ & & & $\mathrm{X}$ & $x$ & $\mathrm{X}$ \\
\hline & $\begin{array}{l}\text { Iterative adaptations of user-requirements } \\
\text { (especially in later stages) place a serious } \\
\text { strain on the budget/time of the project. }\end{array}$ & & & $x$ & $x$ & $x$ \\
\hline \multirow[t]{3}{*}{ Technical challenges } & $\begin{array}{l}\text { Integration of different technologies or } \\
\text { platforms into } 1 \text { telecare service is difficult } \\
\text { (but necessary). }\end{array}$ & $x$ & $x$ & $\mathrm{X}$ & $x$ & $x$ \\
\hline & $\begin{array}{l}\text { Time allowed for telecare development is } \\
\text { short in subsidized projects which causes } \\
\text { problems with robustness in the real life } \\
\text { setting and large scale evaluation research. }\end{array}$ & & & & & $\mathrm{x}$ \\
\hline & $\begin{array}{l}\text { The commercial market is developing similar } \\
\text { products at a rapid pace which makes it } \\
\text { difficult to keep up. }\end{array}$ & $x$ & & $\mathrm{X}$ & $x$ & $\mathrm{x}$ \\
\hline \multirow[t]{3}{*}{ Evaluation } & $\begin{array}{l}\text { Members of the development team are not } \\
\text { the best evaluators because they find their } \\
\text { own 'work-around' to avoid bugs (unaware). }\end{array}$ & & & $x$ & & $\mathrm{X}$ \\
\hline & $\begin{array}{l}\text { Recruitment of patients and professionals for } \\
\text { the longitudinal evaluation of the developed } \\
\text { telecare products/services is time-consuming. }\end{array}$ & $x$ & $x$ & $x$ & $x$ & $\mathrm{X}$ \\
\hline & $\begin{array}{l}\text { Too many different projects/devices are } \\
\text { offered to potential end-users at the same } \\
\text { time. }\end{array}$ & & & & $x$ & $x$ \\
\hline Valorization & $\begin{array}{l}\text { Different partners/companies who are } \\
\text { involved have different ideas about what } \\
\text { makes a good business case. }\end{array}$ & & & & $x$ & \\
\hline
\end{tabular}

EU=End-user, $\mathrm{PU}=$ Professional end-user, EN=Engineer, $\mathrm{MA}=$ Manager, $\mathrm{RE}=$ Researcher. 


\section{Chapter 9}

Table 2. Experienced facilitators in the UCD process of telecare products and services

\begin{tabular}{|c|c|c|c|c|c|c|}
\hline \multirow[t]{2}{*}{ Theme } & \multirow[t]{2}{*}{ Facilitators } & \multicolumn{5}{|c|}{ Participant groups ${ }^{*}$} \\
\hline & & EU & PU & EN & MA & RE \\
\hline \multirow[t]{5}{*}{$\begin{array}{l}\text { Creating a } \\
\text { development team }\end{array}$} & $\begin{array}{l}\text { Team members recognize their } \\
\text { complementary knowledge and skills, which } \\
\text { creates a team spirit. }\end{array}$ & $x$ & $x$ & $x$ & $x$ & $x$ \\
\hline & $\begin{array}{l}\text { Team members agree that end-users should } \\
\text { be involved in the development team from } \\
\text { the beginning of the development process. }\end{array}$ & $x$ & $x$ & $x$ & $x$ & $x$ \\
\hline & $\begin{array}{l}\text { Project leaders and managers advocate that } \\
\text { input of all team members should be treated } \\
\text { as equal. }\end{array}$ & $x$ & & & & \\
\hline & $\begin{array}{l}\text { Researchers report back to end-user } \\
\text { representatives about why their advice was } \\
\text { followed or not. }\end{array}$ & $x$ & & & & \\
\hline & $\begin{array}{l}\text { Researcher visits team members at } \\
\text { home/work (when team meetings are not } \\
\text { possible due to differences in schedules). }\end{array}$ & $x$ & $x$ & $x$ & & \\
\hline $\begin{array}{l}\text { Expectations } \\
\text { regarding } \\
\text { responsibilities and } \\
\text { roles }\end{array}$ & $\begin{array}{l}\text { Team members voice expectations at the } \\
\text { start of the project to prevent } \\
\text { miscommunication at a later stage (but this } \\
\text { may be difficult due to the fact that many } \\
\text { expectations are implicit). }\end{array}$ & $x$ & $x$ & $x$ & $x$ & $x$ \\
\hline $\begin{array}{l}\text { Translation of user } \\
\text { requirements into } \\
\text { technical } \\
\text { requirements }\end{array}$ & $\begin{array}{l}\text { Engineers help researchers to translate user- } \\
\text { requirements into technical requirements to } \\
\text { speed up this process. }\end{array}$ & & & $x$ & $x$ & $x$ \\
\hline \multirow[t]{2}{*}{ Technical challenges } & $\begin{array}{l}\text { Researchers should take enough time to } \\
\text { conduct small scale usability tests and pilot } \\
\text { studies before moving to large trials to } \\
\text { improve technical functioning and robustness. }\end{array}$ & & & & & $x$ \\
\hline & $\begin{array}{l}\text { Products/services developed in the projects } \\
\text { are easier to integrate in care processes } \\
\text { compared to off-the-shelf products. }\end{array}$ & $x$ & $x$ & $x$ & $x$ & $x$ \\
\hline
\end{tabular}


Table 2 continued. Experienced facilitators in the UCD process of telecare products and services

\begin{tabular}{|c|c|c|c|c|c|c|}
\hline \multirow[t]{2}{*}{ Theme } & \multirow[t]{2}{*}{ Facilitators } & \multicolumn{5}{|c|}{ Participant groups } \\
\hline & & EU & PU & EN & MA & RE \\
\hline \multirow[t]{3}{*}{ Evaluation } & $\begin{array}{l}\text { Members of the development team evaluate } \\
\text { prototypes in lab to identify bugs and/or gain } \\
\text { insight into experiences with the } \\
\text { products/services. }\end{array}$ & $x$ & & $x$ & & $\mathrm{x}$ \\
\hline & $\begin{array}{l}\text { Care professionals receive reimbursement for the } \\
\text { increased workload that comes with participating } \\
\text { in an evaluation study. }\end{array}$ & & $x$ & & & $\mathrm{X}$ \\
\hline & $\begin{array}{l}\text { Study participants can be recruited via the } \\
\text { network of the members of the development } \\
\text { team, especially via patient/elderly } \\
\text { representatives. }\end{array}$ & $x$ & & & & $\mathrm{X}$ \\
\hline Valorization & $\begin{array}{l}\text { Allocate part of the budget to the development } \\
\text { of a business case and start with this at the } \\
\text { beginning of the project. }\end{array}$ & & & $x$ & $x$ & \\
\hline
\end{tabular}

$\mathrm{EU}=$ End-user, $\mathrm{PU}=$ Professional end-user, EN=Engineer, $\mathrm{MA}=$ Manager, RE=Researcher.

Multidisciplinary collaboration was positively influenced by the fact that patients and care professionals were involved and recognized as members of the development teams from the start. When managers or supervisors advocated that the input of all members should be treated as equal, this facilitated co-creation and UCD, according to end-users. Furthermore, end-users indicated that they appreciated it when the researcher reported back to them about which parts of their advice were followed and which were not. According to some, this feedback was more important than actually following their advice because it made them feel appreciated as a team member:

I did have the feeling that, the things that we put forward, that they (the researchers) did something with that. And sometimes they (the researchers) just said: "listen, we did not choose this or we did choose this". And I think that is important...Feedback is very important. For example when you put something forward and after that you don't hear anything. Then you don't know whether something was done with it at all or whether it was taken seriously. And then it is also difficult to be in that process together. [P9, female, end-user]

Finally, the organizational aspect of working in multidisciplinary teams was a challenge in most projects. Since most members had different schedules, it was often difficult to 
organize meetings with the whole team. Submeetings were a satisfactory solution according to most. Elderly representatives, care professionals, and engineers indicated that they appreciated the flexible attitude of researchers who visited them at home or at work to offer additional information/explanation or an update.

\section{Implicit expectations regarding responsibilities and roles}

Participants indicated that during the project they discovered differences in expectations regarding responsibilities and roles between members of the development team. Examples of issues where expectations differed between members of the development team were who the project manager is, what the tasks are of different team members, and who delivers content of the services that are being developed. Participants seemed to agree that clearly expressing and communicating expectations at the start of the project would help to ensure that the entire development team was on the same page, which would probably optimize multidisciplinary collaboration. However, some participants experienced that voicing these expectations could be difficult since they are often implicit:

Look, in fact you start this project with an open mind and you create the expectations along the way. Because we work in a certain way: iterative design. We take it a step further every time. So, at the beginning of the project you actually do not know where you will end up. You work towards the end gradually. So, you actually do not have very detailed expectations before the start. [P15, male, engineer]

I expected more vision, more strategy, a clearer picture about this (concept of the project) at the start of the project. Well that disappointed me. That fit with the patient group was created along the way. I would have liked to feed of the available knowledge of the university. But that was disappointing. [P16, male, manager]

I think that we had a very large part in delivering content (for the telecare product and service)... Of course, you have to partly develop the intervention. But this detailed, no I didn't expect that I would do that. I expected another share of the company and thought that was disappointing in hindsight. [P2, female, researcher]

\section{Translating user requirements into technical requirements}

Participants experienced that collecting user requirements and discussing with the development team which requirements deserved priority took longer than expected. One reason for this is that reaching a consensus with a team consisting of members with different backgrounds can be quite challenging.

Another time-consuming part of the process was translating user requirements into the very detailed technical requirements that engineers need to be able to develop the first 
prototypes. Help from the engineers in this translation appeared to be crucial since most researchers did not have a technical background and were not familiar with the technical language that is used to describe technical requirements: "In the concept phase, everything seems possible. But when you have to specify things until the final feedback message, it is very difficult. And it takes a lot of time to think these things through" [P5, female, researcher] and

The researchers are more of less forced into a role in which they have to think along in a technical manner. And they are not used to that, it is not their job. And that creates a certain type of tension. Because they are forced to think about (technical) things that they had not thought about before [P18, male, engineer]

Finally, the identified user requirements evolved during the project as a result of the iterative nature of the UCD processes. Members of the development team agreed that these iterations were necessary to ensure that the developed products and services meet the requirements of the end-users (in the best possible way). Especially engineers and managers pointed out that they tried to be as flexible as possible in incorporating the new and additional requirements in new prototypes because they recognized the importance of the iterations. However, at a certain point, this flexibility ends because deadlines have to be met and personnel will be deployed in other projects after these deadlines:

It is good to get feedback from your target group but it is important to stay in control...I had the feeling that there were too many changes in response to feedback of the target group...At a certain time we froze the specifications and started working with that. [P18, male, engineer]

We had a lot of backwards and forwards and changing. What might be a relatively simple change for an end-user, for instance the change of a bar from one place to another, could take a significant amount of time or require a major change in the way a software program was running. [P19, male, manager]

\section{Technical challenges}

The technical challenges that the development teams were faced with related to the integration of different technologies or platforms, robustness of technology in a real-life setting, and rapid pace of developments on the commercial market.

Integration of different technologies or platforms

The telecare products and services that were developed during the projects all required the integration of various technological components (e.g. integration of a sensor with an application on a mobile device and an online database). Technical and software engineers, and to a lesser extent also other participants, experienced that the integration of these 
components was often more difficult than expected for several reasons. First, engineers experienced that the components sometimes have their own "language" and specifications (e.g. hardware vs software), which makes integration more complicated. Second, the input for the system as a whole, and input regarding the integration of the developed technology in care, was provided by different members of the development team. All team members recognized that integrating the input from all these parties into the products and services can be a real challenge as it does not always match. Third, in some cases the different components are not finished at the same time. This can seriously delay the progress of projects.

Every company developed their part (of the technology)... We develop something nice but then it does not fit. And then the other company develops something nice and our system cannot handle it. And then the researchers provide a new part of the content and then we think: where can we put this? That was difficult to work with sometimes. We resolved it in the end but I think things could have run more efficient in some areas. [P17, male, engineer]

Robustness of telecare products in real-life setting

Researchers experienced that there was often not enough time and budget for the development of the telecare products because funding bodies assume that the technology already exists. Technology development in these projects appeared to be more challenging since the health care setting was taken into consideration, which is often not the case in existing off-the-shelf telecare products. As a result, the technology was sometimes not "mature" enough when projects moved to large trials or evaluation studies, which caused problems regarding robustness. All members of the development teams agreed that robustness is an absolute precondition for the uptake of telecare products and services in practice. Taking enough time for conducting in-lab usability tests and pilot studies before moving to real life settings might prevent problems concerning robustness in large trials according to researchers:

Funding agencies for research often assume that the technologies already exist. However, there is hardly any time for the development of the technology. But we know from experience that this is very difficult and time consuming. We should not jump to large evaluation studies too fast but first do pilots and usability evaluations before we start with the big works. That is something that is often underestimated. [P6, male, researcher]

Developments on the commercial market

Many participants experienced that the commercial market sets the standard for products developed in the R\&D projects; the user requirements for the telecare products and services are often influenced by what is already on the market. According to members of 
the development teams, it is nearly impossible to keep up with the rapid pace at which the commercial market is developing. The reason why the development teams chose to create something new instead of buying off-the-shelf products is that newly developed products can be adapted to fit the health care context and end-user needs.

\section{Evaluation}

In all projects, the developed devices were tested in the lab and in real-life. Issues that relate to the evaluation of the devices in both contexts are described below.

\section{Evaluation in lab}

The developed products were first tested extensively by the members of the development team. Researchers who tested the products indicated that this was not only important for identifying bugs and errors but that it also provided better insight into experiences expected with end-users of the product. However, researchers and engineers indicated that eventually they were less able to identify bugs, as they unconsciously created their own "work-arounds": "Once you actually use it (the technology) yourself than you really bond with it so to speak. And then you become even more alert to improvements" [P2, female, researcher].

\section{Evaluation in real-life}

Participants experienced that the recruitment of patients and professionals who were willing to evaluate the developed products and services was a true bottleneck in the planning of the projects. A possible explanation for this problem, according to the participants, was that usually care professionals have to perform the activities for such R\&D projects (e.g. providing input for requirements or recruitment of patients) on top of their regular activities, which causes an increased workload. In some projects, the professionals did not get reimbursed for recruiting participants. Another problem described was that there were too many different (telecare) research projects in one area at the same time. Possible solutions for these problems, employed during the R\&D projects, were reimbursing care professionals, recruiting participants via the (in)formal network of members of the development team, or organizing meetings with professionals who participate in evaluation studies to increase their awareness and create commitment to the project: "Having patience is very important in research, especially when it concerns including patients in your study. You will come across barriers, it is just like hurdling in a sense" [P24, male, professional end-user] and

Convincing people who have to do it alongside their job. They are doctors, and this comes on top of it...Yes, I think that people are bombarded with something new every time: another technique that would be nice. That makes it pretty difficult. [P14, male, manager] 


\section{Valorization}

Once the effects of the developed telecare products and services have been evaluated, the subsidized R\&D projects will end. Members of all development teams emphasized the importance of scaling up, and valorization of, the developed telecare products and services: "That is one of the problems; it will have to happen on a larger scale in the future. For that you do need a business model. Just doing projects for the sake of doing projects and doing something else when the funding ends does not make sense" [P22, male, manager].

Managers from the R\&D companies and some of the technical engineers indicated that it was too bad that there was little time or budget to focus on the development of a proper business model during the projects. The fact that different companies and organizations are often involved in the delivery of one telecare product and/or service is an important issue in the development of such business models and therefore a concern to most of the managers:

At the basis, you have to start thinking who will be the owner and who will make money on this...Somehow you have to figure out a model that covers the costs and leaves something extra because we are not the type of entrepreneur that keeps investing in something that does not make any money. So I do see possibilities, but it has not been defined clearly yet. [P14, male, manager]

Elderly people, chronic patients, care professionals, and researchers also indicated that they had concerns regarding the upscaling of the developed products and services. Their concerns focused on questions such as who would pay and sell the products/services, how much they should cost, and how roles and responsibilities of patients and professionals would change when telecare products and services were implemented in practice: "I am afraid that it will not be financially viable. Because physiotherapy is not included in the basic health insurance which makes your target group very small" [P7, male, end-user] and

I think that we still have to think about that, make agreements about when you reply or do not reply (to the patient after a certain signal from the telecare product), better agreements on how you communicate with the patients (using the new telecare services). [P25, male, professional end-user]

\section{Discussion}

\section{Principal results and comparison to previous research}

The current study provides insight into how members of multidisciplinary development teams experience the UCD process of telecare products and services. Several barriers and 
facilitating factors were experienced that can influence the UCD process according to different members of four multidisciplinary development teams. Most barriers that were identified were in line with previous research. ${ }^{14,24,25}$ Some of these factors were reported by participants from different backgrounds whereas others seemed to be more specific for a group of participants who share a similar background or role in the UCD process. Furthermore, this study also provided insight into how members of development teams tried to deal with barriers that they encountered and which actions they undertook to facilitate the development process.

All participants experienced that differences in background can cause a language gap between members of the multidisciplinary development team that can negatively affect the development process. Other researchers and designers who have recognized this barrier recommend the use of personas, scenarios, mock-ups, or prototypes to reduce the language gap. ${ }^{13,21,30,31}$ These techniques were also used during the R\&D projects that were the focus of this study. In addition, this study revealed that the gap between members of a development team can be bridged by emphasizing the way that team members can complement each other through their differences, by principal investigators who explicitly advocate equality of team members' input, and by providing feedback to (professional) end-users regarding their input from the start onwards, throughout the development process.

Participants with different backgrounds all recognized that managing expectations regarding responsibilities and roles is a critical factor during the UCD of telecare products and services. Previous research by Gasson suggests that managing expectations regarding work roles and tasks is a critical issue in any UCD process. ${ }^{32}$ The results of the present study revealed that although all members of the development team had read and agreed on the same project plan and UCD methodology to be used, differences in expectations still existed. Goodman-Dean et al. explain that despite agreeing on the same basic nature of the UCD process, differences can still exist between the approaches of the team members. ${ }^{33}$ Explicitly voicing detailed expectations at the start of the development process might prevent delay later in the project. However, participants of the current study recognized that this might be difficult to do. Previous studies have emphasized that project management should identify and allocate responsibilities, tasks, and roles. ${ }^{16,32,34}$ Project managers should facilitate the UCD process in this way without being overly prescriptive or bureaucratic since that might impede the creative nature of the design process. $^{34}$

The results of this study confirmed that time and budget related issues seemed to play an important role during different phases of the UCD process. The main time constraining factor reported in previous studies is that working with users in an iterative way takes too much time, regardless of the methodology that is used. ${ }^{13,14,34,35}$ A literature review by Shah et al suggests that the lack of available end-users is a barrier during the UCD 
process. ${ }^{14}$ The findings of the current study are not entirely in line with this since recruiting users to be involved in the development team and to test prototypes during the iterative UCD process seemed a lesser barrier compared to recruiting participant for longitudinal research. A possible explanation for this could be that for the prior UCD activities, participants were recruited via the (informal) network of end-users and professional end-users who were part of the development team. Through this, the involvement of (professional) end-users from early stages onwards facilitated the progress of the projects. Other studies that have been conducted previously did not indicate which factors were considered too time-consuming. The current study provides insight into causes of time-related barriers as experienced by different members of multidisciplinary development teams. Researchers and engineers were the groups of participants who most frequently reported on time-related barriers and how they tried to deal with them.

A critical factor reported on by all managers is the development of a good business model. Results of this study revealed that budget should be allocated to the development of a business case and that the stakeholders involved should discuss business modeling issues at an early stage. Previous studies have emphasized that business model development should run in parallel with the UCD of eHealth technologies because it contributes to the development of such technologies. ${ }^{16,36}$

\section{Strengths and limitations}

The scope of the four R\&D projects included in this study varied from general services related to care and well-being for elderly people living in the community to specific services for severely ill patients who suffer from cancer (treatment) pain. The variety of projects included increases the generalizability of the findings. Furthermore, all core members of the multidisciplinary development teams were interviewed in order to incorporate all points of view in our analyses. This is a strength of the study design since previous studies aimed at identifying barriers of UCD processes often focused merely on the perspective of the designers or developers. ${ }^{13,33,36}$ Including participants from different backgrounds created triangulation of data resources, which increased trustworthiness of the findings. Furthermore, the member check revealed that participants agreed with the experienced barriers and facilitators that were identified.

When interpreting the results of this study, some limitations of the study design should be taken into account. First, in the interviews participants reflected on development processes that started 1-2 years ago, which might have caused some degree of memory bias. However, reflecting on the development process at later stages might also have benefits over interviewing participants in the middle of the development process. In the latter situation, the answers of participants may be influenced by the stage the project is in at the time of the interview. Second, participants were asked to reflect critically upon development processes in which they were involved and consequently they had to reflect 
on their own actions and the actions of their team members which could have been a sensitive topic. In order to limit this sensitivity, a researcher who was not part of the participant's development team conducted the interview. However, it cannot be ensured that all barriers and facilitators were reported to the interviewers. Third, the authors of this paper had a double role in this study since they interviewed the participants who were not researchers, but they were also core members of the development teams (and hence were interviewed themselves). The involvement and experiences of the researchers with UCD of telecare products and services could have influenced data collection and/or analyses. We aimed to minimize these influences by letting researchers interview only participants who were involved in different $R \& D$ projects than they were, by developing a topic list for the interviews that was used by all interviewers throughout the study, and by developing the coding scheme with 2 researchers. Finally, data from the interviews with the researchers and from the interviews with other team members were treated as equal in the analyses. This is not necessarily a limitation but it might be considered a notable feature of the study design. The main reason for this novel and somewhat unusual approach was that the researchers themselves had experienced and influenced the development process just as much as other members of the development team. Not interviewing the researchers could have resulted in missing barriers and facilitators that they themselves experienced.

\section{Conclusion}

Many similarities seem to exist between the barriers and facilitators experienced by members of multidisciplinary development teams during UCD of telecare products and services. However, differences in experiences between team members with different backgrounds exist as well. Insights into these similarities and differences can improve understanding between team members from different backgrounds, which can optimize collaboration during the development of telecare products and services.

\section{References}

1. United Nations, Department of Economic and Social Affairs, Population Division. World Population Ageing 2009. New York: United Nations, 2009.

2. Wiener JM, Tilly J. Population ageing in the United States of America: implications for public programmes. Int J Epidemiol. 2002;31:766-781.

3. Howse K. Healthy ageing: the role of health care services. Perspect Public Health. 2012;132:171-177. 
4. McLean S, Sheikh A, Cresswell K, Nurmatov U, Mukherjee M, Hemmi A, Pagliari C. The impact of telehealthcare on the quality and safety of care: a systematic overview. PLoS One. 2013;8:e71238.

5. Eland-de Kok P, van Os-Medendorp H, Vergouwe-Meijer A, Bruijnzeel-Koomen C, Ros W. A systematic review of the effects of e-health on chronically ill patients. J Clin Nurs. 2011;20:2997-3010.

6. Kreps GL, Neuhauser L. New directions in eHealth communication: opportunities and challenges. Pat Educ Couns. 2010;78:329-336.

7. Botsis $T$, Hartvigsen $G$. Current status and future perspectives in telecare for elderly people suffering from chronic diseases. J Telemed Telecare. 2008;14:195-203.

8. Koch S, Hagglund M. Health informatics and the delivery of care to older people. Maturitas. 2009;63:195-199.

9. Broens TH, Huis in't Veld RM, Vollenbroek-Hutten MM, Hermens HJ, van Halteren AT, Nieuwenhuis LJ. Determinants of successful telemedicine implementations: a literature study. J Telemed Telecare. 2007;13:303-309.

10. Pagliari C. Design and evaluation in eHealth: challenges and implications for an interdisciplinary field. J Med Internet Res. 2007;9:e15.

11. Teixeira L, Ferreira C, Sousa Santos B. User-centered requirements engineering in health information systems: a study in the hemophilia field. Comput Methods Programs Biomed. 2012;106:160-174.

12. Heeks R. Health information systems; failure, success and improvisation. Int J Med Inform. 2006;75:125-137.

13. Kujala S. User involvement: a review of the benefits and challenges. Behaviour \& Information Technology. 2003;22:1-16.

14. Shah SG, Robinson I. Benefits of and barriers to involving users in medical device technology development and evaluation. Int J Technol Assess Health Care. 2007;23:131-137.

15. McGee-Lennon M, Wolters M, Clark J. User-centered design of technologies to support care at home. In: Turner KJ, editor. Advances in home care technologies. Amsterdam: IOS Press; 2012:138-161.

16. Van Gemert-Pijnen JEWC, Nijland N, Van Limburg M,Ossebaard HC, Kelders SM, Eysenbach G, Seydell ER. A holistic framework to improve the uptake and impact of ehealth technologies. J Med Internet Res. 2011;13:e111.

17. De Vito Dabbs A, Myers BA, McCurry KR, Dunbar-Jacobs J, Hawkins RP, Begey A, Dew MA. User-centered design and interactive health technologies for patients. Comput Inform Nurs. 2009;27:175-183.

18. De Rouck S, Jacobs A, Leys M. A methodology for shifting the focus of e-health support design onto user needs. Intern J Med Inform. 2008;77:589-601. 
19. Shah SG, Robinson I, AlShawi S. Developing medical device technologies from users' perspectives: a theoretical framework for involving users in the development process. Int J Technol Assess Health Care. 2009;25:514-531.

20. Poulson D, Ahby M, Richardson S. Userfit: a practical handbook on user-centered design for assistive technology. Brussels: ECSC-EC-EAEC; 1996.

21. Huis in 't Veld R, Widya IA, Bults RGA, Sandjö L, Hermens HJ, Vollenbroek-Hutten MMR. A scenario guideline for designing new teletreatments: a multidisciplinary approach. J Telemed Telecare. 2010;16:302-307.

22. Abascal J, Arrue M, Garay N, Tomás J. USERfit tool: a tool to facilitate design for all. In: Univeral Access: Theoretical Perspectives, Practice, and experience. Berlin: Springer; 2002 Presented at $7^{\text {th }}$ ERCIM International Conference on User Interfaces for All; October 2002; Paris, France.

23. Gulliksen J, Goransson B, Boivie I, Blomkvist S, Persson J, ASA Cajander. Key principles for user-centered systems design. Beh \& Inform Tech. 2003;22:379-409.

24. Bridgelal RM, Grocott PR, Weir HC. Issues and challenges of involving users in medical device development. Health Expect. 2008;11:63-71.

25. Martin JL, Barnett J. Integrating the results of user research into medical device development: insights from a case study. BMC Med Inform Decis Mak. 2012;12:74.

26. Van der Weegen S, Verwey R, Spreeuwenberg M, Tange $H$, Van der Weijden T, De Witte $\mathrm{L}$. The development of a mobile monitoring and feedback tool to stimulate physical activity of people with a chronic disease in primary care: a user-centered design. JMIR Mhealth Uhealth. 2013;1:e8.

27. Verwey R, Van der Weegen S, Tange H, Spreeuwenberg M, Van der Weijden T, De Witte L. Get moving: the practice nurse is watching you! A case study of the usercentred design process and testing of a web-based coaching system to stimulate the physical activity of chronically ill patients in primary care. Inform Prim Care. 2012;20:289-298.

28. Verwey $R$, van der Weegen $S$, Spreeuwenberg $M$, Tange $H$, van der Weijden $T$, de Witte L. A pilot study of a tool to stimulate physical activity in patients with COPD or type 2 diabetes in primary care. Journal of Telemedicine and Telecare. 2014;20:2934.

29. Vermeulen J, Neyens JCL, Spreeuwenberg MD, Van Rossum E, Sipers W, Habets H, et al. User-centered development and testing of a monitoring system that provides feedback regarding physical functioning to elderly people. Patient Prefer Adherence. 2013;7:843-854.

30. Abras C, Maloney-Krichmar D, Preece J. User-centered design. In: Bainbridge W, editor. Encyclopedia of human-computer interaction. Thousand Oaks: Sage Publications; 2004:763-768. 


\section{Chapter 9}

31. Cooper A, Reimann R, Cronin D. About Face 3: the essentials of interaction design. Indianapolis: Wiley Publishing; 2007.

32. Gasson S. The reality of user-centered design. Journal of End User Computing. 1999;4:3-13.

33. Goodman-Dean J, Langdon P, Clarkson J. Key influences on the user-centered design process. J Eng Design. 2013;21:345-373.

34. Chamberlain S, Sharp $H$, Maiden N. Towards a framework for integrating agile development and user-centred design. In: Abrahamsson P, Marchesi M, Succi G, editors. Extreme programming and agile processes in software engineering. Berlin Heidelberg: Springer; 2006: 143-153.

35. Vredenburg K, Mao JY, Smith PW, Carey T. A survey of user-centered design practice. In: Proceedings of the SIGCHI Conference on Human Factors in Computing Systems. New York: ACM;2002:471-478.

36. Van Limburg M, van Gemert-Pijnen J, Nijland N, Ossebaard HC, Hendrix R, Seydel ER. Why business modeling is crucial in the development of eHealth technologies. J Med Internet Res. 2011;13:e124. 
Appendix 1. Description of four R\&D projects developing telecare products and services

\begin{tabular}{|c|c|}
\hline \multicolumn{2}{|r|}{ Project 1: It's LiFe! I $^{26-28}$} \\
\hline Aim of the project & $\begin{array}{l}\text { Development and evaluation of a monitoring and feedback tool to } \\
\text { support self-management through lifestyle feedback for patients with } \\
\text { chronic diseases in primary care. }\end{array}$ \\
\hline Intended end users & $\begin{array}{l}\text { - Diabetes and COPD patients } \\
\text { - Practice nurses }\end{array}$ \\
\hline $\begin{array}{l}\text { Telecare products and } \\
\text { services developed }\end{array}$ & $\begin{array}{l}\text { The system measures physical activity with an activity monitoring sensor } \\
\text { and gives feedback and dialogue sessions, based on a personal activity } \\
\text { goal, on a smartphone-based application and website. The goal is set in } \\
\text { minutes a day by the care professional together with the patient. Care } \\
\text { professionals can track the progress of their patients via a web-based } \\
\text { monitoring system, in which the data from patients appears } \\
\text { automatically. }\end{array}$ \\
\hline Intended outcome & Increased daily physical activity levels. \\
\hline $\begin{array}{l}\text { Involved stakeholders } \\
\text { in UCD process }\end{array}$ & $\begin{array}{l}\text { - } 6 \text { researchers with different backgrounds (health sciences, medicine, } \\
\text { nursing, movement sciences, and psychology). } \\
\text { - } 8 \text { technical experts ( } 2 \text { technical project leaders and } 6 \text { engineers). } \\
\text { - } 2 \text { patient representatives with chronic conditions. }\end{array}$ \\
\hline $\begin{array}{l}\text { Phases of UCD process } \\
\text { and methods used }\end{array}$ & $\begin{array}{l}\text { Four phases: } \\
\text { 1) Identify end-users and context } \\
\text { - Literature search to identify users and context. } \\
\text { 2) Concept development } \\
\text { - Literature and experts consultation to set up a use case. } \\
\text { 3) Tool (Re) design } \\
\text { - Interviews with } 15 \text { patients and } 16 \text { care professionals/experts } \\
\text { - to identify user requirements. } \\
\text { - } \quad \text { recus group interviews with patients to check user } \\
\text { 4) Evaluation of the prototype in lab and in real-life. } \\
\text { - Heuristic evaluation. } \\
\text { - In lab usability test of smartphone-based application by patients } \\
\text { - } \quad \text { with diabetes or chronic obstructive pulmonary disease (COPD). } \\
\text { - } \quad \text { nilot-study in primary care setting. }\end{array}$ \\
\hline
\end{tabular}


Project 2: Self-management support for patients with cancer pain

Aim of the project

Intended end users

Telecare products and services developed

Intended outcome

Involved stakeholders

in UCD process

Phases of UCD process and methods used
Development and evaluation of a technology supported self-management intervention for outpatients with cancer (treatment) related pain.

- Patients with cancer pain

- Nurses specialized in pain and palliative care

The intervention includes an iPad application for patients that is connected to a web application for nurses. Patients monitor their pain, symptoms and medication use daily. Based on these registrations they are provided with graphical feedback information and educational sessions. Nurses remotely keep track on patient data and provide patients with advice, while collaborating with the treating physician and pharmacist.

Lower pain intensity scores and a better quality of life.

- 3 researchers with different backgrounds (health sciences, pain, palliative care, and telecare).

- 3 technical experts (1 designer, 1 software engineer, and 1 specialist in telemedicine).

- 3 care professionals (1 pain/palliative care specialist and 2 pain/palliative care nurses).

Three iterative phases: In each of these phases a sequence of five iterative steps was performed: research, ideas, prototyping, evaluation and documentation. After the three phases, usability and feasibility of the telecare products and services were evaluated by patients and nurses in an in-lab usability test and in a pilot study.

1) Exploration of context

- Document analyses (guidelines, case reports) to explore patient characteristics and usual care in the outpatient setting.

- $\quad$ Semi-structured interviews (10 care professionals, 2 patients) to identify intervention needs.

2) Specification of content

- Document analyses (pain anamnesis protocols, education materials) and 3 consultation sessions with a multidisciplinary palliative care team to provide input for the different intervention components.

3) Organization of care

- Literature review to provide insight into the presentation of information within the application.

- $\quad$ Semi-structured interviews with 4 care professionals to setup the care organization in which the intervention was to be embedded. 
Project 3: Telecommunication technology supporting care and wellbeing

Aim of the project

Development of a telecommunication portal that can assist frail elderly people in independent living.

Intended end users

Telecare products and services developed

Intended outcomes

Involved stakeholders in UCD process

Phases of UCD process and methods used
- $\quad$ Frail community-dwelling elderly people

The telecommunication portal is provided to the users via a touch-screen computer. It integrates several functionalities, such as: access to information and remote communication between the elderly person and their environment (e.g. family, informal caregivers, healthcare and welfare services). It supports frail elderly people in living independently, with social participation in the community, their wellbeing, and asking for healthcare services when necessary.

Increased independence.

- 2 researchers with different backgrounds (health sciences and medical technology).

- 6 technical experts ( 2 technical project leaders and 4 software engineers).

- 4 elderly user representatives and 1 advisor of the representatives.

Seven phases:

1) Identification of end-users

- Literature search and expert consultation to identify users and context.

2) Selection of end-users

- $\quad$ Experts and elderly representatives were consulted.

3) Needs assessment among end-users

- 3 participatory observations with frail elderly persons.

- 14 semi-structured interviews with frail elderly persons.

- Set up of 5 use cases to discuss in focus groups.

- 2 focus group interviews with frail elderly persons.

4) Identification of needs among healthcare and welfare services

- Healthcare and welfare services were consulted to discuss the requirements for the innovation.

5) Development of a prototype and evaluation

- Regular meetings and contact between the researchers, relevant stakeholders (care professionals, representatives of welfare services and elderly representatives) to discuss the requirements for the innovation.

6) Optimization of the prototype and evaluation

- Heuristic evaluation and usability test of prototype by experts and elderly representatives.

7) Evaluation of the effects in real field

- Usability and feasibility test of the prototype in a pilot study. 


\begin{tabular}{|c|c|}
\hline \multicolumn{2}{|r|}{ Project 4: Monitoring of physical frailty in elderly people ${ }^{29}$} \\
\hline Aim of the project & $\begin{array}{l}\text { Development of a monitoring and feedback system that community- } \\
\text { dwelling elderly people can use to monitor indicators of physical } \\
\text { functioning that are predictors of disability. }\end{array}$ \\
\hline Intended end users & - Community-dwelling elderly people \\
\hline $\begin{array}{l}\text { Telecare products and } \\
\text { services developed }\end{array}$ & $\begin{array}{l}\text { The monitoring and feedback system consists of a bathroom scale that } \\
\text { can measure weight and balance, a Grip-ball that can measure grip } \\
\text { strength, and a mobile phone that can measure physical activity using a } \\
\text { built-in accelerometer. All measurements are automatically forwarded to } \\
\text { the mobile phone using Bluetooth. Via the interface of the mobilephone } \\
\text { feedback is provided to the user regarding (changes in) their physical } \\
\text { functioning. Via the mobile phone, the data can be forwarded to a } \\
\text { database that is accessible for care professionals. }\end{array}$ \\
\hline Intended outcome & Increased self-management. \\
\hline $\begin{array}{l}\text { Involved stakeholders } \\
\text { in UCD process }\end{array}$ & $\begin{array}{l}\text { - } 5 \text { researchers with different backgrounds (medicine, psychology, } \\
\text { health sciences, epidemiology, physiotherapy). } \\
\text { - } 4 \text { technical experts ( } 1 \text { technical project leader, } 2 \text { software engineers, } \\
\text { and } 1 \text { web designer). } \\
\text { - } 3 \text { elderly user representatives and } 1 \text { advisor of these representatives. }\end{array}$ \\
\hline
\end{tabular}

Phases of UCD process and methods used
Five phases:

1) Selection of users

- Elderly representatives volunteered to be part of the development team.

2) Analysis of users and their environmental context

- Literature search.

- Four discussion group meetings with care professionals.

3) Identification of user requirements

- Three user-group meetings with elderly representatives and their advisor.

- Workshop with community-dwelling elderly people.

4) Development of a prototype of the interface (and verification with user requirements)

- Verification of first prototype by elderly representatives.

5) Evaluation of the prototype of the interface (and adaptation to user requirements)

- Heuristic evaluation of prototype by experts and non-experts.

- Usability test of prototype in lab via think aloud procedure.

- Usability and feasibility test of prototype in pilot study. 




\section{CHAPTER 10}

General discussion 

The number of frail elderly people is increasing. Frail elderly people are at increased risk for disability since frailty is considered to be a state of pre-disability. A difficulty in offering interventions to community-dwelling elderly people aimed at disability prevention or reduction is to identify people who might benefit most from such programs at a stage that disability is not yet present or still reversible. Current frailty screening methods that are used for identifying community-dwelling elderly people who are eligible for preventive intervention programs are suboptimal and do not facilitate the participation of elderly people in decision making regarding their own health care. The uptake of information and communication technologies that support remote self-monitoring of health conditions, self-management, and the delivery of interventions in health care is increasing. In combination with the growing use of every day technologies such as smartphones, computers, and internet among elderly people, this creates opportunities for the use of technologies in the daily lives of elderly people to support them in their own health behaviors and involve them in the care process.

The main objective of this thesis was to develop and evaluate a self-monitoring and feedback system that can be used by community-dwelling elderly people to gain insight into (changes in) indicators of physical frailty that predict increased risk of disability. Timely and personalized information regarding such indicators could support elderly people in their self-management regarding physical functioning. In order to accomplish this, the predictive value of physical frailty indicators was studied. In addition, the possibility to perform home-based measurements of weight, balance, grip strength, and physical activity in elderly people using innovative, simple technologies was explored. These technologies were integrated into a monitoring and feedback system in close cooperation with elderly people and care providers. The technical performance and usability of the system were evaluated in a pilot study.

In this chapter, the main findings of the research presented in this thesis are discussed and a reflection on some methodological and theoretical issues is provided. Based on the conclusions that can be drawn from this thesis, future directions are presented.

\section{Main findings}

\section{Predictive value of physical frailty indicators}

A systematic review showed that physical frailty indicators predict development and worsening of ADL disability in community-dwelling elderly people (Chapter 2 ). ${ }^{1}$ Slow gait speed and low physical activity are the most powerful predictors followed by weight loss, lower extremity function, balance, and low muscle strength. Monitoring these indicators can support self-management and might be useful for early identification of elderly people who could benefit from an intervention aimed at disability prevention. 
Most studies included in the review had a follow-up of at least three years but 'shortterm' predictive value of these indicators might be more useful for care professionals and elderly people in decision making regarding the uptake of preventive interventions. Once an elderly person is considered to be at risk of developing disability within the next year, action should be taken on the short term to prevent this. A one-year follow-up study regarding the predictive value of self-reported decline in physical frailty indicators (based on the Fried frailty criteria: weight, exhaustion, walking speed, grip strength, and physical activity) revealed that self-reported decline in physical frailty indicators predicts disability development after one year in community-dwelling elderly people (Chapter 3$)^{2}{ }^{2}$ Selfreported decrease in physical activity was the strongest predictor of increased dependence and increased difficulty in performing daily activities.

\section{Validity and reliability of self-monitoring technologies}

Four studies (Chapter 4-7) were conducted to evaluate the validity and reliability of balance measurements conducted with a modified bathroom scale, grip strength measurements conducted with a Grip-ball, and physical activity measurements conducted with a smartphone-based activity monitoring application. These validation studies have revealed that simple self-monitoring technologies can be used to provide valid and reliable estimates of indicators of physical frailty in community-dwelling elderly people.

The first two validation studies focused on measuring balance with a modified bathroom scale (Chapter 4 \& 5). A cross-sectional study in nursing home patients and community-dwelling elderly people revealed that balance scores of the bathroom scale are in line with the results from clinical balance tests conducted by a geriatric physiotherapist. ${ }^{3}$ The bathroom scale confirmed that nursing home patients have poorer balance compared to community-dwelling elderly people, as did the clinical balance tests. Therefore, the bathroom scale seems a useful tool for monitoring balance in elderly people at home. In addition, a six month follow-up study revealed that test-retest reliability of the balance scores of the modified bathroom scale is acceptable.

Furthermore, there was a cross-sectional relation between balance measured by the modified bathroom scale and falls and disability in elderly people. Despite this crosssectional relation, longitudinal data showed that balance scores have no predictive value for falls and might only have limited predictive value for disability development after 6months follow-up.

The third validation study focused on measuring grip strength with a Grip-ball (Chapter 6). A cross-sectional study in which Grip-ball scores were compared to those of the Jamar dynamometer (which is considered the gold standard) in nursing home patients and community-dwelling elderly people revealed that construct validity of the Grip-ball measurements is acceptable and that these measurements are reliable. Furthermore, 
results of this study indicate that the Grip-ball is capable of detecting 'larger' grip strength differences but might have difficulty detecting 'smaller' differences.

The fourth validation study, focused on measuring physical activity with a smartphone that is equipped with an activity monitoring application and a built-in accelerometer (Chapter 7). The results of this study, in which participants monitored their daily physical activity for one week, revealed that there is a high correlation between the amount of activity registered in counts per minute by the smartphone-based application and the ActiGraph (which is considered the gold standard). Classifying each registered minute into four activity intensity categories (sedentary, low, moderate, and high) revealed structural differences between the smartphone and the ActiGraph in elderly people. The smartphone underestimated the number of sedentary minutes and overestimated minutes spent in the light activity intensity category in elderly people.

\section{User-centered development and testing of the monitoring and feedback system}

The modified bathroom scale, Grip-ball, and smartphone were integrated into a monitoring and feedback system in close collaboration with elderly people and care professionals during a User-Centered Design (UCD) process (Chapter 8). This resulted in a mobile interface that provides feedback regarding (changes in) indicators of physical frailty that is easy to understand. A six-week pilot study revealed that elderly people were able to use the system and appreciated the feedback that was provided to them. ${ }^{4}$ The monitoring and feedback system satisfied most needs and preferences of the elderly people and, despite a few technical errors that occurred during the pilot study which annoyed the users and sometimes caused confusion, they considered the system easy-touse which resulted in good adherence to the daily monitoring regimen.

A qualitative study that was conducted to gain insight into experiences of members of multidisciplinary development teams of four different Research \& Development (R\&D) projects during the UCD process of telecare products and services revealed that such multidisciplinary collaborations can be challenging (Chapter 9). Various barriers and facilitators influenced the development process. ${ }^{5}$ Multidisciplinary team members from different backgrounds often experience similar barriers (e.g. different members of the development team speak a 'different language') and facilitators (e.g. team members should voice expectations at the start of the project to prevent miscommunication at a later stage). However, some barriers and facilitators are only experienced by stakeholders who share a similar background (e.g. only managers of R\&D companies experience that differences of opinion about a business case is a barrier and only end-users express that the project manager has an important facilitating role in end-user participation). Insights into these similarities and differences can improve understanding between team members from different backgrounds which optimizes collaboration during the user- 
centered development of telecare products and eHealth applications that support care and wellbeing.

\section{Methodological considerations}

\section{Predicting disability using physical frailty indicators}

The systematic literature review that included 28 prospective cohort studies of high methodological quality revealed that ADL disability in community-dwelling elderly people can be predicted by physical indicators that are related to frailty. Due to large variations in the measurement instruments used for measuring frailty indicators and ADL disability across the 28 studies, no meta-analysis could be conducted which made it difficult to draw firm conclusions regarding the predictive power of the different indicators compared to each other. Therefore, statements regarding strength of the predictive value of the physical frailty indicators were based on the number of studies per indicator that suggested a significantly increased risk of ADL disability. This is a suboptimal method for studying predictive power of different indicators since it does not take the strength of the reported associations (Odds Ratios and Risk Ratios) nor sample sizes of the different studies into account.

Another methodological issue relates to the different operationalizations that are used to define the concept disability. Disability is often defined as experienced difficulty in performing activities in any domain of life. ${ }^{6}$ Some frequently used measurement instruments only distinguish between independence and dependence of a person in conducting daily activities whereas others instruments also take into account the difficulty that a person might have when conducting daily activities independently. Besides that, some instruments include both Activities of Daily Living (ADL) and Instrumental Activities of Daily Living (IADL) when measuring disability whereas others only focus on one of these domains. ${ }^{7-9}$ In our one-year follow-up study regarding predictive value of self-reported physical frailty indicators on disability in daily activities (ADL and IADL combined) disability was operationalized in two ways: increased dependence in daily activities and increased difficulty in daily activities. The latter operationalization might be a more sensitive measure of disability that captures more subtle decreases in the performance of daily activities. The predictive power of various self-reported physical frailty indicators turned out to be similar for both operationalizations of disability. However, this might be different in other study samples with a longer follow-up.

It is difficult to draw conclusions regarding the clinical relevance of decreased ability to perform daily activities that is predicted by a (combination of) physical frailty indicator(s). It is questionable whether increased difficulty in at least one ADL (e.g. taking care of feet and toenails) or increased dependence in at least one IADL (e.g. wash and iron clothes) 
after one-year follow-up are relevant outcomes for elderly people and care professionals. The fact that decreased self-reported physical activity can predict increased risk of such outcomes in community-dwelling elderly people does not automatically call for screening or preventive interventions. This is only justified when elderly persons consider the predicted outcome as relevant or important for themselves in their context. The perceived relevance of increased dependence or difficulty in performing a certain daily activity (e.g. cooking dinner) will differ between elderly people. Proving personalized information regarding changes in indicators of physical functioning at the moment that these changes occur, can possibly support elderly people in making decisions regarding the relevance of such changes and (preventive) actions that they would like to take.

\section{Validity of home-based measurements of physical frailty indicators}

During the validation studies of the modified bathroom scale and the Grip-ball, the measurements with these technologies were conducted under supervision of a researcher and compared to measurements with the gold standard or measurements that are frequently used in care practice. Conducting balance and grip strength measurements under supervision of a researcher can yield different results compared to home-based measurements. Balance scores of the modified bathroom scale could have been higher during the validation studies because participants might be more alert, step onto the bathroom scale quicker, or try to stand very still when the researcher is present, whereas they might not do this when performing self-monitoring measurements alone. Grip strength measurements with the Grip-ball could also have been influenced by the presence and instructions of the researcher explaining participants not to press their fingers into the ball while squeezing it. During unsupervised home-based measurements people might choose not to follow these instructions which could influence the validity of the measurements.

Estimating how and to which extend the validity and reliability of these measurements are influenced by the setting in which they are conducted (research setting vs. homebased setting) is very difficult and the research presented in this thesis does not provide insight into this. Previous research in other fields, for example high blood pressure diagnostics, has shown that measurements performed under supervision of a care professional can yield different results compared to home-based measurements conducted by the patient. ${ }^{10}$ Furthermore, adherence to a measurement instruction might be lower when people conduct the measurements for themselves in the context of selfmanagement instead of for research purposes, or when the researcher is not present to remind people of these instructions. The latter was apparent in the validation study of the activity monitoring application of the smartphone in which participants were instructed to conduct daily home-based physical activity measurements for one week. The number of missing values was high in this study which was a limitation. Reasons for missing values 
were that participants did not wear the phone on $8 \%$ of the test days, some participants wore the phone only for a few hours per day (despite instructions to wear it during the entire day), and technical errors occurred of which the participant and researcher were not aware during the measurement week. These issues are associated with conducting studies in uncontrolled or home-based settings. Still, validation studies in uncontrolled settings might provide more accurate estimates of the validity of home-based measurement devices and might provide useful insight into how home-based measurements should be handled and interpreted. When the main objective is to detect change over time in certain indicators of physical functioning using home-based telemonitoring devices, it might be not so problematic when people do not follow the exact measurement instructions as long as they use the measuring devices in the same way every day.

All validation studies described in this thesis included participants with different levels of physical functioning, namely community-dwelling elderly people and nursing home patients in the studies regarding the modified bathroom scale and the Grip-ball and young adults and community-dwelling elderly people in the study regarding the activity monitoring application of the smartphone. Due to this, conclusions could be drawn regarding validity and reliability in the entire measurement range of the devices. Since the aim of the self-monitoring devices is to detect decline in physical frailty indicators at an early stage, it is important that the validity of the measurements is still acceptable when these indicators change over time.

In the cross-sectional validation study of the modified bathroom scale and the validation study of the activity monitoring application of the smartphone, data of the different groups of participants were analyzed separately. This resulted in a low number of participants in some of the groups which can be considered a limitation of these studies. Furthermore, the longitudinal validation study regarding the modified bathroom scale had a short follow-up period of six months which is a timeframe in which not many falls or changes in disability level occur in elderly people aged 65 years or older. When interpreting the results of the validation studies regarding the modified bathroom scale it should be taken into account that balance scores may have been influenced by cognitive status of the participant because the time it takes a person to step onto the bathroom scale is one of the four parameters that determine the overall balance score. Since cognitive status was not measured in these studies, no conclusions can be drawn regarding this.

\section{Evaluation of the monitoring and feedback system}

The monitoring and feedback system was evaluated firstly during an in-lab usability study and secondly during a six-week pilot study in a real life setting in which a small number of elderly persons aged between 79 and 83 years used the system on a daily basis. The 
experiences of the participants with the daily use of the monitoring and feedback system cannot be generalized due to the small sample size. However, most usability problems were probably identified during the usability test and the pilot study since, according to Nielssen et al., five participants is in general sufficient to identify $80 \%$ of these problems. ${ }^{11}$ Furthermore, the errors that occurred during the pilot-study probably have influenced the experiences of elderly people with the system in a negative way. These errors need to be remedied since an important prerequisite for the uptake of technology in practice is that the self-monitoring and feedback system should operate without interruptions. ${ }^{12}$ Despite these errors, adherence to the daily monitoring regimen was high.

It should be noted that different versions of a validated usability questionnaire were used to test the usability of the interface in lab and to test the usability of the monitoring and feedback system during the pilot study. Items in the questionnaires were to some extent adapted to the functionalities that were being evaluated. This is a common phenomenon in usability tests that are conducted during the iterative development process of new telecare or eHealth technologies since adapting the questions to the functionalities of the technology can provide more specific feedback on which aspects need improvement. For evaluating the usability of final prototypes or market-ready products, it would be more appropriate to use standardized and validated questionnaires such as the Post-Study System Usability Questionnaire (PSSUQ), Software Usability Measurement Inventory (SUMI), or System Usability Scale (SUS) that enable comparison of usability of different technologies. ${ }^{13-15}$

Based on the results of the six-week pilot study, no conclusions can be drawn regarding the long-term acceptance and experienced added value of the monitoring and feedback system according to community-dwelling elderly people. Despite the fact that adherence to the daily monitoring regimen was high during the pilot study, which might suggest high acceptance, six weeks is too short to study this properly since previous research in the field of telecare and eHealth shows that adherence and use of such technologies reduces over time. ${ }^{16}$

Finally, it should be pointed out that the monitoring and feedback system was not implemented and evaluated in a care context, despite the fact that participants of the pilot study were recruited via a geriatrician. During the pilot study, participants were the only persons who received daily feedback messages regarding (changes in) their physical functioning. So, their self-management was supported independent of care professionals. Integrating the self-monitoring and feedback system in a care context is possible since the smartphone can be used to forward the home-based measurements to a database that is accessible for care professionals. Previous research has shown that such 'blended-care' approaches, where telecare or eHealth technologies are embedded in professional care processes, yield more positive results and are more sustainable. ${ }^{17-19}$ However, one could argue that a more 'independent approach to self-management' might be more suitable in 
some situations and in persons who prefer to monitor their own physical functioning without the interference or control of a care professional. Since the research presented in this thesis did not focus on the acceptance and expected added value of the monitoring and feedback system according to care professionals, it remains unclear how the system should be implemented in current care pathways and which groups of elderly people would prefer this or not.

\section{User involvement and stakeholder collaboration in development of care technologies}

Involvement of end-users during the development of telecare technologies can ensure an optimal fit with the needs and preferences of end-users. ${ }^{20-24}$ Qualitative research presented in this thesis revealed that various barriers and facilitators can influence the User-Centered Design (UCD) processes in which different multidisciplinary stakeholders are involved. A strength of the research that was conducted was that opinions and experiences of team members from all different backgrounds were taken into account and treated as equal, whereas previous studies often focused merely on the perspective of the designers or developers. ${ }^{20,21}$ By asking team members to reflect on the UCD processes, they are also invited to reflect on their own functioning and the functioning of their team members which could be a sensitive topic. Despite this, several opportunities for optimizing collaboration between members of development teams during UCD processes were identified.

A challenge in gaining insight into the experienced barriers and facilitators of different multidisciplinary team members is choosing the right moment to study this. Studying user experiences at the end of the UCD process might in some cases be preferred over interviewing participants in the middle of the development process since in the latter situation, the experiences of participants may be influenced by the stage the project is in at that time. Positive or negative situations that occur during the project (e.g. successful pilot studies, difficulty in recruiting participants, or unforeseen difficulties in technology development) influence the experiences that team members have at that time. The overall experience at the end of the project, when positive or negative situations have passed, might be different from the experiences during those situations. However, studying the experiences at the end of the development process might induce memory bias and, more importantly, the development team can no longer use the outcome of the evaluation to optimize their collaboration. This might plead for evaluation and monitoring of experiences of team members during the different phases of the UCD process. Previously developed tools that facilitate monitoring involvement of end-users during research projects, such as the guideline 'monitoring from the perspective of elderly people' (in Dutch: 'monitoring vanuit ouderenperspectief') that was developed by client organization 'Huis voor de Zorg', can be used to ensure that opinions from all involved stakeholders will be taken into account during such evaluations. ${ }^{25}$ 


\section{Theoretical considerations}

\section{Focusing on physical frailty}

The innovative self-monitoring and feedback system that was developed focuses solely on physical aspects of frailty despite the fact that frailty is considered to be a multidimensional concept by many. However, recent research has revealed that the physical component of frailty is most predictive of disability development in communitydwelling elderly people and that the added predictive value of psychological and social components seems limited. ${ }^{26,27}$ Therefore, monitoring changes in physical frailty indicators over time might be most appropriate for early identification of community-dwelling elderly people with increased risk for disability development. Adding psychosocial components would make frequent monitoring more burdensome and might not necessarily provide additional information regarding the risk for disability or the possible need for preventive interventions.

An advantage of the self-monitoring and feedback system over current frailty screening instruments is that it enables community-dwelling elderly people to monitor changes in physical frailty over time. This innovative approach fits better with the dynamic nature of frailty compared to screening questionnaires, checklists, or performance tests that are conducted only at one moment in time. An additional benefit is that elderly people can use the monitoring and feedback system without interference of health care professionals. Continuous self-monitoring can stimulate active involvement of communitydwelling elderly people in their own care process and could facilitate tailoring of preventive interventions to the needs and current level of physical functioning of the individual.

\section{Interpretation of self-monitoring data regarding changes in physical functioning} Monitoring indicators of physical frailty in order to identify community-dwelling elderly people who could benefit from preventive interventions seems useful since low physical activity, slow gait speed, low grip strength, and poor balance predict disability development. Previous research and research presented in this thesis do not provide any insight into the extent to which these indicators have to decrease in order to predict functional decline. An explanation for this is that most previous cohort studies compare participants in the lowest quartile or quintile of physical functioning to the rest of the cohort when studying the predictive value of physical indicators. ${ }^{28-32}$ As a result, cutoff points used for defining low physical activity, slow gait speed, or low grip-strength vary across studies and across settings. Weight loss appears to be an exception since there seems to be some level of agreement that unintentional weight loss larger than $5 \%$ of the total body weight in one month predicts negative health outcomes such as disability. ${ }^{33}$ 
Such clear and generic cutoff points regarding change over time are not available yet for most other physical frailty indicators.

Based on information from cohort and population studies, guidelines for clinical practice have been developed that provide insight into what would be a 'normal', 'desirable', or 'healthy' score on a certain physical performance test for a person in a certain age category. For example: guidelines regarding healthy behavior state that elderly people should be active (at moderate intensity) for at least 150 minutes per week. ${ }^{34}$ Norm tables show that the 'normal' grip strength of a right handed woman aged 74 years old should be between 32.0 and $44.5 \mathrm{Kg}$. ${ }^{35}$ When an elderly person takes longer that 10 seconds to perform a Timed-Up-and-Go test (TUG) this is considered indicative of mobility problems and frailty. ${ }^{36}$ And a balance score below 19 on the Performance Oriented Mobility Assessment (POMA) is considered predictive for falls. ${ }^{37}$ The absolute norms and cutoff points provided in guidelines are useful in clinical practice when single tests are conducted by a care professional with clinical expertise at a certain moment in time to estimate the current level of physical functioning and risk profile of an elderly person. However, these guidelines often do not provide information on what is considered a clinically relevant change in physical functioning. This might facilitate reactive instead of proactive care.

Applying the cutoff points mentioned above when monitoring indicators of physical frailty longitudinally, in order to detect a decrease that might indicate a need for preventive interventions, introduces several difficulties. Firstly, it is difficult to estimate how much an indicator should decrease to justify uptake of an intervention. For example: if an elderly person usually walks 45 minutes per day from Monday to Friday and goes swimming each Saturday morning, and at a certain point in time stops swimming and walks only 30 minutes from Monday to Friday, this might indicate a highly relevant change in activity that increases the risk for disability despite the fact that the norm for healthy physical activity is still met. Intervening at the time that physical activity decreases in this person, might be more useful opposed to waiting another few months until the physical activity norm is no longer met. Secondly, the relevance of a decrease in an indicator of physical frailty might also depend on the current level of functioning of a person. For example: a grip strength decline of $3 \mathrm{Kg}$ in a person with low overall physical functioning who already suffers from mobility problems might be relevant whereas the same decline might be less relevant and not require attention in a person with higher levels of physical functioning. Thirdly, it is difficult to estimate the optimal timeframe for starting preventive interventions since the dynamic nature of frailty entails that indicators that have decreased will, in some cases, increase after a while without intervening. For example: average balance scores of a person might be lower during a week compared to the month before, but two weeks later they might have increased again. In conclusion; regular selfmonitoring of physical frailty indicators requires new ways of interpreting data that is 
related to physical functioning. Furthermore, different cutoff points are needed that suggest at which moment or during which time period a person could benefit most from preventive interventions. Methods and insights from the field of 'big (health care) data' could be used to study this. ${ }^{38}$

\section{Effective disability prevention programs}

Recent studies conducted in the Netherlands, as part of the 'Dutch National Care for the Elderly Program' (in Dutch: 'Nationaal Programma Ouderenzorg'), and other countries reveal that effects of multicomponent interventions aimed at disability prevention are inconsistent in (frail) community-dwelling elderly people. ${ }^{39-43}$ A possible explanation for lack of effect could be that the participants who were included in the trials were not the ones who could benefit most from the interventions. Also, care professionals do not always conduct disability prevention interventions as intended due to complexity, lack of time, or lack of training which results in no or limited effects.

The fact that the current health care system is organized in a way that is mostly symptom-oriented and reactive might complicate the uptake and implementation of preventive interventions in practice. A more proactive approach with a stronger focus on self-management and tailored prevention programs in community-dwelling elderly people might be more effective in preventing disability. However, it remains difficult to draw firm conclusions regarding the (cost)-effectiveness of different components of disability prevention programs. The large heterogeneity among community-dwelling elderly people makes it difficult to decide which intervention components should be offered to which elderly person.

\section{Self-management support in community-dwelling elderly people}

Until recently, self-management support was especially considered relevant for patients with long-term or chronic diseases. As a consequence, definitions of selfmanagement often refer to a patient's ability to manage symptoms, treatment, physical and psychosocial consequences and life style changes inherent to living with a chronic condition. ${ }^{44}$ Nowadays self-management support is also considered relevant for stimulating healthy or preventive behaviors in people who do not (yet) suffer from longterm or chronic diseases. ${ }^{45}$ The developed self-monitoring and feedback system has the potential to support community-dwelling elderly people in their self-management by providing tailored information regarding (changes in) indicators of physical functioning that are related to frailty. Insight of elderly people into their physical (frailty) status can stimulate and facilitate their active role in the decision making process regarding uptake of healthy behaviors or preventive interventions. In addition, the monitoring and feedback system could be used for training purposes, for example by suggesting relevant exercises to improve balance or increase strength, or for providing tailored disability prevention 
programs to community-dwelling elderly people, for example aimed at stimulating a more active lifestyle.

A prerequisite of self-management is that it focuses on problems that are perceived by the person or patient. ${ }^{46,47}$ This introduces a potential difficulty in self-management support programs that are aimed at early risk detection and stimulation of preventive actions, because in those situations self-management behaviors are directed towards a problem that is not present yet but could develop in the future. This might call for different self-management skills or motivation mechanisms compared to traditional selfmanagement that is focused on patients with chronic conditions. Furthermore, the 'partnership' between an elderly person and care professional, that is often referred to as an important aspect of self-management related to chronic conditions, ${ }^{45}$ might be different when self-management is focused on healthy behavior or preventive actions that do not necessarily require contact with a care professional. The need and preference of an elderly person for involvement of care professionals, type of self-management support, and preventive interventions might change over time due to the changing level of frailty and physical functioning.

\section{Future directions}

Based on the research presented in this thesis, the self-monitoring and feedback system was further optimized so that it can be used by community-dwelling elderly people to gain insight into (changes in) indicators of their physical functioning. This could support and facilitate a more proactive approach in early detection of increased risk for disability with a stronger focus on self-management. The system, or its separate parts, can be used by elderly people with different levels of physical functioning as long as they are able to learn how to use the system, which makes it less applicable for elderly people with cognitive deficits.

Based on the current (lack of) knowledge regarding the variability of indicators of physical functioning and the clinical relevance of changes in such indicators, feedback can now only be based on current guidelines of healthy/normal weight, grip strength, and physical activity. Since the modified bathroom scale is a new measuring instrument for which no guidelines are available, feedback regarding balance is currently more difficult to interpret compared to the other indicators that are measured by the self-monitoring system. The disadvantage of using current guidelines to provide feedback is that these guidelines are mostly reactive. They only signal changes in indicators of physical functioning when they are already below the cutoff point for 'healthy' or 'normal' functioning. Due to this, current guidelines might not stimulate a proactive approach. Furthermore, separate guidelines exist for separate indicators of physical functioning 
which does not facilitate interpretation the combination (of changes in) indicators that are present in one person. A possible strength of the self-monitoring and feedback system could be that the combination of four physical frailty indicators is taken into account which makes it possible to detect changes in multiple indicators at once.

Some elderly persons might prefer to use the system independent of professional care processes whereas others, for example those who already have lower physical functioning, might use the system in a care context with support of care professionals. In case of the latter, a database should be developed in which the self-monitoring data of the elderly person can be stored and presented to a care professional. This database should be seamlessly embedded in the care process and should communicate with existing information infrastructures of involved care professionals. Depending on the care context and purpose with which the monitoring and feedback system is being used, the monitoring regimen that elderly persons choose to follow can differ.

The system can be integrated with other care technologies or services that support health and independent living in community-dwelling elderly people. Examples of such technologies could be Ambient Assisted Living (AAL) technologies (e.g. sensors for fall detection or detection of activity), health risk appraisal services, or services that provide interventions that support people in maintaining an active lifestyle or improving physical functioning. Such integrated proactive systems can support independence in older persons. However, in order for such integrated systems to succeed, new business models should be developed in which the costs and benefits of such interventions for different stakeholders are specified. Such business cases are needed to facilitate implementation of innovations.

Currently, a study is being conducted in which 13 community-dwelling elderly people use the optimized monitoring and feedback system on a daily basis for 6 months independent of a care context. This study will provide insight into the long-term experiences and acceptance of the system. Furthermore, information will be collected regarding falls, disability, illness, health care use, and physical functioning using questionnaires, diaries, and bi-monthly examinations by a geriatric physiotherapist. Combining this information with the self-monitoring data that was collected by community-dwelling elderly people using the self-monitoring and feedback system will provide insight into how the home-based self-monitoring measurements can be interpreted and into the clinical relevance of changes that are detected.

\section{Future research}

Before the self-monitoring and feedback system can be implemented in practice, future research is needed regarding several issues. First, the clinical relevance of changes in (a combination of) indicators of physical frailty that predict disability development should be studied. Large scale cohort studies can provide insight into the development of such 
indicators in elderly people over time. Big data or data mining methodologies could be used to identify patterns or pathways that lead to adverse outcomes. Second, ways to integrate the system in daily care (or welfare) routines should be explored. Different organizations and elderly users of the system might have different requirements for this integration. Needs and preferences of elderly persons and professionals working in such organizations should be taken into account. Third, the possibilities to provide training and/or tailored disability prevention programs to community-dwelling elderly people using the system to support them in their self-management should be examined. Such research should also focus on (cost-)effective components of such interventions. Physical activity might be considered a relevant component of such training or intervention programs since it is an important health behavior for preventing and reducing disability. ${ }^{48}$ Further exploration and improved understanding of the issues mentioned above can support the implementation of the self-monitoring and feedback system in practice which might facilitate a more proactive approach regarding frailty and disability prevention in community-dwelling elderly people.

\section{References}

1. Vermeulen J, Neyens JCL, Van Rossum E, Spreeuwenberg MD, De Witte LP. Predicting ADL disability in community-dwelling elderly people using physical frailty indicators: a systematic review. BMC Geriatr. 2011;11:33.

2. Vermeulen J, Spreeuwenberg MD, Daniëls R, Neyens JCL, Van Rossum E, De Witte LP. Does a falling level of activity predict disability development in community-dwelling elderly people? Clin Rehabil. 2012;0:1-9.

3. Vermeulen J, Neyens JCL, Spreeuwenberg MD, Van Rossum E, Duchene J, Hewson DJ, De Witte LP. Construct validity of a modified bathroom scale that can measure balance in elderly people. J Am Med Dir Assoc. 2012;13:655e1-5.

4. Vermeulen J, Neyens JCL, Spreeuwenberg MD, Van Rossum E, Sipers W, Habets H, Hewson D, De Witte LP. User-centered development and evaluation of an interface that provides feedback to elderly people regarding physical functioning. Patient Prefer Adherence. 2013;7:843-854.

5. Vermeulen J, Verwey R, Hochstenbach LMJ, van der Weegen S, Man YP, de Witte LP. Experiences of Multidisciplinary Development Team Members During User-Centered Design of Telecare Products and Services: A Qualitative Study. J Med Internet Res. 2014;16:e124.

6. Jette AM. Toward a common language for function, disability, and health. Phys Ther 2006;86:726-734. 
7. Kempen GIJM, Miedema I, Ormel J, Molenaar W. The assessment of disability with the Groningen Activity Restriction Scale. Conceptual framework and psychometric properties. Soc Sci Med. 1996;43:1601-1610.

8. Graf C. The Lawton instrumental activities of daily living scale. Am J Nurs. 2008;108:52-62.

9. Mahoney FI, Barthel DW. Functional evaluation: the barthel index. Md State Med J. 1965;14:61-65.

10. Ohkubo T, Kikuya M, Metoki H, Asayama K, Obara T, Hashimoto J, et al. Prognosis of "masked" hypertension and "white-coat" hypertension detected by 24-h ambulatory blood pressure monitoring 10-year follow-up from the Ohasama study. J Am Coll Cardiol. 2005;46:508-515.

11. Nielssen J. Why you only need to test with 5 users. Alertbox 2000. retreived from http://www.useit.com/alertbox/20000319.html on 13 June 2014.

12. Botsis T, Hartvigsen G. Current status and future perspectives in telecare for elderly people suffering from chronic diseases. J Telemed Telecare. 2008;14:195-203.

13. Lewis JR. Psychometric evaluation of the PSSUQ using data from five years of usability studies. Int J Hum Comput Interact. 2002;14:463-488.

14. Kirakowski J, Corbett M. SUMI: the Software Usability Measurement Inventory. Br J Educ Technol. 1993;24:210-212.

15. Bangor A, Kortum PT, Miller JT. An empirical evaluation of the system usability scale. Int J Hum Compt Interact. 2008;24:574-594.

16. Stellefson M, Chaney B, Barry AE, Chavarria E, Tennant B, Walsh-Childers K, et al. Web 2.0 chronic disease self-management for older adults: a systematic review. J Med Internet Res. 2013;15:e35.

17. May CR, Finch TL, Cornford J, Exley C, Gately C, Kirk S, et al. Integrating telecare for chronic disease management in the community: what needs to be done? BMC Health Serv Res. 2011;11:131.

18. Weinstein RS, Lopez AM, Krupinski EA, Beinar SJ, Holcomb M, McNeely RA, et al. Integrating telemedicine and telehealth: putting it all together. Stud Health Technol Inform. 2008;131:23-38.

19. Mohr DC, Cuijpers $P$, Lehman K. Supportive accountability: a model for providing human support to enhance adherence to eHealth interventions. J Med Internet Res. 2011;13:e30.

20. Kujala S. User involvement: a review of the benefits and challenges. Behaviour \& Information Technology. 2003;22:1-16.

21. Shah SG, Robinson I. Benefits of and barriers to involving users in medical device technology development and evaluation. Int J Technol Assess Health Care. 2007;23:131-137. 
22. Van Gemert-Pijnen JEWC, Nijland N, Van Limburg M,Ossebaard HC, Kelders SM, Eysenbach G, Seydell ER. A holistic framework to improve the uptake and impact of ehealth technologies. J Med Internet Res. 2011;13:e111.

23. De Vito Dabbs A, Myers BA, McCurry KR, Dunbar-Jacobs J, Hawkins RP, Begey A, Dew MA. User-centered design and interactive health technologies for patients. Comput Inform Nurs. 2009;27:175-183.

24. De Rouck S, Jacobs A, Leys M. A methodology for shifting the focus of e-health support design onto user needs. Intern J Med Inform. 2008;77:589-601.

25. Stoffers E. Werkboek Monitoring vanuit oudereperspectief van zorgvernieuwingsprojecten. 2012. Retrieved from http://ouderenorganisaties.nl/cso/download/krachtigclientenperspectief/methodiekomschrijving-monitoring-vanuitouderenperspectief.pdf on 13 June 2014.

26. Ament BHL, de Vugt ME, Verhey FR, Kempen GLJM. Are physically frail older persons more at risk of adverse outcomes if they also suffer from cognitive, social, and psychological frailty? Eur J Ageing. 2014;11:213-219.

27. Gobbens RJJ, van Assen MALM. Frailty and its prediction of disability and health care utilization: the added value of interviews and physical measures following a selfreport questionnaire. Arch Gerontol Geriatr. 2012;55:369-379.

28. Ostir GV, Markides KS, Black SA, Goodwin JS. Lower body functioning as a predictor of subsequent disability among older Mexican Americans. J Gerontol A Biol Sci Med Sci. 1998;53:M491-M495.

29. Al Snih S, Markides KS, Ottenbacher KJ, Raji MA. Hand grip strength and incident ADL disability in elderly Mexican Americans over a seven-year period. Aging Clin Exp Res. 2004;16:481-486.

30. Shinkai S, Kumagai S, Fujiwara Y, Amano H, Yoshida Y, Wanatabe S, et al. Predictors for the onset of functional decline among initially non-disabled older people living in a community during a 6-year follow-up. Geriatr \& Gerntol Intern. 2003;3:S31-S39.

31. Van Den Brink CL, Picavet H, Van Den Bos GA, Giampaoli S, Nissinen A, Kromhout D. Duration and intensity of physical activity and disability among European elderly men. Disabil Rehabil. 2005;27:341-347.

32. Sarkisian CA, Liu H, Gutierrez PR, Seeley DG, Cummings SR, Mangione CM. Modifiable risk factors predict functional decline among older women: a prospectively validated clinical prediction tool. The Study of Osteoporotic Fractures Research Group. J Am Geriatr Soc. 2000;48:170-178.

33. Stajkovic S, Aitken EM, Holroyd-Leduc J. Unintentional weight loss in older adults. CMAJ. 2011;182:443-449.

34. World Health Organization. Global recommendations on physical activity for health. 2010. Retreived from 
http://whqlibdoc.who.int/publications/2010/9789241599979 eng.pdf?ua=1 on 13 June 2014.

35. Bohannon RW, Peolsson A, Massy-Westropp N, Dsrosiers J, Bear-Lehman J.

Reference values for adult grip strength measured with a Jamar dynamometer: a descriptive meta-analysis. Physiotherapy. 2006;92:11-15.

36. Podsiadlo D, Richardson S. The timed "Up\&Go": a test of basic functional mobility for frail elderly persons. J Am Geriatr Soc. 1991;39:142-148.

37. Tinetti M. Performance oriented assessment of mobility problems in elderly patients. J Am Geriatr Soc. 1986;34:119-126.

38. Schneeweis S. Learning from big health care data. N Engl J Med. 2014;370:21612163.

39. Metzelthin SF, Rossum E van, de Witte LP, Ambergen AW, Hobma S, Sipers W, Kempen $\mathrm{H}$. Effectiveness of interdisciplinary primary care approach to reduce disability in community dwelling frail older people: cluster randomized controlled trial. British Medical Journal. 2013;347:f5264.

40. Melis RJF, Van Eijken MIJ, Teerenstra S, Van Achterberg T, Parker SG, Borm GF, et al. A randomized study of a multidisciplinary program to intervene on geriatric syndromes in vulnerable older people who live at home (Dutch EASYcare study). J Gerontol A Biol Sci Med Sci. 2008;3:283-290.

41. Li CM, Chen CY, Li CY, Wang WD, Wu SC. The effectiveness of a comprehensive geriatric assessment intervention program for frailty in community-dwelling older people: a randomized, controlled trial. Arch Gerontol Geriatr. 2010;50:S39-S42.

42. Fairhall N, Sherrington C, Kurrle SE, Lord SR, Lockwood K, Cameron ID. Effect of a multifactorial interdisciplinary intervention on mobility-related disability in frail older people: randomised controlled trial. BMC Medicine. 2012;10:120.

43. Cameron ID, Fairhall N, Langron Cl, Lockwood K, Monaghan N, Aggar C, et al. A multifactorial interdisciplinary intervention reduces frailty in older people: randomized trial. BMC Medicine. 2013;11:65.

44. Barlow J, Wright C, Sheasby J, Tuerner A, Hainsworth J. Self-management approaches for people with chronic conditions: a review. Patient Educ Couns. 2002;48:177-187.

45. Lorig KW. Holman H. Self-management education: history, definition, outcomes, and mechnisms. Ann Behav Med. 2003;26:1-7.

46. Bodenheimer T, Lorig K, Holman $\mathrm{H}$, Grumbach K. Patient self-management of chronic disease in primary care. JAMA. 2002;288:2467-2475.

47. Coleman MT, Newton KS. Supporting self-management in patients with chronic illness. Am Fam Physician. 2005;72:1503-1510.

48. Tak E, Kuiper R, Chorus A, Hopman-Rock M. Prevention of onset an progression of basic ADL disability by physical activity in community-dwelling older adults: a metaanalysis. Ageing Res Rev. 2013;1:329-338. 



\section{CHAPTER 11}

\section{Valorization of research results}



This thesis describes the user-centered development and evaluation of a self-monitoring and feedback system that can be used by elderly people to gain insight into changes in indicators of their physical frailty. The system itself and the knowledge gained regarding its usability and the psychometric properties of its three separate components can be considered the foundation for an innovative and proactive approach in care for community-dwelling elderly people in which self-management is supported by longitudinal self-monitoring of several aspects of physical frailty.

Although future research is needed to further explore the experienced added value of the system and possibilities for implementation, various stakeholders can be identified for whom (components of) the system and the insights gained during the user-centered development and evaluation of the system are relevant. In this chapter, these stakeholder groups will be identified and efforts that were made so far to transfer the knowledge and experiences reported in this thesis will be described. In addition, recommendations will be made regarding the actions that could be taken to ensure that knowledge gained from the research presented in this thesis is valorized so that relevant stakeholder groups benefit optimally from it.

\section{Elderly people}

Simple technologies, such as the modified bathroom scale, Grip-ball, and smartphonebased application can be used by elderly people to gain insight into (changes in) their weight, balance, grip strength, and physical activity. These are relevant indicators of physical frailty that are predictive of disability in community-dwelling elderly people. Selfmonitoring of such indicators can support self-management and facilitate involvement of elderly persons in their own healthcare process.

The following efforts have been made so far to transfer this knowledge to elderly people who have participated in the research presented in this thesis. Firstly, all elderly persons who participated in one of the validation studies received a letter via regular mail in which the context and the results of the study in which they participated were explained. Secondly, meetings were organized during which the results of several studies were presented and discussed with elderly people who participated in these studies. During these meetings, elderly people provided additional input to the researchers on how to move forward on this topic and which factors should be taken into account when promoting a technology-supported proactive care approach among community-dwelling elderly people. To inform elderly people who did not participate in one of the studies presented in this thesis, presentations were held at: the yearly conference of the Dutch National Care for the Elderly Program, the yearly open day of Maastricht University Medical Center, and 'Nederweert Vitaal' which is an event for seniors about health and 
activities. In addition, short articles written by elderly people who participated in one of the studies presented in this thesis were published in the magazine of the Catholic Association for Elderly People and in a magazine of a residential care center in the Netherlands. Finally, a symposium was organized at Maastricht University at which the results of this thesis and other research regarding eHealth for elderly people and patients with chronic conditions were presented to a broad audience.

Additional actions should be taken to accelerate the valorization of the selfmonitoring and feedback system, or similar devices, and the knowledge that was gained from this research. The system could be promoted at national events that target senior citizens such as the "50+Beurs", the "Senioren Expo", or the "Gezondheidsbeurs". In addition, the uptake of self-monitoring devices among elderly people could be facilitated by homecare shops and stores that sell these devices and provide related services and assistance to elderly people in learning how to use these devices. Finally, welfare organizations and healthcare organizations could incorporate the devices in their services to facilitate the use of self-monitoring technology among elderly people.

\section{Care professionals}

Information regarding the predictive value of physical frailty indicators on disability development in community-dwelling elderly people is highly relevant to care professionals such as geriatricians, general practitioners, and geriatric physiotherapists. Such information could be incorporated in clinical guidelines for these groups of professionals to support recognition of decreased physical functioning at an early stage and encourage timely offering of preventive interventions aimed at disability prevention.

The possibility of measuring physical frailty indicators using innovative care technologies has been presented at several international and national conferences aimed at geriatricians, gerontologists, general practitioners, and other disciplines. Such devices can be used at the office of the care professional or at the patient's home. An advantage of home-based monitoring by the patient is that it enables multiple measurements over a certain time period whereas care professionals nowadays mostly rely on data that is collected on the day that the patient visits the professional. Since not much is known yet regarding the variability of physical frailty indicators over time, it is difficult for care professionals to draw firm conclusions that can be generalized to the home situation based on the data that they collect during office visits. Several group discussions were conducted with healthcare professionals regarding the interpretation of longitudinal selfmonitoring data and possible cutoff points. More research and experience is needed regarding this topic. 
In order for care professionals to explore the possible added value of multiple measurements of indicators of physical functioning in some of their patients, they should be given the opportunity to use self-monitoring devices in their daily practice. Training and education should be provided to them by a professional company on how to use the devices, how to train elderly people to use the devices, and how to interpret the data that is collected. In addition, help-desk services should be provided to care professionals and elderly users of the technologies.

\section{R\&D companies}

The results presented in this thesis are of relevance to different types of companies. R\&D companies who are interested in developing (and selling) devices to elderly people that can be used for home-based monitoring of indicators of physical functioning can use the knowledge that was gained during the user-centered development process of the system to optimize their products. In addition, companies that already sell self-monitoring devices can integrate the modified bathroom scale, the Grip-ball, and/or the smartphone-based activity monitoring application in their services. Finally, companies that sell and control information systems or databases for care organizations and health care professionals can facilitate data transfer between the self-monitoring and feedback system and existing information systems or databases so that health care professionals can receive information about the current level of physical functioning of (some of) their patients.

Several companies have indicated that they would be interested in (re)developing parts of the system or integrating the modified bathroom scale or Grip-ball with their services. Since the Intellectual Property (IP) of these two devices belongs to the Université de Technology de Troyes (UTT), it is important to facilitate collaboration between these companies and UTT. Such collaborations could contribute to the optimization of the devices and to large scale production, which would make the devices cheaper and easier to obtain by elderly people and care professionals. However, achieving collaboration between different companies and stakeholders who have no experience working with each other appears to be a time consuming process since they all have their own agenda's and interests. This slows down the valorization of knowledge and the large scale implementation of the devices of the system and other care technologies or eHealth applications.

\section{Researchers}

Future research is needed to provide input for the further development of a proactive approach in care for community-dwelling elderly people. Based on the findings presented 


\section{Chapter 11}

in this thesis, researchers should focus on gaining insight into the clinical relevance of changes in indicators of physical frailty, the integration of self-monitoring equipment in daily care routines, and the possibilities to provide training or tailored disability prevention programs to community-dwelling elderly people. Based on the experiences presented in this thesis and on the expertise of other research groups in this field, the Center for Care Technology Research (CCTR, www.caretechnologyresearch.nl) will conduct a new project that aims to develop a self-management support system for communitydwelling elderly people that can be integrated in current care practice. The system can be used by elderly people to detect increased risks of disability at an early stage and provides tailored interventions to the elderly person to stimulate an active lifestyle and to decrease the risk of disability development.

Furthermore, insights gained from this thesis regarding the collaboration between stakeholders from different backgrounds during user-centered design processes are relevant for other researchers in this field, but also for elderly people, care professionals, and R\&D companies. The experiences of researchers and elderly people during the usercentered development process of the system were shared with peers during workshops at conferences and symposia and through interviews that were published in magazines.

Furthermore, the insights were incorporated in guidelines and checklists that are developed by the expertise group 'Methodologies of Client Participation' of the Expertise Center for Innovative Care and Technology.

\section{Healthcare insurance companies}

A technology-supported proactive approach in care for community-dwelling elderly people with a strong focus on self-management and independence is of interest for health care insurance companies. Despite the fact that this thesis does not provide insight into the costs and benefits of such an approach, it suggests that its further development could be worthwhile. To ensure that health care insurance companies are aware of the potential of such an approach, this thesis will be distributed among the innovation departments of Dutch health care insurance companies. 




\section{Summary}

Nederlandse samenvatting

Dankwoord

About the author

List of publications 



\section{Summary}

A difficulty in offering interventions to community-dwelling elderly people aimed at disability prevention or reduction is to identify people who might benefit most from such programs at a stage that disability is not yet present or still reversible. As explained in Chapter 1, various methods are currently being used to screen elderly people in the community to determine their level of frailty; and with that their eligibility for participation in preventive intervention programs since frailty is considered to be a state of pre-disability. Disadvantages of these screening methods are that the decision to offer a preventive intervention program is based on a single cross-sectional assessment of frailty, that the number of false-positive classifications is too high, and that screening methods are often not part of daily routine in primary care. Finally, and more importantly, the current top-down approach in which care professionals decide whether preventive interventions should be started based on the outcome of a frailty screening instrument, does not facilitate the participation of frail elderly people in making decisions regarding their own health care. This is unfortunate since involvement of elderly people in their own care process can empower them and improve patient outcomes. The increasing uptake of every day technologies such as smartphones, computers, and internet among elderly people and in health care, creates opportunities to support elderly people in their own health behaviors and involve them in the care process.

The main objective of this thesis is to develop and evaluate a self-monitoring and feedback system that can be used by community-dwelling elderly people to gain insight into (changes in) indicators of physical frailty that are predictors of increased risk of disability. To achieve this, the following research questions are addressed:

1. What is the predictive value of physical frailty indicators on disability in community-dwelling elderly people? (Chapter 2 \& Chapter 3)

2. Can simple, innovative technologies be used to obtain valid and reliable estimates of physical frailty indicators? (Chapters 4 till 7)

3. How can simple, innovative technologies be integrated into a self-monitoring system that provides regular feedback to elderly people regarding (changes in) physical frailty indicators? (Chapter 8 \& Chapter 9)

\section{Predictive value of physical frailty indicators}

A systematic review was conducted regarding the predictive value of physical frailty indicators on ADL disability in community-dwelling elderly people (Chapter 2). Slow gait speed and low physical activity are the most powerful predictors followed by weight loss, lower extremity function, balance, and low muscle strength. Monitoring these indicators can support self-management and might be useful for identifying elderly people who can 
benefit from an intervention aimed at disability prevention. In addition, a one-year followup study was conducted to investigate the predictive value of self-reported decline in physical frailty indicators (weight, exhaustion, walking difficulty, grip strength and physical activity) on development of disabilities in 401 community-dwelling elderly people aged 70 years or older (Chapter 3). Self-reported decline in physical frailty indicators predicts disability development after one year. Self-reported decrease in physical activity is the strongest predictor of increased dependence and increased difficulty in performing daily activities.

\section{Validity and reliability of self-monitoring technologies}

Four studies evaluated the validity and reliability of balance measurements conducted with a modified bathroom scale, grip strength measurements conducted with a Grip-ball, and physical activity measurements conducted with a smartphone-based activity monitoring application.

A cross-sectional study was conducted to investigate the construct validity of a modified bathroom scale that can be used to measure balance in elderly people (Chapter 4). This study revealed that balance measurements conducted with a modified bathroom scale are in line with the results from clinical balance tests conducted by a geriatric physiotherapist in 47 nursing home patients and 54 community-dwelling elderly people. The modified bathroom scale confirmed that nursing home patients have poorer balance compared to community-dwelling elderly people, as did the clinical balance tests. Next, the relation between balance scores of the modified bathroom scale and falls and disability was investigated in a 6-month follow-up study in 180 elderly people aged 65 years and older (Chapter 5 ). Test-retest reliability of the balance scores of the modified bathroom scale is acceptable. There was a cross-sectional relation between balance measured by the modified bathroom scale and falls and disability in elderly people.

Despite this cross-sectional relation, longitudinal data showed that balance scores have no predictive value for falls and might only have limited predictive value for disability development after 6-months follow-up.

A cross-sectional study was conducted to gain insight into the reliability and validity of measurements conducted with a Grip-ball that can be used for self-monitoring of grip strength (Chapter 6). Grip-ball scores of 35 nursing home patients and 53 communitydwelling elderly people were compared to grip strength measurements of the Jamar dynamometer (which is considered the gold standard). The study showed that concurrent validity of the Grip-ball measurements is acceptable and that its measurements are reliable. The Grip-ball is capable of detecting 'larger' grip strength differences but might have difficulty detecting 'smaller' differences.

A study was conducted in which a smartphone-based application for home-based monitoring of physical activity was compared to the Actigraph GT3X (which is considered 
the gold standard) in 8 adults aged below 65 years and 7 adults aged above 65 years (Chapter 7). The results of this study, in which participants monitored their daily physical activity for one week, revealed that there is a high correlation between the amount of activity registered in counts per minute by the smartphone-based application and the ActiGraph. Classifying each registered minute into four activity intensity categories (sedentary, low, moderate, and high) revealed structural differences between the smartphone and the ActiGraph in elderly people: the smartphone underestimated the number of sedentary minutes and overestimated minutes spent in the light intensity category in elderly people. The algorithm of the smartphone-based activity monitoring application should be optimized before being implemented in practice.

\section{User-centered development and testing of the monitoring and feedback system} A mobile interface of a monitoring system that provides feedback to elderly people regarding (changes in) physical functioning was developed in close collaboration with elderly people and care professionals during a User-Centered Design (UCD) process (Chapter 8). The monitoring system consists of a modified bathroom scale, Grip-ball, and smartphone-based activity monitoring application. The devices are equipped with Bluetooth and the information regarding all measurements is automatically forwarded to the smartphone. Via the interface of the smartphone, feedback is provided regarding the measurements and changes in weight, balance, grip strength, and physical activity. A 6week pilot study was conducted to explore the usability and experiences with the monitoring and feedback system according to 5 community-dwelling elderly people aged 70 years or older. Elderly people were able to use the monitoring system and they appreciated the feedback that was provided to them. The monitoring and feedback system satisfied most needs and preferences of elderly people and, despite a few technical errors that occurred during the pilot study which annoyed the users and sometimes caused confusion, they considered the system easy-to-use which resulted in good adherence to the daily monitoring regimen.

Chapter 9 presents the findings of a qualitative study that investigated the barriers and facilitators that influence the UCD process of telecare products and services according to 25 members of multidisciplinary development teams of four different Research and Development (R\&D) projects. Team members from different backgrounds often experience similar barriers (e.g. different members of the development team speak a 'different language') and facilitators (e.g. team members should voice expectations at the start of the project to prevent miscommunication at a later stage). However, some barriers and facilitators are only experienced by team members who share a similar background (e.g. only managers of R\&D companies experience that differences of opinion about a business case is a barrier and only end-users express that the project manager has an important facilitating role in end-user participation). Insights into these similarities and 


\section{Summary}

differences can improve understanding between team members from different backgrounds which can optimize collaboration during the user-centered development of telecare products and eHealth applications that support care and wellbeing.

In Chapter 10, the main findings of this thesis and methodological and theoretical issues that should be taken into consideration when interpreting the results of the research that was conducted are described. Additionally, implications for practice and recommendations for future research are addressed. Based on the research presented in this thesis, the monitoring and feedback system was further optimized so that it can be used by community-dwelling elderly people to gain insight into (changes in) indicators of their physical functioning. The system could support and facilitate a more proactive approach in early detection of increased risk for disability with a stronger focus on selfmanagement compared to the current methods in health care, that are mostly symptomoriented and reactive which might complicate the uptake and implementation of preventive interventions. Before the monitoring and feedback system can be implemented in practice, further research is needed into the clinical relevance of changes in indicators of physical frailty that predict disability development, the integration of the system in daily care routines, and the possibilities to provide training or tailored disability prevention programs to community-dwelling elderly people using the system to support them in their self-management. Finally, in Chapter 11 possibilities for valorization of knowledge that was gained during the research presented in this thesis are discussed. 




\section{Nederlandse samenvatting}

Het is een uitdaging om ouderen te identificeren die baat kunnen hebben bij een interventie gericht op de preventie van beperkingen in het dagelijks leven op het moment dat dergelijke beperkingen nog niet aanwezig zijn of nog gereduceerd kunnen worden. Zoals in Hoofdstuk 1 beschreven wordt, bestaan er verschillende screeningsmethoden om de mate van kwetsbaarheid bij thuiswonende ouderen in kaart te brengen. Aangezien kwetsbaarheid als voorbode van beperkingen in het dagelijks leven wordt gezien, wordt aan de hand van deze screeningsmethoden bepaald of een oudere in aanmerking komt voor een preventief interventie programma. Nadelen van deze screeningsmethoden zijn echter 1) dat de keuze om te starten met een preventieve interventie hierbij gebaseerd wordt op een enkele meting van de mate van kwetsbaarheid, 2) dat het aantal vals positieve classificaties hoog is, en 3 ) dat de screeningsmethoden vaak geen deel uitmaken van de dagelijkse routine in de eerstelijnszorg. Een nog belangrijker nadeel is dat deze topdown aanpak de deelname van ouderen bij het maken van beslissingen omtrent hun eigen gezondheid niet ondersteunt. In de huidige aanpak zijn het voornamelijk zorgprofessionals die, op basis van de uitkomst van een screeningsinstrument voor kwetsbaarheid, bepalen of een preventieve interventie al dan niet aangeboden wordt aan een oudere. Dit is een gemiste kans aangezien het betrekken van ouderen bij het zorgproces stimulerend werkt en een gunstige invloed heeft op gezondheidsuitkomsten. Het toenemende gebruik van dagelijkse technologieën zoals smartphones, computers en internet door ouderen en in de gezondheidzorg, biedt mogelijkheden om ouderen te ondersteunen bij een gezondere leefstijl en om hen te betrekken bij het zorgproces.

Het doel van deze thesis is om een zelf-monitoring en feedback systeem te ontwikkelen en evalueren dat door thuiswonende ouderen gebruikt kan worden om inzicht te krijgen in (de veranderingen van) fysieke indicatoren die gerelateerd zijn aan kwetsbaarheid. Om dit te bereiken wordt ingegaan op de volgende onderzoeksvragen:

1. Wat is de voorspellende waarde van fysieke indicatoren van kwetsbaarheid op beperkingen in het dagelijks leven bij thuiswonende ouderen? $\underline{\text { Hoofdstuk }}$ 2\& Hoofdstuk 3)

2. Kunnen simpele, innovatieve technologieën gebruikt worden om indicatoren van fysieke kwetsbaarheid te meten op een betrouwbare en valide manier? (Hoofdstuk $4 \mathrm{t} / \mathrm{m} 7$ )

3. Hoe kunnen simpele, innovatieve technologieën geïntegreerd worden in een zelf-monitoring systeem dat regelmatig feedback geeft aan ouderen over (veranderingen in) indicatoren van fysieke kwetsbaarheid? (Hoofdstuk 8 \& Hoofdstuk 9) 


\section{Voorspellende waarde van indicatoren van fysieke kwetsbaarheid}

Een systematische literatuur review is uitgevoerd naar de voorspellende waarde van indicatoren van fysieke kwetsbaarheid op beperkingen in het dagelijks leven bij thuiswonende ouderen (Hoofdstuk 2). Trage loopsnelheid en weinig fysieke activiteit zijn de belangrijkste voorspellers, gevolgd door gewichtsverlies, verminderd functioneren van de lage extremiteiten, slechte balans en verminderde spierkracht. Het monitoren van deze indicatoren kan zelfmanagement ondersteunen en kan helpen bij de identificatie van ouderen die baat kunnen hebben bij een interventie gericht op het voorkomen van beperkingen in het dagelijks leven. Aanvullend op de systematische literatuur review is een longitudinale studie uitgevoerd met een follow-up van 1 jaar om te onderzoeken wat de voorspellende waarde is van zelf-gerapporteerde achteruitgang in indicatoren van fysieke kwetsbaarheid (gewichtsverlies, vermoeidheid, moeite met lopen, knijpkracht en fysieke activiteit) op beperkingen in het dagelijks leven bij 401 thuiswonende ouderen (Hoofdstuk 3). Zelf-gerapporteerde achteruitgang in indicatoren van fysieke kwetsbaarheid voorspelt ontwikkeling van beperkingen in het dagelijks leven. Zelfgerapporteerde vermindering in fysieke activiteit is de belangrijkste voorspeller van toename van afhankelijkheid van andere personen bij het uitvoeren van dagelijkse activiteiten. Daarnaast is deze indicator ook de belangrijkste voorspeller van het hebben van moeite bij het uitvoeren van dergelijke activiteiten.

\section{Validiteit en betrouwbaarheid van zelf-monitoring technologieën}

De validiteit en betrouwbaarheid van balans gemeten met een aangepaste weegschaal, knijpkracht gemeten met een knijpbal, en fysieke activiteit gemeten met een applicatie op een smartphone zijn geëvalueerd in vier studies.

Tijdens een cross-sectionele studie is de construct validiteit geëvalueerd van een aangepaste weegschaal die balans meet bij ouderen (Hoofdstuk 4). Deze studie toonde aan dat er een grote mate van overeenkomst is tussen balans metingen van de aangepaste weegschaal en klinische balans testen die afgenomen werden door een geriatrisch fysiotherapeut bij 47 patiënten van een verpleeghuis en 54 thuiswonende ouderen. Zowel de balans metingen van de aangepaste weegschaal als de klinische balans testen gaven aan dat verpleeghuispatiënten een slechtere balans hadden in vergelijking met thuiswonende ouderen. Daarnaast is tijdens een longitudinale studie met een followup periode van 6 maanden de relatie tussen balansscores van de aangepaste weegschaal en de kans op vallen en beperkingen in het dagelijks leven onderzocht. Aan deze studie namen 180 personen van 65 jaar of ouder deel (Hoofdstuk 5). De test-hertest betrouwbaarheid van de metingen van de aangepaste weegschaal was acceptabel. Er was een cross-sectionele relatie tussen balansscores van de aangepaste weegschaal en de kans op vallen en het ontwikkelen van beperkingen in het dagelijks leven bij ouderen. De data bevestigde hierin geen longitudinale relatie. De balansscores van de aangepaste 
weegschaal hebben geen voorspellende waarde voor de kans op vallen en slechts beperkte voorspellende waarde voor de kans op het ontwikkelen van beperkingen in het dagelijks leven na 6 maanden follow-up.

Tijdens een cross-sectionele studie zijn de validiteit en betrouwbaarheid onderzocht van metingen van een knijpbal die ontwikkeld is voor ouderen om thuis zelfstandig hun knijpkracht te meten (Hoofdstuk 6). Knijpbal metingen van 35 verpleeghuispatiënten en 53 thuiswonende ouderen zijn vergeleken met knijpkracht metingen van de Jamar dynamometer (gouden standaard). De studie toonde aan dat de concurrent validiteit van de knijpbal metingen acceptabel is en dat de metingen betrouwbaar zijn. De knijpbal is in staat om 'grotere' verschillen in knijpkracht te meten maar heeft moeite met het detecteren van 'kleinere' verschillen.

$\mathrm{Er}$ is een studie uitgevoerd waarbij metingen van fysieke activiteit met een applicatie van een smartphone vergeleken zijn met metingen van de Actigraph GT3X (gouden standaard) bij 8 personen jonger dan 65 jaar en 7 personen van 65 jaar of ouder (Hoofdstuk 7). De resultaten van deze studie, waarin deelnemers hun dagelijkse fysieke activiteit gedurende 7 dagen gemeten hebben, tonen aan dat er een hoge correlatie is tussen de hoeveelheid activiteit die door de smartphone en Actigraph geregistreerd wordt in counts per minute. Wanneer echter iedere gemeten minuut geclassificeerd wordt in één van de volgende vier categorieën: sedentair, activiteit van lage intensiteit, activiteit van middelmatige intensiteit, of activiteit van hoge intensiteit, blijkt dat er structurele verschillen zijn tussen de smartphone en de Actigraph. De smartphone onderschat namelijk het aantal sedentaire minuten bij ouderen en overschat het aantal minuten dat geclassificeerd wordt in de lage intensiteit categorie. Het algoritme van de applicatie op de smartphone die beweging meet dient verbeterd te worden voordat het toegepast kan worden in de praktijk.

\section{Co-creatie en evaluatie van het monitoring en feedback systeem}

Samen met ouderen en zorgprofessionals is een interface ontwikkeld voor een smartphone applicatie die informatie geeft aan ouderen over (veranderingen in) hun fysieke functioneren. Het monitoring en feedback systeem bestaat uit een weegschaal die gewicht en balans meet, een knijpbal die knijpkracht meet, en een smartphone met ingebouwde accelerometer waarmee fysieke activiteit gemeten wordt. Alle onderdelen van het monitoring systeem zijn uitgerust met Bluetooth waardoor de metingen direct doorgestuurd kunnen worden naar de smartphone. Via de interface van de smartphone krijgen ouderen feedback over de metingen van hun gewicht, balans, knijpkracht, en fysieke activiteit. Tijdens een pilot-studie van 6 weken zijn de bruikbaarheid en ervaringen met het monitoring en feedback systeem verkend bij 5 thuiswonende ouderen van 70 jaar of ouder die het systeem dagelijks gebruikten. De deelnemers konden met het monitoring systeem omgaan en stelden de feedback op prijs. Het monitoring en feedback systeem 
voldeed aan de meeste wensen en voorkeuren van ouderen. Ondanks enkele technische mankementen, waaraan de gebruikers zich irriteerden, bleek het systeem gemakkelijk in gebruik waardoor het gemiddeld op meer dan $80 \%$ van de dagen gebruikt werd.

In hoofdstuk 9 worden de bevindingen van een kwalitatieve studie gepresenteerd waarin onderzocht is welke belemmerende en bevorderende factoren het User-Centered Design (UCD) proces van telezorg producten en diensten beïnvloeden. Vijfentwintig leden van vier verschillende multidisciplinaire ontwikkelingsteams participeerden in deze studie. Teamleden met verschillende achtergronden ervaren vaak dezelfde belemmerende factoren (bijvoorbeeld: teamleden met een andere achtergrond spreken vaak 'een andere taal') en bevorderende factoren (bijvoorbeeld: teamleden moeten open communiceren over verwachtingen vanaf de start van het project om miscommunicatie te voorkomen). Sommige belemmerende en bevorderende factoren worden echter alleen ervaren door teamleden met dezelfde achtergrond (bijvoorbeeld: alleen managers van bedrijven ervaren dat verschillende meningen over een goede businesscase binnen één team het UCD proces belemmert en alleen eindgebruikers geven aan dat projectmanagers een belangrijke faciliterende rol hebben in de stimulering van betrokkenheid van eindgebruikers tijdens het ontwikkelingstraject). Inzicht in de verschillen en overeenkomsten tussen stakeholers kan eraan bijdragen dat leden van multidisciplinaire teams elkaar beter begrijpen, waardoor samenwerking tijdens de ontwikkeling van telezorg producten en diensten die zorg en welzijn ondersteunen geoptimaliseerd kan worden.

In Hoofdstuk 10 worden de bevindingen uit deze thesis gepresenteerd en worden methodologische en theoretische aspecten besproken die in acht genomen dienen te worden bij het interpreteren van deze bevindingen. Daarnaast worden implicaties van het onderzoek uit deze thesis voor praktijk en vervolgonderzoek besproken. Op basis van de bevindingen uit deze thesis is het monitoring en feedback systeem verder verbeterd zodat het door thuiswonende ouderen gebruikt kan worden om inzicht te krijgen in (de veranderingen van) hun fysieke functioneren. Het systeem kan vroege identificatie van ouderen met een verhoogd risico op beperkingen in het dagelijks leven faciliteren en kan ouderen ondersteunen bij hun zelfmanagement. Een dergelijke aanpak bij fysieke kwetsbaarheid is meer proactief in vergelijking met de huidige aanpak die veelal reactief is en gericht is op het herkennen van symptomen. Voordat het monitoring en feedback systeem geïmplementeerd kan worden in de praktijk, moet er onderzoek gedaan worden naar de klinische relevantie van veranderingen in indicatoren van fysieke kwetsbaarheid, de integratie van het monitoring en feedback systeem met andere systemen die momenteel in de zorg gebruikt worden en de mogelijkheid om met het systeem training of gepersonaliseerde interventies aan te bieden aan thuiswonende ouderen gericht op de preventie van beperkingen in het dagelijks leven en ter ondersteuning van 
zelfmanagement. Tenslotte worden in Hoofdstuk 11 mogelijkheden besproken voor de valorisatie en verdere toepassing van de kennis die in dit proefschrift beschreven wordt. 



\section{Dankwoord}

Het is af! En ik weet zeker dat, behalve ikzelf, hier nog een aantal andere mensen heel blij mee zullen zijn. Want ik ben er inmiddels achter gekomen dat geldt: 'promoveren doe je samen'. Een aantal van de mensen met wie ik samen deze mijlpaal bereikt heb, wil ik bij deze graag bedanken.

Dat 'samen' begon in januari 2010 met een begeleidingsteam bestaande uit Prof. Dr. Luc de Witte, Dr. Jacques Neyens, Dr. Marieke Spreeuwenberg en Dr. Erik van Rossum. Ik wil jullie graag bedanken voor alles wat jullie gedaan hebben om mijn promotietraject en het project 'monitoring van fysieke kwetsbaarheid bij ouderen' tot een goed einde te brengen. Ik heb veel geleerd van jullie als team en van jullie afzonderlijke kwaliteiten die elkaar goed aanvullen. Luc, bedankt voor alle keren dat jij tegen mij gezegd hebt: 'goed idee, moet je doen'. Door mij te stimuleren om verschillende soorten projecten op te pakken, heb je een belangrijke bijdrage geleverd aan mijn ontwikkeling als onderzoeker. Die ontwikkeling heb ik met veel plezier doorgemaakt mede doordat ik jou bij uitdagingen of lastige situaties altijd kon bellen, mailen, of bij je kon binnenlopen met mijn verhaal (ook met de soms wat ongenuanceerde versie) en dan op jou steun kon rekenen. Jacques, jij bent attent tegen iedereen die je pad kruist en daar heb ik grote bewondering voor. Ik heb in de afgelopen jaren ervaren dat jou opgewektheid en positieve instelling een enthousiasmerend effect hebben, niet alleen op mij maar ook op andere mensen in je omgeving. De vele chocolaatjes die je trakteert en de liedjes die overal te horen zijn waar jij over de gang loopt te fluiten dragen hier natuurlijk ook aan bij! Marieke, bij jou kan ik altijd even binnenlopen voor een eerlijk advies, een sparsessie (op rap tempo), een vraag, een kopje thee, of een blikje cola. Je bent een open persoon, what you see is what you get, en dat is 1 van de dingen waardoor ik het fijn vind om me je samen te werken. Erik, jij hebt oog voor detail maar verliest de grote lijnen niet uit het oog. Door soms de rol van advocaat van de duivel te spelen, heb jij ervoor gezorgd dat we tijdens overleggen de zaak van alle kanten bekeken. Ik heb je adviezen en feedback altijd als heel constructief en behulpzaam ervaren en waardeer ook zeker de humor waarmee jij dingen brengt.

Het project 'monitoring van fysieke kwetsbaarheid bij ouderen' en mijn proefschrift zouden niet geworden zijn wat het nu is zonder de speciale (en soms misschien zelfs cruciale) inbreng van een aantal personen die geen deel uitmaakten van mijn begeleidingsteam. Harry, als vertegenwoordiger van het ouderenpanel van het Huis voor de Zorg ben jij vanaf het begin betrokken geweest bij het project. Je hebt hieraan op tal van manieren een positieve bijdrage geleverd: door je actieve en enthousiaste deelname aan vergaderingen, door mee te denken over de ontwikkeling van de technologie, door 
deelnemers te werven voor het onderzoek, en door samen met mij op verschillende plekken in Nederland presentaties te geven over ons project en onze samenwerking. Ik heb onze samenwerking als zeer waardevol en prettig ervaren en wil je bij deze hiervoor bedanken. April, wij zijn een aantal jaren geleden door jou oma aan elkaar voorgesteld omdat ze dacht dat ik jou misschien wel bij je Bachelor stage kon begeleiden. Die stage is uitgegroeid in een student-assistentschap en daar ben ik blij om. Jij bent namelijk de persoon die ervoor gezorgd heeft dat alle dataverzameling en de logistiek eromheen op rolletjes liep. Omdat je oog hebt voor detail en proactief bent, had je de oplossing vaak al bedacht voordat ik wist dat er een probleem was. Sarah, ontzettend bedankt voor alle intakes, huisbezoeken, telefoontjes en andere dingen die je in de laatste periode van mijn promotie traject van me hebt overgenomen. Als ik soms door de bomen het bos niet meer dacht te zien, was het echt een opluchting als jij (op jouw no-nonsense manier) zei: 'dat kan ik dan toch doen...'. Ik weet niet hoe (en of) ik het geregeld had gekregen zonder je hulp.

Daarnaast hebben een heleboel personen en organisaties in de afgelopen jaren hulp, adviezen en inspanningen geleverd waarvoor ik hen bij deze allemaal hartelijk wil bedanken. Hierbij wil ik graag beginnen met alle ouderen die deelgenomen hebben aan 1 van de studies waaruit dit proefschrift bestaat. Zonder al deze mensen die bereid waren om, eenmalig of voor langere tijd, op een weegschaal te gaan staan, in een knijpbal te knijpen, hun beweging te monitoren, vragenlijsten in te vullen en hun input te geven voor de ontwikkeling van het monitoring en feedback systeem was het allemaal niet gelukt. Daarnaast wil ik ook graag de volgende personen en de organisaties waar zij werkzaam zijn bedanken voor hun inspanningen en interesse voor het project en hun hulp bij de werving van deelnemers: Walther Sipers, Sylvia Damen, en Herbert Habets van Orbis Medisch Centrum Sittard; Esther Stoffers, Michelle van der Tier, Ester Janssen van het Huis voor de Zorg; Guy Carlens en Sandra van Krieken van De Riethorst Stromenland; Kim van Venrooij, Tim Hendriks, Miriam Musgens, en Josanne Lemaire van Sevagram; Simone Gerono van het Huis voor de Sport en de instructeurs van alle beweeggroepen die deelgenomen hebben; Jan van Riet van Nederweert Vitaal; Misha Ruiten, Lisette Ars, Suzanne Janssen en Luc Schurer van Groene Kruis Domicura; Hans van Drost van Fysiotherapie Praktijk Raamsdonk; en Wilma Hacking, Anny Hupperetz, en Leonard van Berlo van Vitalis Parc Imstenrade. I also would like to thank David Hewson, Michael Mordefroy, Pauline Hourseau, Ali Hammoud, and Luc Rodrigues de Magalhaes from the Université de Technology de Troyes for the development of the application of the monitoring and feedback system and for the help and assistance that they provided during the studies that were conducted in the past years. Many thanks for your warm welcome during the workings visits to Troyes and for introducing the local cuisine (especially andouillette) to me. 
De leden van de beoordelingscommissie: voorzitter Prof. dr. J.M.G.A. Schols, Prof. dr. A.J.H.M. Beurskens, Prof. dr. C.P. van Schayck, Prof. dr. A.E. Stuck en Prof. dr. M.M.R. Vollenbroek-Hutten, wil ik graag bedanken voor hun bereidheid zitting te nemen in de commissie en hun inspanningen om mijn proefschrift te beoordelen.

Als je geen collega's had, zou een werkweek voor je gevoel denk ik minstens twee keer zo lang duren. Gelukkig heb ik de afgelopen jaren heel veel collega's om me heen gehad om even mee te kletsen, om me van advies te voorzien wanneer projecten niet lopen zoals ze moeten lopen (blijkt een bekend fenomeen), om naar bakker Leon te gaan voor een broodje, om mee naar congressen te gaan, om me feedback te geven op concept artikelen en presentaties, om mee op dagje uit te gaan, en ga zo maar door.... Sommige collega's zijn voor mijn gevoel zelfs een beetje met mij 'mee gepromoveerd' en kennen de ins, outs, ups, en downs van mijn promotie traject waarschijnlijk als geen ander. Sanne en Renée, wat was ik blij met jullie komst op de UNS 40. Het was fijn om wat gezelschap te hebben op die kamer op de $5^{\text {de }}$ verdieping met dat mooie uitzicht. Bovendien heeft het mij veel geholpen dat we altijd even kunnen overleggen over hoe je dat onderzoek naar technologie in de zorg nu het beste aan kunt pakken. Later toen we naar DUB 30 verhuisden hebben Laura en Martine zich ook nog bij onze 'technologie in de zorg' club gevoegd waardoor we nu nog meer mogelijkheden voor overleg maar vooral ook meer gezelligheid hebben. En dan zijn er natuurlijk nog de dames van kamer 0.044. Cindy, Reina, Arianne, en Janneke, over technologie in de zorg hebben wij het zelden met elkaar maar ik weet jullie te vinden voor een gezellige kop koffie of een fijn gesprek.

Wat zou het leven ongelofelijk saai zijn als je geen vrienden had. Lieke, Ang, Elise, Bas, Jeroen, en Dirk (a.k.a. Fuego), op het moment dat ik dit dankwoord aan het schrijven ben zijn we bezig om met z'n allen ons 10 -jarige jubileum weekend te plannen. Dat kan natuurlijk alleen maar een heel groot succes worden als ik kijk naar het vergelijkingsmarteriaal van de weekendjes in Breda, Helmond, Florence, Antwerpen, Puurs en Westvleteren die we met elkaar, en natuurlijk ook met Frits, Jill, Tim, Wendy, en Chantalle, meegemaakt hebben. Ik kijk uit naar de volgende 10 jaar vriendschap met jullie allemaal! Sophie, Leo, Kelly, en Moniek (a.k.a. Manos chickies), hoe lang is het inmiddels geleden dat wij met elkaar samen op een handbalveld gestaan hebben? Zou ik best voor de grap nog eens willen doen. Maar dat vergt dan waarschijnlijk wel een gedetailleerde planning en uitgebreide organisatie aangezien we ons in de afgelopen jaren bijna nooit tegenlijkertijd in hetzelfde land bevonden. Maar daar hebben ze gelukkig skype voor uitgevonden! Ik ben blij dat we onze maandelijkse catch-ups gepland hebben en kijk er altijd naar uit om jullie te spreken om te horen hoe het met jullie gaat. Susan (a.k.a. Suus), 
soms moet je blijkbaar naar de andere kant van de wereld vliegen om vrienden uit Maastricht te leren kennen. Maar het was de hele reis waard want ik vind je een topper!

Zoals veel mensen die aan het promoveren zijn zullen beamen is 'het proefschrift' een onderwerp dat overal en op alle (gewenste en vooral ook ongewenste) momenten je gedachten kan binnensluipen. Ik heb echter gemerkt dat er 1 activiteit is waarbij dit mij nooit overkomt: handbal. Blijkbaar is er geen plaats meer in mijn hoofd voor wat-dan-ook wanneer ik moet rennen, vangen, gooien, en praten tegelijk. En dat was heerlijk! Daarom wil ik bij deze Sanne, Yenna, Anouk, Ivana, Kim, Kyara, Frederike, Judith, Lisa, Naomi, Danja, Paul, Annette, Irma en Marcel bedanken. Hoewel jullie misschien niet zoveel mee gekregen hebben van het hele promotietraject, waren jullie voor mij wel een topafleiding!

Eveline, André en Chiusa, bedankt voor alle keren dat jullie enthousiast gevraagd hebben naar de stand van zaken van mijn proefschrift. En natuurlijk ook voor alle adviezen en hulp die jullie aangeboden hebben voor het regelen van dingen rondom de promotie (van mijn outfit tot aan het aanbod voor het verzorgen van de catering inclusief prikken van sateetjes toe). Of het nu is voor een gezellig avondje film kijken op de bank, een lekker hapje eten of een wandelingetje met Bo, ik voel me bij jullie altijd welkom.

Er wordt altijd gezegd: zoals het klokje thuis tikt, tikt het nergens. Maar ik ken 2 klokjes die voor mij nauwelijks van elkaar verschillen: de ene hangt in Maastricht en de andere in Helmond. Lieve papa en mama, ook al woon ik inmiddels al ruim 10 jaar in Maastricht en moeten mensen soms goed luisteren om een Helmonds accent te herkennen als ik mijn mond open doe, jullie zijn en blijven toch altijd degene die ik bedoel als ik zeg 'bij ons thuis'. Hadden jullie vroeger (bijvoorbeeld toen de klok bij ons thuis vol met briefjes hing omdat ik in groep 4 nog steeds niet kon kloklezen) gedacht dat ik op mijn $17^{\text {de }}$ op kamers zou gaan in Maastricht om te studeren? Ik moet eerlijk toegeven dat ik hier zelf wel eens een beetje verbaasd over ben geweest. Mochten jullie soms stiekem ook een beetje verbaasd zijn geweest dan heb ik daar in ieder geval niks van gemerkt, want ik heb altijd alleen het vertrouwen gevoeld dat jullie in mij hebben. Ik weet dat jullie trots op me zijn en dat doet me goed.

Siem, wanneer kom je weer terug verhuizen? Of ben ik dit keer toch echt aan de beurt? 1 uur rijden is niet zo heel ver, maar ik vind het toch echt veel fijner als je gewoon bij me om de hoek woont. De keren dat jij in het afgelopen jaar gevraagd hebt is je proefschrift al bijna af?' zijn op 1 hand te tellen. En dat vind ik heerlijk. Want ik weet dat het niet komt door desinteresse maar doordat jij er gewoon vanuit gaat dat het vanzelf wel goed komt met mij en dat proefschrift. En ook omdat jij weet dat er al heel veel mensen waren die 
deze vraag aan mij stelden en je mij goed genoeg kent om aan te voelen wanneer deze stresskip de vraag niet meer wilde horen. Bovendien zijn er genoeg andere belangrijkere en leukere dingen waarover wij met elkaar kunnen kletsen, zeuren, lachen, huilen, zeiken, zeveren, mopperen en grapjes maken. Ik weet dat wij er altijd voor elkaar zullen zijn en ben blij en trots dat ik jou mijn zusje mag noemen.

Lieve Damien, jij zegt wel eens dat wij met z'n tweeën niet zo makkelijk in een hokje te plaatsen zijn. Misschien is het daarom ook wel lastig om hier in een paar regels te beschrijven wat jij voor mij betekent zonder het gevoel te hebben dat ik in clichés verval. Maar ik ga natuurlijk toch een poging wagen. Jij, hebt blind vertrouwen in me als ik iets moeilijks moet doen, bent trots op me als het lukt, zoekt met me naar een oplossing als het niet lukt en maakt me weer aan het lachen als ik teleurgesteld ben als het is mislukt. Je zorgt dat ik gas terug neem als ik in de 5 de versnelling zit en zelf niet meer terug kan schakelen, pakt het voortouw als ik even nergens meer puf voor heb, neemt me serieus als ik ergens mee zit, maar kan dingen ook met een korreltje zout nemen en erom lachen als de heetgebakerde Helmonder naar buiten komt. Ik ben trots en blij dat ik jou heb en jij mij. Of het nu de highs of de lows zijn, ik zou ze met niemand anders mee willen maken. Ik hou van je. 



\section{About the author}

Joan Vermeulen was born in Helmond, the Netherlands (1986). After completing her secondary education (VWO), she studied General Health Sciences at Maastricht University, for which she obtained her bachelor degree in August 2007. In September 2008 she started with the Health Sciences Research Master at Maastricht University. During the second year of this master program she started working as a trainee for the international research project 'Monitoring of physical frailty in community-dwelling elderly people; an innovative approach supporting self-management and care' which was a collaboration between Maastricht University and the Université de Technologie de Troyes (France). After obtaining her master's degree in October 2010, she continued working on this international research project as a PhD student at CAPHRI, first at the department of Social Medicine and later at the department of Health Services Research at Maastricht University.

During her $\mathrm{PhD}$ trajectory she got involved in various other research projects and working groups. Since October 2012, she is a project group member of the Trial Innovation Project (TrIP) which is conducted by the Institute for Evidence-based Medicine in Older persons (IEMO). During this project she coordinates a work package that is responsible for the development, optimization, and testing of a home-based digital data collection platform that can be used by offspring of dementia patients for research and selfmanagement purposes. Since December 2012, she is involved in the preparation and establishment of research project EXHALE and the Health in Slums foundation which is a collaboration between Maastricht University, Zuyd University of Applied Sciences, and various Indian research and healthcare institutes. The aim of project EXHALE is to develop a solution for indoor air pollution in slums to reduce pulmonary disease and improve health. She is currently still involved in the realization and coordination of the project which is conducted by the Health in Slums Foundation. Since March 2013, she is a member of the working group Methodologies for Client Participation (MCP) that is embedded in the Centre of Expertise on Innovative Care and Technology (EIZT). This working group aims to stimulate and facilitate participation of clients, patients, and endusers during the development, implementation, and education of innovative care technologies by providing tools and support to all partners of the EIZT network.

Since September 2013, Joan works in a post-doc function at CAPHRI at the Department of Health Services Research of Maastricht University. She is coordinator and researcher for the eLabEL research project that is conducted by the Center for Care Technology Research (CCTR) which is a collaboration between Maastricht University, University Twente, Nivel, and TNO. Her research focusses on the impact of large scale implementation of existing eHealth products and services in primary care on experiences of patients, care professionals, and organization of care. 



\title{
List of publications
}

\author{
International journals
}

- Vermeulen J, Neyens JCL, Spreeuwenberg MD, van Rossum E, Hewson DJ, de Witte LP. Measuring grip strength in older adults: comparing the Grip-ball with the Jamar dynamometer. J Geriatr Phys Ther. 2014; In press.

- Vermeulen J, Willard S, Aguiar B, de Witte LP. Validity of a smartphone-based fall detection application worn on a belt or in a trouser pocket. Assist Technol. 2014; In press.

- Vermeulen J, Verwey R, Hochstenbach LMJ, van der Weegen S, Man YP, de Witte LP. Experiences of multidisciplinary development team members during user-centered design of telecare products and services: a qualitative Study. J Med Internet Res. 2014;16:e124.

- Vermeulen J, Neyens JCL, Spreeuwenberg MD, van Rossum E, Sipers W, Habets H, Hewson D, de Witte LP. User-centered development and evaluation of an interface that provides feedback to elderly people regarding physical functioning. Patient Prefer Adherence. 2013;7:843-854.

- Vermeulen J, Neyens JCL, Spreeuwenberg MD, van Rossum E, Duchêne J, Hewson DJ, de Witte LP. Construct validity of a modified bathroom scale that can measure balance in elderly people. J Am Med Dir Assoc. 2012;13:655e1-e5.

- Vermeulen J, Neyens JCL. Predicting disability and institutionalization in elderly people: how strong is the evidence for the predictive value of the short physical performance battery? Physical Therapy Reviews. 2012;17:138-139.

- Vermeulen J, Spreeuwenberg MD, Daniëls R, Neyens JCL, van Rossum E, de Witte LP. Does a falling level of activity predict disability development in community-dwelling elderly people? Clin Rehabil. 2013;27:546-554.

- Vermeulen J, Neyens JCL, van Rossum E, Spreeuwenberg MD, de Witte LP. Predicting ADL disability in community-dwelling elderly people using physical frailty indicators: a systematic review. BMC Geriatr. 2011;11:33.

\section{National journals}

- Verwey R, Hochstenbach L, Vermeulen J, Van der Weegen S. Technologie ondersteunt patiënt bij zelfmangement. TVZ. 2013;6:14-17.

- Vermeulen J, Neyens JCL, Spreeuwenberg MD, van Rossum E, de Witte LP. Klinimetrie: is er plaats voor een slimme weegschaal die balans meet? Tijdschr Gerontol Geriatr. 2012;43:270-271. 
- Vermeulen J, van der Heijden H, van der Tier M, Stoffers E. Ouderen participatie in onderzoek: voor en met ouderen. Zorg + Welzijn. 2012;1:32-33.

- Vermeulen J, Spreeuwenberg M, Sipers W, Neyens J, van Rossum E, Hewson D, de Witte L. Samenwerking met stakeholders tijdens de ontwikkeling van een monitoring systeem en feedback en adviessysteem voor thuiswonende ouderen. Fysiotherapie en Ouderenzorg. 2011;25:29-38.

\section{Congress proceedings and abstracts}

- Vermeulen J, Willard S, Aguiar B, de Witte LP. Validity of a smartpone-based activity monitoring and fall detection application for older persons. $67^{\text {th }}$ Annual Scientific Meeting of the Gerontological Society of America, 5-9 November 2014, Wahington DC, USA.

- Hochstenbach L, Courtens A, Zwakhalen S, Vermeulen J, Van Kleef M, de Witte L. Cancer pain in the outpatients setting: development of a technology supported selfmanagement intervention. 7th World Congress of the World Institute on Pain, 7-10 May 2014, Maastricht, The Netherlands.

- Huygens MWJ, Vermeulen J, de Witte LP. Expectations of middle-aged and elderly persons towards using telecare technologies and eHealth applications in primary care. $6^{\text {th }}$ International Conference on eHealth Telemedicine and Social Medicine, 2327 March 2014, Barcelona, Spain.

- Vermeulen J, Neyens JCL, Spreeuwenberg MD, van Rossum E, Sipers W, Habets, H, Hewson DJ, de Witte LP. Balance scores of a modified bathroom scale as an indicator of disability and falls in older people. $66^{\text {th }}$ Annual Scientific Meeting of the Gerontological Society of America, 20-24 November 2013, New Orleans, USA.

- Hewson DJ, Jaber R, Chkeir A, Hammoud A, Gupta D, Bassement J, Vermeulen J, Yadav S, de Witte LP, Duchêne J. Development of a monitoring system for physical frailty in independent elderly. Conf Proc IEEE Eng Med Biol Soc. 2013;2013:62156215.

- Vermeulen J, Kuiper D, Bielderman A, Peters-Hanssen D. Bevorderen van eigen regie van kwetsbare ouderen. Congres Nationaal Programma Ouderenzorg, 12 november 2013, Den Bosch, The Netherlands.

- Vermeulen J, Neyens JCL, Spreeuwenberg MD, van Rossum E, Sipers W, Habets H, Hewson DJ, de Witte LP. Usability of a home-based monitoring system for community-dwelling elderly people during a pilot study. $5^{\text {th }}$ International Conference on eHealth Telemedicine and Social Medicine, 28 Feb 2013, Nice, France.

- Vermeulen J, Bedaf S, Man YP. Nieuwe technologie in de ouderenzorg: hoe ouderen en onderzoekers samen producten ontwikkelen die aansluiten op de behoefte van de gebruikers. Tijdschr Gerontol Geriatr. 2012:43;213-215. 
- Vermeulen J, Neyens JCL, Spreeuwenberg MD, van Rossum E, Hewson DJ, de Witte LP. Validity of a modified bathroom scale measuring balance. Gerontechnology. 2012;11:263.

- Vermeulen J, Neyens JCL, Spreeuwenberg MD, van Rossum E, Hewson D, de Witte LP. The added value of user involvement during the development of a feedback system for community-dwelling elderly people regarding physical functioning. Int J Integr Care. 2012; 12: 1-2.

- Vermeulen J, Spreeuwenberg M, Sipers W, Neyens J, van Rossum E, Hewson D, de Witte L. Development of a system that provides tailored feedback and advice to elderly people regarding physical functioning. $8^{\text {th }}$ International Congress of the Association for the Advancement of Assistive Technology in Europe, 31 August - 2 September 2011, Maastricht. Assistive Technology Research Series. 2011;29:10-19.

- Vermeulen J, Neyens J, Spreeuwenberg M, van Rossum E, Hewson D, de Witte L. Monitoring van fysieke kwetsbaarheid bij ouderen; een innovatief systeem ter ondersteuning van zelfmanagement en zorg. Nationaal Congres Nederlandse Vereniging voor Fysiotherapeuten in de Geriatrie, 13 mei 2011, Ede, The Netherlands.

- Vermeulen J, Neyens JCL, Spreeuwenberg MD, van Rossum E, de Witte LP. Using physical frailty indicators to predict disability in activities of daily living in communitydwelling elderly people: a systematic review. Aging Clin Exp Res. 2011;23:115.

- Vermeulen J, Neyens J, Spreeuwenberg M, van Rossum E, Hewson D, de Witte LP. Monitoring of physical frailty in older people to support self-management and care. J Clin Nurs. 2010;19:90-91.

- Vermeulen J, Spreeuwenberg MD, Daniëls R, Neyens JCL, van Rossum E, de Witte LP. The predictive value of physical frailty indicators on disability in activities of daily living in community-dwelling elderly people. EGM. 2010;1S:1.

- Neyens J, Vermeulen J, Spreeuwenberg M, van Rossum E, Hewson D, de Witte LP. Monitoring of physical frailty in elderly people: An innovative system supporting selfmanagement and care. Gerontechnology. 2010;9:177-178.

\section{Awards}

- Award for Best Poster at CAPHRI Research Day, 19 May 2011. Joan Vermeulen, Jacques CL Neyens, Marieke D Spreeuwenberg, Erik van Rossum, Luc P de Witte. Development of a system that provides tailored feedback and advice to elderly people regarding physical functioning. 
